\title{
Millican Bench (41TV163) A Multicomponent Site in Travis County, Texas
}

\author{
Raymond P. Mauldin \\ Center for Archeological Research, University of Texas at San Antonio \\ Steve A. Tomka \\ Raba Kistner \\ Harry J. Shafer
}

Follow this and additional works at: https://scholarworks.sfasu.edu/ita

Part of the American Material Culture Commons, Archaeological Anthropology Commons, Environmental Studies Commons, Other American Studies Commons, Other Arts and Humanities Commons, Other History of Art, Architecture, and Archaeology Commons, and the United States History Commons

Tell us how this article helped you.

This Article is brought to you for free and open access by the Center for Regional Heritage Research at SFA ScholarWorks. It has been accepted for inclusion in Index of Texas Archaeology: Open Access Gray Literature from the Lone Star State by an authorized editor of SFA ScholarWorks. For more information, please contact cdsscholarworks@sfasu.edu. 


\section{Millican Bench (41TV163) A Multicomponent Site in Travis County, Texas}

\section{Licensing Statement}

This is a work produced for the Texas Department of Transportation (TxDOT) by the report producer. TxDOT and the report producer jointly own all rights, title, and interest in and to all intellectual property developed under TXDOT's contract with the report producer. The report may be cited and brief passages from this publication may be reproduced without permission provided that credit is given to both TxDOT and the report producer. Permission to reprint an entire chapter, section, figures or tables must be obtained in advance from either the Supervisor of the Archeological Studies Branch, Environmental Affairs Division, Texas Department of Transportation, 125 East 11th Street, Austin, Texas, 78701 or from the report producer. 


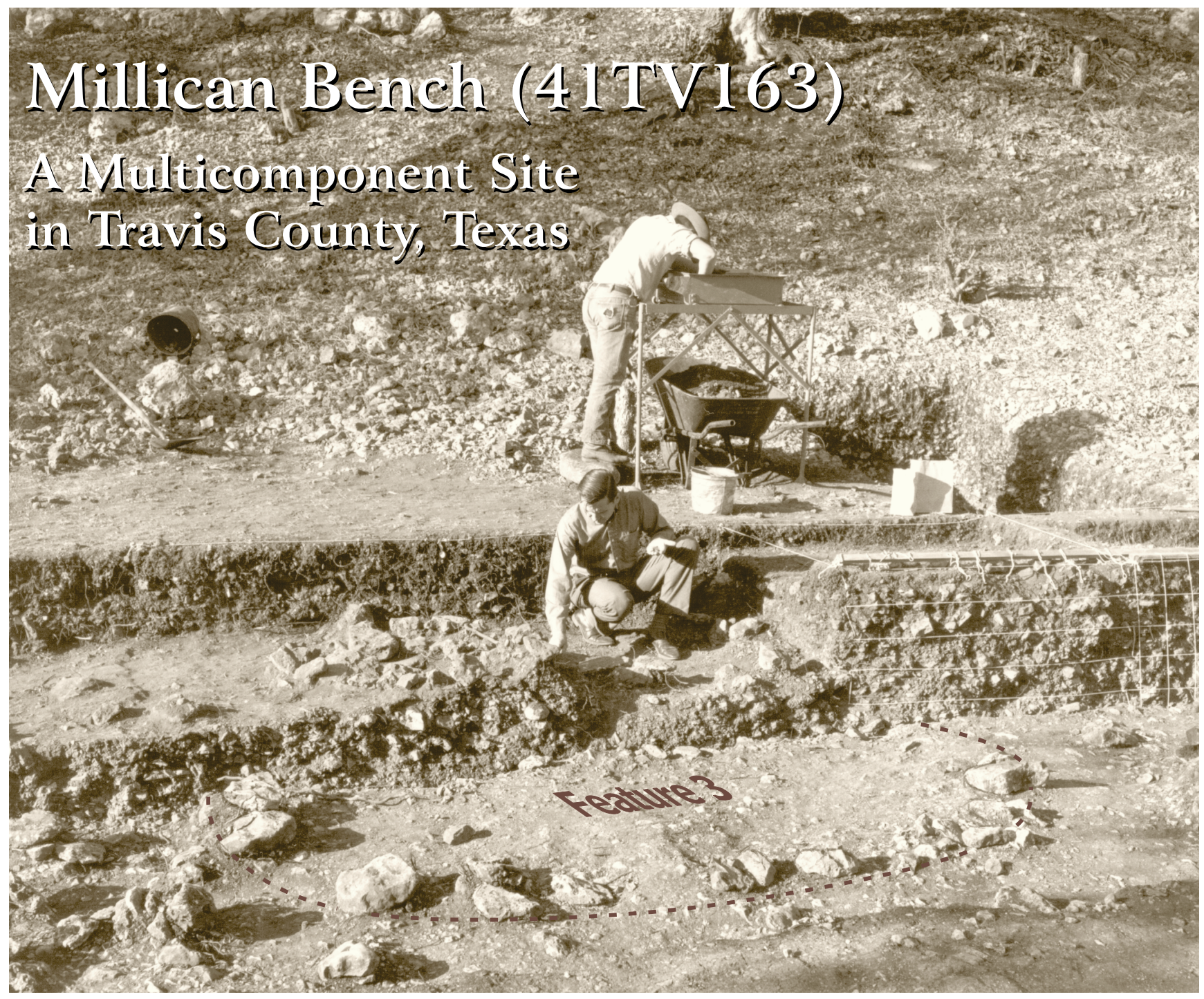

by

\section{Raymond P. Mauldin, Steve A. Tomka, and Harry J. Shafer}

with Contributions by

Frank A. Weir, J. Philip Dering, Russell D. Greaves, Richard B. Mahoney, Barbara A. Meissner, Jason D. Weston, and Marybeth S. F. Tomka

Work Authorization No. 57014 PD004

Contract No. 570 XX PD004

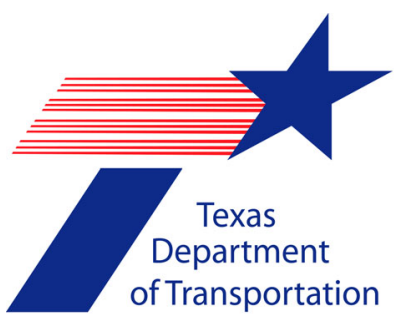

Environmental Affairs Division

Texas Department of Transportation

Archeological Studies Program, Report No. 66

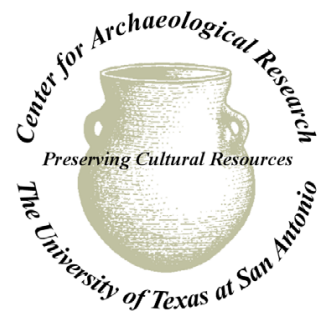

Center for Archaeological Research The University of Texas at San Antonio Archaeological Survey Report, No. 351 


\title{
Millican Bench (41TV163) \\ A Multicomponent Site in Travis County, Texas
}

\author{
by \\ Raymond P. Mauldin, Steve A. Tomka, and Harry J. Shafer \\ with Contributions by \\ Frank A. Weir, J. Philip Dering, Russell D. Greaves, Richard B. Mahoney, \\ Barbara A. Meissner, Jason D. Weston, and Marybeth S. F. Tomka
}

\section{Raymond P. Mauldin \\ Principal Investigator}

Work Authorization No. 57014 PD004

Contract No. 570 XX PD004

Prepared for:

Environmental Affairs Division

Texas Department of Transportation

Archeological Studies Program, Report No. 66

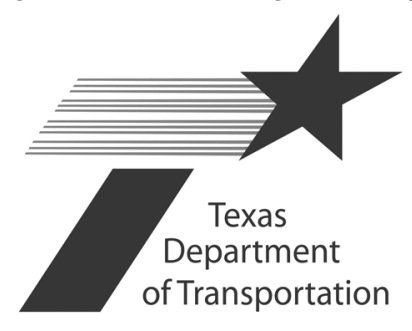

2004
Prepared by:

Center for Archaeological Research The University of Texas at San Antonio Archaeological Survey Report, No. 351

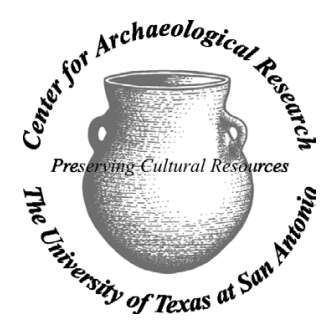




\title{
Millican Bench (41TV163) A Multicomponent Site in Travis County, Texas
}

\author{
Copyright ${ }^{\circledR} 2004$ \\ Texas Department of Transportation (TxDOT) and Center for Archaeological Research, \\ The University of Texas at San Antonio (CAR-UTSA)
}

\begin{abstract}
All rights reserved
TxDOT and CAR-UTSA jointly own all rights, title, and interest in and to all data and other information developed for this project under Contract 570 XX PD004. Brief passages from this publication may be reproduced without permission provided that credit is given to TxDOT and CAR-UTSA. Permission to reprint an entire chapter, section, figures or tables must be obtained in advance from the Supervisor of the Archeological Studies Program, Environmental Affairs Division, Texas Department of Transportation, 125 East 11th Street, Austin, 78701. Copies of this publication have been deposited with the Texas State Library in compliance with the State Depository requirements.
\end{abstract}

\author{
Printed by Kwik Kopy Printing on Main, San Antonio \\ 2004 \\ jointly published by \\ Texas Department of Transportation \\ Environmental Affairs Division \\ Archeological Studies Program \\ Owen Lindauer, Ph.D., Supervisor
}

Archeological Studies Program, Report No. 66

A. McGraw, Series Editor

and

Center for Archaeological Research

The University of Texas at San Antonio

Archaeological Survey Report, No. 351

Printed on acid-free, $60 \mathrm{lb}$. paper

ISBN: 1-930788-36-3 


\section{Abstract:}

Between September of 1970 and February of 1971, the Texas Highway Department, now the Texas Department of Transportation (TxDOT), carried out extensive hand and mechanical excavations at 41TV163, the Millican Bench site. The highway maintenance crew was ably directed by Frank Weir. Millican Bench represented the first archeological site excavated by the then Texas Highway Department (THD) under their archeological program. In 2001, TxDOT contracted with the Center for Archaeological Research at The University of Texas at San Antonio to provide an assessment of the documents and data and develop research topics that may be successfully pursued with the materials from the site. Based on the assessment it was determined that dependent on data types, four broad analytical units could be defined (Late Prehistoric, and Late, Middle and Early Archaic), and two diachronic and one synchronic research topic would be pursued: changes in subsistence strategies and lithic technological organization, and the evaluation of Feature 3, a possible structure noted at the site. The analysis of the faunal material from the site and comparison with other archeological collections indicates that hunter-gatherers may have pursued a broad-spectrum adaptation, even when bison were present in the region. The lithic assemblage, characterized by predominantly expedient and minimally retouched tool forms, supports this contention. The percentages of what we think are nonlocal raw materials increases through time. This increase hints at changes in the level or scope of mobility. Patterns in projectile point discard and replacement strategies suggest some premium on preventive tool replacement. Although the photographic documentation strongly supports the likelihood of Feature 3 representing a structure, we have little surviving direct data in support of this possibility. The artifactual data that we can investigate suggests, however, that the circular area may have at least represented some type of maintained space.

All artifacts retained, in consultation with the Texas Historical Commission and TxDOT, and all site documentation are permanently curated at the Center for Archaeological Research. The remains of the single skeleton recovered from the site are also permanently curated at the Center. 


\section{Table of Contents:}

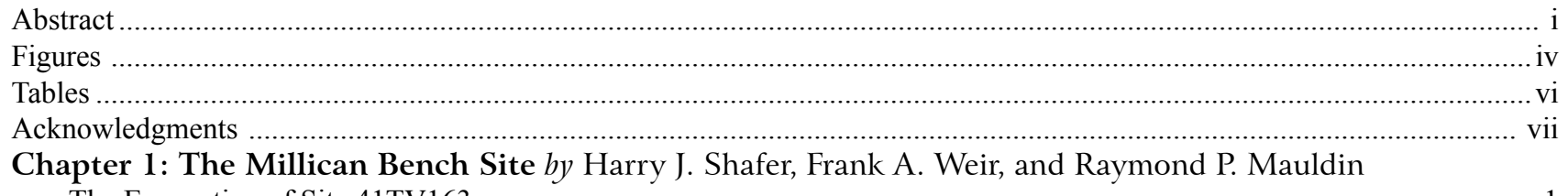

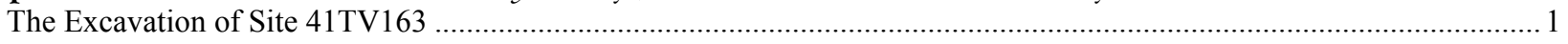

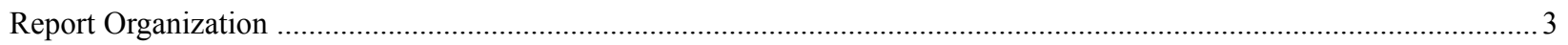

Chapter 2: Environmental Setting by Raymond P. Mauldin

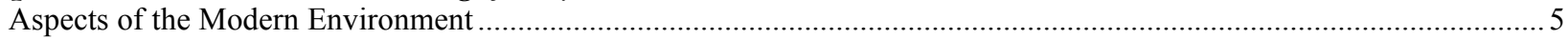

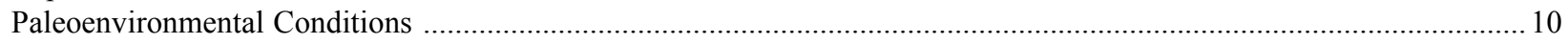

Chapter 3: Previous Research and Archeological Background by Harry J. Shafer and Steve A. Tomka

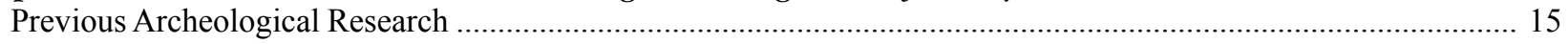

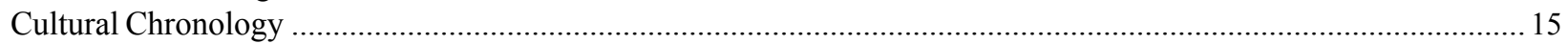

Chapter 4: Field and Laboratory Methods by Harry J. Shafer, Marybeth S. F. Tomka, Richard B. Mahoney, Frank A. Weir, and Raymond P. Mauldin

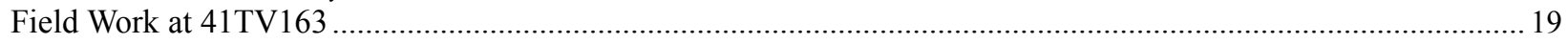

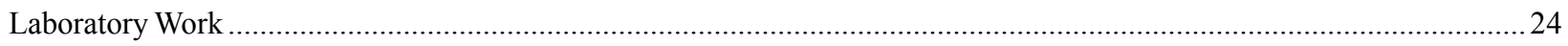

Chapter 5: Recovered Data by Raymond P. Mauldin, Richard B. Mahoney, Harry J. Shafer, and Barbara A. Meissner

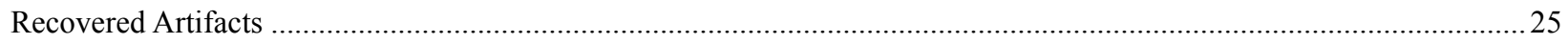

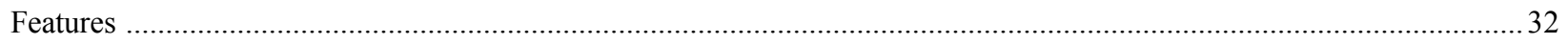

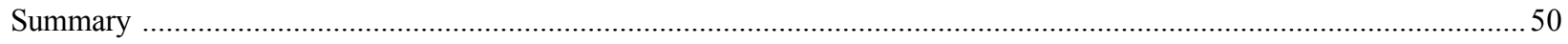

Chapter 6: Research Issues by Raymond P. Mauldin, Steve A. Tomka, and Russell D. Greaves

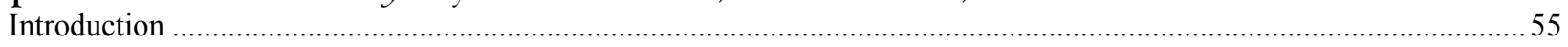

Diachronic Research Issues: Changes in Subsistence Patterns and Lithic Technology ..............................................55

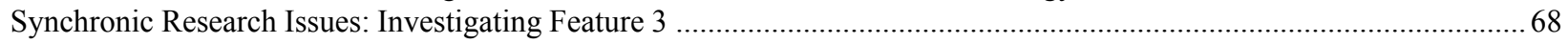

Chapter 7: Late Prehistoric and Late Archaic Subsistence Practices by Steve A. Tomka, Raymond P. Mauldin, and Russell D. Greaves

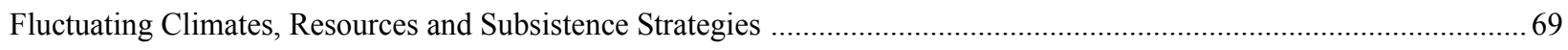

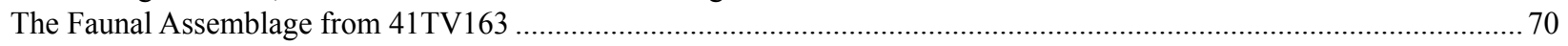

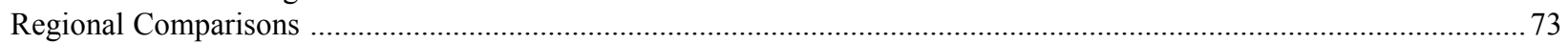

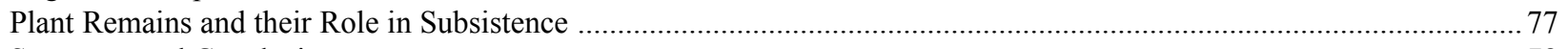

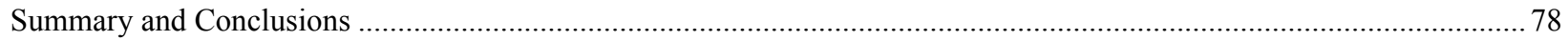

Chapter 8: Technological Organization at 41 TV163 by Raymond P. Mauldin, Steve A. Tomka, Harry J. Shafer, and Jason D. Weston

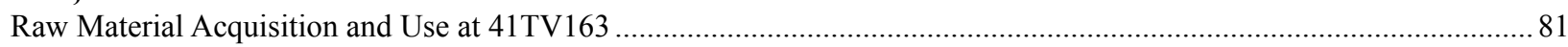

Technological Organization: Tool Design and Projectile Point Technology at 41TV163 .............................................8

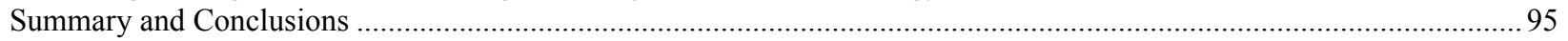

Chapter 9: Exploration of Feature 3: A Possible Late Prehistoric Structure at Millican Bench

by Harry J. Shafer, Steve A. Tomka, and Raymond P. Mauldin

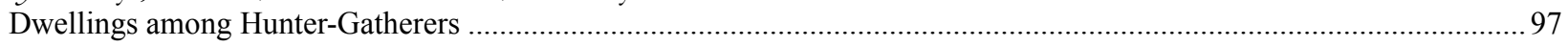

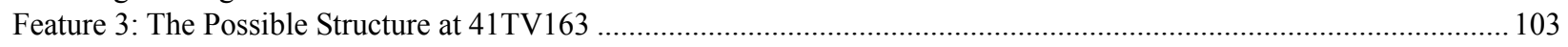

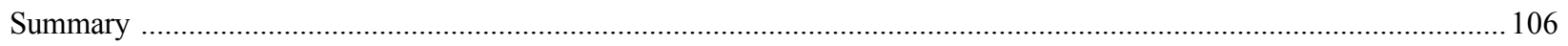

Chapter 10: Summary and Conclusions by Steve A. Tomka and Raymond P. Mauldin

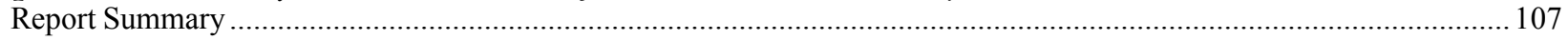

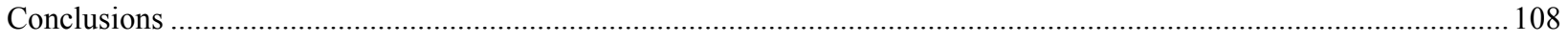

References Cited

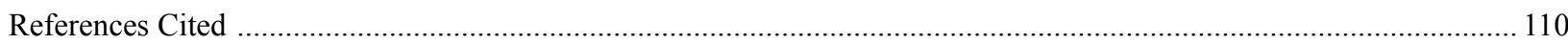


Appendix A: Vertebrate Faunal Remains

Vertebrate Faunal Remains

Appendix B: Human Remains by Richard B. Mahoney

Human Remains

Appendix C: Radiocarbon Results

Radiocarbon Results ....

Appendix D: Plant Remains from 41TV163 by J. Philip Dering

Plant Remains from 41TV163... 166

Appendix E: Selected Projectile Points from 41TV163

Selected Projectile Points from 41TV163 


\section{Figures:}

Figure 1-1. Location of 41TV163 in northwest Austin, Travis County, Texas. .............................................................. 2

Figure 1-2. Portion of aerial photo with sketched locations of Areas A-G at 41TV163 ............................................... 3

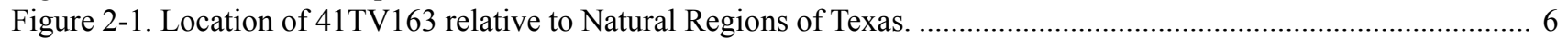

Figure 2-2. Average maximum and minimum temperatures for Austin, Texas (1971-2000). .......................................... 7

Figure 2-3. Average monthly rainfall for Austin, Texas (1971-2000). .................................................................... 7

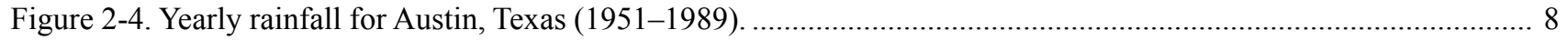

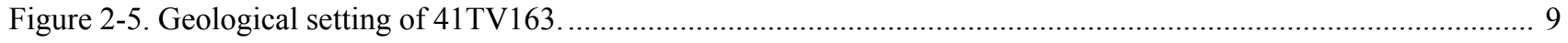

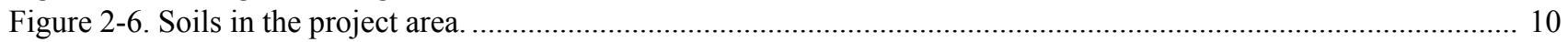

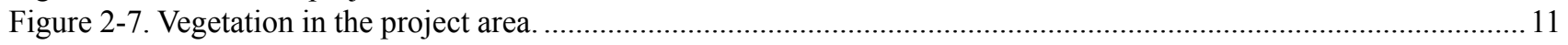

Figure 2-8. Comparison of several climatic reconstructions for central Texas............................................................ 12

Figure 2-9. Estimated arboreal canopy coverage from the Patschke Bog pollen core. .................................................. 14

Figure 4-1. Site map showing distribution of excavation areas and units................................................................... 20

Figure 4-2. Initial trench across Areas B, C, and D at 41TV163. Looking west. .......................................................... 21

Figure 4-3. Backhoe trenches in Area B (foreground) and Area A (background) at 41TV163. Looking north. ............... 22

Figure 4-4. Overview of excavations in Area C at 41TV163. Looking south. ........................................................... 23

Figure 4-5. Excavations in Area F (foreground) and Area E (background) at 41TV163. Looking west. ........................ 23

Figure 4-6. Excavations in Area E: note screens and Gradall. Looking west. ............................................................. 24

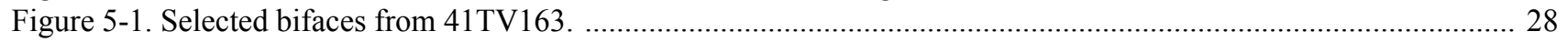

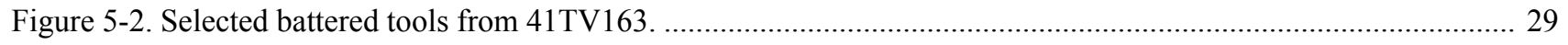

Figure 5-3. Possible bone tool tips found in Area C. ........................................................................................ 31

Figure 5-4. Adult skeleton recording form showing elements recovered from the burial, Feature 10, at 41TV163........ 33

Figure 5-5. Site map showing midden areas and feature locations at 41TV163. ........................................................ 34

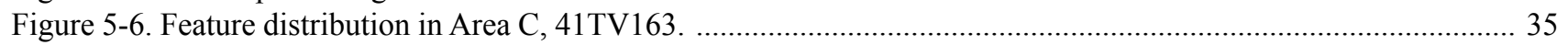

Figure 5-7. Feature 1, a slab-lined pit in Area C. Note uniface/mussel shell cache among burned rock.......................... 36

Figure 5-8. Feature 2, pit feature in backhoe trench wall, Area C. ......................................................................... 37

Figure 5-9. Oblique view of Feature 3. Crew members are working in Area C, Area B midden is at upper right. ............ 38

Figure 5-10. Feature 3, a possible structure in Area C. .................................................................................... 39

Figure 5-11. Feature 4, limestone pavement of primarily unburned cobbles, Feature 3 is to the right in the photo. ......... 40

Figure 5-12. Feature 5, slab-lined pit bisected by backhoe trench. Note uniface/mussel shell cache in foreground. ........ 41

Figure 5-13. Feature 5, Area C. Note uniface/mussel shell cache at edge of feature. .................................................. 42

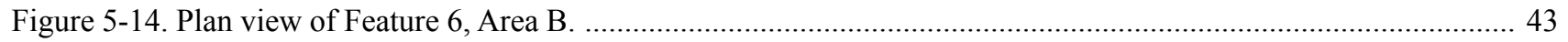

Figure 5-15. Schematic profile of Feature 6 showing the vertical position of artifacts relative to the boulder. ................ 44

Figure 5-16. Selected projectile points recovered from Feature 6, Area B. .............................................................. 45

Figure 5-17. Feature 7, rock concentration in unit S185/E170-175, Area C. ............................................................ 46

Figure 5-18. Plan view of Feature 8, a possible slab-lined hearth, Area F. ................................................................... 47

Figure 5-19. Plan view of Feature 9, cluster of burned rocks in association with Feature 7, Area C. ............................. 47

Figure 5-20. Feature 10, plan view of burial pit capped by slabs of rocks, Area C . ................................................... 48

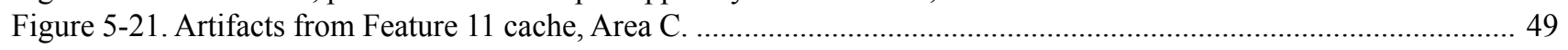

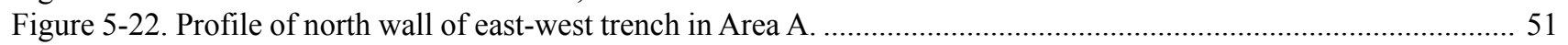

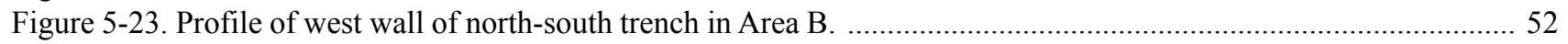

Figure 5-24. Profile of east wall of northwestern-most three units in Area C. ............................................................... 53

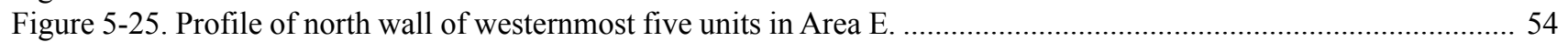

Figure 6-1. Schematic cross-section of Area B, 41TV163, with diagnostic point types and analytical units identified. ... 59

Figure 6-2. Schematic cross-section of Area C, 41TV163, with diagnostic point types and analytical units identified. ... 62

Figure 7-1. Location of archeological sites mentioned in the comparative faunal analysis discussion. ........................... 75

Figure 8-1. Range of raw material groups and the coefficient of variation on flake size. ............................................. 83

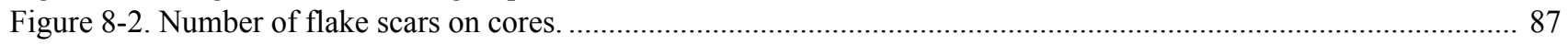

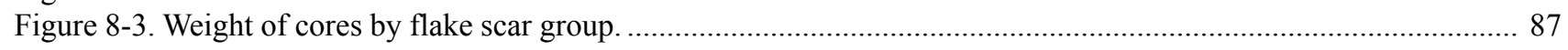


Figure 8-4. Suggested relationship between core weight and number of flake scars. ................................................ 88

Figure 9-1. Numa encampment of brush shelters near St. George, Utah, 1873 .................................................. 99

Figure 9-2. Southern Paiute encampment near Kanab, Utah, in 1873, showing the use of a shade tree for a

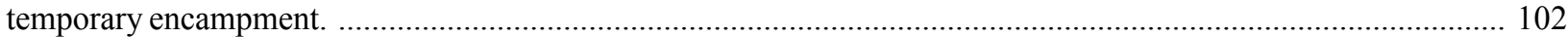

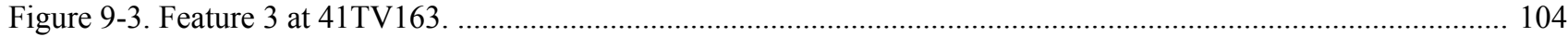

Figure E-1. Selected projectile points from Area A. Numbers identify specimen within database. ............................ 172

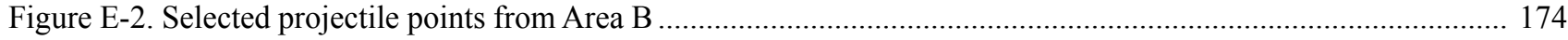

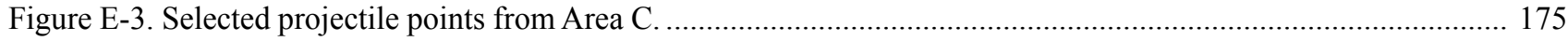

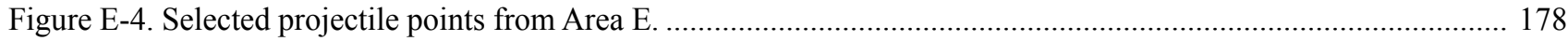

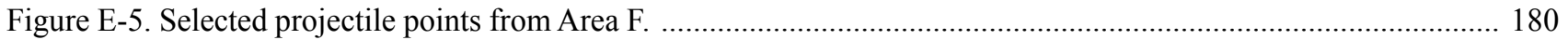




\section{Tables:}

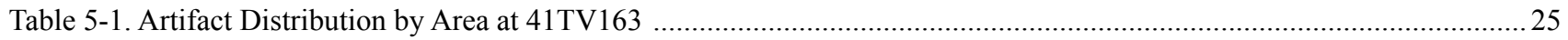

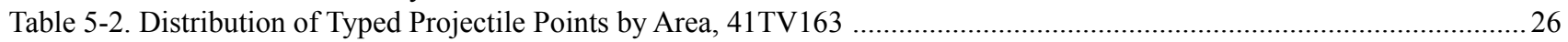

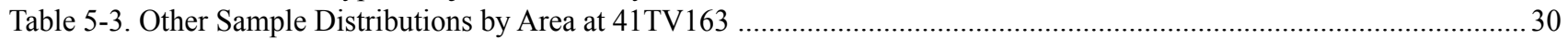

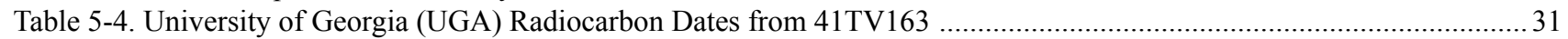

Table 6-1. Projectile Point Distributions by Unit and Level, Area A ..................................................................................57

Table 6-2. Projectile Point Distributions by Unit and Level, Area B ...............................................................................58

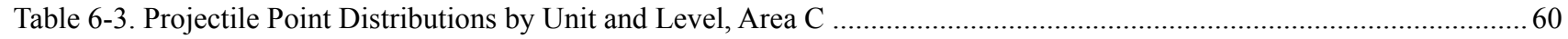

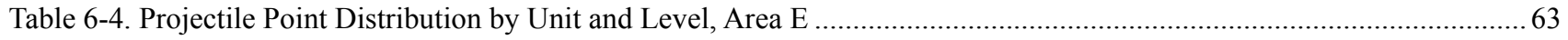

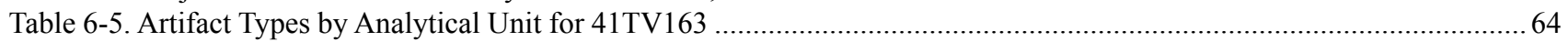

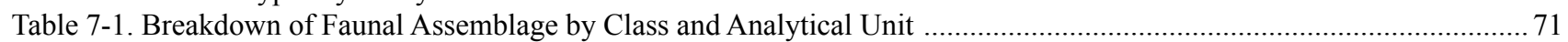

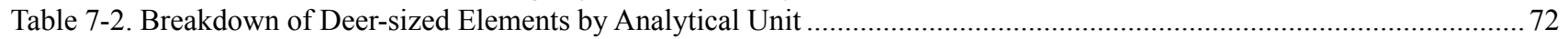

Table 7-3. Late Prehistoric and Late Archaic Fresh-broken Deer Bone Size ................................................................ 72

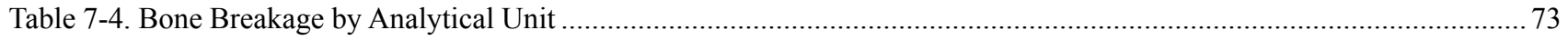

Table 7-5. The Ages of Archeological Components with Bone Assemblages Used for Regional Comparison ........................ 74

Table 7-6. Archeological Sites with Bone Assemblages Used for Regional Comparison ........................................................74

Table 7-7. Number of Genera Identified by Component within the Comparative Faunal Assemblage .....................................76

Table 7-8. Breakdown of Faunal Assemblages by Phase/Time Period and Body Size ..................................................... 77

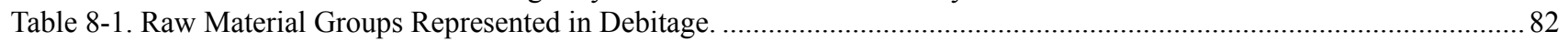

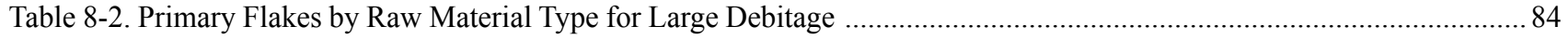

Table 8-3. Comparison of Potentially Non-local and Local Stone Debitage to Tools and Cores ..........................................85

Table 8-4. Percentage of Cortex Groups for Four Temporal Periods at 41TV163 …......................................................85

Table 8-5. Frequency of Debitage by Raw Material Groups for Four Temporal Periods at 41TV163 ....................................86

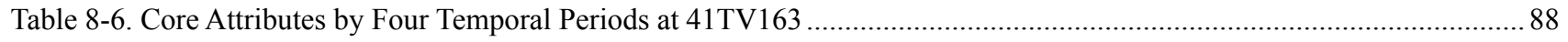

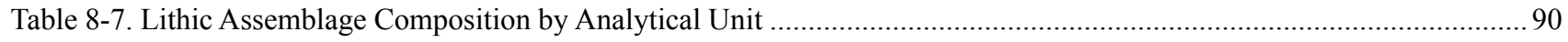

Table 8-8. Breakdown of Non-projectile Point Tools by Manufacture Type within Analytical Units ...................................91

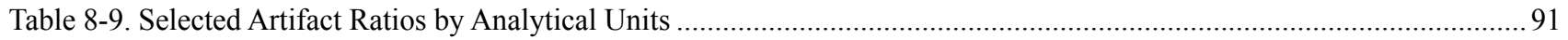

Table 8-10. Breakdown of Bifaces by Reduction Stage and Adjusted Residual Values .......................................................92

Table 8-11. Mean Blade Length and Blade Width by Temporal Period ..............................................................................93

Table 8-12. Mean Blade Length and Blade Width for Selected Point Types ................................................................93

Table 8-13. Complete Specimens and Stem Fragments by Time Period .......................................................................94

Table 8-14. Number and Percent of Complete Points and Stem Fragments for Selected Point Types ...................................94

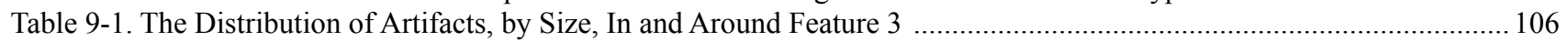

Table A-1. Composition of Faunal Assemblages Employed in the Comparative Faunal Analysis Section of Chapter 7 ........... 126

Table A-2. Size Classification of Animal Species Encountered in the Archeological Assemblage Consulted ........................ 128

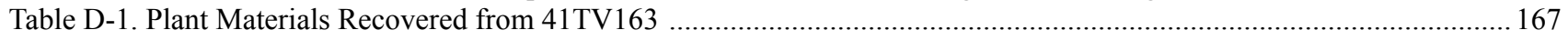

Table D-2. Overview of Allium Finds from Sites along the Northern and Eastern Periphery of the Edwards Plateau ............. 168 


\section{Acknowledgments:}

The original data recovery investigations at 41TV163 were conducted by members of the Texas Department of Transportation, under the direction of Dr. Frank A. Weir. Subsequent to the excavations preliminary laboratory processing was carried out on a large portion of the collections by TxDOT staff. CAR would like to extend its thanks and appreciation to the staff of TxDOT who made it possible for us to learn about a piece of the history of Texas archeology and about the prehistory of central Texas. We are especially thankful to Frank Weir who provided useful memories of the excavations and reviewed aspects of the methods chapter.

The analyses and write-up presented in this report were facilitated by the hard work, dedication, and contributions of many individuals. We want to extend our sincere thanks to the personnel of the Environmental Affairs Division of the Texas Department of Transportation. Dr. Owen Lindauer, Dr. Nancy Kenmotsu, and Al McGraw worked closely with CAR personnel providing useful and constructive comments during the development of the research directions followed in this document. They have also been extremely helpful in scheduling progress report meetings and providing useful advice during these meetings, and approving changes in research direction on a timely basis.

Similarly, our thanks also are extended to the laboratory staff that initially scoured the numerous boxes and provided the raw data for the initial site assessment. They included Antonia Figueroa, Rebecca Galdeano, Jennifer NeelHartman, Cindy Muñoz, Bryant Saner, Matt Senn, Kristi Ulrich, Stacy Wagner, Jason Weston, José Zapata, and Marybeth Tomka who oversaw this large group.

Special analysts who contributed to this project include: Phil Dering, macrobotanical; Richard Mahoney, human osteology; Barbara Meissner and Russell Greaves, vertebrate faunal; Harry Shafer, Steve Tomka, and Jason Weston, lithics.

Bruce Moses and Rick Young of the CAR Graphics Department drafted the illustrations in the report. Johanna Hunziker edited and formatted the report, greatly improving the disjointed bits and pieces she was presented with (usually at the last minute). Our thanks and appreciation goes out to all. 



\title{
Chapter 1: The Millican Bench Site
}

\author{
Harry J. Shafer, Frank A. Weir, and Raymond P. Mauldin
}

Located in Travis County, the Millican Bench site (41TV163) was the first archeological site excavated by the Texas Department of Transportation (TxDOT; then Texas Highway Department) as a mitigation effort for highway construction under the requirements of the National Environmental Protection Act of 1966. The excavation was conducted between September of 1970 and February of 1971 under the direction of Frank Weir, then of the Texas Highway Department. In August of 2002, TxDOT contracted with the Center for Archaeological Research (CAR) at The University of Texas at San Antonio (Work Authorization \#57014PD004) to conduct an inventory and assessment of the archeological collections and documentation associated with site 41TV163, develop possible research questions that could be pursued with the site data, and to prepare the project material for permanent curation. Based on that assessment (Mahoney et al. 2003a), and following consultation with TxDOT, CAR further was directed to produce a final report. This document constitutes the final report on the TxDOT work at 41TV163. Included in this report are a description of the site, excavation procedures, and an analysis of selected components of the data collected over three decades ago.

To report on excavations and analyze data collected over 30 years ago presents several challenges. Foremost among these is that if one wishes to avoid a primarily historical perspective, data collected using earlier field methods to investigate earlier theoretical concerns must be molded to address current questions. In this case, the disconnect between the theoretical and methodological considerations that guided the excavation of 41TV163, which appear to have been focused on chronology and cultural history, and current research interests in Texas archeology is exacerbated by the loss of a large portion of the field notes, some photo logs, and some of the artifacts and samples during the intervening years. Nevertheless, in the assessment document (Mahoney et al. 2003a), we identified a series of current research issues that could be addressed using data generated by the work at 41TV163. These include investigating temporal changes in subsistence patterns and changes in lithic technology. In addition, we investigate several aspects of site use during the Late Prehistoric occupation of 41TV163.

\section{The Excavation of Site 41TV163}

Site 41TV163 was located in northwest Austin in Travis County. The site was about $0.6 \mathrm{~km}$ southwest of what is now the intersection of State Highway 183 with Loop 360 (N. Capital of Texas Highway; Figure 1-1). Preston Millican, a surveyor for the Lower Colorado River Authority, first recorded 41TV163 in the 1950s, and the site was named after Mr. Millican and a natural limestone bench that formed a prominent topographic feature within the site. Site 41TV163 covered an area roughly 235 meters by 85 meters. Burned rock and chipped stone were visible over most of the surface, with individual burned rock middens and several concentrations of chipping debris, bone, shell, and burned rock evident.

Work at Millican Bench was conducted in conjunction with the construction of Loop 360. As noted previously, 41TV163 was the first archeological site excavated by the then Texas Highway Department (THD) under their archeological program. That program was established in 1970 in an effort to comply with the National Environmental Protection Act (NEPA). No formal procedures or research designs were in place to provide basic guidelines for survey and salvage of archeological sites when 41TV163 was excavated. The general procedure consisted of verbal communication between THD and the Texas Antiquities Committee followed by letter agreement (Frank Weir, personal communication 2003). In the case of 41TV163, this letter of authorization was sent to Mr. J. C. Dingwall, State Highway Engineer, on September 22, 1970 and signed by Fred Wendorf, Chairman of the newly formed Texas Antiquities Committee. The procedures to require State Antiquities Permits for each highway archeological project had not yet been established. Therefore, decisions to mitigate were made solely by Weir's office, and the principal criterion was that a site contained intact deposits and appeared to be "promising." "Promising" usually meant that new information on the archeology of a particular region would be forthcoming. Thus, justification for excavating 41TV163 was based on the observation that burned rock middens, a terrace, and the topographic relief presented by the limestone bench were in close association creating a "unique site condition" (Frank Weir, personal communication 2003). 


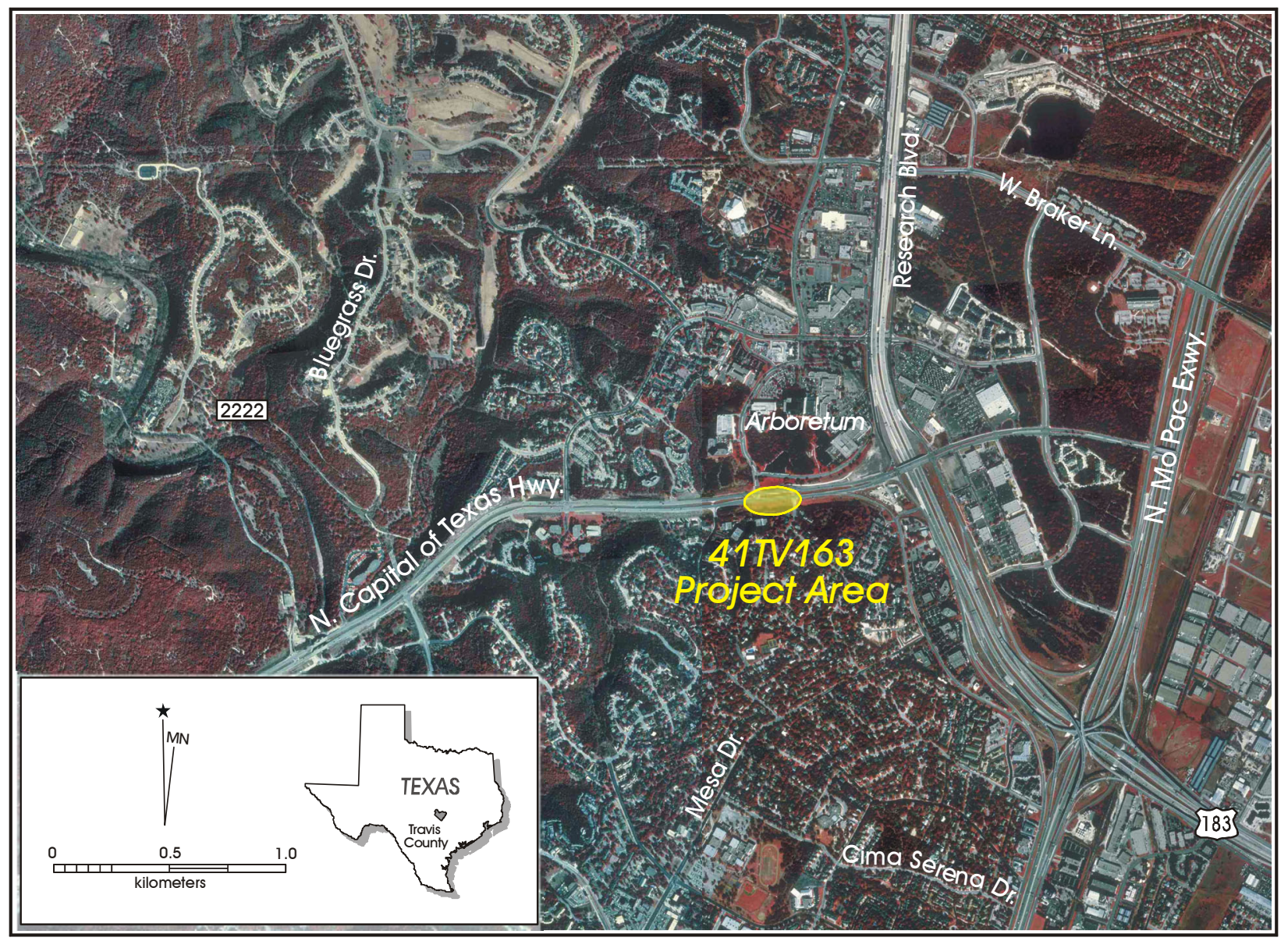

Figure 1-1. Location of 41 TV163 in northwest Austin, Travis County, Texas.

Initially, seven discrete areas, designated A through G, were identified at Millican Bench. Figure 1-2 presents a section of an aerial photo with the sketched locations of these seven areas, along with the Loop 360 centerline. The photo appears to have been created at the time of the fieldwork. Area A consisted of a burned rock midden located on a topographic bench. Another probable burned rock midden, Area B, was situated on the slope and creek terrace below the bench. Located just to the west of Area B were two other areas, designated $\mathrm{C}$ and $\mathrm{D}$. These appeared to be occupation areas with burned rock and other debris present. Three additional areas, designated E, F, and G, were located across the creek east of Areas A-D. Area E was a burned rock midden that measured approximately four meters in diameter. Area $\mathrm{F}$ contained a concentration of occupation refuse with burned rock and chipped stone, while Area G was a broad bedrock exposure containing scattered chipped stone debris.
With the exception of Area G, where only surface collection was conducted, all areas (A through F) had some level of excavation. At 41TV163, TxDOT personnel recorded 11 features, including a human burial (Feature 10) and a possible structure (Feature 3). In addition, more than 200 cores, 1,400 tools, 400 projectile points, and 42,500 pieces of debitage were collected. With the exception of any evidence for Paleoindian occupation, the 41TV163 materials seem to reflect most prehistoric periods. Collected projectile point types thought to be diagnostic include Wells, Early Split Stem, Early Triangular, Martindale, and Uvalde forms dating to much of the Early Archaic (8000-6000 BP); Nolan, Travis, and a single Andice point, all dating to the Middle Archaic (6000-4000 BP); Bulverde, Pedernales, Williams, Lange, Marshall, Montell, Castroville, Ensor, Frio, Fairland, and Darl forms dating throughout the Late Archaic (4000$1250 \mathrm{BP})$; and Scallorn points, dating to the early portion of 


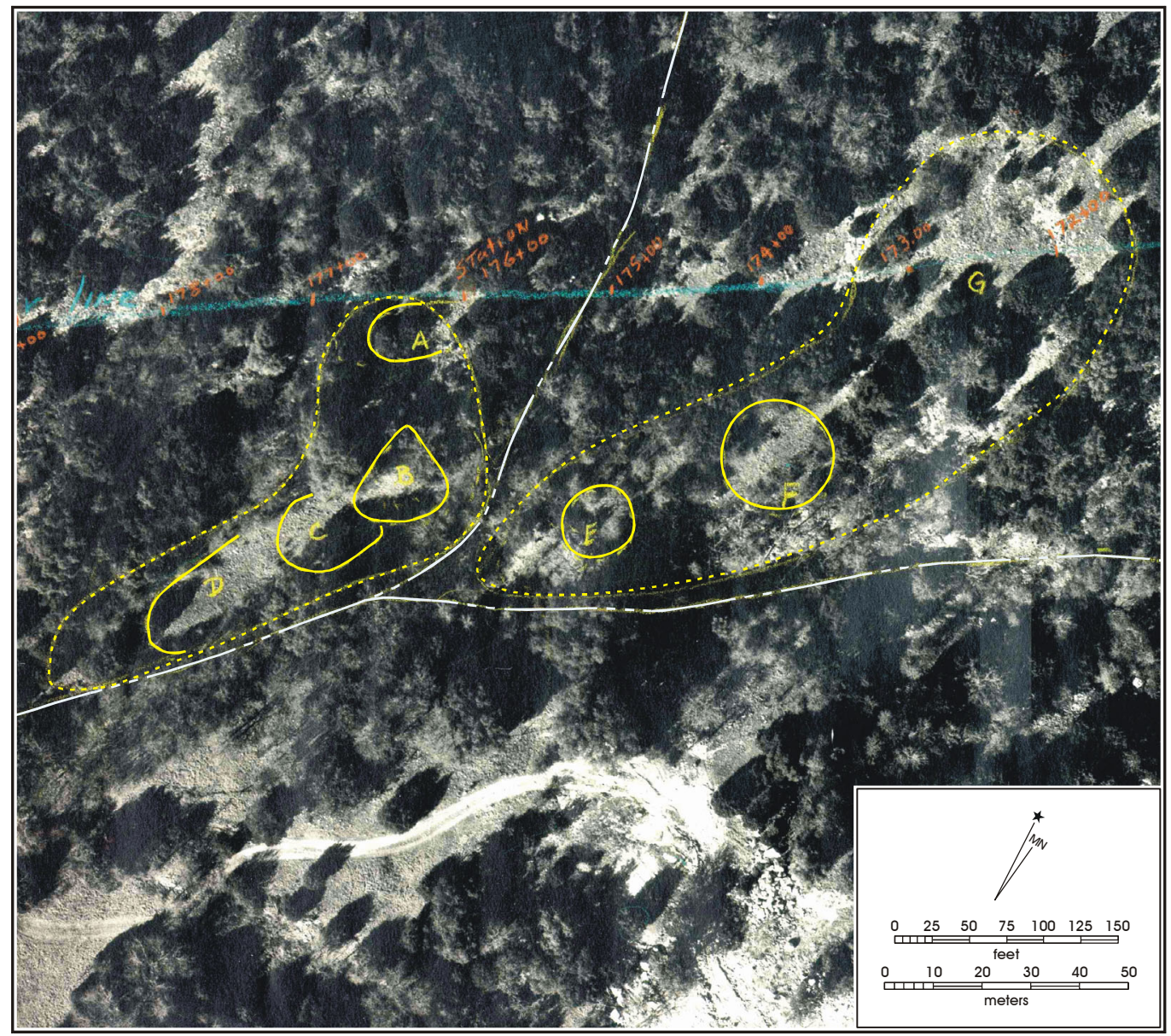

Figure 1-2. Portion of aerial photo with sketched locations of Areas A-G at 41TV163.

the Late Prehistoric (1250-700 BP). A small amount of historic and/or modern material was also collected, though it is not considered in any detail in this report.

\section{Report Organization}

This report contains 10 chapters. Following this introduction, Chapter 2 outlines the environmental setting of the site, including information on paleoenvironmental conditions. Chapter 3 provides an overview of cultural history concerns. Chapter 4 discusses the field methods employed in the 19701971 excavations and laboratory methods. Chapter 5 outlines the data recovered and includes a discussion of the 11 features identified on the site. Chapter 6 discusses research interests that guided the current analysis. Included in that chapter is the identification of several analytical units that contain data from specific time periods that are used in subsequent chapters. Chapter 7 presents the results of our investigation into subsistence change between the Late Archaic and the Late Prehistoric at Millican Bench. Included in that chapter is comparative data on several other Late Archaic and Late Prehistoric sites. Chapter 8 discusses changes in the lithic assemblages at the site from the Early Archaic through the Late Prehistoric. The ninth chapter contains an investigation of data related to Feature 3, suggested to be a structure. Chapter 10 provides a summary of the report. The analyses conducted in Chapters 7,8 , and 9 are supported by a number of appendices. These include data on vertebrate faunal material (Appendix A), human remains (Appendix B), the results of recently obtained radiocarbon dates (Appendix $C$ ), and ethnobotanical analysis (Appendix D). Scans of selected projectile points from various areas of the site are presented in Appendix E. 



\title{
Chapter 2: Environmental Setting
}

\author{
Raymond P. Mauldin
}

This chapter provides an overview of the environment of 41TV163. Included are discussions of the physiographic setting, climate, geology and soils, hydrology, vegetation, and faunal resources of the site area. The second section provides an overview of paleoenvironmental conditions during the long period of occupation at Millican Bench.

\section{Aspects of the Modern Environment}

As presented in Chapter 1, the site of Millican Bench (41TV163) was located in what is now northwest Austin in north-central Travis County (see Figure 1-1). The site was on the extreme eastern edge of the Edwards Plateau. While CAR personnel have visited the general site location, construction of Loop 360, and associated developments with that highway, have essentially destroyed the site and significantly altered the appearance of the landscape.

\section{Physiographic Setting}

The site of Millican Bench was located in the valley head of a tributary stream to Bull Creek that confluences with the Colorado River about $6 \mathrm{~km}$ to the southwest. The location is near the juncture of the Edwards Plateau with the Blackland Prairie (Figure 2-1). Along this eastern edge, the Plateau is characterized by an extensively dissected limestone uplift, known as the Balcones Escarpment. Many springs, seeps, and streams characterize the Escarpment area. The Blackland Prairie is a relatively low, flat landform underlain by limestone and marl. The black, limestonederived soil from which the landform takes its name is easily cultivated and this region has been dominated by farming (see Riskind and Diamond 1988; Swanson 1995). To the northwest of the site is the Llano Uplift, a basin of metamorphic and granitic rocks surrounded by limestone, while the Oak Woods and Prairies region is to the east.

\section{Climate}

Presently, the climate is humid subtropical with hot summers and mild winters (Werchan et al. 1974:117). Figure 2-2 presents the average minimum and maximum temperatures for Austin between 1971 and 2000 (Southern Regional Climate Center [SRCC] 2003a, 2003b). During this period, July and August were the warmest months, with December and January being the coolest. The growing season at Austin averages about 274 days per year. An average of 21 days a year are at or below freezing, although 44 such days were recorded in the winter of 1939-1940. Ten days a year are, on average, at or above $100^{\circ} \mathrm{F}$. However, one of the hottest summers was in 1963 , when 40 days were $100^{\circ} \mathrm{F}$ or above. Using pre-1995 records, the coldest temperature ever recorded was $-2^{\circ} \mathrm{F}$ in late January of 1949 , with the hottest being $109^{\circ} \mathrm{F}$ in July of 1994 (Bomar 1995:214-225).

The average annual precipitation between 1971 and 2000 at Austin was 33.65 inches. The data in Figure 2-3 show that the rainfall is, on average, bimodal during a year, with peaks in May and October and minimums in January, February, and July (SRCC 2003c). Figure 2-4 presents the yearly rainfall totals between 1951 and 1989 (National Climate Data Center [NCDC] 2003). These data suggest considerable yearly variability, with 51.3 inches of precipitation recorded in 1957 and a low of about 10 inches in 1954. Using pre-1995 records, the wettest day was on June 11 of 1981 when 5.66 inches of rain was recorded (Bomar 1995:227).

\section{Geology and Soils}

Figure 2-5, adapted from the Austin Sheet of the Geological Atlas of Texas (Barnes 1974), shows the geology of the general site area. With the exception of small deposits of recent Quaternary alluvium (Qal, Qt) associated with rivers and streams in the area, the geology is dominated by a variety of Cretaceous age deposits that are primarily chalk, limestone, marl, and dolomite. Deposits associated with the Fredericksburg Group (e.g., Kbc, Ked, Kft, Kc) commonly include a variety of abundant white to gray colored chert nodules. The younger Austin Chalk (Kau) deposits, as well as the limestone and dolomite of the older Glen Rose Formation (Kgr), however, do not appear to have chert present (Barnes 1974).

Figure 2-6 presents the soils of the immediate site area of 41 TV163 (Werchan et al. 1974). The site appears to be located on Brackett soils with rock outcrops (BoF). Werchan et al. (1974:15-16) describe the surface of this mapping unit as dominated by " 2 to 4 inch limestone fragments" with slopes in the range of 15 to 30 percent. The surface is "a light brownish-gray gravelly clay loam or gravely loam about 


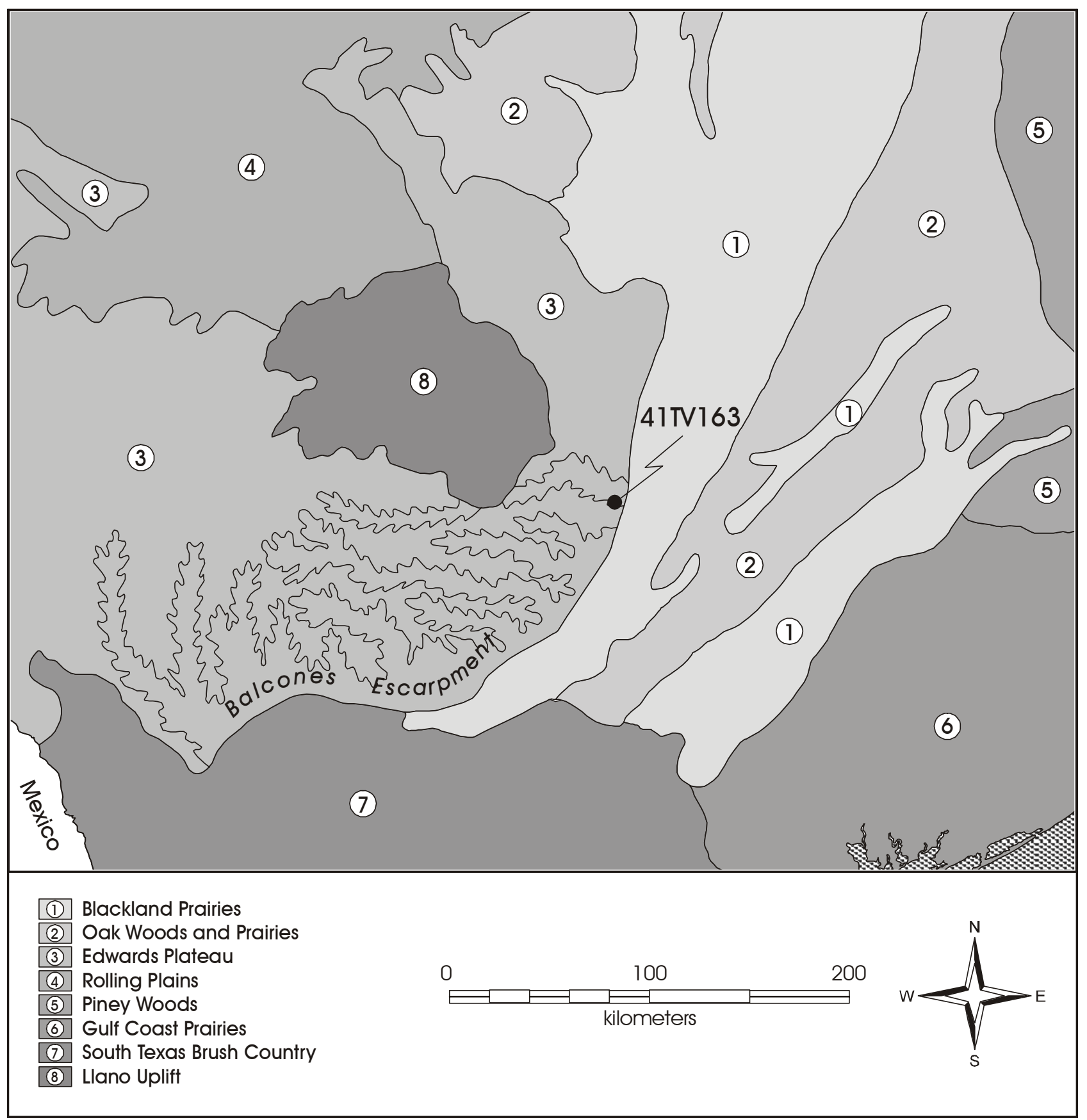

Figure 2-1. Location of 41 TV163 relative to Natural Regions of Texas.

4 inches thick." Below this layer is a pale-brown clay loam extending to roughly 15 inches. This deposit is resting on limestone and marl. Volente soils (VoD) are also present near the site location (Werchan et al. 1974:44). The Volente series are deeper, well-drained soils. Characterized by silty clay loam and silty loam deposits, these soils have high water-holding capacity and slow permeability. Off the slope to the east of Millican Bench, Tarrant soils (TcA, TeA, TeE), characterized as "shallow to very shallow, well-drained, stony, clayey" deposits, are present (Werchan et al. 1974:39). 


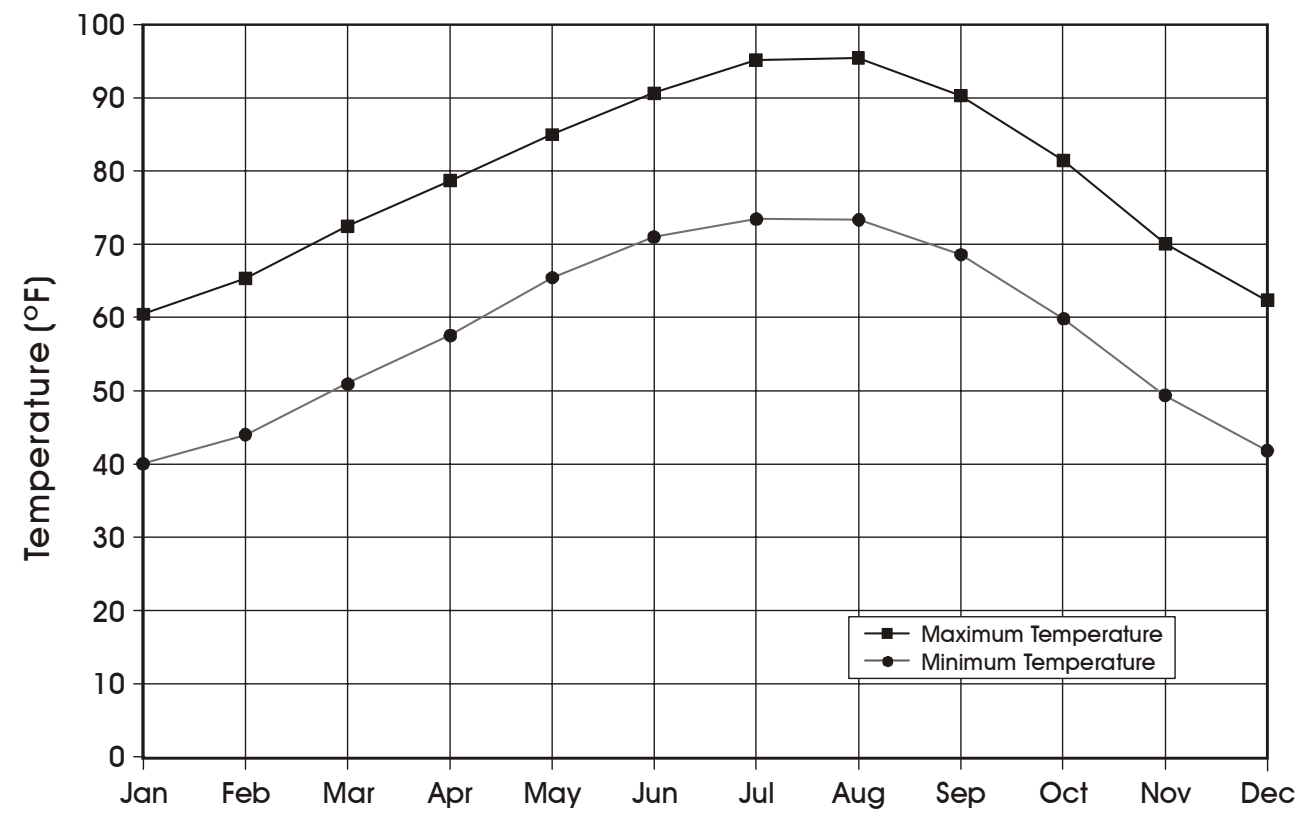

Figure 2-2. Average maximum and minimum temperatures for Austin, Texas (1971-2000).

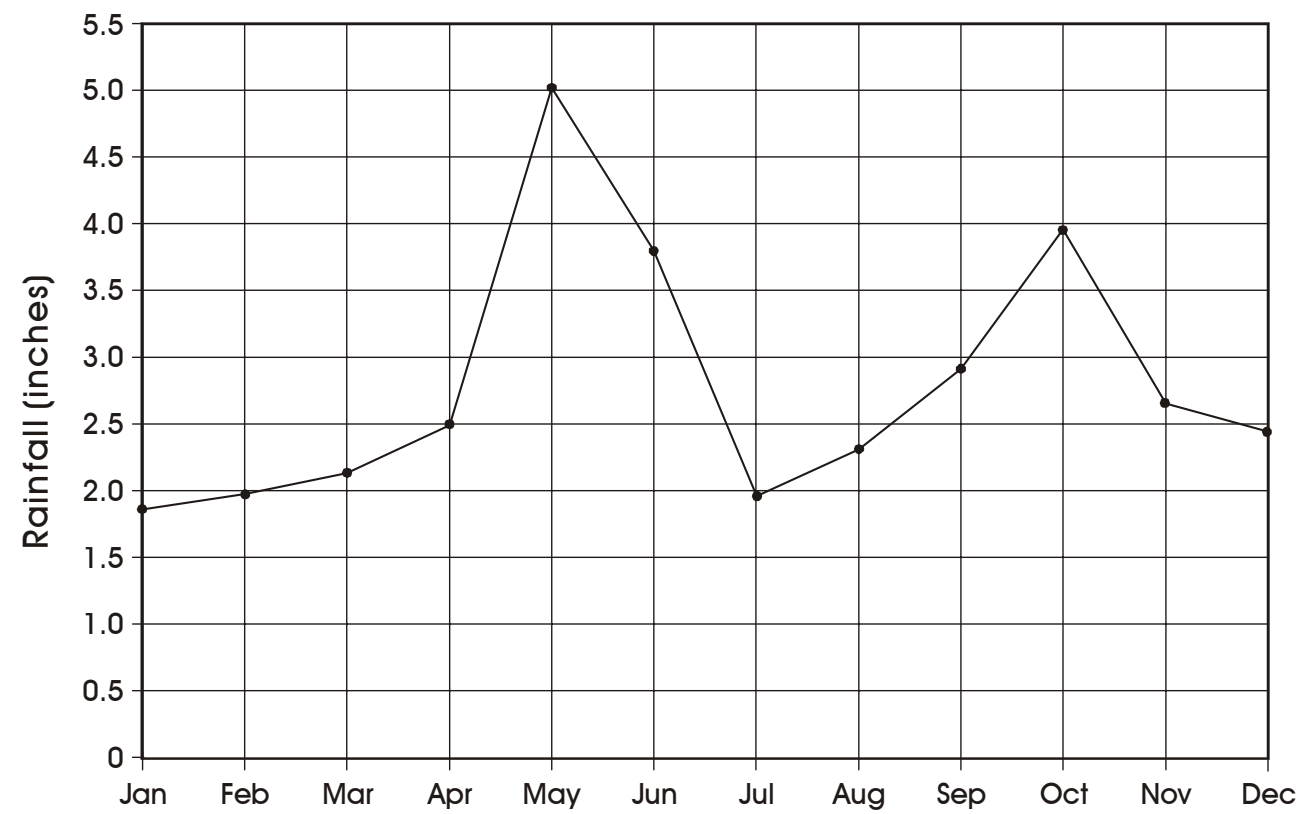

Figure 2-3. Average monthly rainfall for Austin, Texas (1971-2000). 


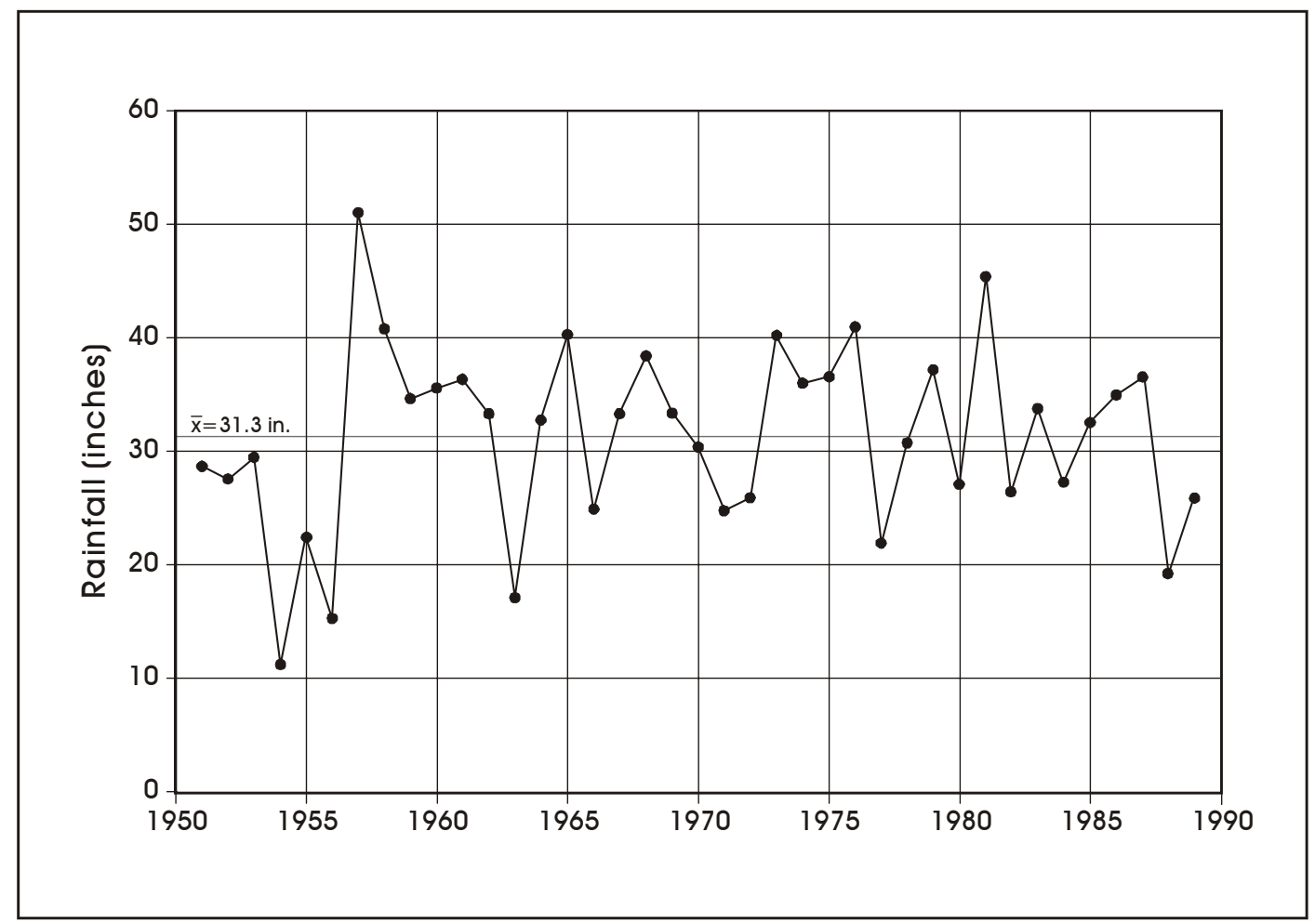

Figure 2-4. Yearly rainfall for Austin, Texas (1951-1989).

\section{Hydrology}

As noted previously, the edge of the Balcones Escarpment has a variety of springs, seeps, and drainages. Reference to Figures 2-5 and 2-6 will show that within a few kilometers of 41TV163, a variety of drainages, creeks, and rivers are present. Foremost among these is the Colorado River, located about $6 \mathrm{~km}$ to the southwest. Bull Creek is roughly $1.5 \mathrm{~km}$ to the west of the site, and several drainages into Bull Creek are in close proximity. In the immediate vicinity are two unnamed drainages with intermittent flows that eventually lead into Bull Creek and the Colorado River. Although several springs are noted on the Jollyville and Austin West USGS 1:24,000 quadrangles, none are noted within $2 \mathrm{~km}$ of 41TV163. However, Kelley (1971:3) notes that the drainage associated with the site was "spring-fed," although the nearby creek beds were dry during the fieldwork (Weir 2004:1).

\section{Floral and Faunal Resources}

Riskind and Diamond (1988) provide an overview of the current vegetation of the Edwards Plateau, including the Balcones Escarpment. Much of the area can be described as a brushland. Dominant trees and shrubs found in the area include ashe juniper (Juniperus ashei) and several species of oak (Quercus sp.), with cedar elm (Ulmus crassifolia), hackberry (Celtis sp.), and Arizona walnut (Juglans major) also present in many areas. The understory commonly includes yaupon (Ilex vomitoria), hoptree (Ptelea trifoliata), Mexican buckeye (Ungnadia sceciosa), and deciduous holly (Ilex deciduas). A variety of grasses are also present. A species list from the Balcones Canyonlands National Wildlife Refuge, an 80,000-acre refuge managed by the U.S. Fish and Wildlife Service (FWS) and located about $30 \mathrm{~km}$ to the northeast of the current site area, lists over 690 species and varieties of plants observed on the refuge (FWS 2003).

The modern vegetation in the general area of 41TV163 is depicted in Figure 2-7 (Texas Parks and Wildlife Department [TPWD] 1984). Oak, mesquite, juniper parkland and woods dominate the region, with the site located on the edge of a large expanse area characterized as Live Oak and Ashe Juniper woods and parkland. Coming off of the Plateau to the east, grasslands are present. It is likely that prior to European settlement of the region in the mid-1800s, grassland was much more common and juniper, along with woody brush and shrubs that dominate the region today, had a much more restricted distribution. 


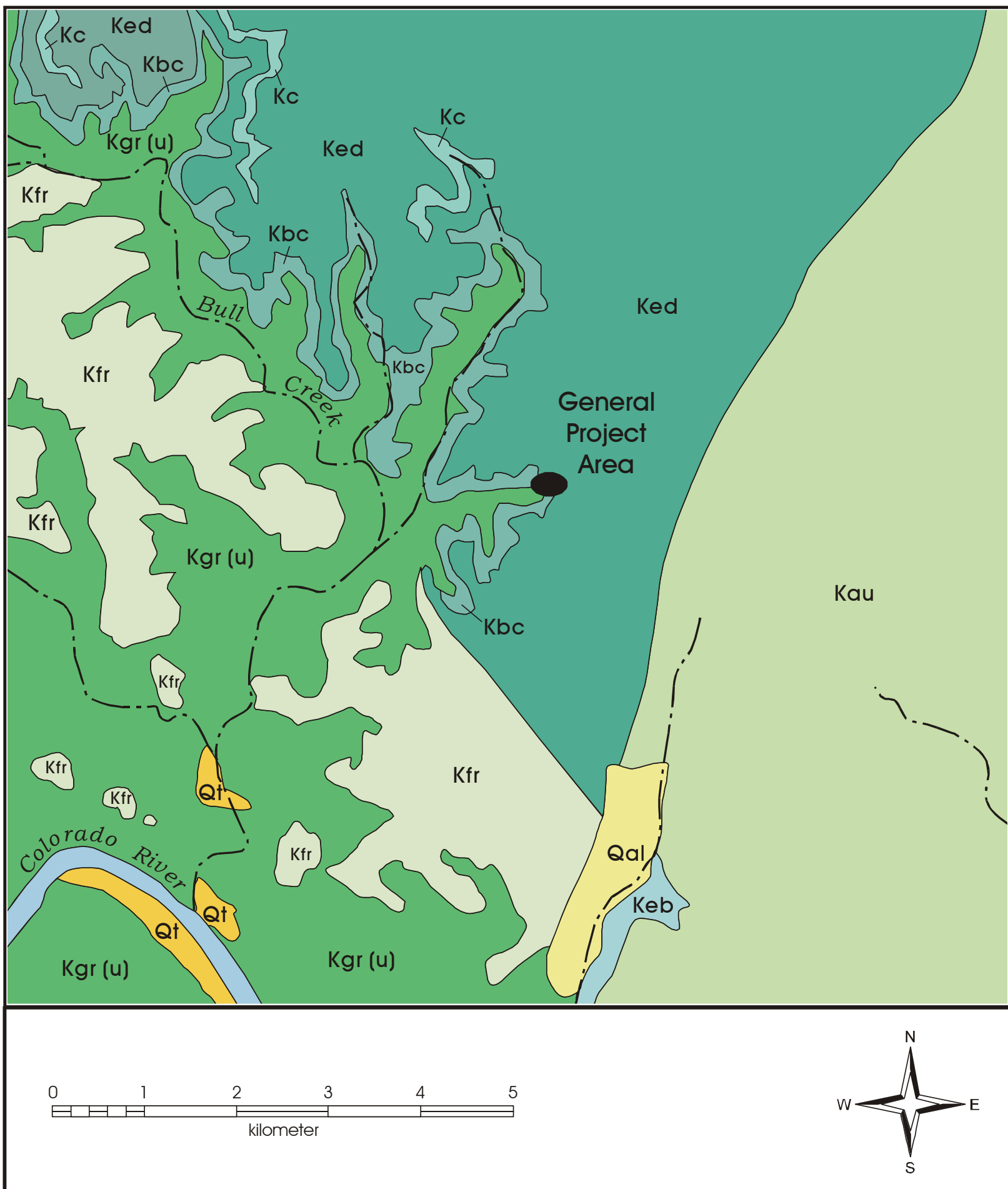

Figure 2-5. Geological setting of 41TV163. 


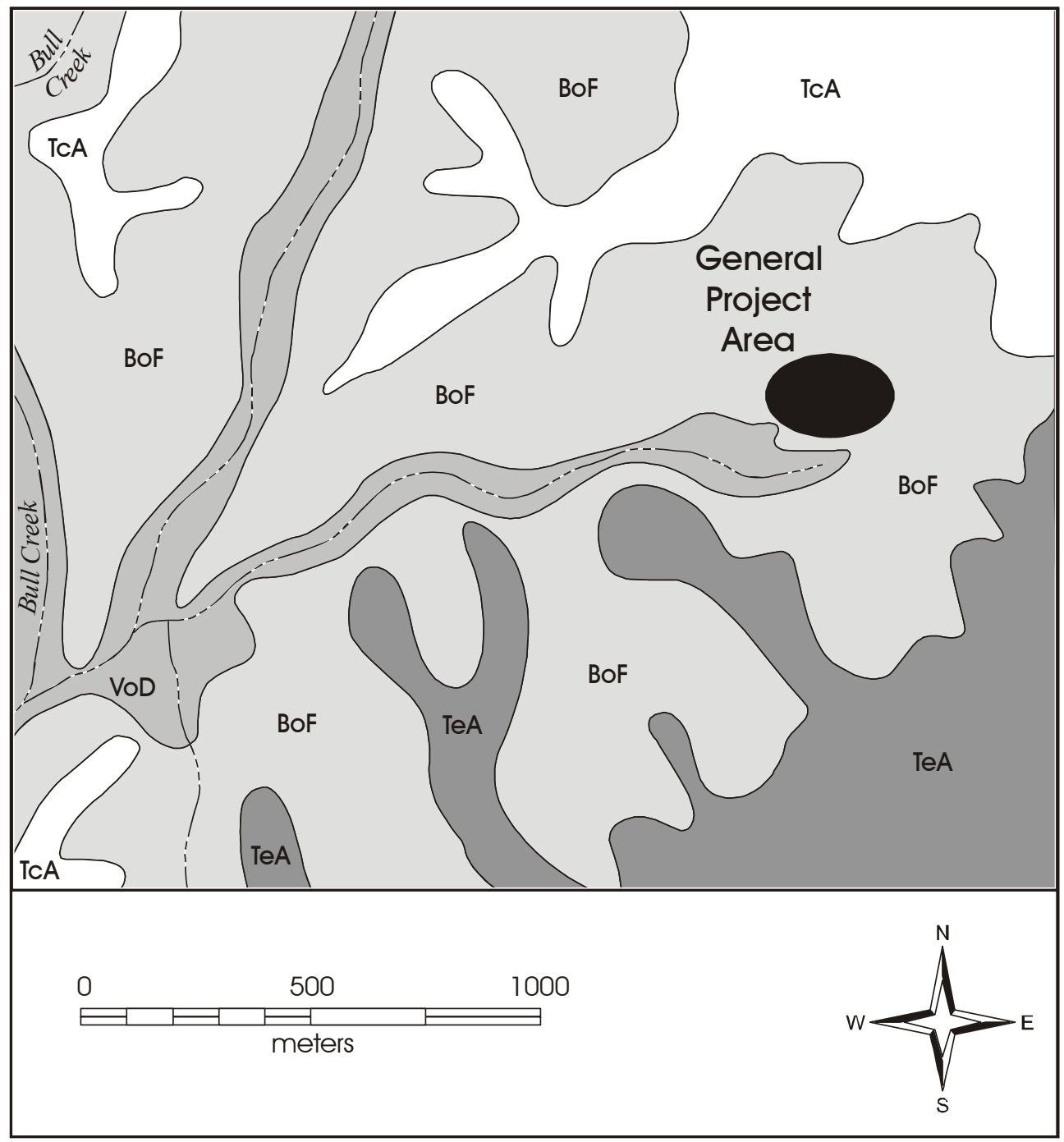

Figure 2-6. Soils in the project area.

Large numbers of white-tailed deer (Odocoileus virginianus) are currently present in the region. Estimates by the Texas Parks and Wildlife Department are that within a 25 county area on the Edwards Plateau, an area that includes Travis County, in excess of 1.5 million white-tailed deer are consistently present (TPWD 2003). However, it is unlikely that the abundance of this game animal is characteristic of the historic or prehistoric periods. Vegetation changes noted previously have clearly allowed the expansion of the deer population. Historically and prehistorically, the grassland savannah that characterized the Plateau probably had significant numbers of grazers such as bison and antelope that are not present today (see Davis and Schmidly 1994). The current vegetation does, however, support a variety of mammals, and Davis and Schmidly (1994) note that the
Plateau has one of the highest mammalian diversity within the state. The species lists from the Balcones Canyonlands National Wildlife Refuge note 35 mammalian species in the confines of the preserve. Some of the more common species listed include black-tailed jackrabbit (Lepus californicus), raccoon (Procyon lotor), eastern cottontail (Sylvilagus floridanus), and a variety of carnivores (FWS 2003).

\section{Paleoenvironmental Conditions}

During the long, though clearly intermittent occupation of the Millican Bench site, most aspects of the environment described in the previous section were certainly different. European settlement has altered the landscape in a number 


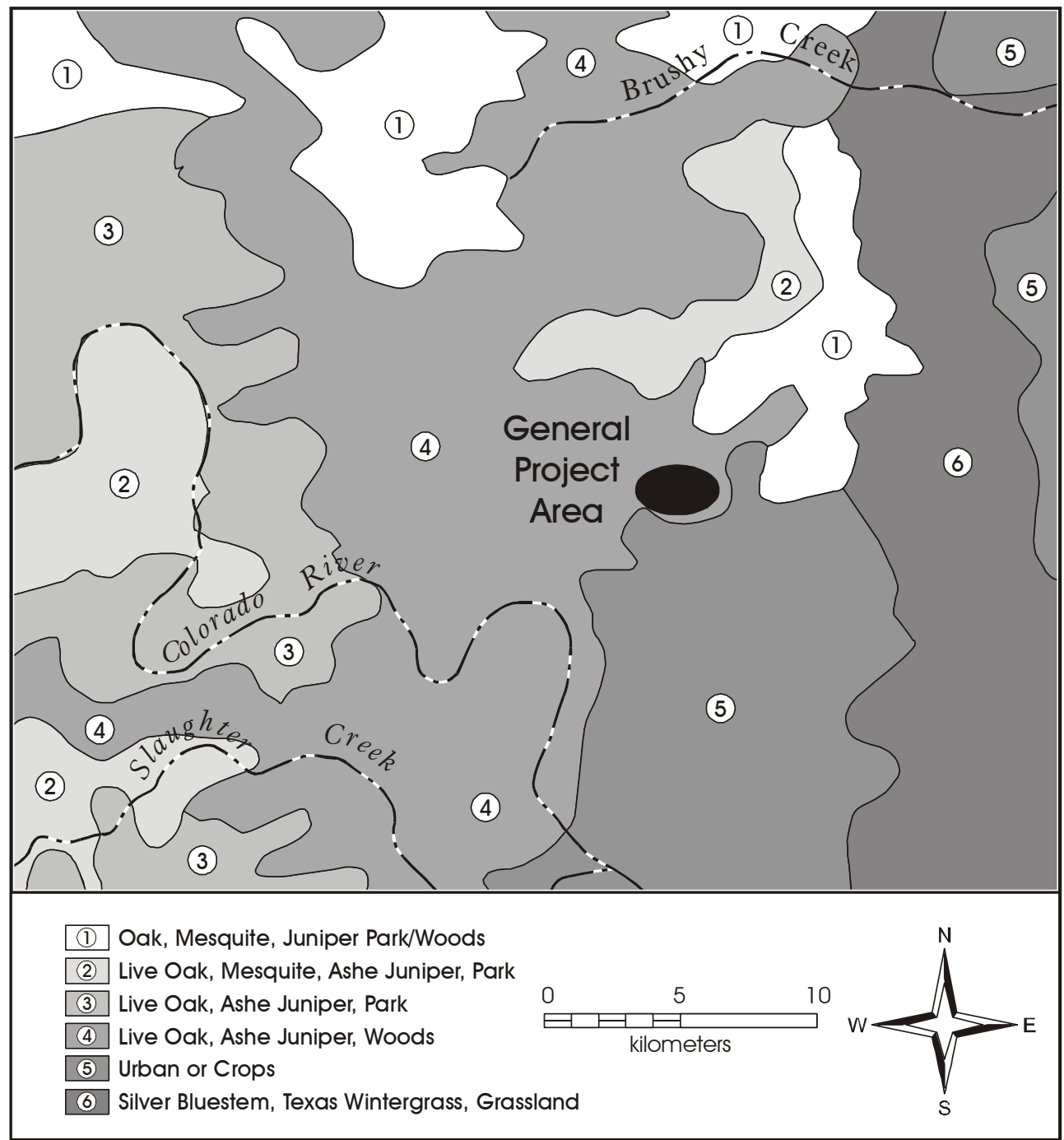

Figure 2-7. Vegetation in the project area.

of ways. The most significant impacts probably were related to the introduction of domestic livestock, fencing, and fire suppression. Several researchers have, using different proxy measures of temperature and precipitation, concluded that major changes have occurred in temperature and precipitation during the last 8,000 years (see Bousman 1998; Collins 1995; Johnson and Goode 1994; Toomey 1993; Toomey et al. 1993). What is not at all clear, however, is the exact nature of these temperature and precipitation changes. There is no consensus on when these changes began, their magnitude, or even the direction of change in some cases. Figure 2-8 makes this point by contrasting a variety of different climate reconstructions for the last 12,000 years in central Texas. Included in the figure are the arboreal canopy estimates based on pollen from Boriack and Weakly bogs in Lee and Leon counties (Bousman 1998), temperature estimates that appear to be based on both changes in fluvial geomorphology and microfaunal remains (Johnson and Goode 1994), changes in moisture regimes based on the presence/absence of bison in archeological sites in Texas (Collins 1995; Dillehay 1974), and two versions of changes in temperature and moisture based on changes in microfaunal remains (Collins 1995; Toomey et al. 1993). While additional sources could have been presented, comparison of the various graphs demonstrates that for certain periods, there is good agreement from several of the models. However, there is a clear lack of consensus during certain periods (e.g., 6000 to $2000 \mathrm{BP}$ ). 
In part, this lack of agreement regarding the nature of past climates in central Texas may be related to the use of different proxy measures that probably are responding to different temporal, moisture, and spatial scales, as well as problems with chronological assignment of specific data sets. For example, changes in effective moisture are measured by a variety of environmental proxies such as vegetation changes reflected in alterations in bog pollen frequencies, the relative abundance of bison recovered from archeological sites, and the frequencies of desert shrews relative to other shrews in cave deposits. It is unlikely that all of these will respond in a similar way given similar environmental changes. That is, differences in rainfall regimes that are of sufficient magnitude to cause threshold changes in the frequencies of certain species of shrews are probably of a different order from those necessary to cause changes in bison abundance, abundance of grass pollen in bog sequences, or changes in rates of flooding in certain streamflow regimes. While any detailed consideration of these types of concerns is beyond the ken of the current section of this chapter, we can limit the potential impact of the problems with scale by limiting the types of data that are investigated as well as focusing on data that may be operating at similar scales. Consequently, in the remaining portion of this chapter we focus primarily on changes in pollen from a single bog, Patschke, located in Lee County (Camper 1991). The bog is relatively well dated and the dates span the occupation range of 41TV163. In addition, Patschke Bog is located only about $60 \mathrm{~km}$ to the east of Millican Bench. While additional paleoenvironmental sources are considered at the close of this section, the focus of our discussion is on Patschke Bog.

\section{Patschke Bog}

Located in Lee County in what is now at the margin of the Post Oak Savannah, Patschke Bog was originally investigated by Potzger and Tharp $(1943,1947)$ more than 50 years ago. Located next to Boriack Bog (Bousman 1998), the early work at Patschke produced evidence of spruce and fir pollen near the bottom of the peat deposits. In addition, Potzger and Tharp (1947) demonstrate shifts in pollen frequencies, especially in oak and grass pollen, which clearly suggest significant vegetation change over the life of the bog. Unfortunately, these early studies of Potzger and Tharp were hindered by a lack of chronometric dates.

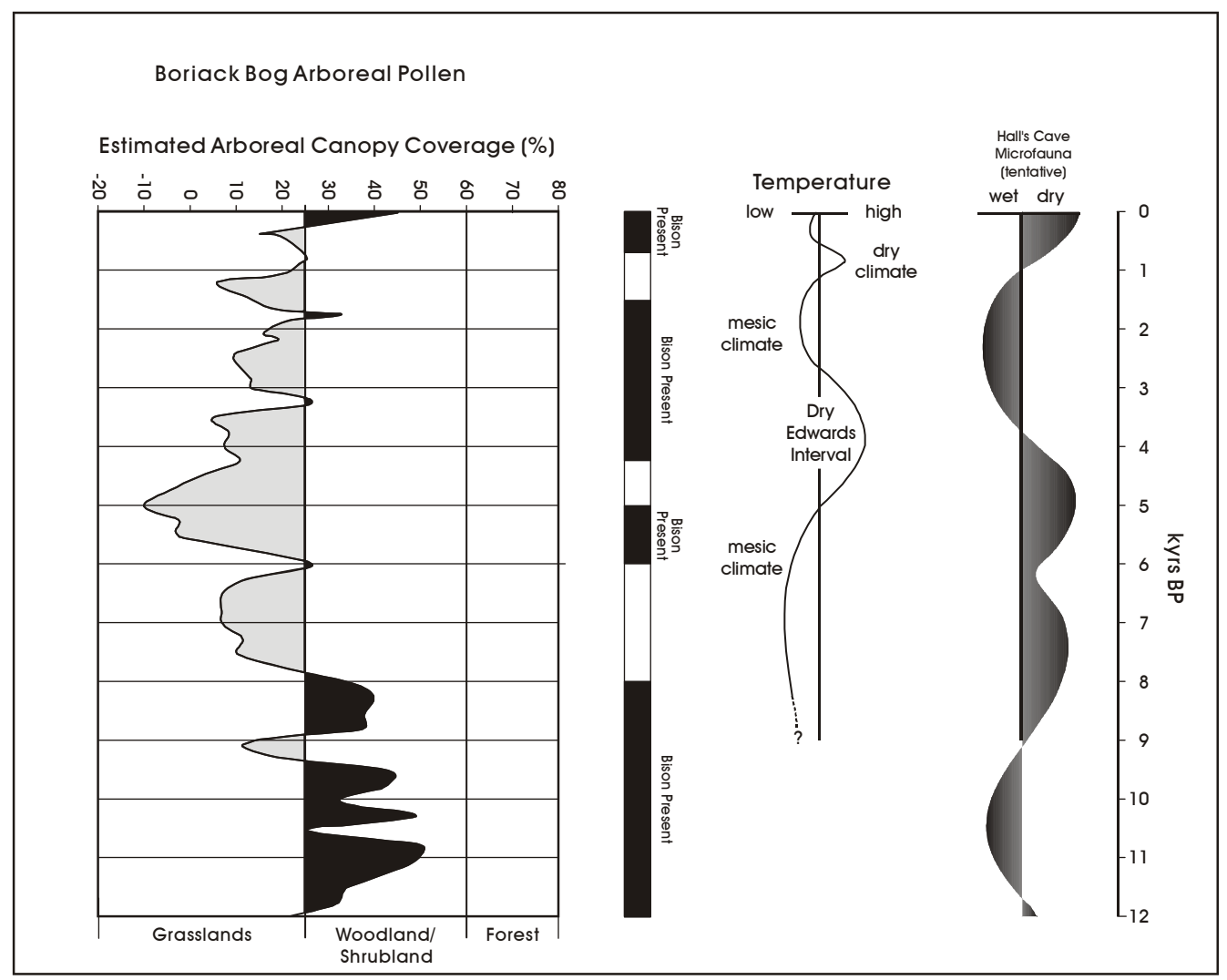

Figure 2-8. Comparison of several climatic reconstructions for central Texas. 
Subsequently, Camper (1991) analyzed an additional set of samples from this bog. These samples, taken from Core 4 at Patschke, reflected roughly 4.66 meters of sediment, and 51 separate samples were analyzed (Camper 1991). The dating of the samples is based on four radiocarbon dates taken from the core at $35 \mathrm{~cm}$ below surface $(1590 \pm 60 \mathrm{BP})$, $190 \mathrm{~cm}(10,090 \pm 130 \mathrm{BP}), 274.5 \mathrm{~cm}(13,470 \pm 170 \mathrm{BP})$, and $462 \mathrm{~cm}(17,280 \pm 270 \mathrm{BP})$. These dates are consistent with others obtained from an additional core (Core 2) located less than two yards away from Core 4 (Camper 1991:31).

The samples analyzed by Camper appear to represent a continuous and relatively well-dated sequence stretching back to 17,000 BP. However, this particular core has frequently been downplayed in regional overviews as these data have significant frequencies of local marsh taxa, such as Alnus and Cyperaceae (see Bousman 1998:207-208). These local taxa make the identification of regional vegetation shifts difficult. In an attempt to clarify the pattern of regional change indicated at Patschke Bog, Nickels and Mauldin (2001) reviewed the raw pollen grain counts from Patschke (Camper 1991). While Bousman (1998) is correct in noting the high level of marsh taxa throughout the deposits, Nickels and Mauldin (2001) note that Camper's grain counts are extremely high, with an average of just over 370 grains per sample, and a minimum count of 270 grains for any single sample. They reworked the original data, eliminating the potential contaminants from the Patschke Bog pollen sequence (Nickels and Mauldin 2001:34-35). The reworked Patschke data have an average of 215 counted grains per sample, and in only three cases do counts fall below 100 grains. All three cases with counts of less than 100 pollen grains date before $11,000 \mathrm{BP}$, and two of these date well before any human occupation in the region.

The line graph in Figure 2-9 uses the revised counts of arboreal pollen to estimate habitat type over the last 12,000 years. Following Bousman's (1998:212) study of Boriack Bog and Weakly Bog pollen, the figure was derived using the linear regression formula of Shaw et al. (1980) that relates arboreal pollen percentages and arboreal canopy cover on the Edwards Plateau, as well as definitions of canopy cover and habitat type developed by Diamond et al. (1987). Surprisingly, the sequence presented in Figure 2-9 suggests that grasslands probably dominated much of what is now post oak woodland over the last 12,000 years. Woodlands and shrublands are the dominant habitat for much of the period between 12,000 and about 10,000 years ago, with forest habitats only reflected for a brief period around $10,500 \mathrm{BP}$. Between approximately 10,000 and 6,000 years ago, grasslands dominated the area, with a woodland/shrub community indicated between about $6000 \mathrm{BP}$ and $5000 \mathrm{BP}$. Over the next 3,000 years, the vegetation seems to have fluctuated between grasslands and woodland/shrub vegetation. Grasslands were clearly established after about 1800 BP. About 400 years ago, the woodland/shrub vegetation currently present in the region replaced that grassland community.

Note that multiple data points support several of the patterns summarized above, and the estimates of habitat type are strongly expressed. That is, they are, in most cases, not borderline interpretations. We suggest that the vegetation changes of sufficient magnitude to result in the strong patterns in Figure 2-9 probably reflect regional changes in effective moisture, with periods characterized as woodlands/ shrub vegetation correlated with increased effective moisture, and grasslands characterized by reduced effective moisture. As such, these changes should be reflected in other data sets that operate at a similar scale. Below the Figure 2-9 line graph we present one such data set, derived from Dillehay (1974) and Collins (1995), which reflects the presence/absence of bison in Texas (see Figure 2-8). While the timing of bison presence/absence may certainly have as much to do with climate and vegetation conditions in the central plains as with conditions in Texas, there does seem to be some general relationship between the reconstructed vegetation and the presence of bison. Bison tend to be present during all periods when woodland/shrub vegetation is reflected by the Patschke arboreal pollen. While bison are also present in some cases with a grassland vegetation regime (e.g., 10,000-8,000 years ago), they are always present when a higher effective moisture regime is indicated in the Patschke sequence.

Finally, note that while there are general similarities between the reconstruction of habitat presented by Bousman (1998) from the combined Boriack and Weakly bogs (see Figure 2-8) and the reconstructions presented here based on Patschke (Figure 2-9), there are also several important differences. The two major differences in the sequences are the suggestions in the Patschke reconstruction of a brief woodland/shrub community between about 5,000 and 6,000 years ago, and a grassland setting between roughly 8,000 and 9,000 years ago. Reasons for these differences are not known, though it may certainly be related to the assignment of dates to the various sequences. While the four radiocarbon dates used to assign ages to the Boriack Bog samples probably are an accurate reflection of the Boriack pollen sequence ages, note that the dates are not from the pollen core, but rather from a second core (Core A) located just to the east of the pollen core. 


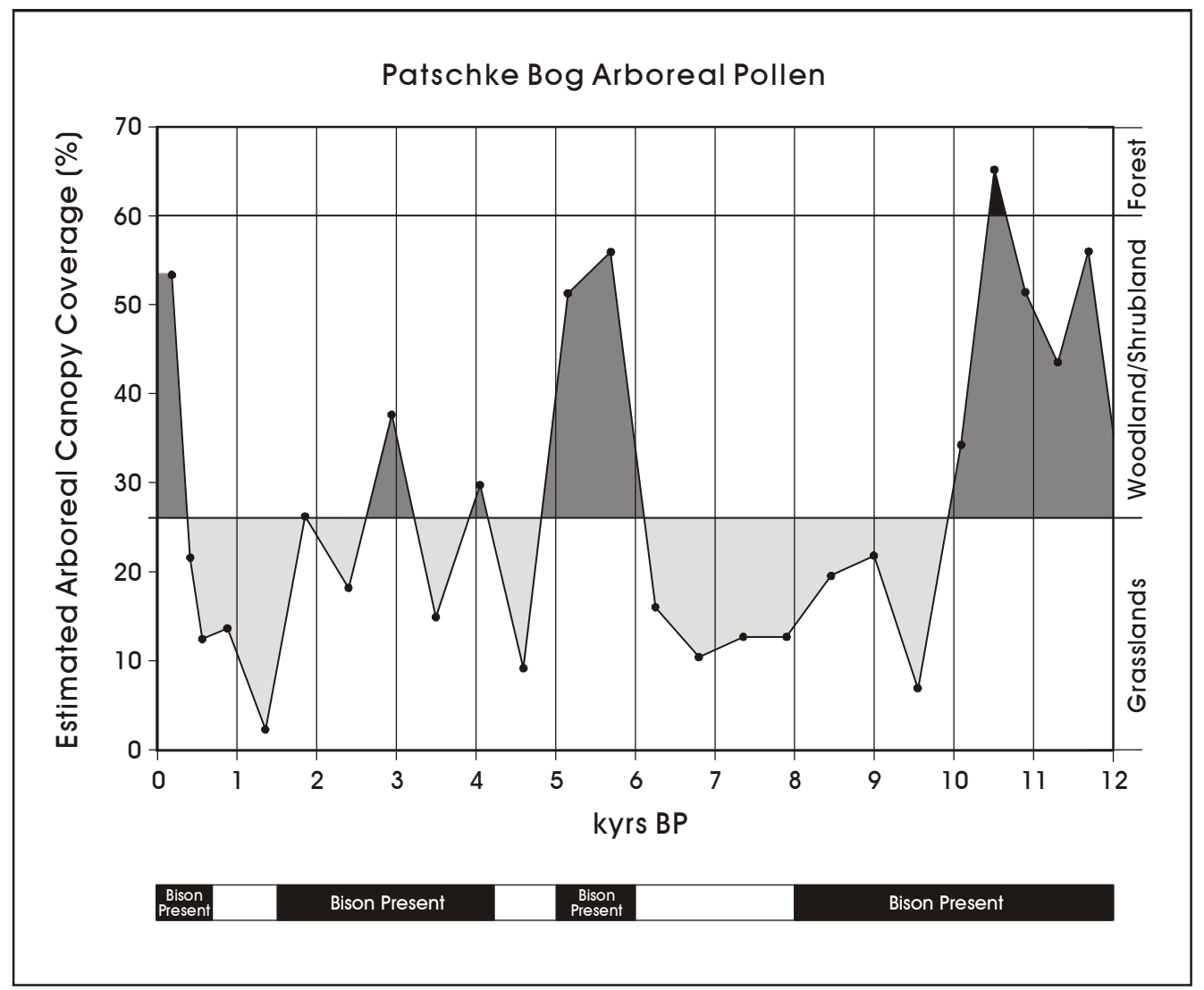

Figure 2-9. Estimated arboreal canopy coverage from the Patschke Bog pollen core.

\section{Summary}

As noted in the previous chapter, diagnostic projectile points from Millican Bench reflect occupation during most periods from the Early Archaic through the Late Prehistoric. Over this roughly 7,500-year period, the environment has clearly undergone a number of changes. Relying primarily on pollen data from Patschke Bog, we can suggest that the earliest occupation of the site, which seems to be reflected by the recovery of several Early Split Stem points (ca. 8000 BP), probably occurred during a relatively dry period in the Early Archaic. The presence of several Martindale and Uvalde points suggest that occupation probably continued throughout the dry Early Archaic. The early portion of the Middle Archaic, from roughly $6000 \mathrm{BP}$ to $5000 \mathrm{BP}$, seems to be a relatively wet period as indicated by both the return of a woodland habitat to the Patschke area and the return of bison to the region. Interestingly, this relatively mesic period is not well represented at 41TV163, with only a single Andice point present. A return to a more xeric climate after $5000 \mathrm{BP}$ is accompanied by a substantial occupation at 41TV163 as reflected by the recovery of roughly 39 Travis and Nolan points (ca. 4800-4000 BP). Occupation continues through the Middle Archaic, the Late Archaic, and into the early Late Prehistoric (ca. 4000-1250 BP). The lack of Late Prehistoric point forms dating after 700 BP (e.g., Perdiz) at Millican Bench suggests the site may have not been used after that date. The early portion of this period (ca. 4000$1800 \mathrm{BP}$ ) was characterized by a climatic regime that seems to have fluctuated between slightly mesic and xeric conditions. The period between $1800 \mathrm{BP}$ and roughly 400 BP seems to reflect primarily xeric conditions, after which a more mesic regime seems to have been present. 


\title{
Chapter 3: Previous Research and Archeological Background
}

\author{
Harry J. Shafer and Steve A. Tomka
}

The eastern edge of the Edwards Plateau in central Texas has the best-defined cultural chronology within the state. This well-defined chronology is the result of three factors: (1) a region of intense archeological activity throughout much of the twentieth century; (2) well-preserved archeological sites, including deeply buried stratified deposits along streams; and (3) a continuous cultural chronology lasting about 11,500 years. In this chapter, we present a brief overview of the history of archeological research and a summary of the regional cultural chronology. As one reads this summary, however, it is worth remembering that in 1971, at the time of the fieldwork at 41TV163, much less was known both about the regional chronological sequence as well as the changes in land-use strategies and subsistence patterns documented subsequently from dozens of excavations throughout central Texas.

\section{Previous Archeological Research}

Archeologists have been active in Travis County, and indeed in the vicinity of 41 TV163, for nearly a century. J. E. Pearce became interested in central Texas burned rock middens, or "kitchen middens" as he described them, as early as 1919. $\mathrm{He}$, and later his primary field archeologist A. T. Jackson, excavated numerous burned rock middens in Travis, Williamson, Burnet, Llano, San Saba, and Hays counties prior to and during the Works Progress Administration projects (Collins 1972; Jackson 1938; Prewitt n.d.; Suhm 1957; Woolsey 1938). Among these sites was the Rogers Springs site that was located around a cluster of springs that formed the waters of Shoal Creek in north Austin not far from 41TV163. Rogers Springs had four burned rock middens, and Pearce and his crews excavated three (Prewitt n.d.). The Texas Archeological Survey excavated the fourth in 1973 (Prewitt n.d.).

Numerous archeological investigations of prehistoric sites have been conducted in Travis County and the surrounding region, and have provided a good resolution to the local archeology. Some of these studies helped to establish the basic foundation for central Texas archeology (Collins 1972; Greer and Benfer 1975; Kelley 1947; Kelley and Campbell 1942; Prewitt 1974, n.d.; Suhm 1955, 1957, 1959; Weir 1979; Wesolowski et al. 1976). Others contributed significantly to ongoing chronological refinements (Coffman et al. 1986;
Collins 1998a; Prewitt 1974; Ricklis and Collins 1994; Suhm 1955; among others), and to the study of burned rock middens (Black et al. 1998a, 1998b; Collins 1972, 1998b; Kelley and Campbell 1943; Nickels et al. 2001; Prewitt 1974; Ricklis and Collins 1994; Sorrow 1969).

On a regional scale, recent investigations have resulted in refined chronological models for the Edwards Plateau and the Canyonlands, of which 41TV163 and western Travis County are on the periphery (Collins 1995, 1998b; Collins et al. 1990; Henderson 2001; Johnson 1991, 2000; Johnson and Goode 1994; Kibler and Scott 2000; Mahoney et al. 2003b; Nickels et al. 2001; Shafer 1963; Sorrow et al. 1967; Wesolowski et al. 1976). Most significant of these are the investigations at the Gault Site (Collins 1999:185-190; Shafer and Waters 2001) and Wilson-Leonard (Collins 1998c) in Bell and Williamson counties, respectively. Together, these two sites have yielded evidence for an unbroken chronology from Clovis to Late Prehistoric times.

\section{Cultural Chronology}

On a regional scale, archeologists have divided this chronology into periods and intervals in order to better isolate blocks of time for study and interpretation (Black 1995; Collins 1995, 1998a; Hester 1995; Nickels et al. 2001). The broad periods are roughly defined on the basis of lifestyles and hunting and gathering technologies and are identified by general similarities in artifact assemblages. Four broad periods have been defined: Paleoindian, Archaic, Late Prehistoric, and Historic. Intervals within each of these time units are defined by diagnostic artifacts and artifact assemblages used during shorter increments of time.

Recent archeological summaries of central Texas have been presented by Collins (1995, 1998a), Nickels et al. (2001), and Ricklis and Collins (1994). The chronological model followed in this report is that of Collins (1998a:Figure 4.1). He used both the chronological data at the Wilson-Leonard site and comparative data from 31 sites across central Texas. This chronological model extends from the initial occupation of the state by Clovis hunters beginning about 11,500 radiocarbon years ago (Ferring 2001:205) to the period of European contact, which occurred in parts of central Texas by 1690 (Foster 1995; Gilmore 1969; Wade 
2003). Although Collins' scheme differs from Weir's (1976) original divisions of the chronology, it is used here simply as a chronological anchor rather than a statement on the appropriateness of one scheme as opposed to another.

No Paleoindian or historic components were identified in the excavations at 41TV163. Prehistoric occupation at 41TV163 was confined to the Archaic and early part of the Late Prehistoric periods. While a small amount of glass and metal was found, suggesting the possibility of historic occupation, much of that material appears to be of fairly recent age. Therefore, the following brief review of the region's cultural history will not address the Paleoindian or Historic periods.

\section{Archaic Period}

The Archaic period, dating from 7000 B.C. to A.D. 800 (9000-1200 BP), marks a long time span of hunting and gathering as the main lifestyle (Black and McGraw 1985; Collins 1995, 1998a). Beginning the period at 9000 BP is arbitrary, and somewhat misleading. There was no sudden change from big game hunting to hunting and gathering. This was a gradual process that took place over many generations, and to varying degrees. Archeologists assume that sites that lack extinct fauna and contain stemmed points, burned rock, and white-tailed deer remains reflect Archaic land-use strategies and identify the Archaic period.

\section{Early Archaic (9000 BP to 6000 BP)}

Human populations in the Early Archaic were highly mobile (nomadic) groups sparsely scattered across the land. Projected population density was low (Weir 1976:119-140), but these estimates lack a quantitative basis. We will never know the rate or density of ancient populations since there is no way of correlating the number of people to various levels and characters of the archeological signatures without the benefit of culturally defined parameters (such as rooms, cemeteries, or villages).

The incipient stage for earth oven baking first documented in the late Paleoindian period continued in the Early Archaic, and eventually resulted in the formation of burned rock middens. One of the important characteristics of Early Archaic sites is the presence of burned rock features and the use of limestone in earth oven cooking, sometimes resulting in dense clusters of burned rocks or "proto burned rock middens" (Collins et al. 1998). Hearth features and/or dense concentrations of burned rock attest to the presence of earth ovens (Collins et al. 1998; Sorrow et al. 1967).
Deer, jackrabbits, cottontail rabbits, turtles, fishes, mollusks, and other small game provided the major resources for meat, while seasonal nuts and fruit, bulbous plants, and probably succulent green vegetables surely helped to provide a more balanced diet. Charred bulbs of wild hyacinth from hearth feature 181 at Wilson-Leonard and the presence of manos and metates provide solid evidence for plant use (Collins et al. 1998:216-239). It was during the Early Archaic that the Paleoindian lanceolate dart point forms gave way to stemmed forms. Diagnostic artifacts for the Early Archaic include projectile point forms and types such as Angostura, Early Split Stem, early bifurcated stem (Uvalde, Gower), Bandy, and Martindale. Other tools include triangular adze blades (Clear Fork tools), elongated or "trihedral" adzes (Guadalupe tools), unifacial flake knives, manos, and notched pebbles (Waco sinkers). Sites with Early Archaic components include the Barton Site (Ricklis and Collins 1994), Granite Beach (Crawford 1963), Landslide (Sorrow et al. 1967), Youngsport (Shafer 1963), Jetta Court (Wesolowski et al. 1976), Wilson-Leonard (Collins et al. 1998), Gault (Shafer and Waters 2001), Richard Beene (Thoms et al. 1996), and Panther Springs (Black and McGraw 1985). The only site with mortuary evidence dating to this period is Bering Sinkhole, where burials were deposited in the flesh, as cremations, or as secondary interments (Bement 1994). Human burials were deposited in this sinkhole throughout much of the Archaic period.

\section{Middle Archaic (6000 BP to $4000 \mathrm{BP}$ )}

Middle Archaic artifact assemblages show a continuation of the broad hunting and gathering patterns established in the preceding period. Point styles change and the notched pebbles are no longer produced. The frequency of adze blades is greatly reduced, and they tend to be unifacially made (Collins et al. 1998). These changes suggest subtle shifts in regional ecology and lifeways, perhaps brought about by the presence of bison. Diagnostic artifacts include the projectile point types Andice, Bell, Early Triangular, Nolan, Travis, and (to the southwest) Pandale. Other tool types include manos, metates, and unifacial knives. The use of limestone in earth oven baking increased due to more intensive use of plant resources. Weir (1976) attributes the greater visibility of material remains at this time to population increase. Deer and bison were the larger animal species exploited; plant foods included bulbous plants, possibly sotol or other succulents, walnuts, pecans, acorns, and undoubtedly green and flowering vegetables. One hallmark of the Middle Archaic period is a more intensive use of local resources, presumably brought about, in part, by population increases and perhaps circumscription. 
Middle Archaic components were documented at Landslide (Sorrow et al. 1967), Wilson-Leonard (Collins et al. 1998), Jetta Court (Wesolowski et al. 1976), Sleeper (Johnson 1991), Bering Sinkhole (Bement 1994), Camp Pearl Wheat (Collins et al. 1990), Crumley (Kelly 1961), and Cibolo Crossing (Kibler and Scott 2000). Recently, the Royal Coachman site (41CM11) produced a well-dated Early Archaic component consisting of Early Triangular points and radiocarbon dates of 5880-5320 BP (Mahoney et al. 2003b). Again, mortuary evidence is lacking except for Bering Sinkhole that was used as a depository during this period. Burials occurred in the flesh or as cremations (Bement 1994:Table 17).

\section{Late Archaic (4000 BP to 1200 BP)}

The Late Archaic period represents a further development of Middle Archaic patterns and probably the first archeological indication of established group territories. Weir (1976) sees the population approaching its peak at this time. The exploitation of local plant foods intensifies, perhaps in response to increased population sizes or reduced territory sizes. Climate becomes more mesic, and these conditions may have increased the natural populations of deer and economic plants, thus increasing the carrying capacity. The results are greater frequency of burned rock middens and other thermal features for cooking. Deer and bison were the larger game species exploited, but small game such as jackrabbits, cottontail rabbits, turtles, fishes, mollusks, and snails also were consumed. Plant lists are scant, but among those known to have been used were sotol (probably western Travis County and westward) and bulbous plants such as prairie turnip, wild onions, and camas (Black and Creel 1997; Dering 2000, 2003).

Diagnostic artifacts for the period include the projectile point types Bulverde, Pedernales, Montell, Castroville, Marshall, Marcos, Ensor, Fairland, and Darl, and knife forms such as the butted knife, corner tang, and base tang knives (Collins et al. 1998; Turner and Hester 1999:243). The generally accepted sequence for these point styles is (from earliest to latest) Bulverde, Pedernales, Montell/Castroville/ Marshall/ Marcos, Ensor/Fairland, and Darl.

Excavated Late Archaic components were recorded at Evoe Terrace (Sorrow et al. 1967), John Ischy (Sorrow 1969), Wilson-Leonard (Collins et al. 1998), Jetta Court (Wesolowski et al. 1976), Jonas Terrace (Johnson 1995), Mustang Branch and Barton sites (Ricklis and Collins 1994), Kenyon Rockshelter (Coffman et al. 1986), Rogers Springs (Prewitt n.d.), Crumley (Kelly 1961), and Collins (Suhm 1955).
More information is available on mortuary patterns during this interval than the previous ones. Mortuary patterns varied somewhat according to location within the landscape. West of the Balcones Escarpment in the karstic limestone environment where solution cavities, rockshelters, and sinkholes occur, sinkholes and rockshelters were used as ossuaries (e.g., Bement 1994; Benfer and Benfer 1981; Givens 1968). Burials were deposited in the flesh (probably wrapped in bundles cf. Aveleyra et al. 1956), or as cremations (Bement 1994:Table 17). Cemeteries are not generally present west of the escarpment although isolated single burials occur in burned rock middens and other open-air sites (Steele and Olive 1989:Table 7). Ossuaries do occur east of the escarpment (e.g., Polecat Hollow [Greer and Benfer 1975; Johnson 2000; Lukowski 1988; Prewitt 1974], 41BX1, Loeve-Fox, and Pat Parker). Burials tend to be tightly clustered, perhaps enclosed within a designated structure or marked space. This pattern begins in the Late Archaic and continues into the Austin Phase of the Late Prehistoric period. For instance, in a small burial pit at the Bessie Kruze site (41WM13) archeologists recovered the uncremated remains of at least three, and more likely four, individuals. The burials appear to be contemporaneous (1480 B.C.) with the manufacture of Pedernales points. At the Pat Parker site in eastern Travis County a small cemetery containing flexed burials dates to the Late Archaic and Late Prehistoric (Austin Phase; Greer and Benfer 1975). While the burials were assumed to belong to the Austin Phase, several Darl points also were found in association. Whether the latter were accidentally intermixed with the burial fill or dated the burials cannot be determined based on the information provided. More likely, the cemetery was used during both time intervals. An almost identical situation occurred at Polecat Hollow on Walnut Creek in Austin where burials were interred from deposits yielding Late Archaic (Darl and Fairland) and Austin Phase materials (notes in Travis County files at TARL). Other Late Archaic cemetery sites include Bering Sinkhole (Bement 1994:Table 17) and 41BX1 in Bexar County (Lukowski 1988).

\section{Late Prehistoric Period}

The Late Prehistoric (A.D. 800 to A.D. 1690, as per Collins 1995) is marked by a major technological change, the introduction of the bow and arrow. Archeologists have divided the period into two intervals or phases, Austin and Toyah, based on differences in the archeological assemblages (Henderson 2001; Jelks 1962; Kelley 1947; Shafer 1977). Evidence for the change is seen in the replacement of the larger Ensor, Fairland, and Darl points by small delicately shaped corner-notched arrow points. 


\section{Austin Phase}

The first part of the Late Prehistoric shows no significant change in subsistence from the Late Archaic period, as extensive use of earth ovens continued along with the formation of burned rock middens (Black and Creel 1997). Deer and small game were the most important meat sources along with mollusks and snails. Plant resources included sotol (where available), pecans, acorns, walnuts, wild fruit, and various green vegetables. The corner-notched arrow points occur in three recognizable styles: Scallorn, Edwards, and Sabinal. Scallorn points are the earliest style in the northern half of central Texas (Jelks 1962), while Edwards may be the earliest in the southern Edwards Plateau (Henderson 2001; Hester 1978; Sollberger 1978). Sabinal was suggested to be the more recent form. Evidence form Rainey Sinkhole, however, suggests that while Edwards appeared in the earlier deposits, all three forms were contemporaneous in later lenses (Henderson 2001:221).

Austin Phase components were recorded at Collins Site (Suhm 1959), Smith Rockshelter (Suhm 1955), Mustang Branch (Ricklis and Collins 1994), Kenyon Rockshelter (Coffman et al. 1986), Frisch Auf! (Hester and Collins 1969), and Pat Parker (Greer and Benfer 1975).

Formal cemeteries or ossuaries suggest some adherence to territorial claims and seasonal settlements. Loeve-Fox in Williamson County (Prewitt 1974), Pat Parker (Greer and Benfer 1975) and Polecat Hollow in Travis County (notes on file at TARL), and Frisch Auf! in Fayette County (Hester and Collins 1969) are examples. Burials were mostly single, flexed, and in the flesh, but a small number were cremated.

\section{Toyah Phase}

The most significant change occurs in the latter part of the Late Prehistoric period with the Toyah Phase. There is little question that the Toyah "techno-complex" (Ricklis 1994a) is associated with the return of bison across central Texas and the Canyonlands. Henderson (2001), using the dated stratified deposits at Rainey Sinkhole, places the beginning of the Toyah Phase at about A.D. 1250. The Toyah Phase lasted at least until A.D. 1650 (or later; see Collins 1995 and Johnson 1994), and may have been absorbed into the Spanish Mission period (Hester 1995). Deer and antelope continued to be exploited, but the quest for bison may have changed traditional territorial ranges and the human landscape. Perdiz arrow points replace the corner-notched forms as the major arrow point style, and pottery was produced in the region for the first time. The overall artifact assemblage reflects an economy that emphasized hunting and hide processing. End scrapers, flake perforators, large, thin bifaces (often with beveled edges), a blade technology, and locally made pottery constitute the diagnostic assemblage. Rock-lined hearths, ash basin hearths, and bone concentrations constitute the major site features (Henderson 2001; Johnson 1994). The fact that many Central Texas burned rock middens produce radiocarbon dates contemporary to the Toyah Phase suggests that bulk plant processing may have been practiced at least on a seasonal basis (Mauldin et al. 2003). Toyah material culture has been attributed historically to the Jumano and related groups (Kelley 1986). There is virtually no mortuary data for the Toyah Phase. Jelks (1962) reports a cremation at the Kyle Site. The dead may simply have been disposed on the surface covered with brush (Campbell 1983).

During the later part of the Late Archaic, the Woodland period, archeological evidence from northeast Texas suggests that hunter-gatherer adaptations took on a more sedentary nature (Perttula et al. 1993). This process of increased sedentism eventually appeared to culminate in the emergence of food producing adaptations and increased social complexity noted within the western Gulf Coastal Plains Caddoan area of northeast Texas (Perttula 1997: Figure 1). This development is critical because beginning with the Formative Caddoan period through the early Historic period, the Caddoan culture area plays a major roll in regional interaction spheres and the movement of prestige goods and economic resources (i.e., bow wood) across large areas. Because we have not noted any direct or indirect evidence of Caddoan materials within the collection from the Millican Bench site, we will not discuss in detail the cultural processes that unfolded in the Caddoan culture area contained within Texas. Rather, we refer the reader to the extensive and varied literature cited by Perttula (1997). 


\title{
Chapter 4: Field and Laboratory Methods
}

\author{
Harry J. Shafer, Marybeth S. F. Tomka, Richard B. Mahoney, \\ Frank A. Weir, and Raymond P. Mauldin
}

This chapter provides a review of the field and laboratory methods used to excavate and process the archeological material from site 41TV163. As noted in Chapter 1, the fieldwork, conducted in 1970 and 1971, was under the direction of Dr. Frank Weir. Unfortunately, a large portion of the Field Director's journal was lost, and no general description of the site exists in the available notes. The description of the excavation that follows was reconstructed primarily from unit/level forms, feature forms, profiles, specimen inventory forms, correspondence, photographs, and notes on field sacks. Additional information is taken from a preliminary hand-written draft manuscript by Weir penned sometime after the end of the 1971 season. The recollections of Dr. Weir, as well as those of Dr. Shafer who visited the site during excavation, supplemented these sources.

\section{Field Work at 41TV163}

The Millican Bench site was situated in a small, protected, steep-sided valley near the head of an unnamed dry tributary of the Colorado River. The site consisted of large concentrations of burned rock and chipped stone situated on a topographic bench, an adjoining slope, a creek terrace, and a topographic prominence, the last separated from the former by the creek (Figure 4-1). Area A was located at the northern extremity of the site on the topographic bench which extended south approximately $12 \mathrm{~m}$ from a low limestone bluff. The bluff, approximately $3.65 \mathrm{~m}$ high, consisted of thick layers of hard limestone sandwiching thin layers of chalky marls. No evidence of cultural materials existed above the bluff. The bench was a limestone outcrop topped with soils made up of decayed marls and humus at least 50 $\mathrm{cm}$ in thickness at the bluff with a south inclination of less than 15 degrees. In addition, a burned rock midden, roughly $12 \mathrm{~m}$ in diameter, was situated on the bench with a surface dip from 10 to 15 degrees. From the approximate south edge of the limestone bench, the slope broke in a 20-degree or more talus from the bench, flattening to a five-degree slope on the terrace below. A second burned rock midden (Area B) was situated on this slope. This burned rock midden measured about $7 \mathrm{~m}$ east-west and $12 \mathrm{~m}$ north-south. Located on the terrace immediately west of Area B was a scatter of burned rock and chipped stone that measured approximately $12 \mathrm{~m}$ north-south and $15 \mathrm{~m}$ east-west. This concentration was identified with two different area designations, $\mathrm{C}$ and D. Area D consisted of a stony surface of scree deposit and severely diminished numbers of burned rock and chipping debris. The surface elevation of the terrace was less than $1.6 \mathrm{~m}$ above the adjoining creek bed. On a topographic prominence located southeast across the creek from Areas $\mathrm{B}$ and $\mathrm{C}$, comparably situated on the same formation as Area A, were three additional areas, E, F, and G. Area E was a small burned rock midden that measured roughly $4 \mathrm{~m}$ in diameter. Area F, which measured about $30 \mathrm{~m}$ east-west, can best be described as an area of occupation refuse consisting of occasional burned rock and chipped stone. Area $\mathrm{G}$, east of Area F (Figure 1-2), existed primarily as a lithic scatter on bedrock.

\section{Excavation Strategy}

Before excavations began, a vertical datum point was established and given the arbitrary elevation of 0.00 feet. Two separate horizontal grid systems, with north-south lines oriented parallel to the centerline of the then proposed Loop 360 , were established on the site. Grid north was 90 degrees to that centerline. The grid system that served Areas A, B, $\mathrm{C}$, and D consisted of 5-x-5-foot (1.5-x-1.5 m) squares with the S190/E100 point located at the extreme southwestern edge of the grid (Figure 4-1). The grid that served Areas E and $\mathrm{F}$ had different east-west reference points. These reference points were shot directly off of station markers along the highway right-of-way (e.g., $2+00=200$ feet). Station markers record both horizontal and vertical datums along highway right-of-ways. The north-south grid lines were measured off of a S0 baseline that extended across both areas (Figure 4-1). Squares were designated by northeast corner grid intersections.

The excavation strategy employed at 41TV163 was designed to determine the areas of the site that were most intensively occupied and provide information on the chronology and material content for each area of occupation. Excavation procedures included backhoe trenching, hand excavation of units, and the use of a Gradall Excavator (hereinafter referred to as Gradall). Weir initiated work at 41TV163 by excavating a 100-foot-long backhoe trench across the terrace paralleling the creek (Figure 4-1). The trench, designed to expose the site stratigraphy in this location and determine 


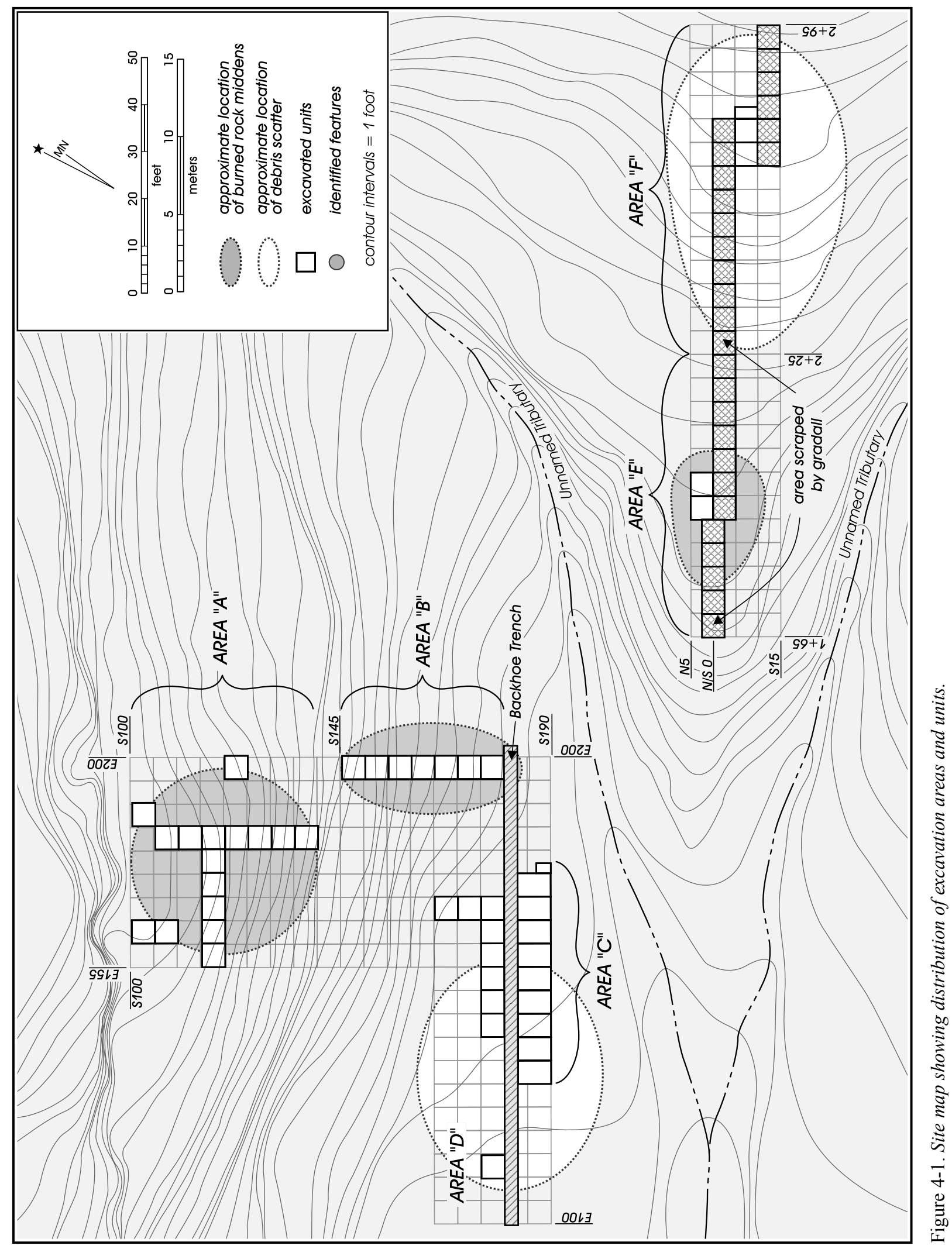


the depth of the deposits, was three feet wide and three feet deep (Figure 4-2). Hand-excavation units, placed in areas of the site designated $\mathrm{B}, \mathrm{C}$, and $\mathrm{D}$, were located along this trench. Area A was entirely excavated by hand. Excavation in Areas E and F was carried out using a Gradall, supplemented by a small number of hand-excavated units (Figure 4-1). As was common at the time, most hand excavations used five-foot squares as the basic unit. Exceptions to this size were a series of units excavated in Area $\mathrm{C}$ off the south face of the backhoe trench, as well as a single unit measuring 2.5 feet by five feet excavated in Area F (see Figure 4-1). Possibly for the first time on burned rock midden sites in central Texas, contiguous units were opened simultaneously to provide horizontal exposures in an attempt to identify possible living surfaces and associated features. Due to various constraints, the exposed units were not explored as extensively as initially intended (Weir 2004:3).

Information recorded on the outside of excavation sacks indicates that excavation levels were commonly six inches in thickness, with level measurements taken from the ground surface. Relative elevations were recorded on the bags.
These elevations were shot from several different subdatums, and reconstruction of the absolute elevations was not possible. The excavations were nominally conducted in six-inch levels. These levels were assigned to stratigraphic zones where possible and when recognized zones were crosscut, material from each zone was bagged separately within each level. Five to six different "zones" were identified on profile drawings. Identified by Roman numerals on profiles, detailed descriptions of these zones could not be located, though some information was present in the notes.

Excavations in Area A consisted of 16 5-x-5-foot squares. Units formed a north-south trench and an east-west trench across the burned rock midden, with four additional units, not connected to the trenches, also excavated (see Figure 4-1). A maximum depth of 3.5 feet was reached in units S115/E175, E180, and E185. Seventy-five arbitrary six-inch levels were excavated, removing about 937.5 cubic feet $(26.5$ cubic meters) of fill in Area A.

Excavations in Area B consisted of a north-south trench composed of seven 5-x-5-foot squares. Depths ranged from

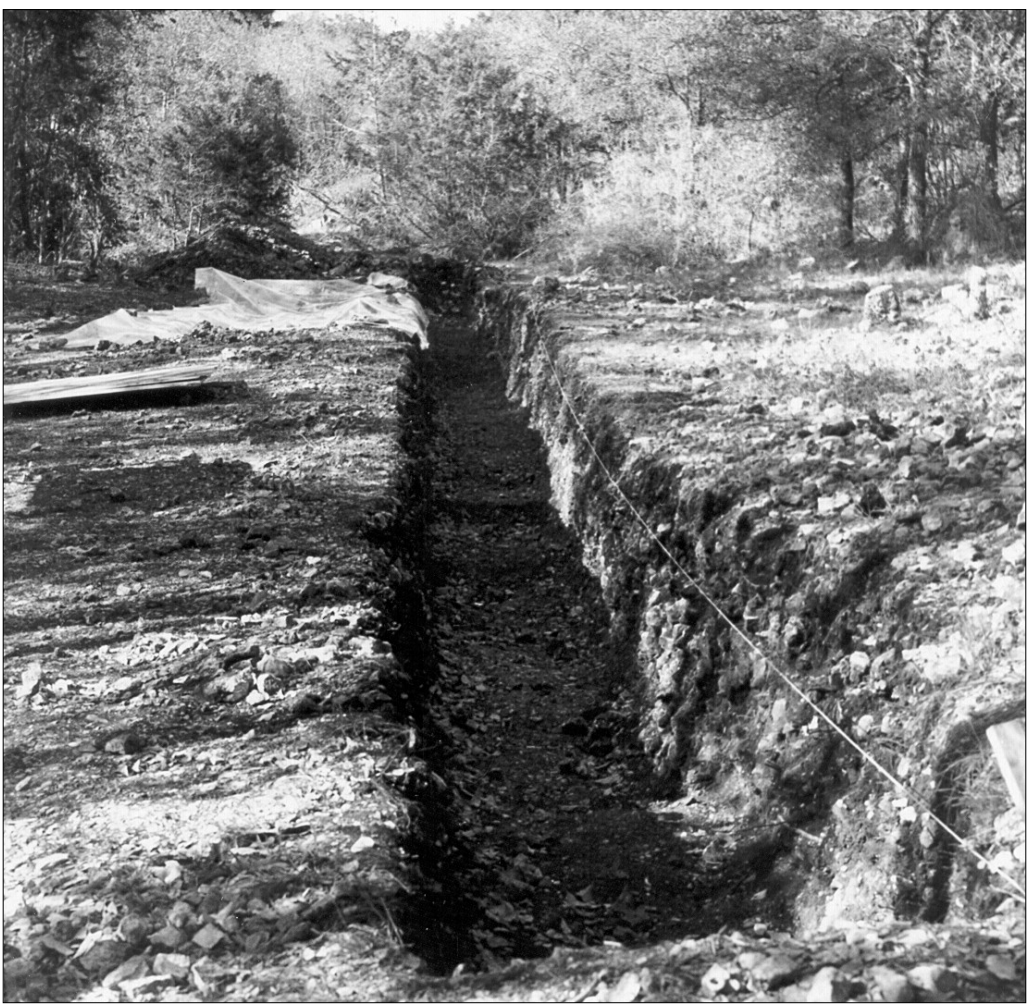

Figure 4-2. Initial trench across Areas B, C, and D at 41TV163. Looking west. 
one foot in S145/E200 to five feet in S175/E200 (Figure 4-1 and Figure 4-3). Fifty six-inch levels are listed in the specimen catalog, and about 625 cubic feet (17.7 cubic meters) of fill were excavated by hand in this area.

Areas $\mathrm{C}$ and $\mathrm{D}$ probed the terrace deposits exposed along the center and western sections of the backhoe trench. Area $\mathrm{C}$ was considered the most promising choice for excavation. Excavations in Area $\mathrm{C}$ consisted of 17 designated units, with eight 5-x-5-foot squares excavated on the north side of the backhoe trench, and nine 5-x-7-foot units excavated on the south side of the backhoe trench (see Figure 4-1 and Figure 4-4). The odd dimension of the southern units was due to the backhoe trench location relative to the grid. The backhoe trench was approximately two feet north of the S180 line, and this additional fill was included in each unit with the S180 designation (Figure 4-1). The deepest unit, S175/E165, reached a depth of 3.5 feet. Roughly 882.5 cubic feet $(25$ cubic meters) of fill was removed in Area C. Excavation in Area D was located to the west of Area C along the S175 line and consisted of a single 5-x-5-foot square, S175/E115. Four levels were completed, with 50 cubic feet $(1.4$ cubic meters) of fill removed. The return in this area was minimal and no further work was done in Area D.
Time constraints forced Weir to use a Gradall to excavate in Areas $\mathrm{E}$ and $\mathrm{F}$. Three trenches, each measuring five feet in width, were placed in Areas E and F. Note that the division between the two areas was arbitrary and was designated as the $2+25$ grid line. Units to the west were in Area E; those to the east in Area F (Figure 4-1 and Figure 4-5). The trenches were skimmed in six-inch levels within five-foot sections defined by grid units. The dirt from each level was dumped directly into $1 / 4$-inch hardware cloth screens set nearby, and the contents bagged in the same manner as in the case of the hand-excavated units (Figure 4-6). Area E consisted of 14 5-x-5-foot squares excavated along an east-west trench connecting the two burned rock middens. Twelve of the units were dug with the Gradall machine, and two units $(1+95 /$ N5 and 2+00/N5) were hand-dug. All units were excavated to a depth of 1.5 feet at which point bedrock was reached in some units. In all, approximately 537.5 cubic feet $(15.2$ cubic meters) of fill was removed in Area E. Area F consisted of 18 5-x-5-foot squares and one 2.5-x-5-foot unit oriented along an offset trench. All but three units in Area F were excavated with the Gradall. The hand-excavated units were $2+70 / \mathrm{S} 5,2+75 / \mathrm{S} 5$, and $2+77.5 / \mathrm{S} 5$. The deepest unit in this area was $1+70 / \mathrm{S} 0$, which reached a depth of three feet. Approximately 800 cubic feet (22.7 cubic meters) of fill was removed in Area F.

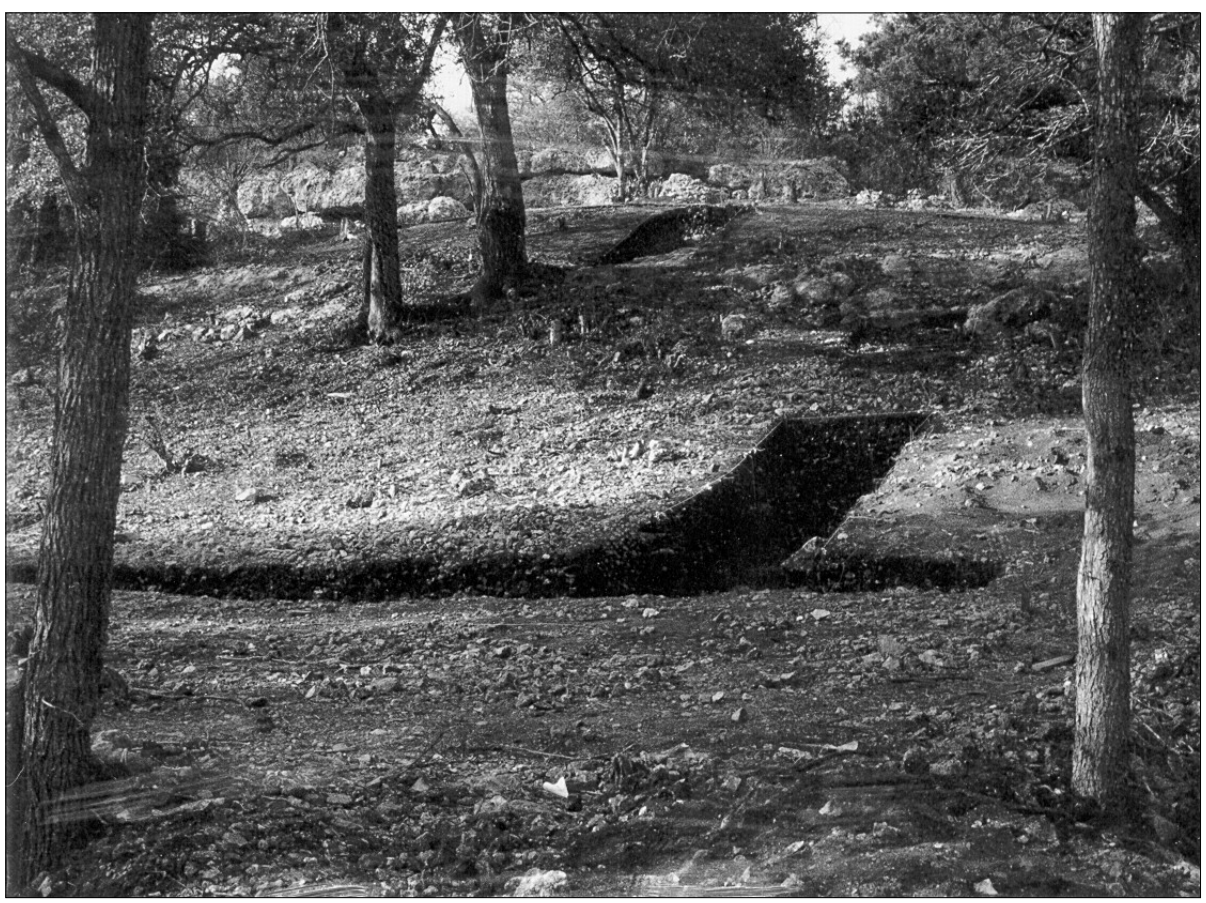

Figure 4-3. Backhoe trenches in Area B (foreground) and Area A (background) at 41TV163. Looking north. 


\section{Laboratory Work}

The collection and records from the Millican Bench site (41TV163) arrived at CAR in 29 boxes of cultural materials and two boxes of notes. During initial lab processing by TxDOT in the early 1970s, the artifacts were washed and lot numbers were assigned. Inventory sheets were then prepared. These sheets, tied to lot numbers, contained a numerical listing of the contents of each bag. The information listed for each lot number included the unit designation and level number. Some of the lithic material had been labeled with site and lot number in India ink. Where appropriate, artifact labels were re-written onto a bottom coat of B-72 (with acetone) in archival ink and sealed with another coat of B72. CAR lab staff repackaged the lithic materials into archival plastic bags with acid-free tags containing provenience and class information. In doing the repackaging, the lab staff also separated tools and points from the debitage and recorded the counts of all three classes of material along with the counts and weights of the small quantity of burned rock in the collection. The faunal materials (mussel shell, snail shell, and vertebrate bones) were removed from their field bags and placed into archival plastic bags with acid-free tags containing provenience and class information. The bone was identified, counted and weighed, and the snail and mussel shell was weighed. The re-inventory counts and weights for all material were used to create a Microsoft Access database of the collection. The acidic records and photographic materials were repackaged into appropriate archival holders.

In some cases, the negatives had been cut from negative strips and placed in envelopes onto which the print of the image had been glued. The prints were removed from the envelopes and placed into polyethylene photographic strip holders. Polaroid images had also been glued to pages. These were removed from the paper backings and placed into holders after being cleaned. Acid-free, foil-backed labels were applied to each photographic print and slide. The Polaroid photos were scanned and saved onto a

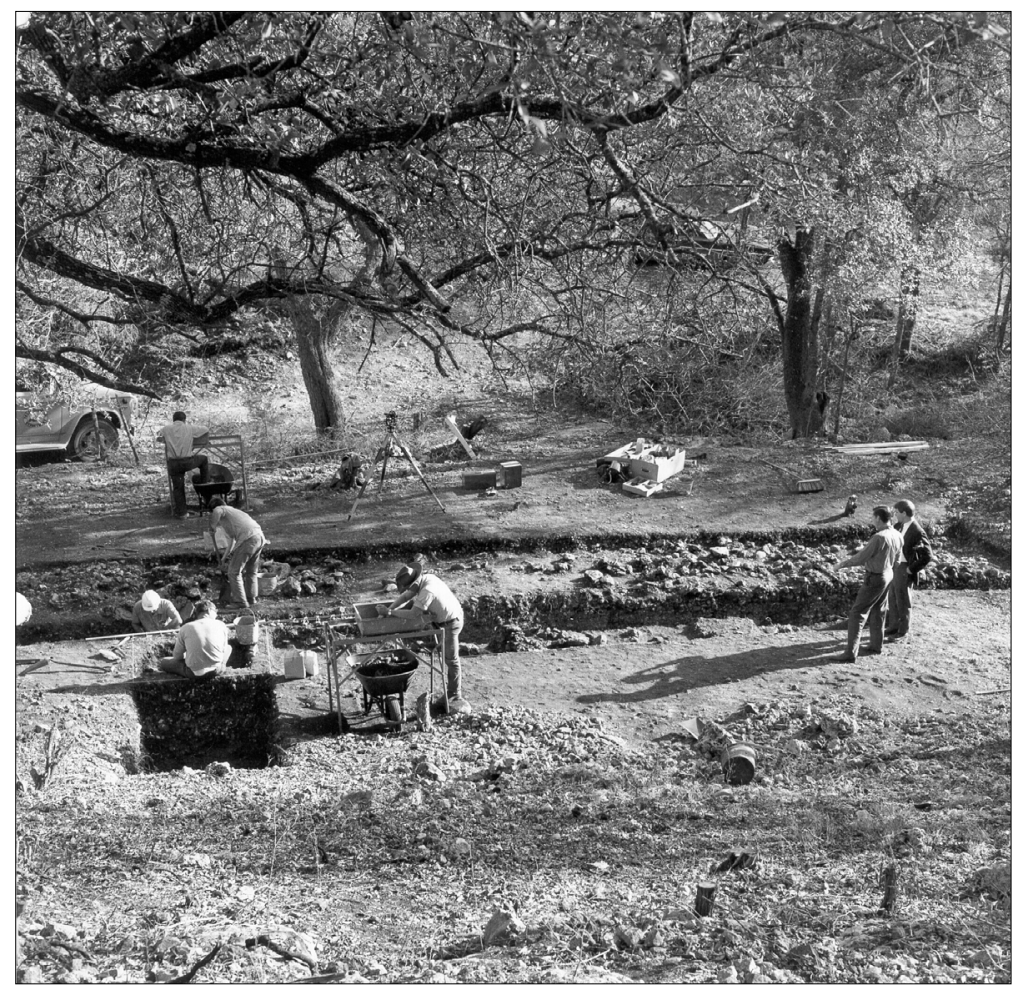

Figure 4-4. Overview of excavations in Area C at 41TV163. Looking south.

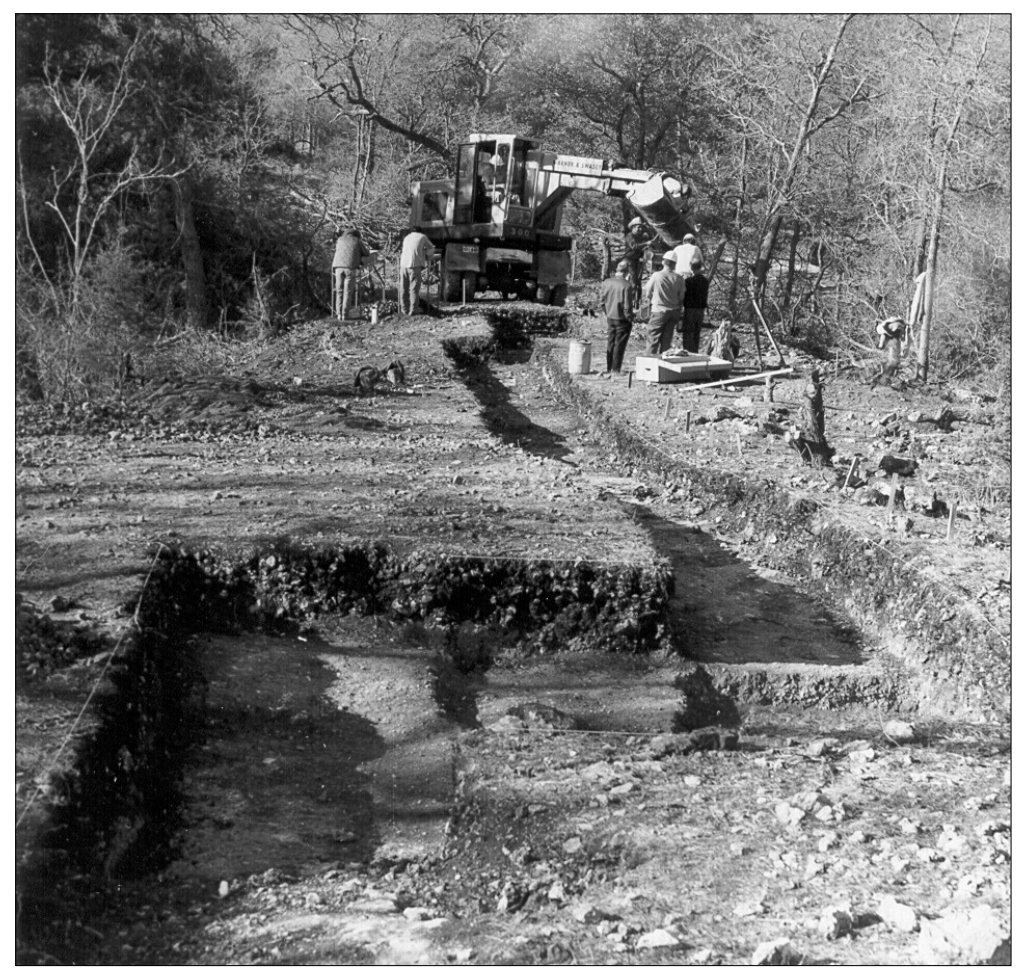

Figure 4-5. Excavations in Area F (foreground) and Area E (background) at 41TV163. Looking west. 


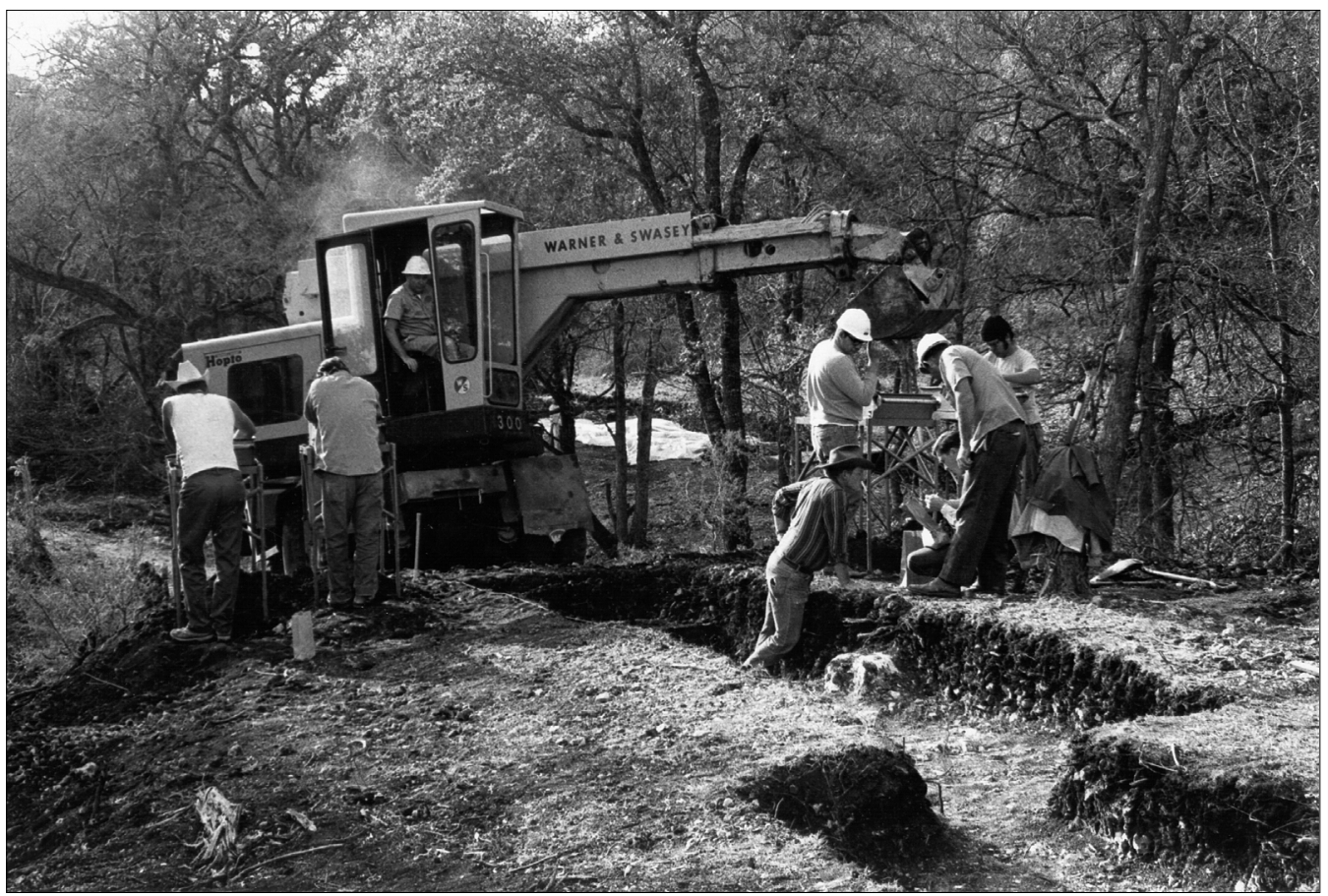

Figure 4-6. Excavations in Area E: note screens and Gradall. Looking west.

CD. All paper records were copied onto acid-free paper and placed in archival folders. The labeled portions of the original paper bags were retained for cross-referencing, and copies were made to accompany the archival records because most of the field bags contained information not recorded elsewhere.

The analyses reported in the later chapters focus on a series of specific analytical units (defined in Chapter 6) and the materials that could be securely associated with them. Unfortunately, much of the material recovered from the site could not be attributed to even broad temporal analytical units. Therefore, in consultation with the Texas Department of Transportation and the Texas Historical Commission, selected artifacts from a number categories were discarded following the completion of this report. The discarded materials include all debitage, cores and ground stone fragments, animal bones, snail shells, and mussel shells from proveniences not in the selected analytical units (ca. 33,918 items). In addition, all burned rock, regardless of location and analytical unit association, and all historic and modern road debris were discarded. The site database and all report tables include material counts established prior to discard. 


\title{
Chapter 5: Recovered Data
}

\author{
Raymond P. Mauldin, Richard B. Mahoney, Harry J. Shafer, and Barbara A. Meissner
}

In this chapter we provide a summary of the results of the 1970-1971 TxDOT work at 41TV163. Included in this chapter are summaries of chipped stone debitage, cores, projectile points and other chipped stone tools, ground stone, historic/modern material, vertebrate faunal remains, mussel and snail shell, charcoal samples, soil samples, and human remains. Note that some types of collected material, such as burned rock, were present in the collections processed by CAR but are not summarized in this chapter. In the case of burned rock, this was because it was not systematically collected during the excavation.

\section{Recovered Artifacts}

Counts of the major artifact classes present in the collections in 2003 are provided in Table 5-1. The artifact classes are presented by each of the major excavation Areas (i.e., A, B, $\mathrm{C}, \mathrm{D}, \mathrm{E}$, and F). Note that because only a single $5-\mathrm{x}-5$-foot (1.5-x-1.5-m) unit was excavated in Area D, we discuss the data from this unit in conjunction with Area $\mathrm{C}$, located just to the west of Area D. In addition, Area G materials, along with a small number of items simply identified as "general surface" and a few items with unknown provenience, are included in the table. Each of these primary artifact classes is briefly discussed.

\section{Projectile Points}

Projectile points are common in the collection, with 431 specimens being identified (Table 5-1). With the exception of one item made from petrified wood, a variety of cherts are represented in this collection. Of the 428 items recovered from the six major areas of the site, 58 are complete. Thirtyseven (9\%) of the 428 points were damaged by heat, with several specimens being badly burned. As can be seen in Table 5-1, 209 (49\%) of the points came from Area C/D, with Area F having the fewest number of items, 13 (3\%). Area C/D also had the highest density of points, with 7.9 projectile points recovered per cubic meter of fill. Area $\mathrm{F}$ had the lowest density, with only 0.6 points per cubic meter of excavation.

Of the 431 points, $310(72 \%)$ could be assigned to a recognized type, with the remaining items being either too fragmentary to type, reflecting untyped and untypable arrow points and arrow point preforms $(\mathrm{n}=29,7 \%)$, or reflecting untyped and untypable dart points and dart point preforms $(n=56,13 \%)$. Scans of many of the points are presented in Appendix E.

Table 5-1. Artifact Distribution by Area at 41TV163

\begin{tabular}{|l|c|c|c|c|c|c|c|}
\cline { 2 - 9 } \multicolumn{1}{c|}{} & \multicolumn{9}{c|}{ Area Designations } \\
\hline Artifact Class & $\mathbf{A}$ & $\mathbf{B}$ & $\mathbf{C} / \mathbf{D}$ & $\mathbf{E}$ & $\mathbf{F}$ & $\begin{array}{c}\text { G and General } \\
\text { Surface }\end{array}$ & Total \\
\hline Projectile Points & 45 & 81 & 209 & 80 & 13 & 3 & 431 \\
\hline Bifaces & 74 & 175 & 485 & 140 & 56 & 24 & 954 \\
\hline Edge Modified Items & 17 & 30 & 153 & 117 & 28 & 1 & 346 \\
\hline Battered Tools & 2 & 3 & 12 & 4 & 2 & 1 & 24 \\
\hline Unifaces & 4 & 41 & 28 & 18 & 18 & 2 & 111 \\
\hline Cores & 9 & 31 & 125 & 32 & 3 & 7 & 207 \\
\hline Debitage & 1,361 & 6,443 & 23,692 & 9,869 & 943 & 255 & 42,563 \\
\hline Ground Stone & 2 & 3 & 12 & 0 & 2 & 0 & 19 \\
\hline Total Prehistoric & $\mathbf{1 , 5 1 4}$ & $\mathbf{6 , 8 0 7}$ & $\mathbf{2 4 , 7 1 6}$ & $\mathbf{1 0 , 2 6 0}$ & $\mathbf{1 , 0 6 5}$ & $\mathbf{2 9 3}$ & $\mathbf{4 4 , 6 5 5}$ \\
\hline & & & & & & & 517 \\
\hline Glass & 1 & 2 & 66 & 374 & 72 & 2 & 517 \\
\hline Metal & 1 & 1 & 18 & 130 & 2 & 0 & 152 \\
\hline Ceramic & 0 & 0 & 3 & 19 & 2 & $\mathbf{6 3}$ & 24 \\
\hline Total Historic/Modern & $\mathbf{2}$ & $\mathbf{3}$ & $\mathbf{8 7}$ & $\mathbf{5 2 3}$ & $\mathbf{7 6}$ & $\mathbf{2}$ & $\mathbf{6 9 3}$ \\
\hline
\end{tabular}


Table 5-2 provides a list of the diagnostic points grouped by types and by excavation area. Note that points assigned to a type that lacked an Area provenience are not included in Table 5-2. With the exception of any evidence for Paleoindian occupation, projectile points from 41TV163 reflect most prehistoric periods, with diagnostic points suggesting some level of use from the Early Archaic (8000 $6000 \mathrm{BP})$ through the early portion of the Late Prehistoric (1250-700 BP). Points dating to the Late Archaic are by far the most common ( $\mathrm{n}=201,65 \%$ ), with Late Prehistoric points also represented by numerous specimens ( $\mathrm{n}=57,18 \%)$. Areas $\mathrm{C} / \mathrm{D}$ and $\mathrm{E}$ contained all of the Late Prehistoric point forms recovered from the site, with most (86\%) concentrated in Area C/D. In addition, all of the untyped and untypable arrow points and arrow point preforms $(\mathrm{n}=29)$ recovered from the site were in Areas $\mathrm{C} / \mathrm{D}(\mathrm{n}=26)$ and $\mathrm{E}(\mathrm{n}=3)$. While Areas $\mathrm{C} /$ $\mathrm{D}$ and $\mathrm{E}$, then, contained all of the Late Prehistoric forms, they also contained a variety of Late Archaic forms, ranging from Darl points, characteristic of the terminal Late Archaic, through Bulverde and Pedernales forms, characteristic of the beginning of the Late Archaic. Late Archaic occupation was also present in Areas A and B. Middle Archaic point forms were primarily concentrated in Areas A and B, with these two areas containing 39 of the 40 points. The remaining

Table 5-2. Distribution of Typed Projectile Points by Area, 41TV163

\begin{tabular}{|c|c|c|c|c|c|c|}
\hline & \multicolumn{6}{|c|}{ Areas } \\
\hline Point Type & $\mathbf{A}$ & B & C/D & $\mathbf{E}$ & $\mathbf{F}$ & Total \\
\hline \multicolumn{7}{|l|}{ Late Prehistoric } \\
\hline Alba & & & 1 & & & 1 \\
\hline Bonham & & & 1 & & & 1 \\
\hline Fresno & & & 1 & & & 1 \\
\hline Scallorn & & & 46 & 8 & & 54 \\
\hline \multicolumn{7}{|l|}{\begin{tabular}{|l|} 
Late Archaic \\
\end{tabular}} \\
\hline Darl & 1 & 1 & 37 & 3 & & 42 \\
\hline Ensor & & 1 & 11 & 1 & & 13 \\
\hline Frio & & & & 2 & & 2 \\
\hline Fairland & & & 23 & & & 23 \\
\hline Marcos* & & & 2 & 1 & & 3 \\
\hline Montell & & 3 & 2 & 9 & & 14 \\
\hline Castroville & & 1 & 2 & 4 & & 7 \\
\hline Langtry & 1 & & & & & 1 \\
\hline Lange & 3 & 3 & 10 & 7 & & 23 \\
\hline Marshall & & 4 & 1 & 1 & & 6 \\
\hline Williams & & 1 & & & & 1 \\
\hline Pedernales & 11 & 13 & 7 & 21 & 1 & 53 \\
\hline Bulverde & 3 & 7 & 1 & 2 & & 13 \\
\hline \multicolumn{7}{|l|}{ Middle Archaic } \\
\hline Nolan & 7 & 17 & & & & 24 \\
\hline Travis & 10 & 5 & & & & 15 \\
\hline Andice & & & & & 1 & 1 \\
\hline \multicolumn{7}{|l|}{ Early Archaic } \\
\hline Martindale & & & & & 1 & 1 \\
\hline Uvalde & & & & & 2 & 2 \\
\hline Early Split Stem & & 1 & & & 3 & 4 \\
\hline Early Triangular & & 2 & & & & 2 \\
\hline Wells & 2 & & & & & 2 \\
\hline Total & 38 & 59 & 145 & 59 & 8 & 309 \\
\hline
\end{tabular}

* 1 Marcos point is not shown in table as it lacked Area designation. 
Middle Archaic point, an Andice usually assigned to the onset of that temporal period, was recovered from Area F. No Middle Archaic points, or points assignable to the Early Archaic, were recovered from Areas C/D or E. Early Archaic forms were present in small numbers in Areas A, B, and F. With the exception of the aforementioned Andice fragment and two Pedernales points found on the surface, Area F contained mainly Early Archaic typed points.

No area of the site, then, has artifacts reflecting only a single temporal period. Areas $\mathrm{C} / \mathrm{D}$ and $\mathrm{E}$ appear to have roughly similar sequences, with both Late Archaic and Late Prehistoric projectile points present. Both areas also lacked Middle and Early Archaic forms. Areas A and B are also similar, with a variety of Middle Archaic and Late Archaic forms present. Both areas also contained a small number of Early Archaic forms. Finally, Early Archaic point forms dominated Area F, but two of the eight points recovered from this area date to other temporal periods. Spatially, then, all areas had points reflecting multiple time periods. However, as will be discussed in subsequent chapters, several locations within selected areas can be isolated that allow consideration of period-level assemblages.

\section{Other Chipped Stone Tools}

In addition to projectile points, a variety of other chipped stone tools are present in the 41TV163 collection (Table 5-1). Over 1,400 of these other tools were recovered from the site. This total includes a substantial number of bifaces (Figure 5-1), unifaces, and edge modified flakes. Several retouched tools with substantial battering along one or more edges were also recovered (Figure 5-2). Functional classification of the entire tool assemblage was not attempted; however, all tools that could be assigned to analytical units (as defined in Chapter 6) were classified according to function (see Chapter 8).

Bifaces were the most common chipped stone tool recovered from the site with over 950 specimens (Table 5-1). As can be seen in Figure 5-1, bifaces from the site reflect the full range of bifacial reduction technology as examples reflecting both early and late reduction are present. While many of the bifaces recovered represent abandoned or broken items, other specimens appear to have been used or designed for specific tasks. The highest number of bifaces was recovered from Area C/D. The highest density of bifaces was also from this Area, where roughly 18.4 items were recovered per cubic meter of fill. Recall that this area also had the highest density of projectile points. The lowest bifacial densities were in Areas F (2.5 per cubic meter) and A (2.8 per cubic meter).

Unifaces were much less frequent than bifaces at this site, with only 111 of these items recovered (Table 5-1). The highest density of unifaces was recovered in Area B, with 2.3 items per cubic meter. The lowest density was in Area A, with 0.2 items per cubic meter of removed fill.

Edge modified items are much more common than unifaces in the assemblage, being represented by 346 items (Table 5-1). This class of tools includes a wide range of forms. The highest density of this class of tool was in Area E (7.7 per cubic meter), though Area $\mathrm{C} / \mathrm{D}$ also had a significant number with 5.8 per cubic meter of fill. The lowest density of this tool form was in Area A, with 0.6 items per cubic meter.

Finally, a small number of items are classified as battered tools (Figure 5-2). Several of these appear to have been retouched to form a more acute edge angle. These items do not appear to reflect hammerstones involved in chipped stone reduction, but may have been used in more of a chopping or pounding activity or, in some cases, to refurbish ground stone. Battered tools were not common on the site relative to other tool types, with only 24 items (Table 5-1). The highest density of these tools was in Area C/D with 0.5 specimens per cubic meter. Rounded or ovate pebbles with marginal battering, specimens that would normally be identified as hammerstones, were not noted in the Millican Bench assemblage. Their absence may indicate that hammerstones were a very highly curated element of personal gear. Interestingly, unifacially or bifacially flaked distally beveled tools, that constitute gouges and possibly adzes in functional terms, also are not present in the Millican Bench collection. Although many unifacial end scrapers are present, the angle of the distal retouch and the shape of the working edge suggest that these tools represent scrapers rather than gouges or adzes. The absence of gouges in the Millican Bench collection suggests a functionally distinct tool kit compared to that commonly seen in assemblages from along the southern edge of central Texas (i.e., Choke Canyon).

\section{Debitage and Cores}

By far the most common item recovered during the excavation at 41TV163 was chipped stone debitage (Table 5-1). While petrified wood, quartzite, and limestone are represented in the debitage, chert is by far the most common raw material. Of the over 42,500 items in the collection, almost $56 \%$ of 


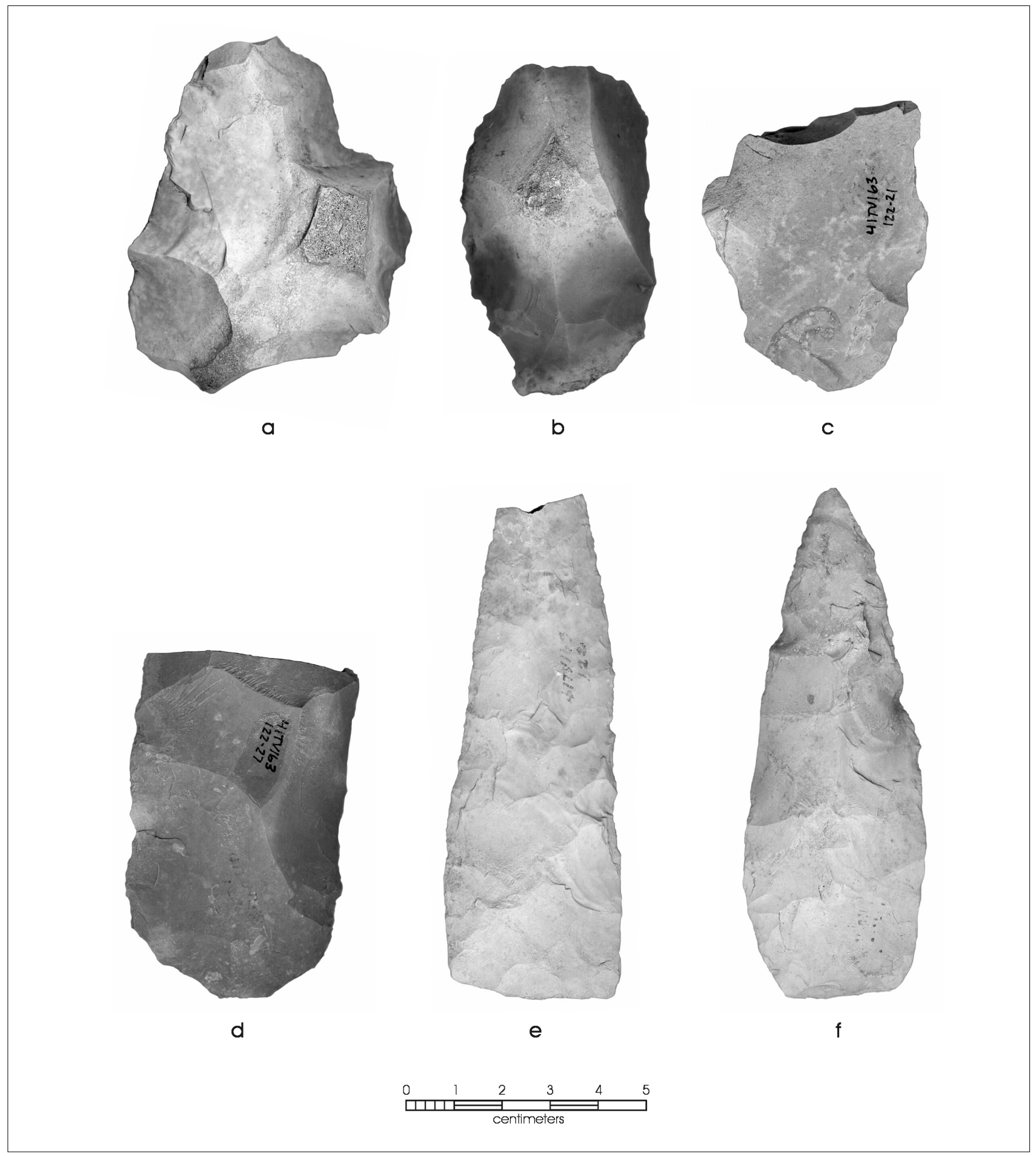

Figure 5-1. Selected bifaces from 41TV163. a, b) early stage reduction bifaces, Area E; c, d) middle reduction stage bifaces, Area $\mathrm{B} ; \mathrm{e}, \mathrm{f})$ late reduction stage bifaces, Area B. 


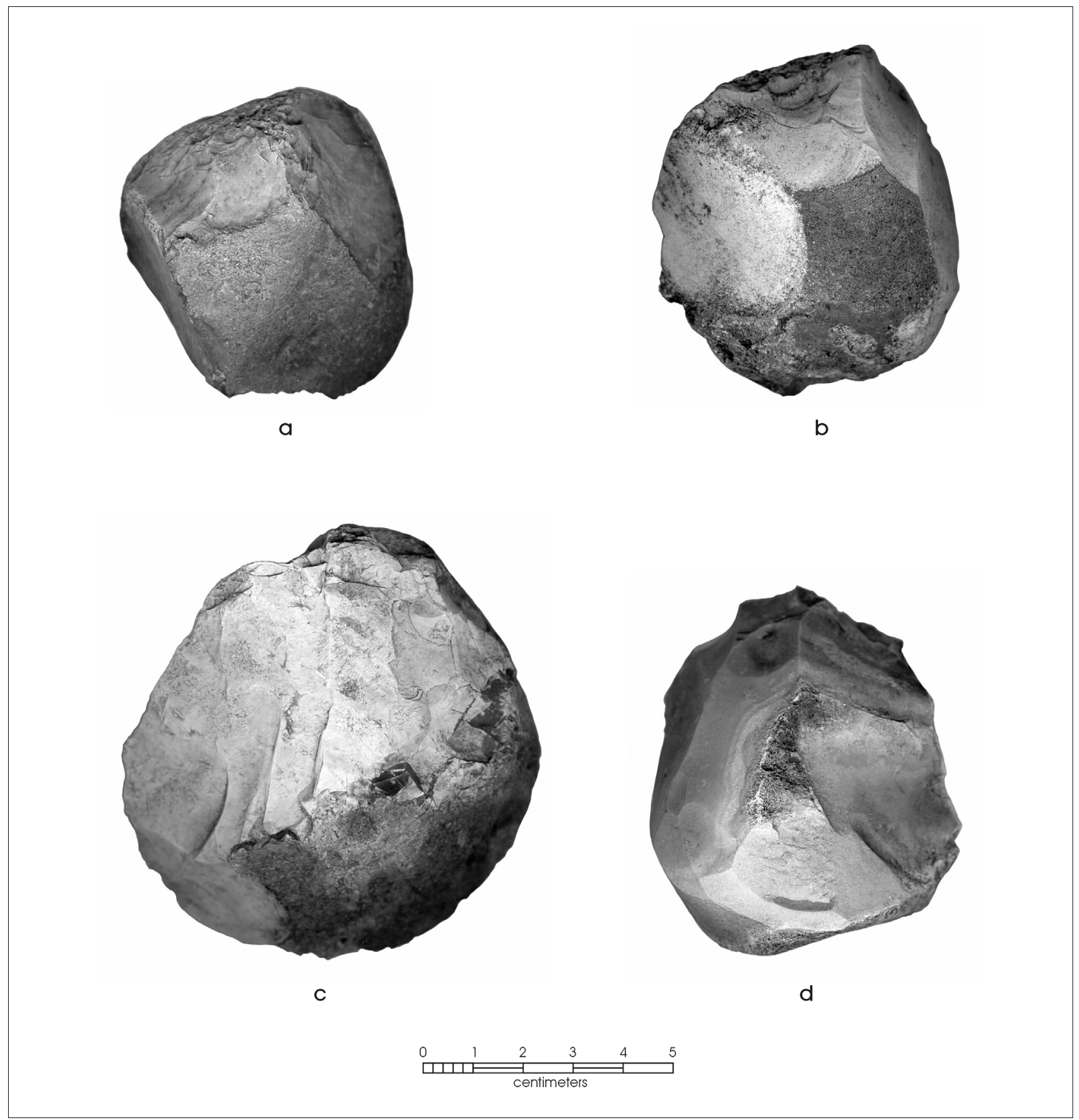

Figure 5-2. Selected battered tools from 41TV163. a, d) Area B; b, c) Area C. 
that total was associated with the excavations in Area C/D. This area also had the highest overall density, with almost 950 pieces of debitage per cubic meter of fill. In contrast, both areas $\mathrm{F}$ and $\mathrm{A}$ had low debitage densities, with densities of 41.5 and 51.0 items per cubic meter, respectively.

Two hundred seven items in the assemblage were recorded as cores (Table 5-1). All of the cores in the collection were chert. As with many of the other classes of items, cores were most common in Area C/D. This single excavation area accounted for $60 \%$ of the cores, with a density of 4.5 cores per cubic meter of excavated fill. Area $\mathrm{F}$ had only three cores recovered, and an overall density of only 0.13 cores per cubic meter of sediment.

\section{Ground Stone}

Reference to Table 5-1 will show that 19 items classified as ground stone are present in the collections from 41TV163. Thirteen of these are classified as manos or mano fragments and there are six metate fragments in the collection. Quartzites and sandstones dominates the raw materials used to produce these items. As with most other artifacts, Area $\mathrm{C} / \mathrm{D}$ produced both the highest number of specimens $(\mathrm{n}=12)$ as well as the highest overall density ( 0.45 per cubic meter). Areas $\mathrm{E}$ and $\mathrm{G}$ had no ground stone recovered (Table 5-1).

\section{Historic/Modern Artifacts}

Finally, a variety of modern and historic items were recovered during the excavation (Table 5-1). For the current discussion, these have been broken down into glass $(n=517)$, metal $(n=152)$, and ceramics $(n=24)$. The metal category includes a variety of cartridge casings, a metal door hinge, barbed wire, a nail, and a variety of miscellaneous metal fragments. Glass fragments represent a variety of colors, including amber, aqua, brown, green, and purple, along with shards of clear glass. The small number of ceramics include whitewares and brownwares. Reference to Table 5-1 will show that over $75 \%$ of the metal, glass, and ceramic material came from Area E. This class of material was primarily restricted to the surface and the upper six inches of the deposits across the site. Of the 690 items with provenience data, 647 (ca. 93.8\%) were found either on the surface or within the upper six inches, and only 24 items were at a depth below $30 \mathrm{~cm}$ ( $1 \mathrm{ft}$.). All 24 of these deeper items were in Area E, suggesting that the context of much of the prehistoric material collected from this area is suspect.

\section{Other Samples}

A variety of other samples, including vertebrate faunal material, snail and mussel shells, sediment samples, charcoal samples, and human remains were collected from 41TV163. These are briefly discussed in this section. Table 5-3 presents the weights of animal bone, snail shell, and mussel shell recovered from the site for each of the primary excavation areas. Table 5-4 lists the radiocarbon dates derived from the charcoal samples recovered from 41TV163.

\section{Vertebrate Faunal Remains}

Vertebrate faunal remains recovered during the project consist of 4,072 specimens weighing 3,218.7 grams. The bone is in good condition, with only a few lots showing changes that suggest atmospheric weathering. Some minor root etching and minor pitting caused by biological activity (especially fungi) was noted on some bones. As shown in Table 5-3, most of the animal bone was recovered from excavation Area C/D. Roughly $81 \%$ of the animal bone, both by weight and by number $(n=3,321)$, was collected in this area. No animal bone was recovered from Area F, and only four specimens were present in the excavations in Area A. The inspection of the faunal remains did, however, identify several possible bone and antler tools (Figure 5-3). Appendix A provides additional information on this material, and a portion of this assemblage is analyzed in detail in Chapter 7.

Although the animal bone is in good condition, and there are few signs of serious postdepositional destruction of the bone, the collection is highly fragmented. Examination of the bone suggests that most of the fragmentation may have

Table 5-3. Other Sample Distributions by Area at 41TV163

\begin{tabular}{|l|c|c|c|c|c|c|}
\cline { 2 - 7 } \multicolumn{1}{c|}{} & \multicolumn{6}{c|}{ Area Designations } \\
\hline Sample & A & B & C/D & E & F & Total \\
\hline Bone (grams) & 8.09 & 218.6 & 2611.8 & 380.2 & 0 & 3218.7 \\
\hline Mussel Shell (grams) & 105.4 & 11.1 & 590.7 & 145.3 & 15.9 & 868.4 \\
\hline Snail Shell (grams) & 2198.5 & 6596.8 & 7466.5 & 5449 & 1207.6 & 22918.4 \\
\hline
\end{tabular}


Table 5-4. University of Georgia (UGA) Radiocarbon Dates from 41TV163

\begin{tabular}{|c|c|c|c|c|c|c|c|}
\hline UGA \# & Area & Unit & Feature & Depth (ft.) & $\begin{array}{c}\text { Radiocarbon } \\
\text { Age (YBP) }\end{array}$ & $\begin{array}{c}\text { Corrected Age } \\
\text { (YBP) }\end{array}$ & 2-Sigma Range \\
\hline 12300 & $\mathrm{~B}$ & $\mathrm{~S} 180 / \mathrm{E} 200$ & ----- & $\mathrm{ca} .4 .0-5.0$ & $3040+/-80$ & $3050+/-80$ & $1500 \mathrm{BC}-1040 \mathrm{BC}$ \\
\hline 12301 & $\mathrm{~B}$ & $\mathrm{~S} 175 / \mathrm{E} 200$ & ------ & $3-3.5$ & $2830+/-110$ & $2840+/-110$ & $1400 \mathrm{BC}-800 \mathrm{BC}$ \\
\hline 12302 & $\mathrm{C}$ & $\mathrm{S} 175 / \mathrm{E} 145$ & 2 & $\mathrm{uk}$ & $1270+/-40$ & $1270+/-40$ & $\mathrm{AD} 660-880$ \\
\hline 12303 & $\mathrm{C}$ & $\mathrm{S} 175 / \mathrm{E} 150$ & 1 & $\mathrm{uk}$ & $1510+/-40$ & $1520+/-40$ & $\mathrm{AD} 430-640$ \\
\hline 12304 & $\mathrm{C}$ & $\mathrm{S} 185 / \mathrm{E} 165$ & ----- & $2.5-3.0$ & $1630+/-100$ & $1610+/-100$ & $\mathrm{AD} 230-650$ \\
\hline 12305 & $\mathrm{C}$ & $\mathrm{S} 175 / \mathrm{E} 160$ & ------ & $0-.5$ & $570+/-40$ & $580+/-40$ & $\mathrm{AD} 1300-1430$ \\
\hline 12306 & $\mathrm{C}$ & $\mathrm{S} 185 / \mathrm{E} 160$ & ----- & $0-.5$ & $40+/-40$ & $20+/-40$ & ----- \\
\hline 12307 & $\mathrm{C}$ & $\mathrm{S} 175 / \mathrm{E} 155$ & 10 & $1.0-1.5$ & $1640+/-40$ & $1590+/-40$ & $\mathrm{AD} 380-570$ \\
\hline 12308 & $\mathrm{E}$ & $1+70 / \mathrm{N}+2.50$ & ------ & $0-.5$ & $60+/-40$ & $60+/-40$ & \\
\hline
\end{tabular}

occurred before deposition. Our preliminary analysis of a sample of the faunal remains suggests that a large percentage, perhaps over 50 percent, was heat altered. David's (1990) experiments have confirmed those of Shipman et al. (1984), which indicate that cooking of meat, even over a direct fire, is unlikely to do more than char bone, and only where there is no meat. The large percentage of burned bone in the assemblage that is calcined and partially calcined suggests that the burned bone was subjected to much higher heat for a much longer duration than would normally be seen in campfire cooking. It seems likely that at least some of the bone was added, either incidentally or deliberately, to fires.

Because the bone is in relatively good condition, one would expect butcher marks to be easily identified. A cursory inspection in fact indicates that butchering scars and impact marks derived from bone breakage are present on some specimens. The impact scars tend to be found on the shafts of long bones of deer-sized animals. The preliminary analysis of the sample of faunal remains recovered from 41TV163 indicates that roughly one-third of the bone inspected represents deer-sized animals and a significant portion of these remains are splinters of long bone diaphyses, with the bone broken while it was fresh. This is evidence of intensive processing of the long bones of large mammals, especially since in order to acquire marrow from a long bone it is necessary only to break it in half. There are few long bone epiphyses identified in this collection, and the few present are all fragments. Tools such as the battered flakes and cobbles described in the previous section (see Figure 5-2) would certainly have been effective in bone breakage of this type, though we have no direct evidence that these tools were used in this manner. The fact that deer bone, which does not contain a great deal of fat during most seasons, was processed in this way suggests that some of the occupation of Millican Bench occurred during seasons when other food sources were not abundant.

\section{Mussel and Snail Shell}

Roughly 868 grams of mussel shell was collected from 41TV163. Most of this is highly fragmentary. The mussel shell was concentrated in Area C/D, with a weight of 590.71 grams recovered in this area. Area $\mathrm{C} / \mathrm{D}$ had an overall density of 22.38 grams of mussel per cubic meter of fill. This density was significantly higher than any other area of the site. With the exception of Area E, with a density of 9.56 grams per cubic meter of fill, no other area had a density of more than 4 grams per cubic meter. While this distribution may reflect cultural factors, note that both Areas $\mathrm{C} / \mathrm{D}$ and $\mathrm{E}$ are located closest to the unnamed tributaries that drained the area, and

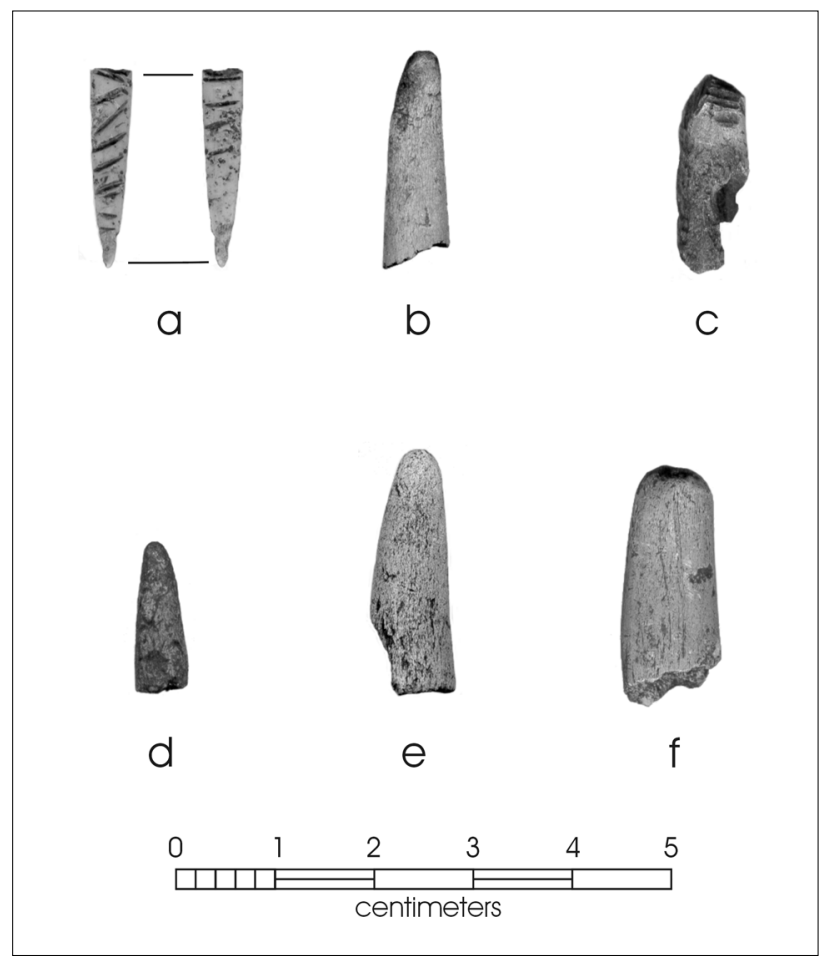

Figure 5-3. Possible bone tool tips found in Area C. 
some of the concentration of mussel shell may represent natural deposits associated with that tributary.

Almost 23 kilograms of snail shell were collected at the site. A cursory inspection of the snails suggest that the genus Rabdotus dominates the assemblage. An examination of several proveniences failed to identify any other genus. Unfortunately, this pattern could be due to the $1 / 4$-inch screens employed, since Helicina and Polygyra specimens would not be recovered. Similarly, it is likely that only the adult Rabdotus specimens have been systematically recovered in the available samples. Like many of the other classes of material discussed in this chapter, snail shells, by weight, were concentrated in Area C/D (Table 5-3). However, the relative density of snails was highest in Areas B (372.7 grams per cubic meter) and $\mathrm{E}$ (358.5 grams per cubic meter). Area C/D had a density of 282.8 grams per cubic meter of fill. The lowest snail shell densities were in Areas A (83.0 grams per cubic meter) and $F$ (53.2 grams per cubic meter).

\section{Sediment Samples}

Twenty-six individual sediment samples were received by CAR as part of the materials from 41TV163. Areas A and B were best represented, with a total of 14 samples, seven coming from each area. In addition, five samples were collected from Area C/D, two samples from Area E, and five samples from Area F. With the exception of a single sample from a feature (Feature 10), all other matrix samples are from general excavation levels. Nine of these samples from selected areas were floated at CAR and the light fraction submitted to Dr. J. Philip Dering of Shumla Archeobotanical Services for ethnobotanical analysis. The results of this analysis are discussed in Chapter 7, and additional information can be found in Appendix D.

\section{Charcoal Samples}

While a number of charcoal samples were collected during the initial work at the site, and most were submitted to the Radiocarbon Laboratory at The University of Texas for dating, only a single date was obtained prior to this report. This sample (TX. \#1511), from Level 2 in unit S175/E155, produced an uncorrected date of $500 \pm 80 \mathrm{BP}$. The sample was collected near Feature 10 (see the feature discussion in this chapter). Seven charcoal samples were present in the collection when CAR received the materials for assessment. CAR extracted sufficient charcoal from two sediment samples for two additional dates, producing a total of nine radiocarbon samples. Of these nine, two were from Area B, six came from Area $C$, and a single sample was present from Area E. All nine samples were submitted to the Center for
Applied Isotopic Studies at the University of Georgia. Discounting two modern dates, the corrected dates for the remaining samples range in age from $3050 \pm 80$ BP to $580 \pm$ $40 \mathrm{BP}$. Table 5-4 presents these dates. Details of these dates are presented in Appendix C. While these dates are discussed in more detail in the subsequent chapter, note that one of the two modern dates, UGA \#12308, is from Area E, an area that contained the majority of the historic/modern items recovered during the 1970-1971 excavations. Weir (2004:5) notes that due to the extent of bioturbation at the site, most dates should be viewed with skepticism. In addition to the charcoal samples submitted for radiocarbon dating, a single charred item, identified as a possible nut fragment, was found in the collection. That sample was submitted to Shumla Archeobotanical Services for ethnobotanical analysis (see Chapter 7 and Appendix D).

\section{Human Remains}

The partial remains of a single burial were encountered in Area C (Feature 10). The remains are represented primarily by elements of the skull and arms (Figure 5-4). Specific cranial elements present include the frontal, both parietals, the temporals, the occipital, both malars, a portion of the palatine and maxilla, the left half of the mandible, two sphenoid fragments, and five teeth. Postcranial elements include both humeri, the left ulna, the left radius, 13 hand phalanges, four metacarpals of the left hand (MC-1 through MC-4), two carpals of the right hand, 10 vertebral fragments, two rib fragments, and a portion of the right scapula. It cannot be determined whether the burial represents a primary or secondary interment.

A complete inventory of the human remains is presented in Appendix B. The analyses comport with the minimum reporting standards as set forth in Standards for Data Collection from Human Skeletal Remains (Buikstra and Ubelaker 1994). The feature notes and numerous photographs document that only the upper portion of the individual was well represented in the feature. Approximately 40 grams of small $(<1 \mathrm{~cm}$ in diameter) unidentifiable fragments comprise the balance of human skeletal material recovered. No duplication exists in the collection, and the remains appear to be of a single individual.

\section{Features}

Eleven features were defined during the excavations at 41TV163. These features consisted of stone-lined pits or thermal features (Features 1, 5, and 8), a possible pit or tree root mold (Feature 2), a possible structure (Feature 3), 
natural layers of cobbles (Features 4, 7, and probably 9), a concentration of points and debitage (Feature 6), a cairn burial (Feature 10), and a biface cache (Feature 11). The burned rock middens in Area A and Area E, and the potential burned rock midden in Area B, were not assigned feature numbers during the excavation. Figure 5-5 provides the locations of the features. Nine of the 11 features assigned in the field were located in Area C. Figure 5-6 is an enlargement of Area $C$ that shows these nine features. Feature 6 was located in Area B, and Feature 8 was located in Area F (Figure 5-5).

\section{Feature 1}

Feature 1 was recorded in Area C, in units S175/ E145 and S175/E150 (Figures 5-6 and 5-7). The backhoe trench through this section of the site truncated the southern portion of the feature. The feature was a slab-lined, stone-filled pit with evidence of burning. The pit, which appeared to originate beneath the dark A horizon in Area C, was roughly circular in plan and approximately $1.5 \mathrm{~m}$ in diameter. Below the A horizon, a dense, roughly $10-\mathrm{cm}$-thick lens of Rabdotus shells capped the feature and in approximately the same configuration as the top of the basin (Figure 5-7). Stones lining the pit were not discovered until the snail mass had been removed. The topmost stones occurred about $30 \mathrm{~cm}$ beneath the surface. The stones remaining in the pit, after the feature had been bisected by the backhoe, were large pebble to large cobble in size and numbered about 30 . All stones were burned and dipped toward the center of the pit except for three stones which

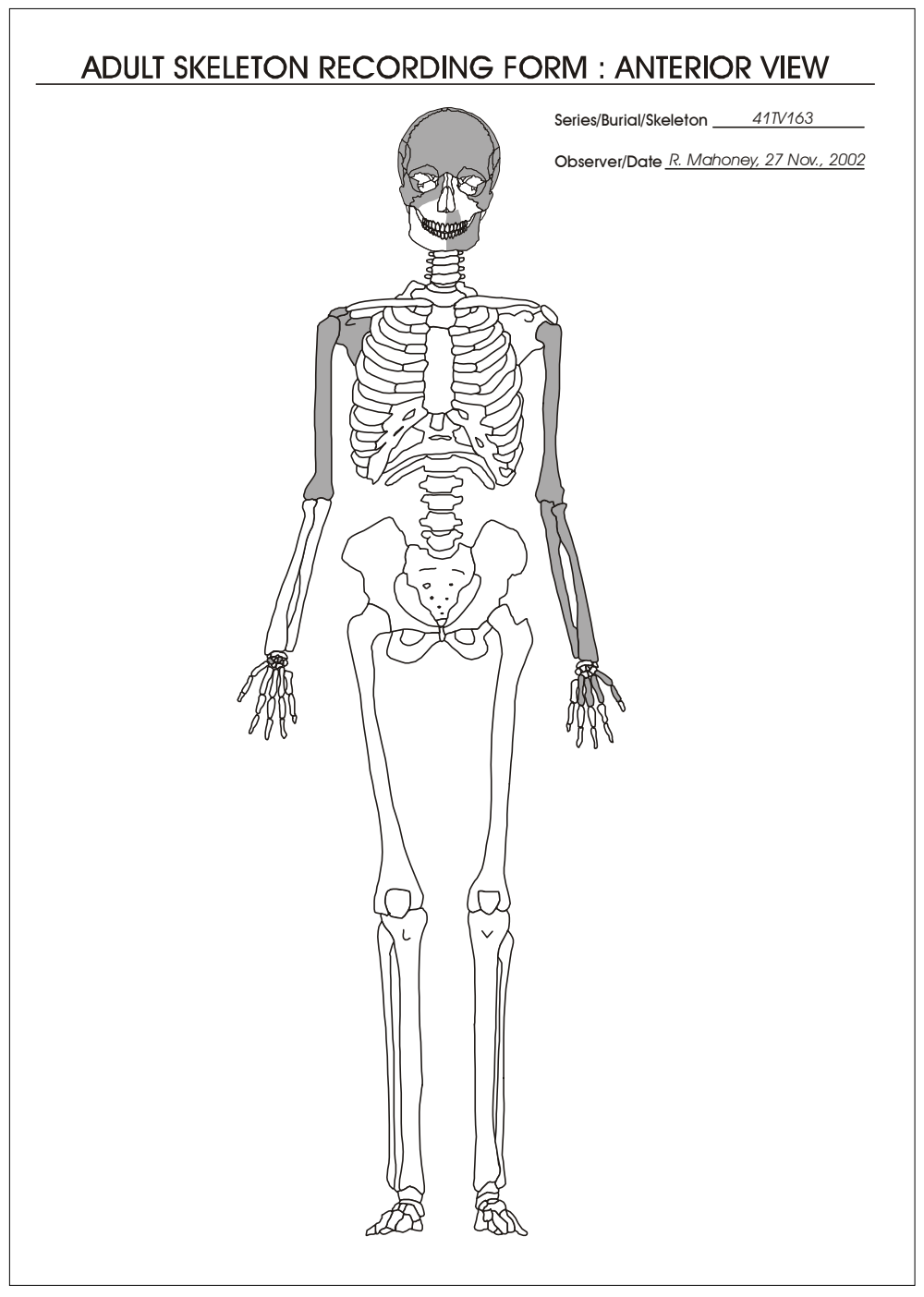

Figure 5-4. Adult skeleton recording form showing elements recovered from the burial, Feature 10, at 41TV163. were on edge and one limestone slab which lay flat at the top of the pit. The stone slabs did not extend to the maximum depth of the pit which was about $75 \mathrm{~cm}$ deep and roughly formed a deep basin in profile (Figure 5-7). It appeared that some of the stones had been dislocated by an animal burrow which exited near the bottom west side of the basin. A single radiocarbon date, UGA \#12303, was obtained from within the feature, though the exact location is not known (see Table 5-4). The corrected, calibrated date at a two-sigma range, using the OxCal calibration program (Ramsey 2000), is A.D. 430 to 640 , suggesting that the feature was probably used during the end of the Late Archaic period. Lithic debitage, utilized flakes, an untypable medial fragment of a projectile point, animal bone fragments, and about three pounds of snail shells were removed from the feature. In addition, a small cache consisting of a large uniface and two large mussel shell valves was also found near the top of the feature among the rocks lining the pit.

\section{Feature 2}

This feature was a pit recognized in the north face of the backhoe trench at the S180/E140 grid intersection (Figure 5-6). The pit, defined by dark brown sediment, had no clear boundaries (Figure 5-8). Weir speculated at the time of recording that the pit might represent a tree-root mold, but acknowledged that the inhabitants of 41TV163 may also have produced the feature. The pit measured $73 \mathrm{~cm}(2.4 \mathrm{ft}$.) 


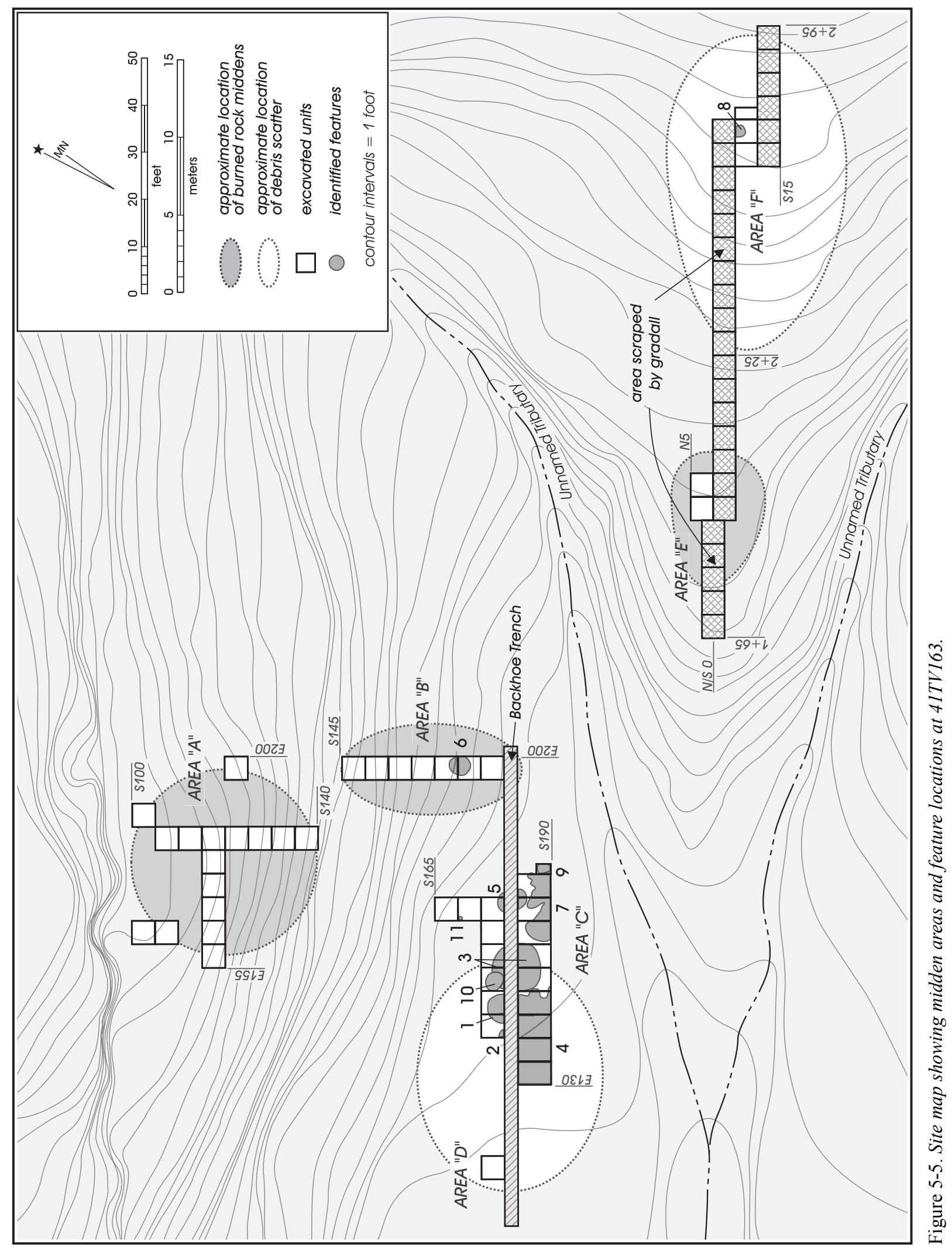




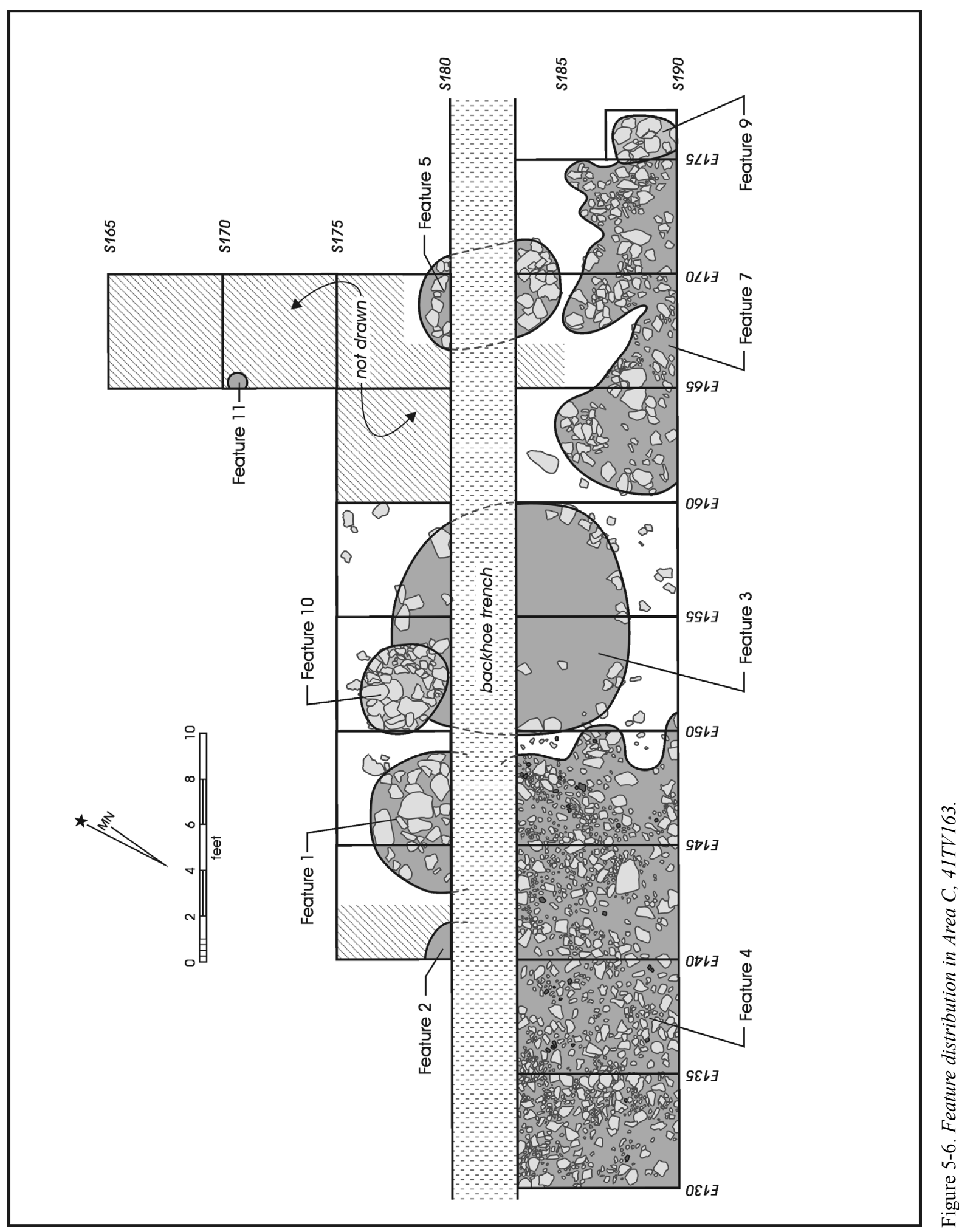




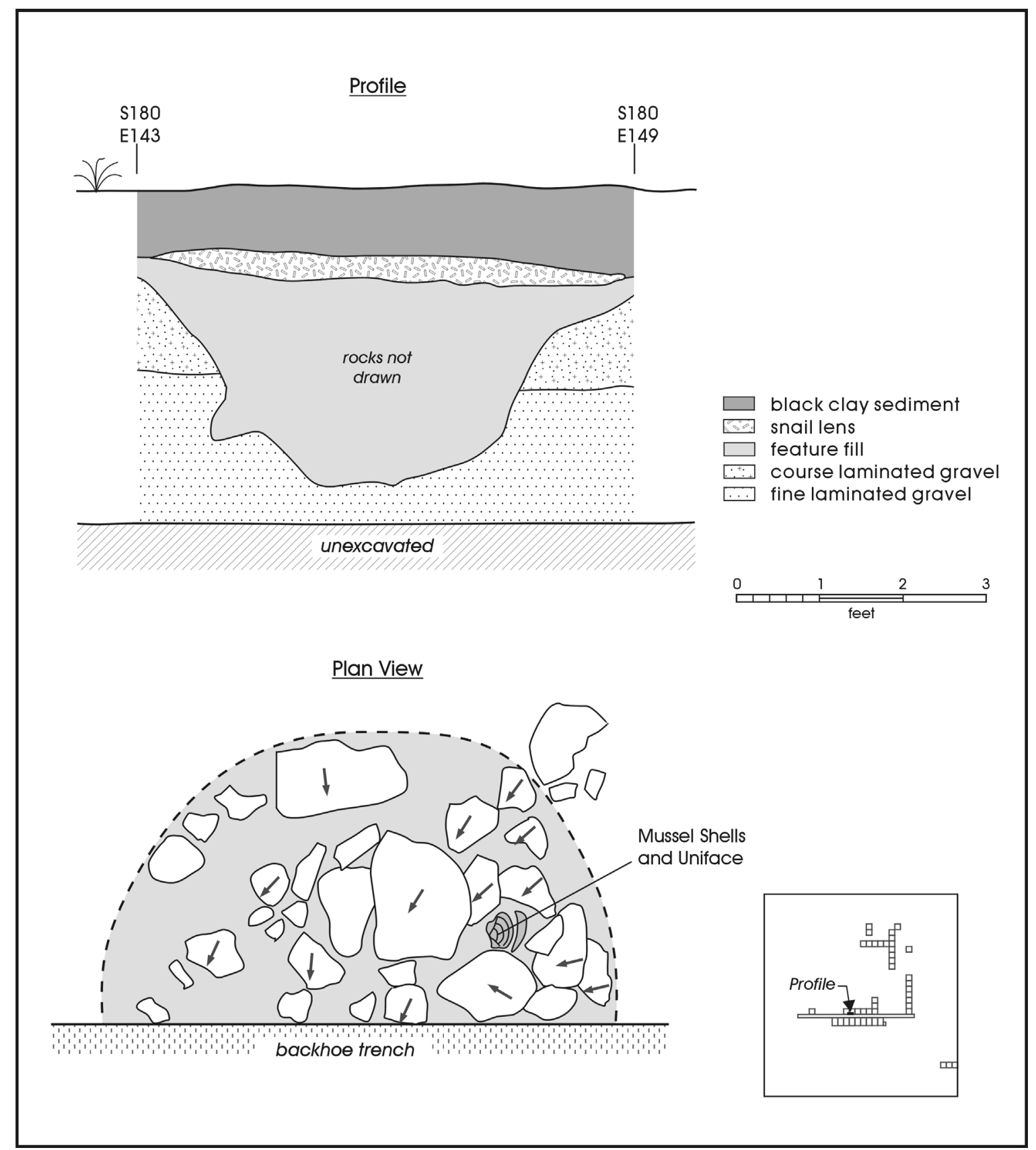

Figure 5-7. Feature 1, a slab-lined pit in Area C. Note uniface/mussel shell cache among burned rock.

in diameter and was $82 \mathrm{~cm}$ (2.7 ft.) deep. Temporally diagnostic dart points (Ensor and Darl) suggest the pit fill is Late Archaic in age. Reference to Table 5-4 will confirm this suggestion. A single radiocarbon date, UGA \#12302, was obtained from within the feature, though the exact location is not known. The corrected, calibrated date at a two-sigma range, using the OxCal calibration program (Ramsey 2000), is A.D. 660 to 880 , suggesting that the feature was probably used during the end of the Late Archaic or early in the Late Prehistoric. 


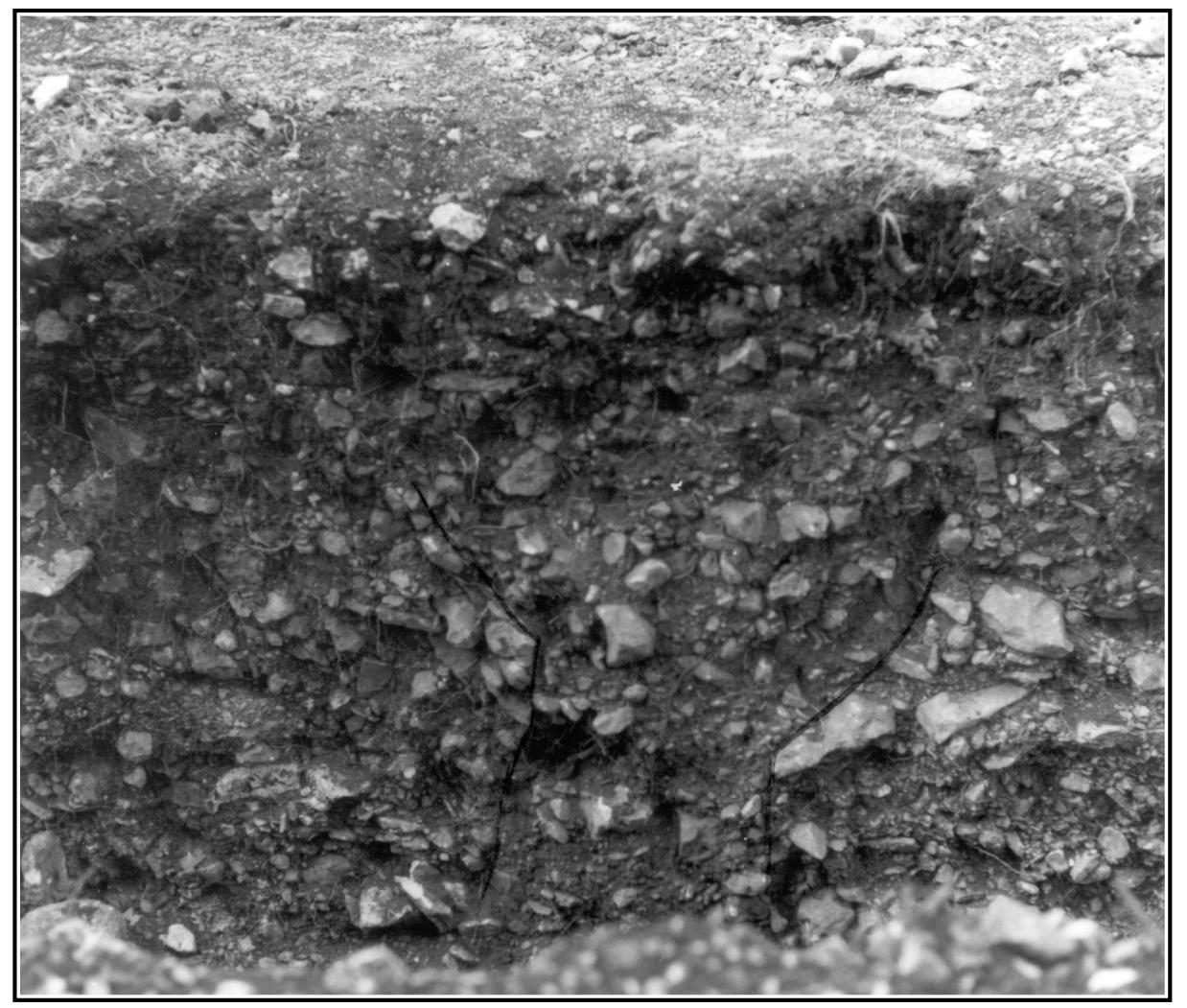

Figure 5-8. Feature 2, pit feature in backhoe trench wall, Area $C$.

\section{Feature 3}

Feature 3 consisted of the remains of a possible habitation structure in Area C (Figure 5-6). The feature was marked by a series of cobbles forming a circular pattern roughly $2.5 \mathrm{~m}$ to $3 \mathrm{~m}(8-10 \mathrm{ft}$.) in diameter (Figure 5-9). The feature was bisected by the backhoe trench excavated through this area. The circular pattern did not become apparent until manual excavations exposed the cobbles in Level 2 ( 0.5 to $1.0 \mathrm{ft}$. below surface). The feature was encountered in portions of units S185/E155, S185/E160, S175/E155, and S175/E160, with the approximate center of the pattern at S183/E155. The pattern of cobbles appeared intact and no evidence of significant disturbance was noted (Figure 5-10). During excavations, no postholes or clearly defined floors were encountered, although the notes suggest a dearth of artifacts within the circle relative to the surrounding squares.

The likelihood that this feature was a habitation area is supported by the lack of an interior scatter of cobbles and small boulders that characterized the equivalent surface to the east (Feature 7), south and west (Feature 4 ) of Feature 3.
The surface upon which the stones rested may have been the same surface extant at the time of occupation.

The deposits that contained the possible structure yielded predominantly Late Prehistoric Scallorn arrow points, though some Late Archaic materials, including Darl and Fairland dart points, were also recovered. The single radiocarbon date obtained soon after the 1970-1971 excavation, TX \#1511, was from a sample collected just outside of this structure at Level 2 in unit S175/E155. While the date has not been corrected for fractionation, the calibrated date, using $\mathrm{OxCal}$ (Ramsey 2000), is A.D. 1310 to 1490 . An additional date, from Level 1 (0-0.5 ft.) of square S175/E160, was obtained by CAR (see Table 5-4; UGA \#12305). That calibrated, corrected date, at a two-sigma range, is A.D. 1300 to 1430. Finally, a second CAR obtained date, UGA \#12306, came from Level 1 of S185/E160 (Table 5-4). This sample returned a modern date. However, it is unclear if either the modern date or the A.D. 1300-1430 date are from within the structure. We can only assign the samples to their respective 5-x-5-foot excavation squares. Nevertheless, two Late Prehistoric dates, along with the predominance of Late Prehistoric points, 


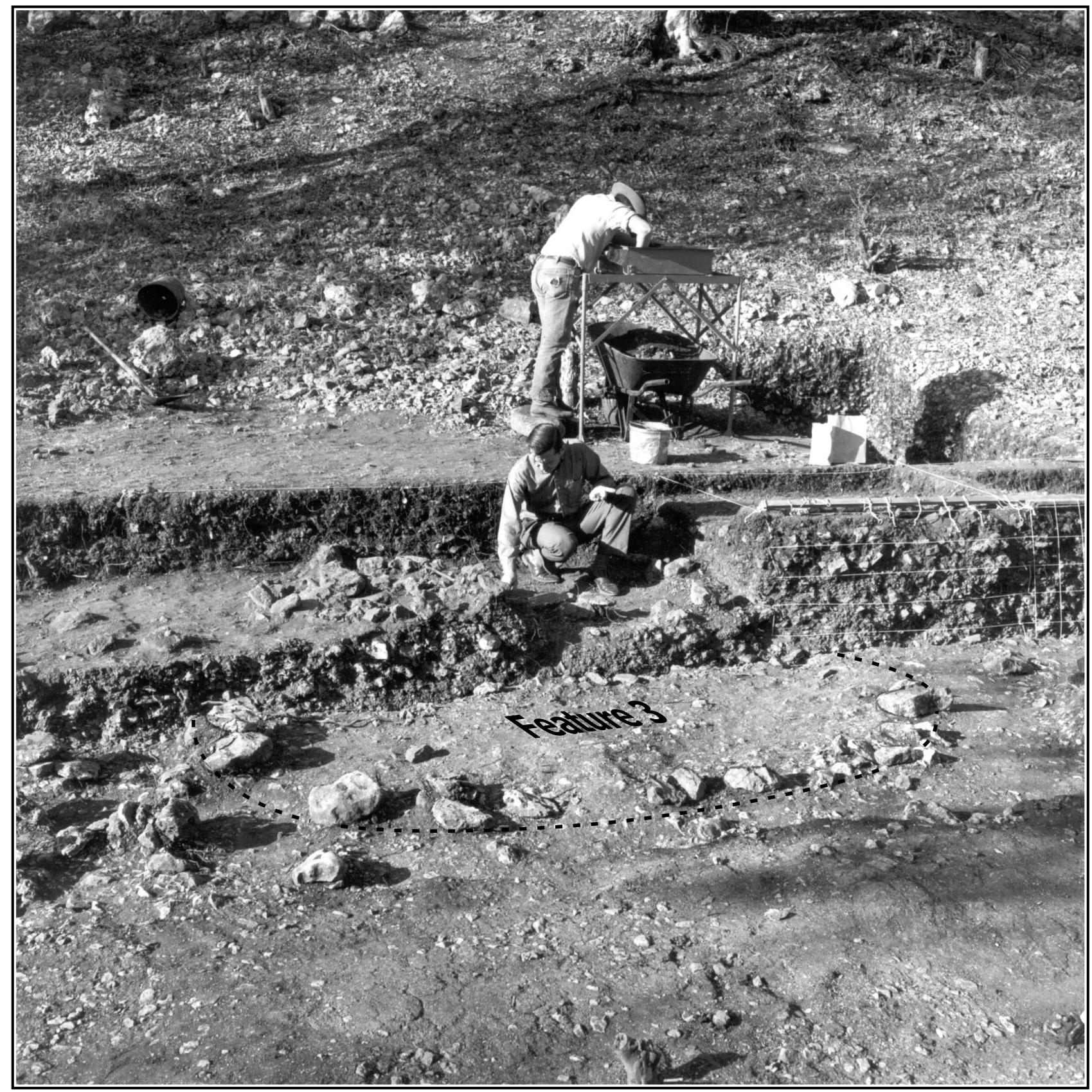

Figure 5-9. Oblique view of Feature 3. Crew members are working in Area C, Area B midden is at upper right. 


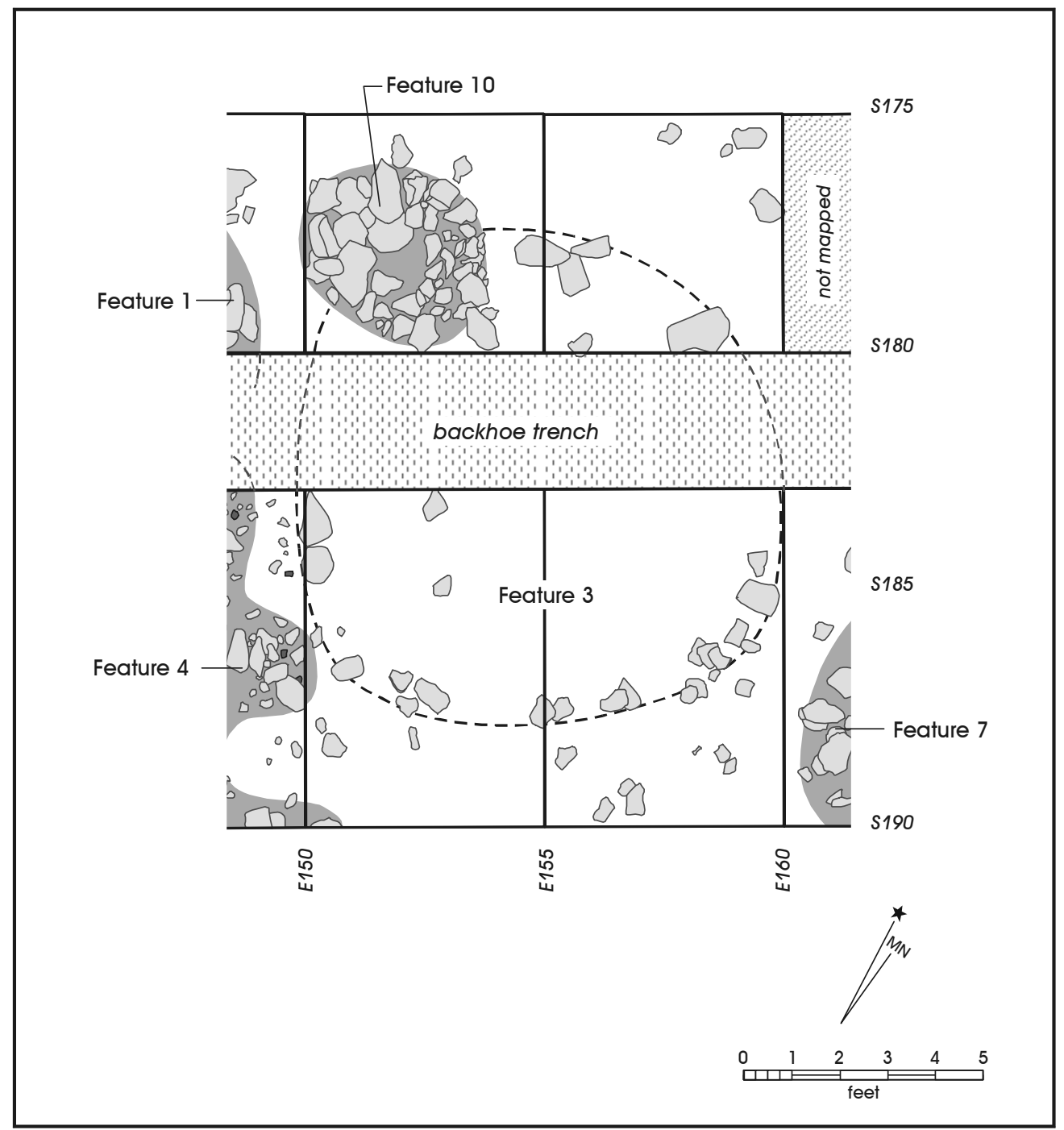

Figure 5-10. Feature 3, a possible structure in Area $C$.

suggests that the feature was probably used during the Late Prehistoric period.

\section{Feature 4}

This feature consisted of an accumulation of cobbles and pebble-sized limestone rocks in Area C (Figure 5-6). The feature extended over units S175/E135 through E150 in Level 2. As can be seen in Figure 5-11, the area for Feature 3 appeared to have been deliberately cleared of cobbles. Only 29 of the 1,267 rocks shown in Feature 4 at the site (Figure 5-6) were noted as being burned. The rock pattern that comprised Feature 4, then, was determined to be a natural colluvial slope or scree deposit that had accumulated on the terrace prior to the late occupations. This stony pavement extended westward through Area D where it was exposed on the surface. Excavation in the units of Area $C$ containing Feature 4 were terminated at Level 2 and the rocks comprising this feature were never removed during the fieldwork.

\section{Feature 5}

The backhoe trench in Area $\mathrm{C}$ bisected this oval slab-lined pit, destroying much of the feature (Figure 5-6). The approximate center of the feature was at grid intersection S182/E169. Originally, the pit probably measured about 1.5

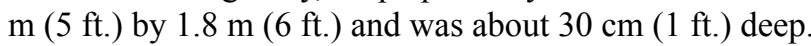




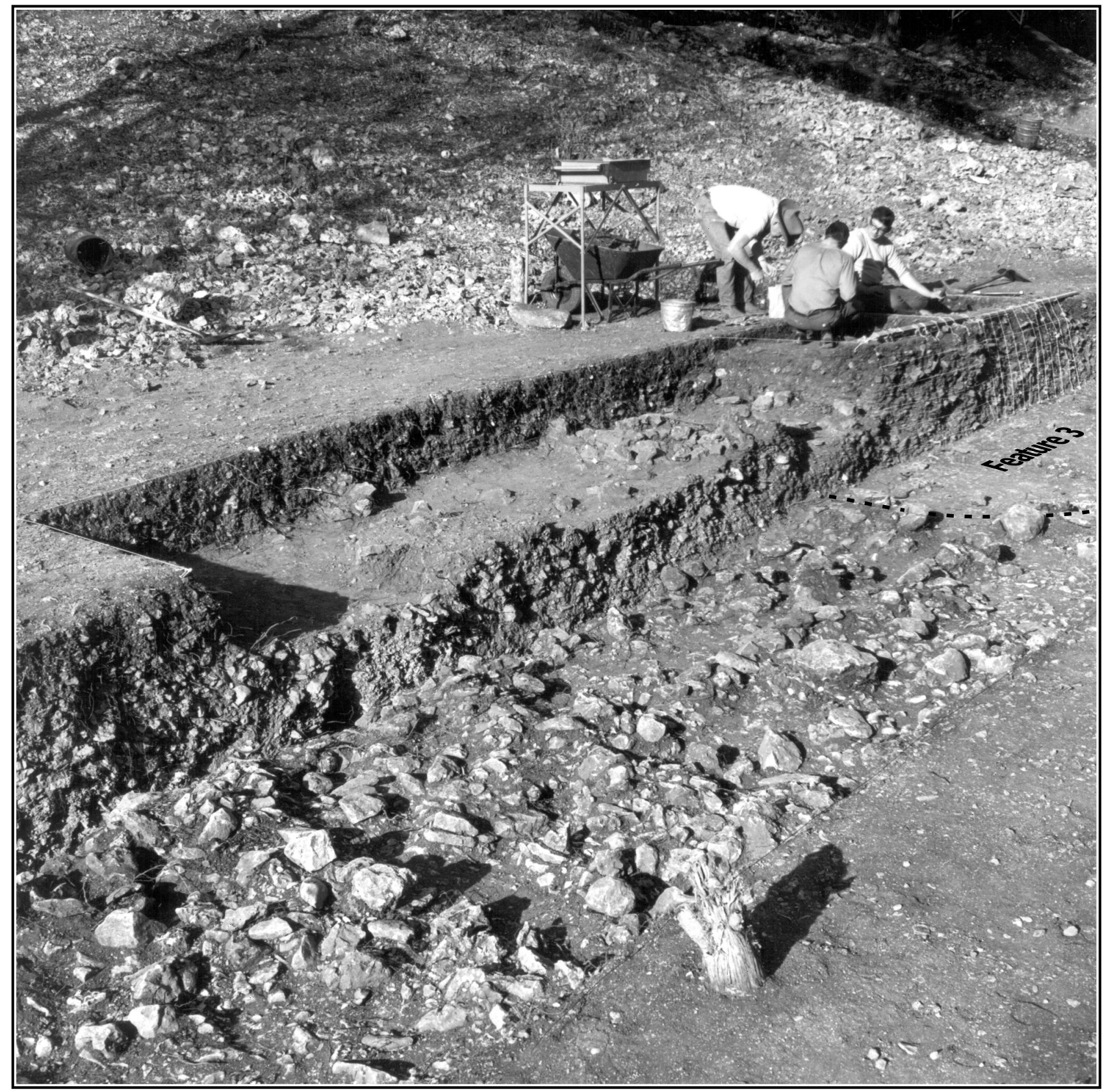

Figure 5-11. Feature 4, limestone pavement of primarily unburned cobbles, Feature 3 is to the right in the photo. Field crew working in Area $C$, midden in Area B behind crew members. 
As can be seen in the photograph (Figure 5-12), as well as in Figure 5-13, most of the extant rocks are sloping toward the center of the feature, and many are large, with several in excess of $30 \mathrm{~cm}$ in maximum dimension. The feature was lined with rock, and was a large hearth; however, no charcoal was observed during excavation. Artifacts thought to be associated with Feature 5 included a Fairland dart point, suggesting a possible Late Archaic age for the feature fill. A cluster of three mussel shell valves and a "scraper plane" were recovered from Level 2 immediately adjacent to the perimeter of the circular line of rocks. This apparent cache was similar to the grouping of items recovered from Feature 1. This tight association of a uniface between two mussel valves has not been recognized or reported on before in other reports. Because of the idiosyncratic nature of the caches, Weir suggests that the two features may not only be contemporaneous but may also be the work of the same individual. Given the two mussel shell/uniface caches found in direct association with separate stone-lined features, Weir speculates that there may be more to these features than simply cooking (Weir 2004:7).

\section{Feature 6}

This feature in Area B (Figure 5-5) was a concentration of debitage and projectile points clustered around and near the base of a boulder (Figures 5-14 and 5-15). It was discovered in Levels 5 and 6 in unit S170/E200, and continued into S165/E200. When discovered, the excavators described the feature as a chipping location. Several of the points associated with the concentration are shown in Figure 5-16. In all, 21 points were assigned to this feature, with Middle Archaic Nolan forms dominating $(\mathrm{n}=12)$. Also present were a single Late Archaic Bulverde point, two Early Triangular points dating to the Early Archaic, and two Middle Archaic Travis points. There were also four untyped and untypable dart points. Bifaces were common, with 25 items being assigned to this feature, along with five unifaces, five cores, and several edge modified tools. In addition, over 1,000 pieces of debitage were associated with this feature. The number of projectile points, bifaces in the late stages of reduction, unifaces and cores suggests that the feature had accumulated over a considerable period of reuse.

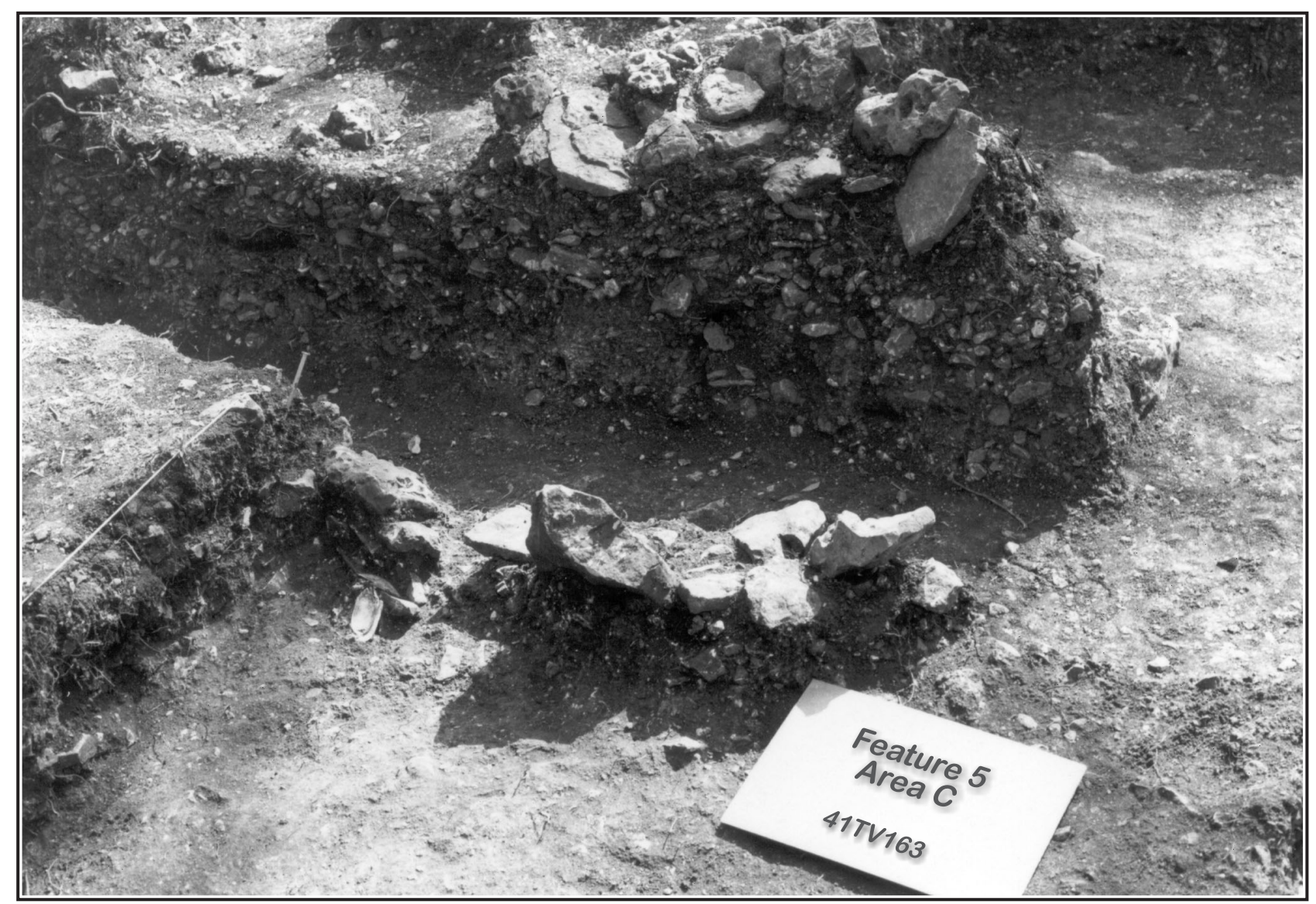

Figure 5-12. Feature 5, slab-lined pit bisected by backhoe trench. Note uniface/mussel shell cache in foreground at left-center of photo. 


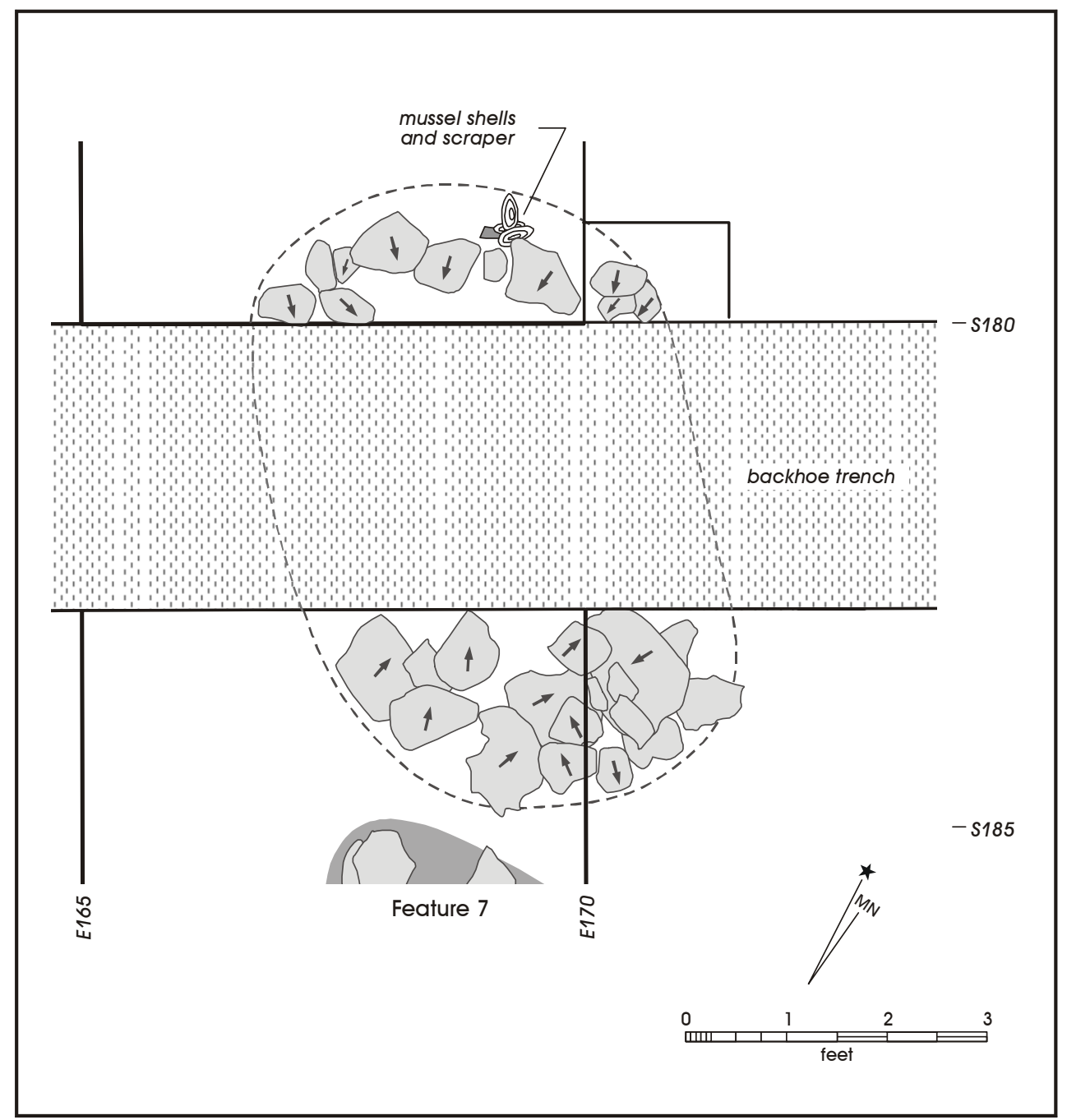

Figure 5-13. Feature 5, Area C. Note uniface/mussel shell cache at edge of feature.

\section{Feature 7}

This feature was a rock concentration in Area $\mathrm{C}$ recorded in Level 2 of units S185/E170-E175 (Figure 5-6). Only a plan view (Figure 5-6) and photographs (Figure 5-17) exist of the feature. No descriptive information was present in the field notes. The feature consisted of a small semicircular arrangement of cobbles in the southeast quadrant of S185/ E165 and apparent piles of cobbles and small boulders in the adjacent units S185/E170 and S185/E175. Weir speculates that these stone piles could have been deposited during aboriginal clearing of work and habitation spaces in the area. While such piles of rocks were not noted in Feature 4, Weir suggests that Feature 7 is a continuation of Feature 4 (Weir 2004:8).

\section{Feature 8}

Although there were isolated burned cobbles found within Area F, this possible hearth, located in unit $2+70 / \mathrm{S} 0+5.5$, was the only feature recorded in the area (Figure 5-5). It was revealed in the third level of the unit and consisted of a cluster of 41 pebble- to cobble-sized burned rock with some cracked in place (Figure 5-18). Originally about $45 \mathrm{~cm}$ in diameter, the feature probably extended into the adjacent unit, $2+70 / \mathrm{S}+0$, and was cut by the Gradall. The stones were flatly distributed at the same elevation within the unit. No basin or pit was noted. Although the rocks were fire cracked, no charcoal or soil stain was observed during the excavation of this feature. Since only Early Archaic projectile points were found in the same soil formation and level as this 


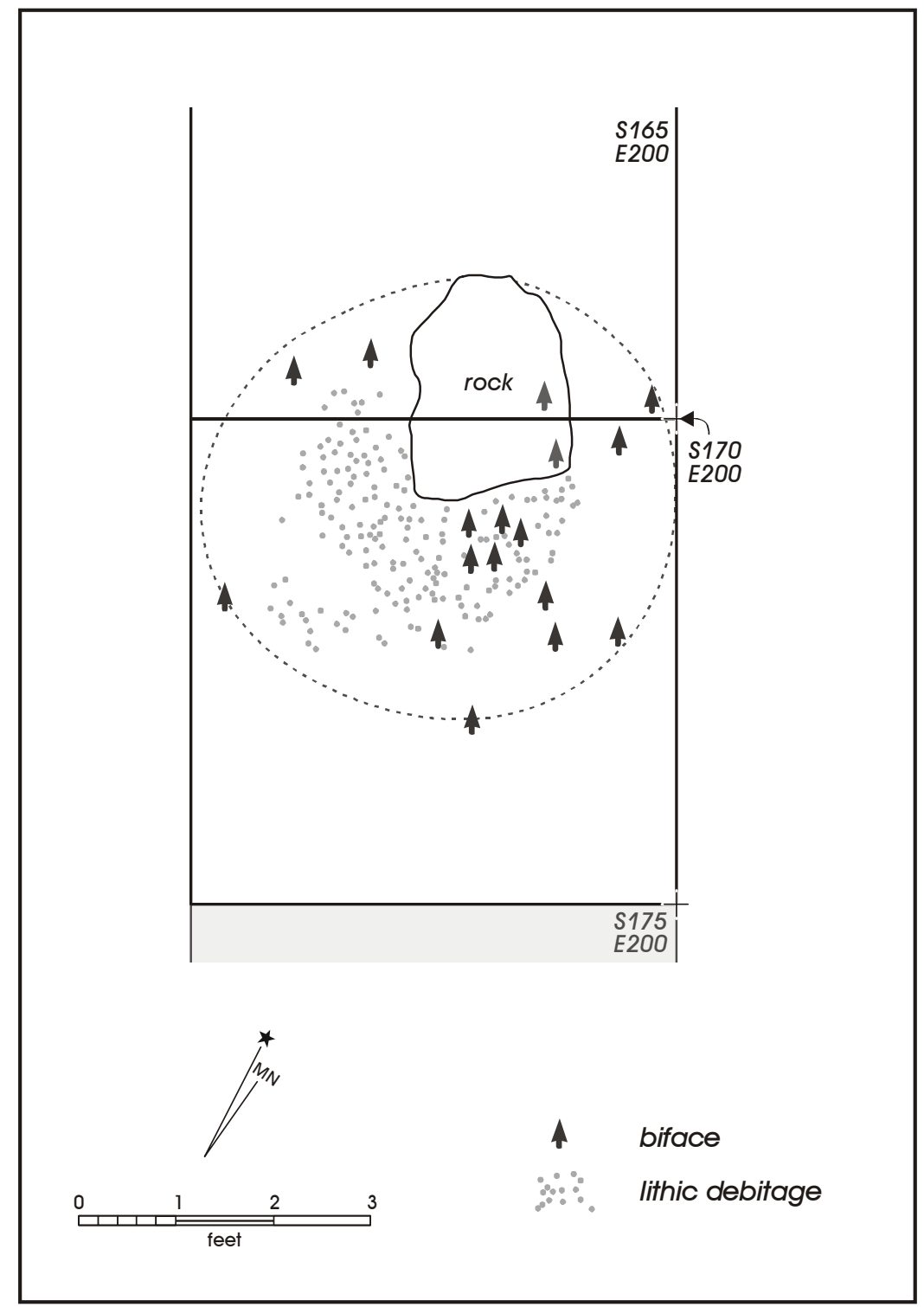

Figure 5-14. Plan view of Feature 6, Area B.

feature, in Levels 3 and 4 of the adjoining unit (see Figure E-5, \#15, \#17, and \#18 in Appendix E), it is assumed that the hearth was also Early Archaic.

\section{Feature 9}

A small alignment of burned rock was noticed protruding from the east profile of unit S185/E175. Although the unit in which the alignment was located was not planned for excavation, an abbreviated excavation was conducted to expose this feature. This was done at the end of the fieldwork. No feature form exists for Feature 9 other that a plan view drawing included on the Feature 7 form. Located in Area C (Figure 5-6), this feature appeared to have been a cluster of seven cobble-sized slabs of limestone contained in an area approximately 60 by $70 \mathrm{~cm}$ in dimension (Figure 5-19). All of the slabs seemed to have been burned and cooled in place with three of the larger stones exhibiting severe thermal cracks, but still articulated. Because the cracked stones were articulated, each was counted as a single stone rather than counting each fragment. The cluster was not sectioned, therefore it is unknown what lay within or below the feature (Weir 2004:8). The only attributes that distinguish this feature is the slightly elevated and apparent undisturbed and 


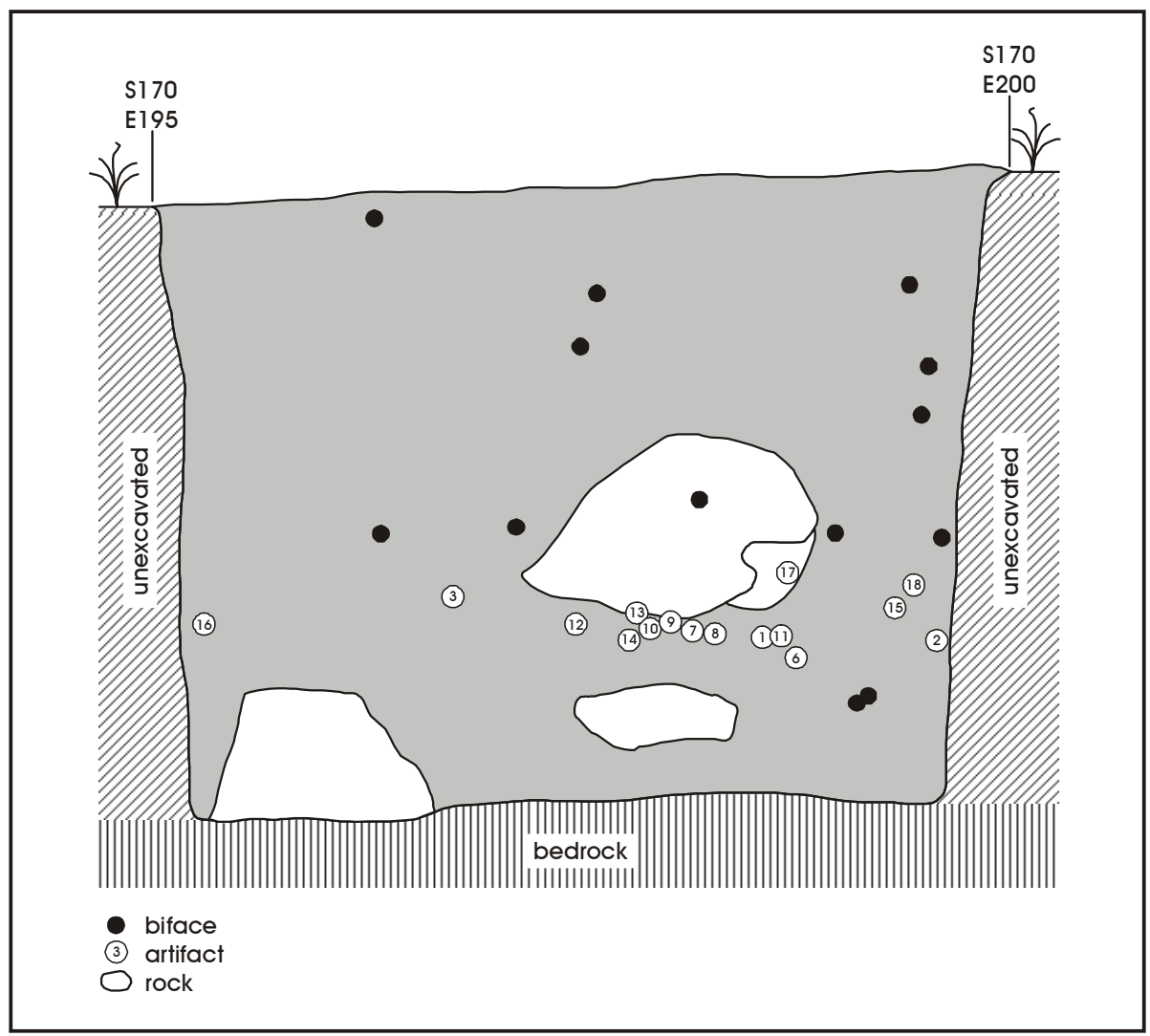

Figure 5-15. Schematic profile of Feature 6 showing the vertical position of artifacts relative to the boulder.

burned condition of the stones contained within. There was no physical separation between Features 9 and 7, and it is likely that Feature 9 is a continuation of the rock distribution of Feature 7.

\section{Feature 10}

The partial remains of a human burial were discovered beneath a rock cairn in Area C in unit S175/E155, Levels 2 and 3 (Figures 5-6 and 5-20). The rock cairn over the burial

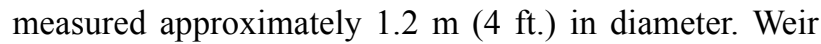
suspects that the individual was buried in an existing slablined pit. He recalls that the boulders of the cairn covered only the position of the body, while the circular diameter of the pit was larger than the interment (Weir 2004:9). It appears as though the cairn was incorporated into the wall and/or wall support system of the circular pattern of Feature 3, although Weir feels the burial feature was not part of Feature 3 , the possible structure (Weir 2004:9). The burial was flexed on its left side with the head to the east and face directed toward the south. As discussed previously, many postcranial bones were missing, but those present suggest the majority, if not the entire skeleton was once present (see Figure 5-4). It remains unclear whether this represents a primary or secondary burial; however, both humeri are present and occur in relative position to the cranium consistent with a flexed burial. Postdepositional trauma is evident on some skeletal elements that may account for the absence of the inferior portion of the interment. During the excavation, Weir had surmised that the burial was in a primary flexed context (Weir 2004:9).

Associated artifacts with the burial included one Darl point, although the point was removed from the collection some time in the 1970s and is no longer contained in the artifact assemblage. The presence of this point suggests that the burial may date to the later part of the Late Archaic. A single radiocarbon date was obtained on charcoal found in the burial pit. The calibrated, corrected date range at two-sigma is A.D. 380-570 (Table 5-4). In January 1980, Richard Shoup of TxDOT completed a preliminary report on the human skeletal material from the site. This report is curated with all other documentation from 41TV163. 


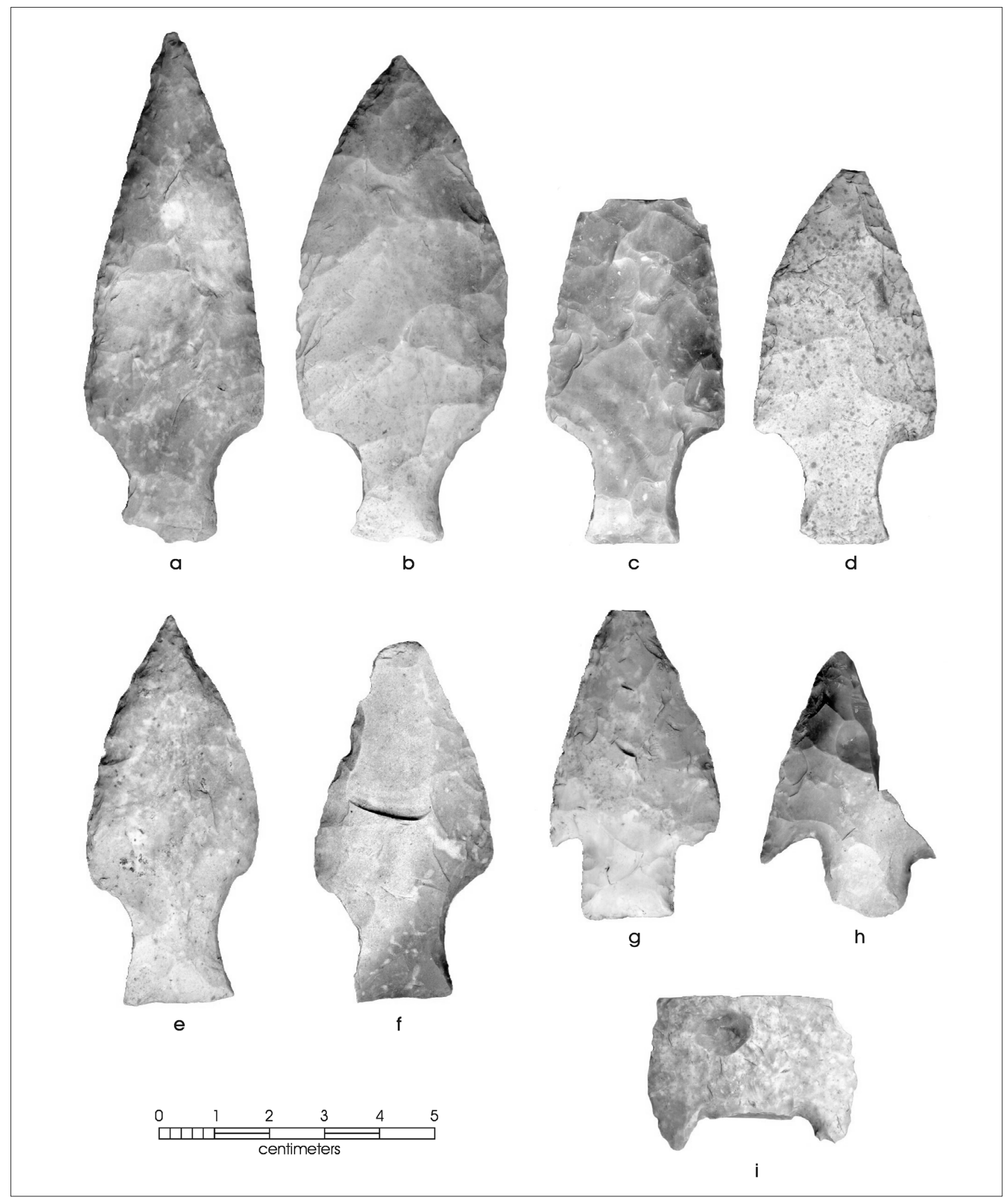

Figure 5-16. Selected projectile points recovered from Feature 6, Area B. a-f) Nolan; g) Bulverde; h, i) untypable fragments. 


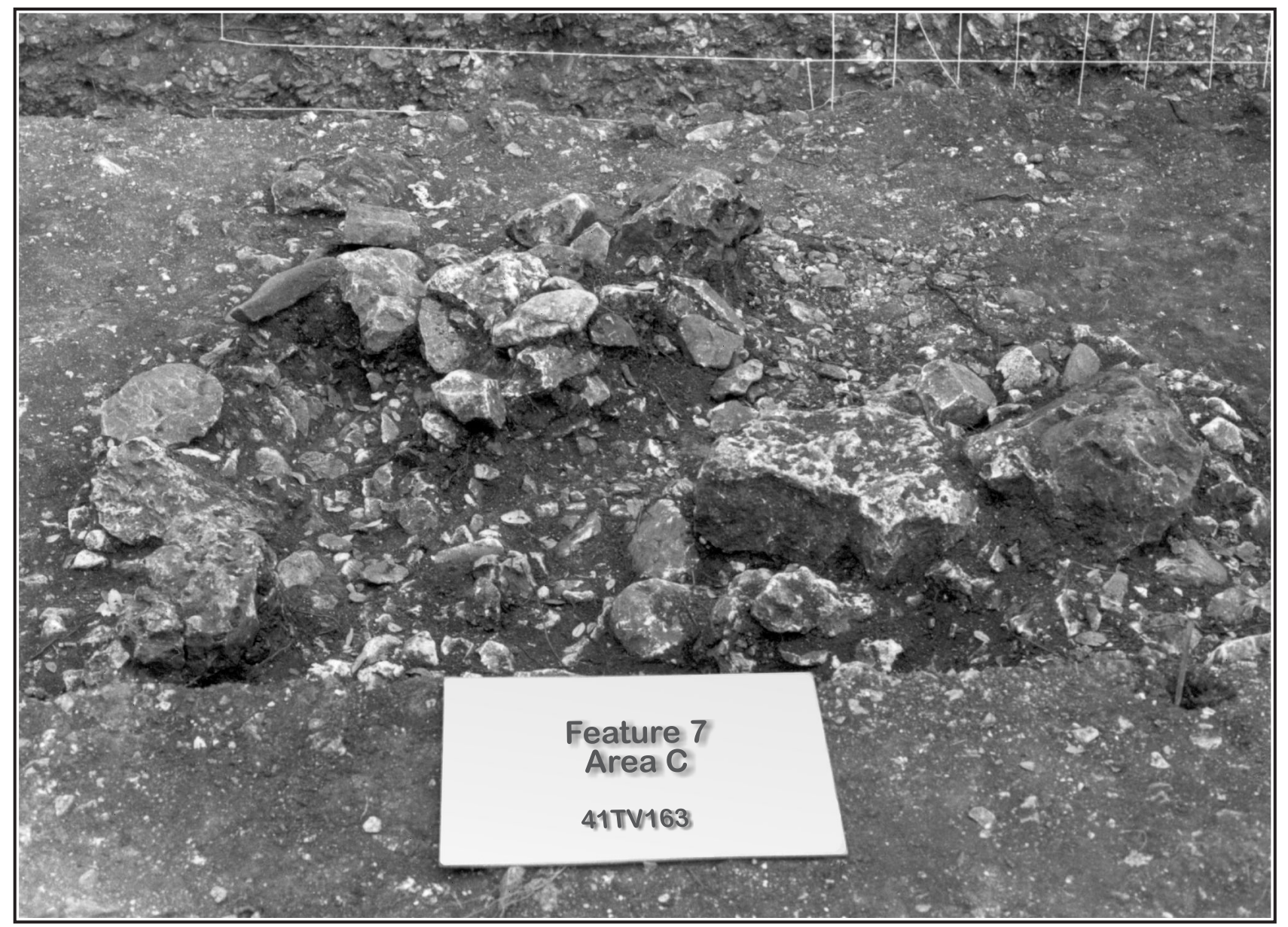

Figure 5-17. Feature 7, rock concentration in unit S185/E170-175, Area C.

\section{Feature 11}

Feature 11, also discovered in Area C, consisted of a cluster or cache of nine items, including two bifaces, two edgemodified flakes, a core, and four large flakes (Figure 5-21). These were found in S170/E165 in Level 5 (Figure 5-6). The two bifaces appear to be blanks. We have no information on when this feature may date as none of the material was diagnostic of any single time period. However, an early Late Archaic Pedernales point (Figure E-3, \#296) was found in unit S165/E170 at the same level and within $30 \mathrm{~cm}$ of the cache.

\section{Additional Features}

There were three additional features on this site, the burned rock middens in Areas A and E. In addition, a possible burned rock midden was identified in Area B.
Figure 5-22 presents a profile of the east-west trench through the Area A midden. The Area A midden appears to have been primarily confined to Zones 2, 3 and 4 in the profile. A possible edge of the feature is visible between E160 and E155. Artifacts and other samples collected from this midden have been described previously. The midden appears, based on the diagnostic points recovered, to have been primarily used during the Middle Archaic with use continuing into the early portion of the Late Archaic (see Table 5-2). Unfortunately, no charcoal samples were available from this midden to confirm this temporal assignment.

Figure 5-23 presents a profile of the west wall through Area B. Burned rock is most abundant in Zones 3 and 4, although it is noted in some quantity in Zones 2 and 5. Small burned rocks seem to dominate the zone descriptions for this area. Weir states that burned rock appeared to extend from Zone 2 through Zone 5 (Weir 2004:11). It is probable, given the small size of the rock, that the burned limestone is a 


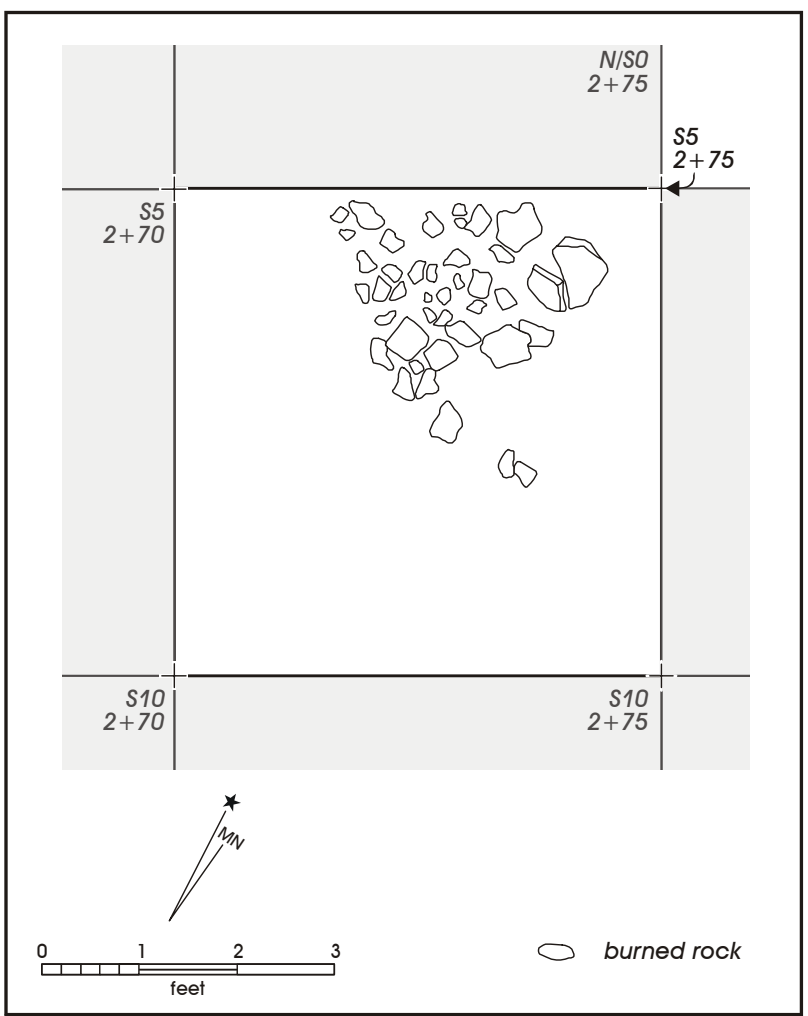

Figure 5-18. Plan view of Feature 8, a possible slab-lined hearth, Area F.

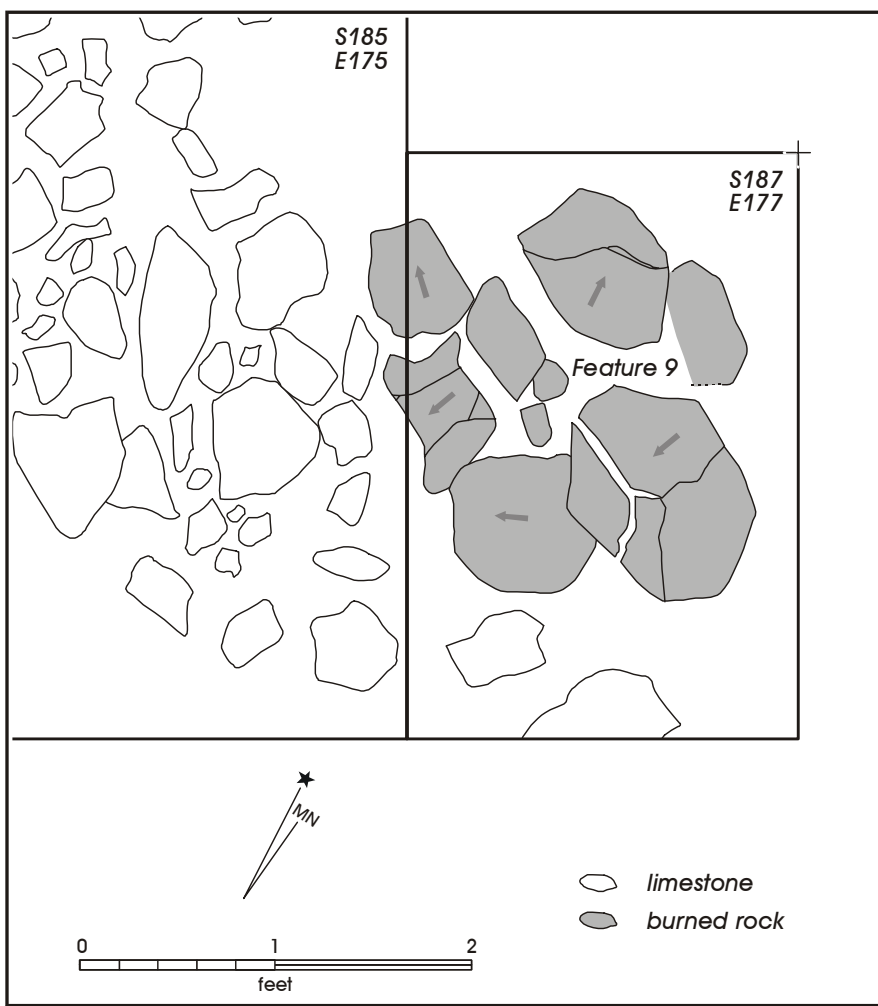

Figure 5-19. Plan view of Feature 9, cluster of burned rocks in association with Feature 7, Area $C$. 


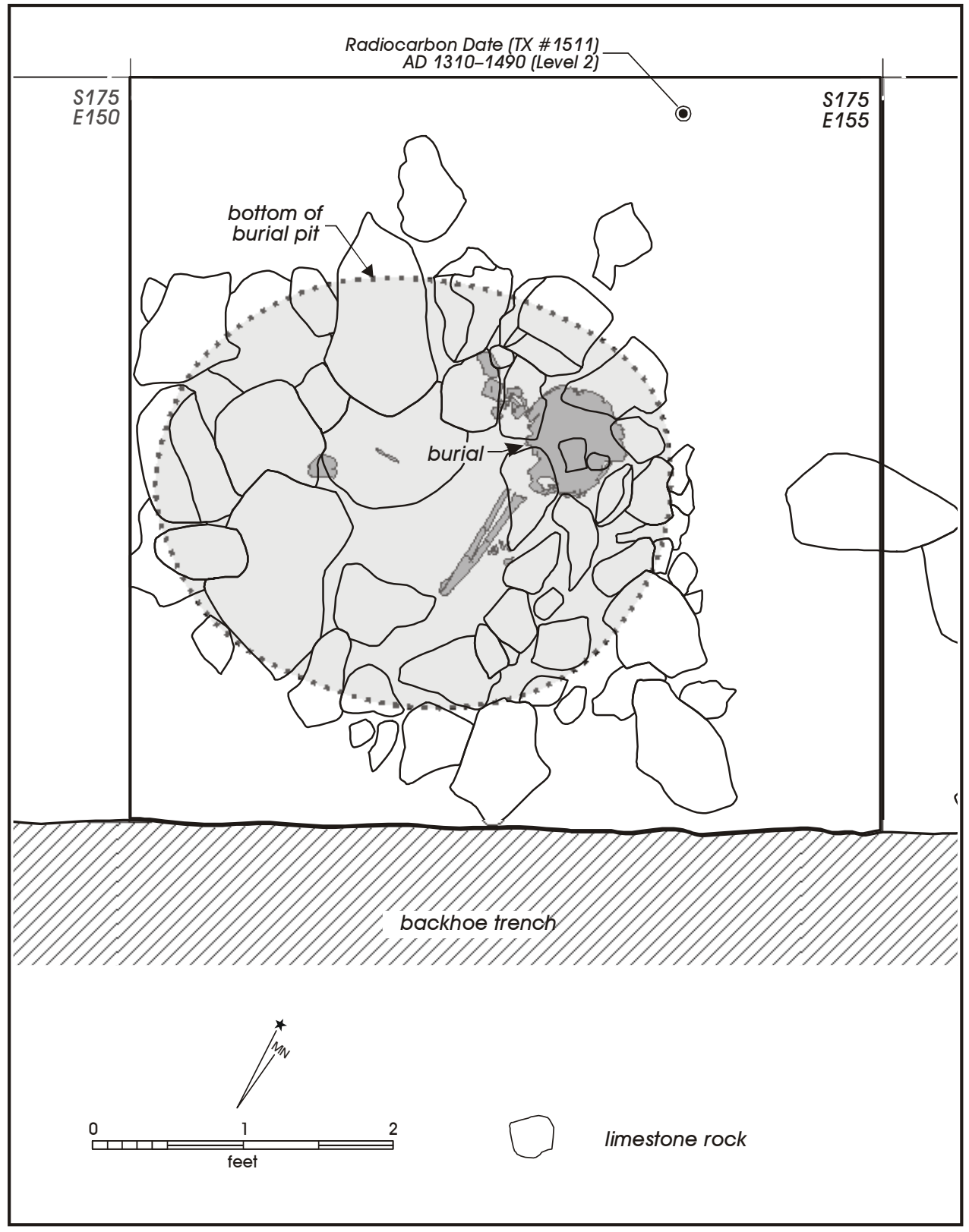

Figure 5-20. Feature 10, plan view of burial pit capped by slabs of rocks, Area C. Note bouldersized rocks above postcranial portion of burial. 


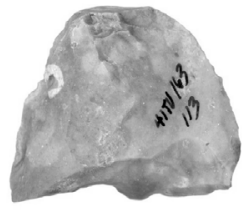

a

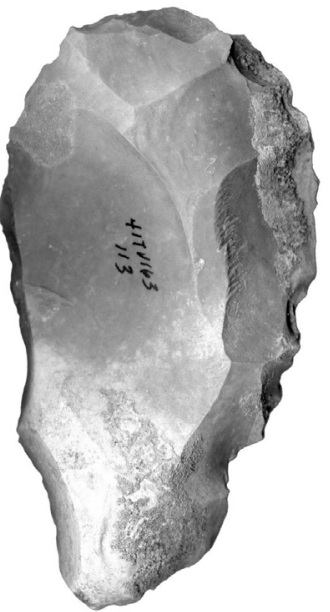

d

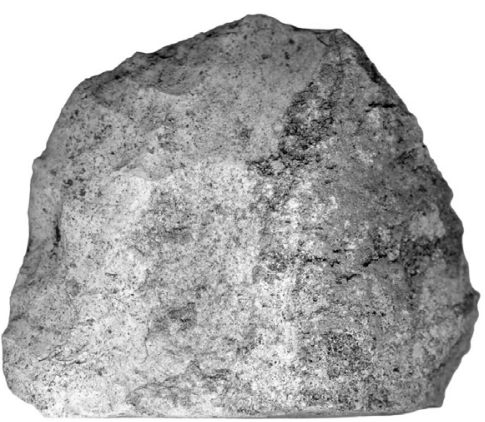

g

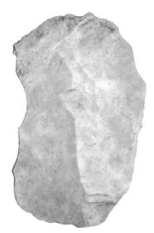

b

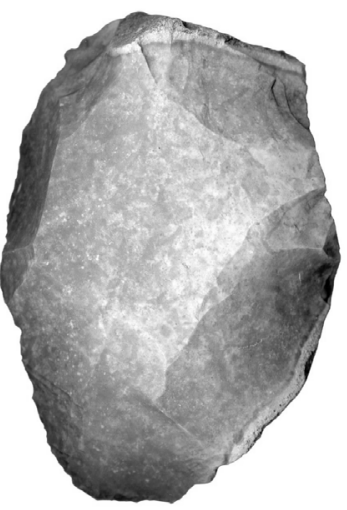

e

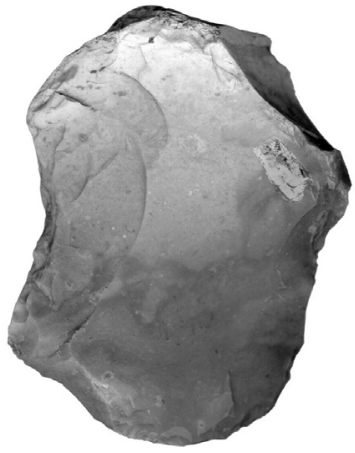

h

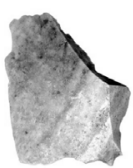

C

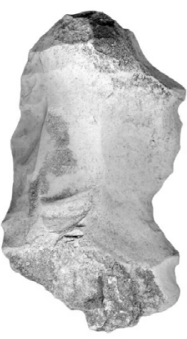

f

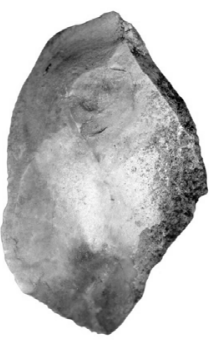

i

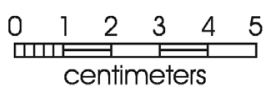

Figure 5-21. Artifacts from Feature 11 cache, Area $C$. a) early reduction stage biface; b) expedient knife on biface thinning flake; c) unmodified debitage; d, e) middle reduction stage bifaces; f) minimally retouched uniface (spoke shave); g) early reduction stage biface; h) core; i) unmodified debitage. 
secondary deposit related to the burned rock midden in Area A and does not constitute a separate feature. Support for this suggestion can be seen in Figure 5-24, a profile of the upper portion of Area C. Note that Zone 8 in this profile is dominated by small burned rock. The presence of these rocks, and the overall shape of the zone, clearly suggests that the sediment is being deposited from the Area A midden, located upslope. Weir disagrees with this interpretation and maintains that there was clear separation between the Area A and Area B middens. The Area A midden was entirely contained on an upper bench while the Area B midden was on the slope below this bench making it an entirely separate feature (Weir 2004:11).

Figure 5-25 presents a profile of the north wall through Area $\mathrm{E}$, a second area identified as containing a burned rock midden. Recall that this area also had a high frequency of modern/historic material (see Table 5-1), and a modern radiocarbon date was obtained from Level $1(0-0.5 \mathrm{ft}$.) in square $1+70 / \mathrm{N}+2.50$ (see Table 5-4). An examination of the profile, as well as the description of the zones in Figure $5-25$, shows some evidence for a burned rock midden being present in the Zone 3 deposits, though the description is not compelling. If the Zone 3 deposits do represent a burned rock midden, the prehistoric materials from this area (see Table 5-2) suggest Late Archaic and possibly Late Prehistoric use. Weir indicates that Zones 2 and 3 in this area were part of a burned rock midden that extended from $1+60$ to $1+95$. The size of the burned rock was apparently smaller than that noted in the middens in Area A and Area B (Weir 2004:11).

\section{Summary}

Using the field methods described in the previous chapter, TxDOT removed and screened roughly 108.5 cubic meters of fill from the site of Millican Bench (41TV163). A variety of prehistoric artifacts, as well as some historic/modern material, were collected from the site. In addition, 11 features were recorded, including a possible structure (Feature 3) and a burial (Feature 10), and two burned rock middens were tested. Also collected were vertebrate faunal remains, snail and mussel shell, as well as charcoal and sediment samples. While aspects of these data, collected to pursue questions of chronology and culture history, are limited for consideration of many current research questions, the data are amenable to several specific research domains. These domains are discussed in the subsequent chapter. 


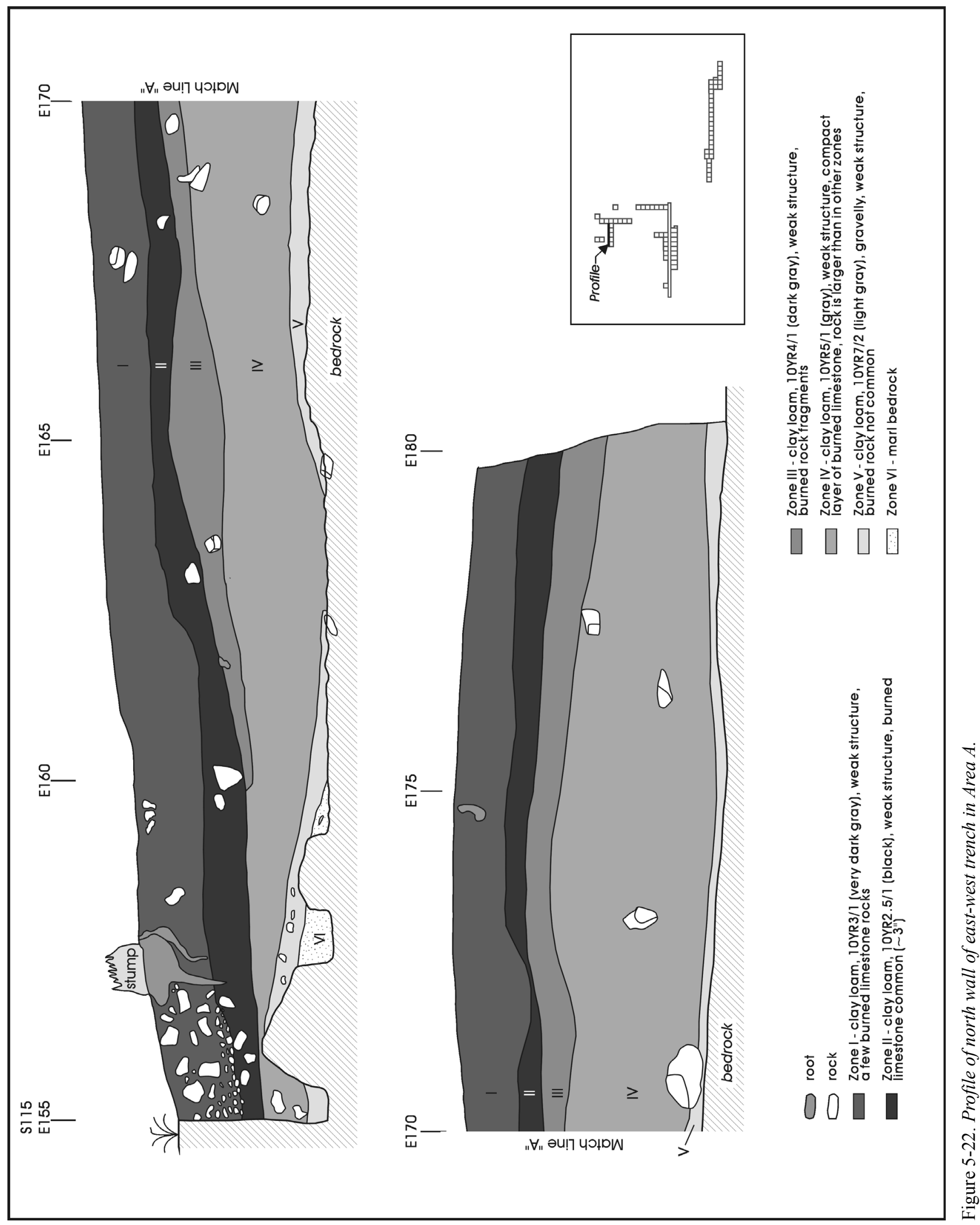




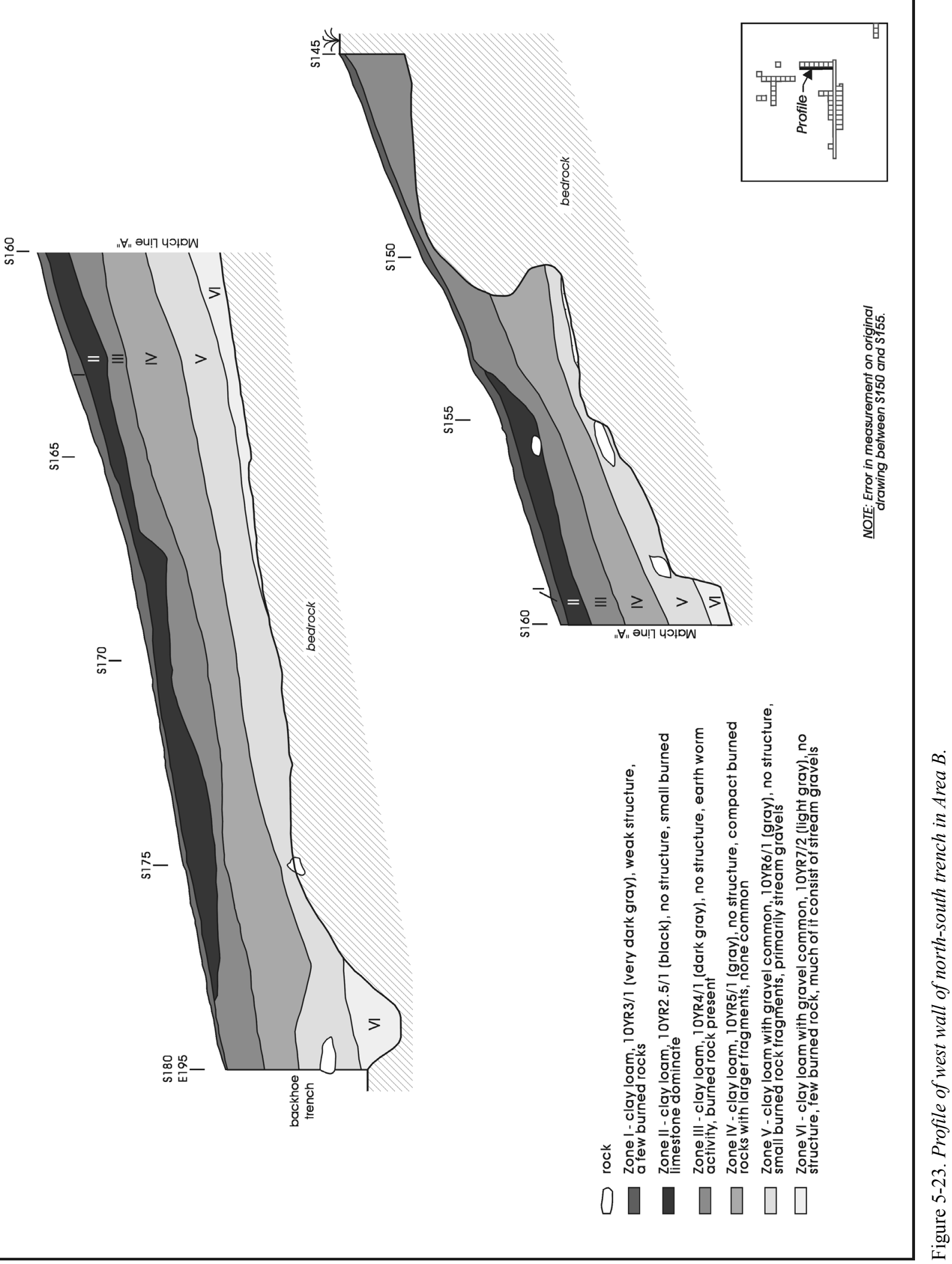




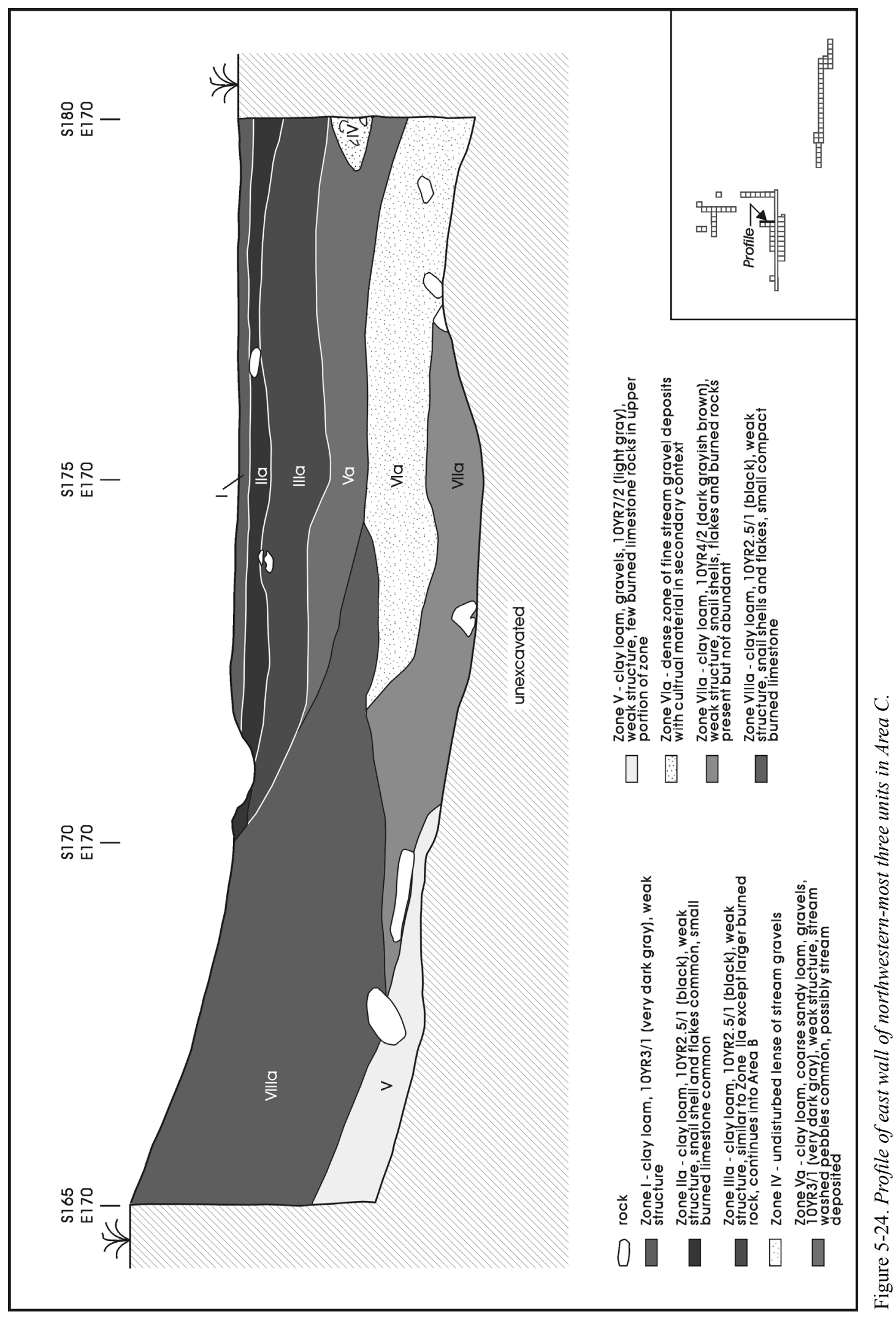




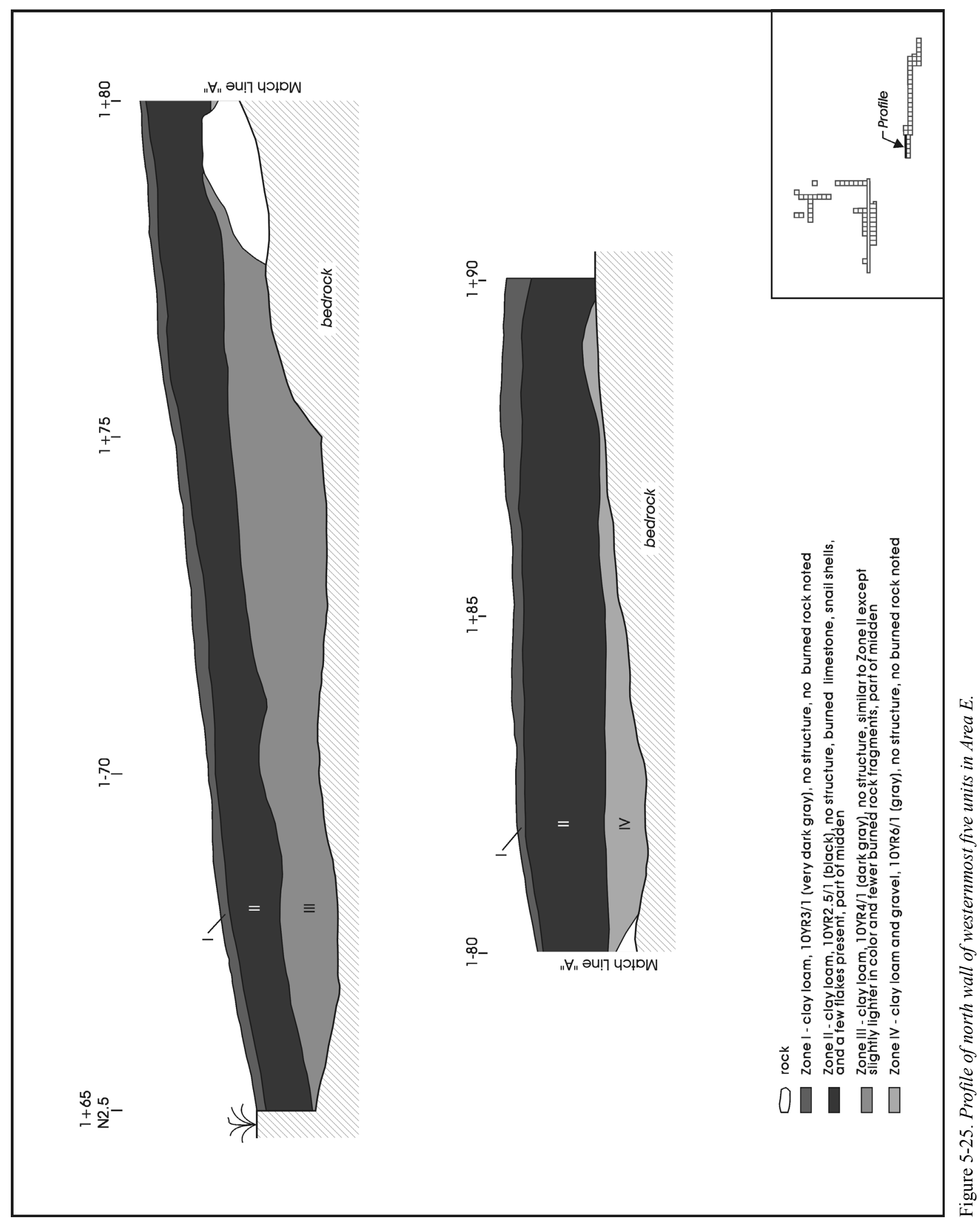




\title{
Chapter 6: Research Issues
}

\author{
Raymond P. Mauldin, Steve A. Tomka, and Russell D. Greaves
}

\section{Introduction}

In the previous chapters we summarized various data sets collected from 41TV163. The site was excavated over thirty years ago using a variety of field techniques that were designed to collect information primarily for the investigation of cultural chronology. As such, data sets commonly collected today in order to address current research questions were only of incidental interest. In addition, some records (e.g., field journal and original profiles) have been lost over the last three decades. Nevertheless, the data from 41TV163 can make a significant contribution to understanding selected aspects of Texas prehistory. This chapter outlines several current research domains that can be addressed with extant data from the site of Millican Bench.

The first two research issues are explicitly concerned with diachronic change. Specifically, we proposed to investigate changes in subsistence patterns and changes in lithic technology. For this component of the investigation, it was necessary to identify deposits that can be assigned to a given temporal period. The temporal analytical units defined at 41TV163 are broad relative to traditional "componentbased" analysis. They frequently consist of selected levels from clusters of excavated units identified on the basis of diagnostic projectile points that reflect a single period. The individual analytical units span a temporal range from the Early Archaic through the Late Prehistoric. The material associated with these analytical units, which primarily consists of chipped stone and faunal material, was specifically used to investigate changes in subsistence patterns from the Late Archaic through the Late Prehistoric periods, and changes in lithic technology from the Early Archaic through the Late Prehistoric.

The third research area considered focuses more on a specific feature type represented at the site. This research domain is more synchronic in focus. Specifically, it centers on the investigation of the possible structure (Feature 3) at this site. Few houses have been reported for the prehistoric record in central Texas. If Feature 3 at the Millican Bench site does represent a structure, a number of implications, both for the use of the site as well as the nature of the overall Late Prehistoric adaptation, follow. Note that in our original assessment of this site (Mahoney et al. 2003a) we had proposed a fourth research domain which involved the investigation of the "veneer" hypotheses for burned rock midden formation (see Collins 1994). That investigation hinged on having two data sets from specific contexts. We had proposed to use fluoride dating of animal bones (see Ezzo 1992; Gregory and Schurr 2000) and radiocarbon dating from several areas of the site in order to more finely date the deposits in several of the burned rock midden features. Unfortunately, we were unable to isolate sufficient charcoal for the radiocarbon dating. In addition, the condition of the faunal material was such that we could not isolate faunal samples representing the same species and same element (see Gregory and Schurr 2000; Schurr 1989) from the appropriate contexts. We were, then, unable to pursue this fourth research domain.

\section{Diachronic Research Issues: Changes in Subsistence Patterns and Lithic Technology}

As outlined in the previous chapters, 41TV163 contains an abundant material record generated over a significant time span. Diagnostic projectile points span several thousand years and suggest occupation of the site, at some level, from the Early Archaic through the Late Prehistoric. Sites generated by repeated occupations over long periods of time, such as 41TV163, dominate the record in Texas. While such sites contain an extremely complex archeological assemblage that makes it difficult to isolate clear temporal analytical units, they also provide the opportunity to study specific research questions, many of which are focused on documenting and understanding diachronic changes in adaptation while holding site location constant. That is, in these situations it can be assumed that whatever differences are seen in subsistence or technological aspects of distinct analytical units is likely due to different adaptive strategies rather than simply changes in site location.

\section{Definition of Analytical Unit}

One of the initial problems that must be considered when investigating diachronic issues at sites generated over long periods of time is how to isolate distinct analytical units for comparison. In part because of the limitations of the available records, and in part because the site was excavated in arbitrary, six-inch levels, the analytical units we propose 
for 41TV163 are not at the phase or interval scale, but rather at the broader, period temporal scale (e.g., Early Archaic, Late Prehistoric). The boundaries between periods traditionally used in Texas archeology are assumed by most researchers to represent points in time at which significant changes occurred in subsistence and technological practices. The periods themselves (e.g., Late Archaic) are assumed to reflect relatively consistent adaptations internally relative to other periods. Therefore, assuming that period-level designations can be made, certain analytical comparisons (e.g., technological organization) between periods can yield significant research results, especially when, as is the present case, only a single site is being compared.

As discussed in the previous chapter, over 400 projectile points were recovered from 41TV163. The projectile point styles were identified based primarily on Turner and Hester (1999) and supplemented by H. J. Shafer's typological assessments. In order to divide the 41TV163 temporal record into period-level analytical units, we initially searched for vertical clusters of like projectile points in the various excavation areas identified at the site. The vertical provenience unit in which material was collected during the excavation at the site consisted of six-inch levels. While the original excavators tried to place these arbitrary levels into larger zone designations that were potentially indicative of natural stratigraphic units, our review of these data suggest that this attempt is not useful for our purposes. Using these thicker "zonal" assignments, which were often several levels thick and occasionally assigned a given level to more than one zone (e.g., Zone II/III), grouping material failed to produce results that reflected consistent temporal periods. Consequently, we used the smallest available vertical designation, the six-inch level, as a starting point to search for period-level analytical units. Relying on these six-inch levels for vertical control, we investigated each of the five spatial areas designated at the site. The point distributions were compared, where appropriate, to the radiocarbon dates available from the site (see Table 5-4).

Our investigation suggests that Area A and Area D contain deposits with little or no temporal integrity based on the distribution of temporally diagnostic projectile points. However, making the assumption that the material associated with temporally diagnostic points reflects a similar age as those points, we can isolate assemblages for comparison in each of the remaining areas. We can isolate two different analytical units in Area B, one of which represents primarily Late Archaic material and a second that represents Middle Archaic material. For Area C, we can isolate a series of excavation units and levels that reflect primarily Late
Prehistoric material. Area E contains units that can be assigned to the Late Archaic, while Area F appears to be primarily Early Archaic in age. We discuss our investigation of each of these five spatial areas below.

\section{Area A}

As outlined in the previous chapter, 38 temporally diagnostic projectile points were collected and identified from this area of the site. There are 19 Late Archaic point types, which span the entire period. Seventeen points date to the Middle Archaic period. In addition, two Early Archaic points are present. Table 6-1 presents the distribution of each point type by unit and level, with the types grouped chronologically. The Middle Archaic section of the table is shaded. Examination of the table clearly demonstrates that there is considerable overlap within the deposit. Each of the five levels with points has both Late Archaic and Middle Archaic specimens present. None of the components appear to be separated vertically. The percentage of Late Archaic diagnostics by level fluctuates substantially, with the two lowest percentages occurring in Level 5 (25\%) and Level 1 (44\%). In addition, note that the Early Archaic Wells points appear in the two highest levels. No spatial clustering of levels with point types reflecting a consistent period assignment is apparent. Based on the distribution of point types in Table 5-1, our assessment is that the deposits in Area A lack integrity. We cannot define an artifact sample that would even broadly represent a temporal period.

\section{Area B}

The sample of diagnostic points from Area B consists of 59 specimens that primarily reflect Late $(\mathrm{n}=34)$ and Middle $(n=22)$ Archaic production, although three Early Archaic points are also present. Three of the 59 points were collected from the backhoe trench at the south end of this area, and the precise provenience of two other points is not known. Table 6-2 presents the vertical distribution of the remaining 54 points by type and level. As with Table 6-1, the Middle Archaic point types are shaded. Within this area, excavation was only conducted along the E200 line. Figure 6-1 is a schematic of the distribution of diagnostics along E200 from S145 through S175 that reflects all 54 diagnostics recovered. Comparison of the percentages of Late Archaic point types by level, presented to the right of the schematic in Figure 6-1, clearly suggests that good vertical separation is present between the Late and Middle Archaic in Area B. All of the 15 diagnostic points from the upper four levels reflect a Late Archaic age. Conversely, Late Archaic points make up only $27.3 \%$ of the 33 points found below Level 5, and these lower levels are dominated by Middle Archaic point forms $(66.7 \%)$. 
Table 6-1. Projectile Point Distributions by Unit and Level, Area A

\begin{tabular}{|c|c|c|c|c|c|c|c|c|c|c|}
\hline Unit & Level & $\overline{\bar{E}}$ & 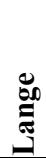 & 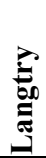 & 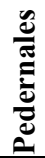 & $\frac{\stackrel{0}{0}}{2}$ & $\frac{\tilde{z}}{0}$ & $\stackrel{n}{=}$ & $\stackrel{0}{\overline{0}}$ & $\overline{\underline{\sigma}}$ \\
\hline S105/E165 & 1 & & & & & 1 & & & & 1 \\
\hline S115/E170 & 1 & 1 & & & & & & & & 1 \\
\hline S115/E175 & 1 & & & & 1 & & & 2 & & 3 \\
\hline S115/E180 & 1 & & & & 1 & & & & & 1 \\
\hline S115/E185 & 1 & & & & & & 1 & & 1 & 2 \\
\hline S120/E185 & 1 & & & & & & 1 & & & 1 \\
\hline Level 1 Total & & 1 & $\mathbf{0}$ & $\mathbf{0}$ & 2 & 1 & 2 & 2 & 1 & 9 \\
\hline S110/E185 & 2 & & & & & 1 & & & & 1 \\
\hline S115/E170 & 2 & & & & & & & & 1 & 1 \\
\hline S115/E180 & 2 & & & & 1 & & & 2 & & 3 \\
\hline S115/E185 & 2 & & & 1 & 1 & & & & & 2 \\
\hline S120/E185 & 2 & & & & 2 & & & & & 2 \\
\hline S120/E200 & 2 & & & & & & 1 & & & 1 \\
\hline Level 2 Total & & $\mathbf{0}$ & $\mathbf{0}$ & 1 & 4 & 1 & 1 & 2 & 1 & 10 \\
\hline S105/E165 & 3 & & & & 1 & & & & & 1 \\
\hline S110/E185 & 3 & & 1 & & 1 & & & & & 2 \\
\hline S115/E160 & 3 & & & & & 1 & & & & 1 \\
\hline S115/E165 & 3 & & & & & & & 1 & & 1 \\
\hline $\mathrm{S} 115 / \mathrm{E} 170$ & 3 & & 1 & & & & & & & 1 \\
\hline S115/E175 & 3 & & & & & & & 1 & & 1 \\
\hline S120/E185 & 3 & & & & & & & 2 & & 2 \\
\hline S125/E185 & 3 & & & & 1 & & & & & 1 \\
\hline S135/E185 & 3 & & & & & & 1 & & & 1 \\
\hline Level 3 Total & & $\mathbf{0}$ & 2 & $\mathbf{0}$ & 3 & 1 & 1 & 4 & $\mathbf{0}$ & 11 \\
\hline S100/E165 & 4 & & & & & & 1 & & & 1 \\
\hline S105/E185 & 4 & & & & 2 & & & & & \\
\hline S115/E180 & 4 & & & & & & & 1 & & 1 \\
\hline Level 4 Total & & $\mathbf{0}$ & $\mathbf{0}$ & $\mathbf{0}$ & 2 & $\mathbf{0}$ & 1 & 1 & $\mathbf{0}$ & 4 \\
\hline S110/E185 & 5 & & & & & & 1 & & & 1 \\
\hline S115/E165 & 5 & & & & & & 1 & & & 1 \\
\hline S115/E170 & 5 & & 1 & & & & & 1 & & 2 \\
\hline Level 5 Total & & $\mathbf{0}$ & 1 & $\mathbf{0}$ & $\mathbf{0}$ & $\mathbf{0}$ & 2 & 1 & $\mathbf{0}$ & 4 \\
\hline
\end{tabular}

Overall, then, the Late Archaic forms are higher in the excavation relative to the Middle Archaic forms. The point distribution data also suggests several concentrations of period-level diagnostics in certain excavation units. It is possible to define two analytical units (AUs), identified in Figure 6-1 by hatching, that reflect Late and Middle Archaic point concentrations. The Late Archaic analytical unit consists of a block of nine proveniences confined to the upper three levels of three excavation units. Only Late
Archaic points $(n=11)$ are present, and this analytical unit is separated vertically from any Middle Archaic points by one six-inch level. The Middle Archaic analytical unit consists of eight proveniences, located in Levels 6, 7, and 8. Middle Archaic point forms account for 21 of the 24 points $(87.5 \%)$. Note that much of this Middle Archaic material is associated with Feature 6, the concentration of points and debitage described in the previous chapter (see Figure 5-14 and Figure 5-16). 
Table 6-2. Projectile Point Distributions by Unit and Level, Area B*

\begin{tabular}{|c|c|c|c|c|c|c|c|c|c|c|c|c|c|c|}
\hline Unit & Level & $\begin{array}{l}\bar{\Xi} \\
\text { อ̆ }\end{array}$ & 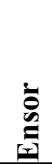 & 氖 & 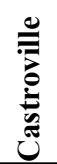 & 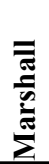 & 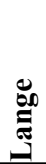 & 兑 & $\frac{\tilde{e}}{\tilde{E}}$ & 营 & $\begin{array}{l}\bar{\Xi} \\
\bar{\theta} \\
\bar{Z}\end{array}$ & 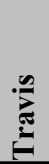 & 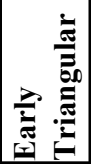 & Total \\
\hline S170/E200 & 1 & & 1 & & & & & & & & & & & 1 \\
\hline S175/E200 & 1 & & & 1 & & & 2 & & 1 & & & & & 4 \\
\hline Level 1 Total & & $\mathbf{0}$ & 1 & 1 & $\mathbf{0}$ & $\mathbf{0}$ & 2 & $\mathbf{0}$ & 1 & $\mathbf{0}$ & $\mathbf{0}$ & $\mathbf{0}$ & $\mathbf{0}$ & 5 \\
\hline S170/E200 & 2 & & & & & & & & 1 & & & & & 1 \\
\hline S175/E200 & 2 & & & & & & & 1 & & & & & & 1 \\
\hline Level 2 Total & & $\mathbf{0}$ & $\mathbf{0}$ & $\mathbf{0}$ & $\mathbf{0}$ & $\mathbf{0}$ & $\mathbf{0}$ & 1 & 1 & $\mathbf{0}$ & $\mathbf{0}$ & $\mathbf{0}$ & $\mathbf{0}$ & 2 \\
\hline S150/E200 & 3 & & & & & & & & & 1 & & & & 1 \\
\hline S155/E200 & 3 & & & 1 & & & & & & & & & & 1 \\
\hline S165/E200 & 3 & & & & & 1 & & & 2 & & & & & 3 \\
\hline S170/E200 & 3 & & & & 1 & & & & & & & & & 1 \\
\hline Level 3 Total & & $\mathbf{0}$ & $\mathbf{0}$ & 1 & 1 & 1 & $\mathbf{0}$ & $\mathbf{0}$ & 2 & 1 & $\mathbf{0}$ & $\mathbf{0}$ & $\mathbf{0}$ & 6 \\
\hline S175/E200 & 4 & & & 1 & & & 1 & & & & & & & 2 \\
\hline Level 4 Total & & $\mathbf{0}$ & $\mathbf{0}$ & 1 & $\mathbf{0}$ & $\mathbf{0}$ & 1 & $\mathbf{0}$ & $\mathbf{0}$ & $\mathbf{0}$ & $\mathbf{0}$ & $\mathbf{0}$ & $\mathbf{0}$ & 2 \\
\hline S150/E200 & 5 & & & & & & & & & 1 & & & & 1 \\
\hline S170/E200 & 5 & & & & & 2 & & & 1 & & 1 & & & 4 \\
\hline S175/E200 & 5 & & & & & 1 & & & & & & & & 1 \\
\hline Level 5 Total & & $\mathbf{0}$ & $\mathbf{0}$ & $\mathbf{0}$ & $\mathbf{0}$ & 3 & $\mathbf{0}$ & $\mathbf{0}$ & 1 & 1 & 1 & $\mathbf{0}$ & $\mathbf{0}$ & 6 \\
\hline S160/E200 & 6 & & & & & & & & & & 1 & & & 1 \\
\hline S165/E200 & 6 & & & & & & & & & 1 & 2 & 2 & & 5 \\
\hline S170/E200 & 6 & & & & & & & & & & 4 & 2 & 1 & 7 \\
\hline S175/E200 & 6 & 1 & & & & & & & 3 & 1 & 1 & & & 6 \\
\hline Level 6 Total & & 1 & $\mathbf{0}$ & $\mathbf{0}$ & $\mathbf{0}$ & $\mathbf{0}$ & $\mathbf{0}$ & $\mathbf{0}$ & 3 & 2 & 8 & 4 & 1 & 19 \\
\hline S160/E200 & 7 & & & & & & & & & & & 1 & & 1 \\
\hline S165/E200 & 7 & & & & & & & & & 1 & 4 & & & 5 \\
\hline S175/E200 & 7 & & & & & & & & 2 & 1 & & & & 3 \\
\hline Level 7 Total & & $\mathbf{0}$ & $\mathbf{0}$ & $\mathbf{0}$ & $\mathbf{0}$ & $\mathbf{0}$ & $\mathbf{0}$ & $\mathbf{0}$ & 2 & 2 & 4 & 1 & $\mathbf{0}$ & 9 \\
\hline S165/E200 & 8 & & & & & & & & & & 4 & & 1 & 5 \\
\hline Level 8 Total & & $\mathbf{0}$ & $\mathbf{0}$ & $\mathbf{0}$ & $\mathbf{0}$ & $\mathbf{0}$ & $\mathbf{0}$ & $\mathbf{0}$ & $\mathbf{0}$ & $\mathbf{0}$ & 4 & $\mathbf{0}$ & 1 & 5 \\
\hline
\end{tabular}

*Five points lacking detailed proveniences not included in table.

We assume, given the dominance of Late Archaic points, that the upper nine levels in Figure 6-1 contain associated Late Archaic deposits. A similar assumption is made for the eight Middle Archaic levels identified in Figure 6-1. Two radiocarbon dates are available from Area B (see Table 5-4). Unfortunately, neither is directly associated with either of the two AUs. One, UGA\#12301, comes from S175/E200, Level 7, a location just to the south of our Middle Archaic AU. A second, UGA\#12300, appears to be associated with the north face of the backhoe trench (S180/E200), and is associated with "Zone 5" though no level is indicated. While the precise provenience is not clear, we estimate, given the location of Zone $\mathrm{V}$, that this sample is equivalent to Levels
9 or 10 . The location associated with UGA\#12301 contained two Late Archaic Pedernales points and a Late Archaic Bulverde point. The associated deposits should, therefore, date to sometime between about 2500 BP and 4000 BP (Collins 1995:376). UGA\# 12301 returned a corrected date of $2840 \pm 110 \mathrm{BP}$, within the expected time range. UGA \#12300, from roughly 1.5 feet below UGA \# 2301, returned a date of $3050 \pm 80$ BP (see Table 5-4).

\section{Area $C$}

The projectile point sample from Area C consisted of 142 points that could be assigned to specific types. Late Prehistoric projectile points, primarily Scallorn in type, 


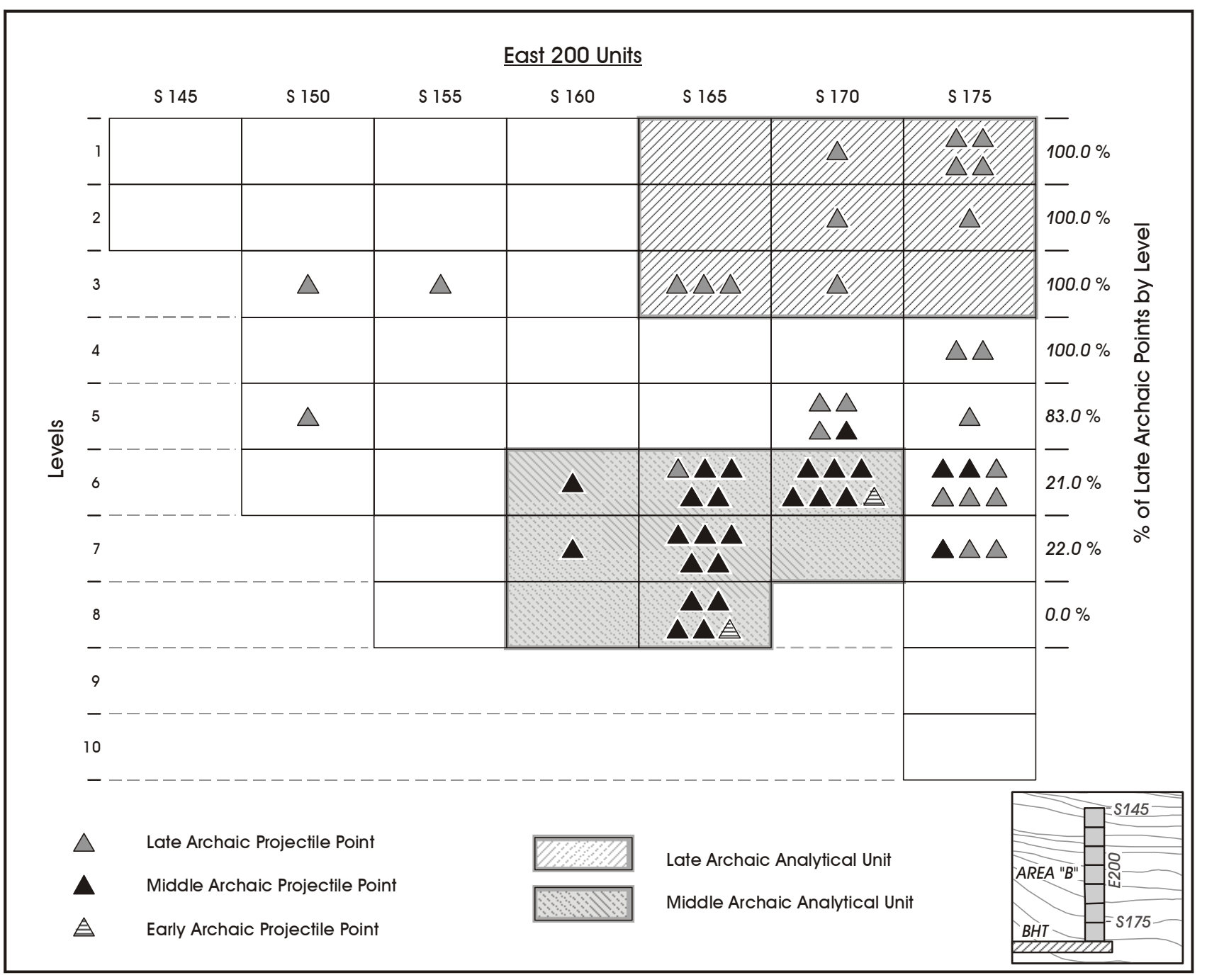

Figure 6-1. Schematic cross-section of Area B, 41TV163, with diagnostic point types and analytical units identified.

accounted for 49 items, and the remaining 93 diagnostic types were Late Archaic in age. Eight of the 142 typed points were from the backhoe trench, and six others lacked detailed provenience. Table 6-3 summarizes the distribution of 128 of the diagnostic projectile points by unit and level. Shading in Table 6-3 identifies the Late Prehistoric forms. The data presented in Table 6-3 clearly show that Late Prehistoric points are confined to the upper three levels, and only Late Archaic forms are present below Level 3. However, the vertical distribution of projectile points also shows that the upper three levels contain a substantial number of Late Archaic point forms. Level 1 contains 68 diagnostic points, 38 (59\%) of which are Late Prehistoric in age. Of the 35 diagnostic points in Level 2, roughly 23\% are Late Prehistoric in age, and Late Prehistoric points also make up $8 \%$ of the Level 3 material. While we can certainly isolate a
Late Archaic assemblage based on the data presented in Table 6-3, the Late Prehistoric material in the upper three levels appears mixed with Late Archaic remains.

Figure 6-2 presents a schematic of point distributions for two areas, however, that suggest a predominately Late Prehistoric assemblage may be present in one portion of Area C. The schematic, which covers the eastern end of excavation units placed off the backhoe trench, encompasses units along the S175 (top) and S185 (bottom) squares from E150 through E170. Note that three proveniences, all representing Level 1, are stippled as a Late Prehistoric analytical unit. Sixteen typed Late Prehistoric points are in these three levels. While four Late Archaic points are also present in this Late Prehistoric AU, Late Prehistoric forms account for $80 \%$ of the diagnostic points. Also identified in 
Table 6-3. Projectile Point Distributions by Unit and Level, Area C

\begin{tabular}{|c|c|c|c|c|c|c|c|c|c|c|c|c|c|c|c|}
\hline Unit & Level & $\stackrel{\overbrace{}}{\varrho}$ & Е & 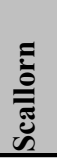 & 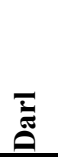 & 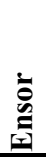 & 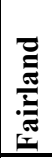 & 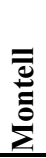 & 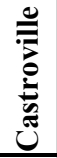 & 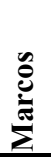 & 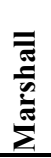 & 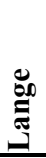 & 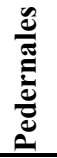 & 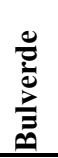 & Total \\
\hline S165/E170 & 1 & & & 1 & & & & & & & & 1 & & & 2 \\
\hline S170/E170 & 1 & & 1 & 8 & 5 & & 2 & & & & & & & & 16 \\
\hline S175/E145 & 1 & & & 1 & 1 & & & & & & & & & & 2 \\
\hline $\mathrm{S} 175 / \mathrm{E} 150$ & 1 & & & 1 & 1 & 1 & & & & & & & & & 3 \\
\hline S175/E155 & 1 & & & 9 & 1 & & & & & 1 & & & & & 11 \\
\hline S175/E160 & 1 & & & 4 & 1 & & & & & & & & & & 5 \\
\hline S175/E170 & 1 & & & 1 & 1 & & & & & & & & & & 2 \\
\hline S185/E140 & 1 & & & & & & 1 & & & & & & 1 & & 2 \\
\hline S185/E145 & 1 & & & 1 & & & 1 & & & & & & & & 2 \\
\hline $\mathrm{S} 185 / \mathrm{E} 150$ & 1 & & & 2 & 1 & & & & & & & & & & 3 \\
\hline S185/E155 & 1 & & & & 2 & & & & & & & & & & 2 \\
\hline S185/E160 & 1 & & & 3 & & & 1 & & & & & & & & 4 \\
\hline S185/E165 & 1 & 1 & & 2 & 1 & & 2 & & & & & & & & 6 \\
\hline S185/E170 & 1 & & & & & & 1 & & & & & & & & 1 \\
\hline S185/E175 & 1 & & & 3 & 2 & & 1 & & & & & & 1 & & 7 \\
\hline Level 1 Total & & 1 & 1 & 36 & 16 & 1 & 9 & $\mathbf{0}$ & $\mathbf{0}$ & 1 & $\mathbf{0}$ & 1 & 2 & $\mathbf{0}$ & 68 \\
\hline S165/E170 & 2 & & & 3 & & & & & & & & & & 1 & 4 \\
\hline $\mathrm{S} 170 / \mathrm{E} 170$ & 2 & & & 1 & 2 & & & & & & & & & & 3 \\
\hline S175/E145 & 2 & & & & 1 & & 3 & & & & & & & & 4 \\
\hline $\mathrm{S} 175 / \mathrm{E} 150$ & 2 & & & 1 & 2 & & 1 & & & & & & & & 4 \\
\hline S175/E155 & 2 & & & 1 & 3 & 1 & 1 & & & & & & & & 6 \\
\hline S175/E160 & 2 & & & 2 & & & 1 & & & & & & & & 3 \\
\hline S175/E165 & 2 & & & & 2 & & 1 & & & & & & & & 3 \\
\hline S175/E170 & 2 & & & & 2 & 1 & 1 & & & & & & & & 4 \\
\hline S185/E165 & 2 & & & & 3 & & & & & & & & & & 3 \\
\hline S185/E170 & 2 & & & & & & 1 & & & & & & & & 1 \\
\hline Level 2 Total & & $\mathbf{0}$ & $\mathbf{0}$ & 8 & 15 & 2 & 9 & $\mathbf{0}$ & $\mathbf{0}$ & $\mathbf{0}$ & $\mathbf{0}$ & $\mathbf{0}$ & $\mathbf{0}$ & 1 & 35 \\
\hline S165/E170 & 3 & & & & & & & & & & & 1 & & & 1 \\
\hline S170/E170 & 3 & & & & & & 1 & & & & & 2 & & & 3 \\
\hline S175/E145 & 3 & & & & & & & & & & & & 1 & & 1 \\
\hline S175/E150 & 3 & & & & & & 1 & & & & & & & & 1 \\
\hline S175/E155 & 3 & & & & 1 & & 1 & & & & & & & & 2 \\
\hline S175/E160 & 3 & & & 1 & & & & & & & & & & & 1 \\
\hline S175/E170 & 3 & & & & & 1 & & 1 & & & & & & & 2 \\
\hline S185/E165 & 3 & & & & & 1 & & & & & & & & & 1 \\
\hline Level 3 Total & & $\mathbf{0}$ & $\mathbf{0}$ & 1 & 1 & 2 & 3 & 1 & $\mathbf{0}$ & $\mathbf{0}$ & $\mathbf{0}$ & 3 & 1 & $\mathbf{0}$ & 12 \\
\hline S165/E170 & 4 & & & & & & & & & 1 & & & & & 1 \\
\hline S170/E170 & 4 & & & & & & & & & & & 1 & & & 1 \\
\hline S175/E165 & 4 & & & & 1 & & & & & & & & & & 1 \\
\hline S175/E170 & 4 & & & & & & 1 & & & & & & & & 1 \\
\hline Level 4 Total & & $\mathbf{0}$ & $\mathbf{0}$ & $\mathbf{0}$ & 1 & $\mathbf{0}$ & 1 & $\mathbf{0}$ & $\mathbf{0}$ & 1 & $\mathbf{0}$ & 1 & $\mathbf{0}$ & $\mathbf{0}$ & 4 \\
\hline
\end{tabular}


Table 6-3. continued...

\begin{tabular}{|c|c|c|c|c|c|c|c|c|c|c|c|c|c|c|c|}
\hline Unit & Level & $\stackrel{\text { }}{\gtrless}$ & 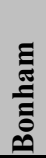 & 节 & $\overline{\bar{\Xi}}$ & 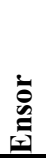 & 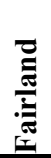 & 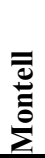 & 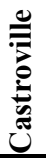 & 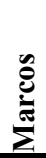 & 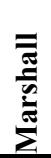 & 总 & 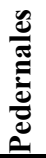 & 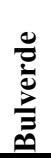 & Total \\
\hline S165/E170 & 5 & & & & & & & & & & & & 1 & & 1 \\
\hline S175/E170 & 5 & & & & & & & & & & & 1 & & & 1 \\
\hline S185/E165 & 5 & & & & & & & & & & & 1 & & & 1 \\
\hline S185/E170 & 5 & & & & & 1 & & & & & & & & & 1 \\
\hline Level 5 Total & & $\mathbf{0}$ & $\mathbf{0}$ & $\mathbf{0}$ & $\mathbf{0}$ & 1 & $\mathbf{0}$ & $\mathbf{0}$ & $\mathbf{0}$ & $\mathbf{0}$ & $\mathbf{0}$ & 2 & 1 & $\mathbf{0}$ & 4 \\
\hline S170/E170 & 6 & & & & & & & & & & & & 1 & & 1 \\
\hline S175/E170 & 6 & & & & & & & & & & & 2 & & & 2 \\
\hline Level 6 Total & & $\mathbf{0}$ & $\mathbf{0}$ & $\mathbf{0}$ & $\mathbf{0}$ & $\mathbf{0}$ & $\overline{0}$ & $\mathbf{0}$ & $\mathbf{0}$ & $\mathbf{0}$ & $\overline{0}$ & 2 & 1 & 0 & 3 \\
\hline S175/E165 & 7 & & & & & & & & 1 & & 1 & & & & 2 \\
\hline Level 7 Total & & $\mathbf{0}$ & $\mathbf{0}$ & $\mathbf{0}$ & $\overline{0}$ & $\mathbf{0}$ & $\mathbf{0}$ & $\mathbf{0}$ & 1 & $\overline{0}$ & 1 & $\mathbf{0}$ & $\mathbf{0}$ & 0 & 2 \\
\hline
\end{tabular}

the figure are 11 proveniences that form a Late Archaic analytical unit. These proveniences, which contained nine Late Archaic diagnostic projectile points, lack any Late Prehistoric forms and are separated from the Late Prehistoric AU by two six-inch levels.

Four radiocarbon dates exist which are relevant to assessing the integrity of these AUs. Three of these were submitted by CAR (see Table 5-4), and the forth was obtained in the early 1970s. This last sample was collected from the north edge of square S175/E155, roughly 18 inches from the eastern grid wall, at the base of Level 2. It sits below our Late Prehistoric AU, and is associated with a single Late Prehistoric point and five Late Archaic forms (Figure 6-2). The date, run by the Radiocarbon Laboratory at the University of Texas (TX\#1511), is reported at $500 \pm 80 \mathrm{BP}$. Note that the UT Radiocarbon Laboratory reported dates using a ${ }^{14} \mathrm{C}$ half-life of 5,568 years (M. Collins, personal communication February 2003), shorter than the established half-life of 5,730 years. This would result in a slightly more recent date relative to other laboratories. In addition, the date is not corrected for carbon fractionation, and details of the sample are not known. Nevertheless, the Oxcal calibration program (Ramsey 2000) produced a calibrated age range of A.D. 1310-1490 for this assay. The three dates submitted by CAR are UGA \#12305, \#12306, and \#12307 (see Table 5-4; Appendix C). UGA \#12305 comes from Level 1 of S175/E160, a level assigned to our Late Prehistoric AU. The corrected, calibrated date is A.D. 13001430, a date range within the Late Prehistoric period. UGA \#12306 was from Level 1 within S185/E160, another Late Prehistoric level. This date was essentially modern. The final date, UGA \#12307, was from Level 3 of S175/E155, below the Late Prehistoric AU levels, and below the date run by UT. That sample, associated with a Darl and a Fairland point which are late in the long Late Archaic period, produced a corrected, calibrated date of A.D. 380-570 (see Table 5-4; Appendix C). Considering these radiocarbon dates as a group, it appears that the UT date is clearly too young given the Level 2 location. UGA \#12305 is consistent with the Late Prehistoric AU designation, though the date is slightly more recent than the associated Scallorn points would suggest. UGA \#12307 is consistent with the Late Archaic points recovered. The modern date of UGA \#12306 from Level 1 is difficult to evaluate given that we lack any details regarding where, within the 5-x-5-foot unit, the sample was obtained.

\section{Area $D$}

Only a single typed projectile point, a Late Archaic Ensor, was recovered from the excavation of the single unit in Area D. In addition, an untyped arrow point fragment was present. Two other typed points were associated with the backhoe trench. Given the co-occurrence of arrow and darts points, the limited excavation, and the minimal sample size of points, a Late Prehistoric or Late Archaic component could not be separated in this Area. Consequently, we cannot define any clear analytical units in this area.

\section{Area $E$}

Late Archaic point types dominated Area E, with 51 of the 59 diagnostics falling within this period. Eight Late Prehistoric Scallorn points were also present. Table 6-4 presents the distribution of 58 of these points by unit and 


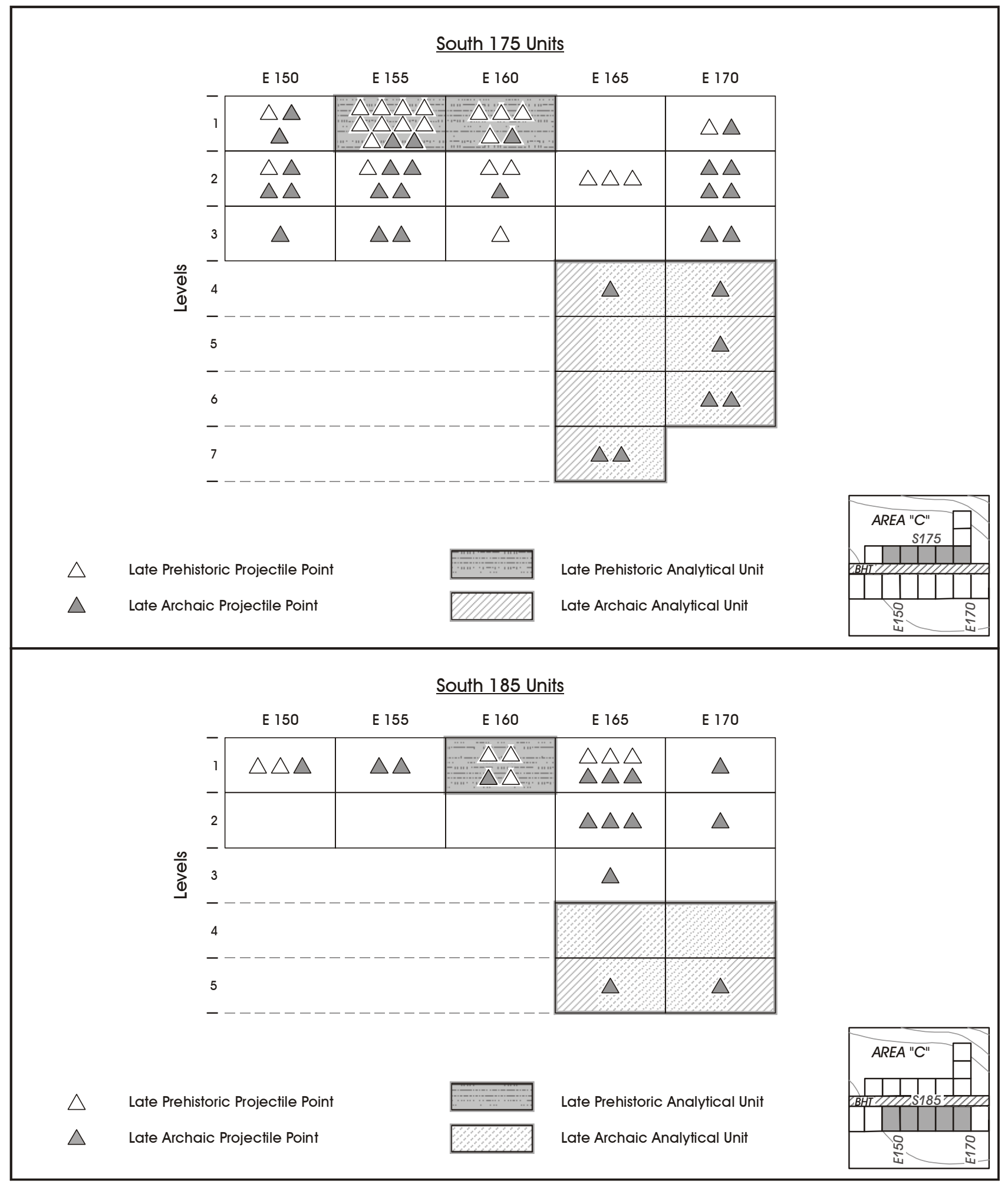

Figure 6-2. Schematic cross-section of Area C, 41TV163, with diagnostic point types and analytical units identified. Top, South 175 units. Bottom, South 185 units. 
level. Note that one point was recovered from the surface, and is not included in the table. All Late Prehistoric points were recovered from Level 1 in this area, with the lower levels containing only Late Archaic forms (Table 6-4). Given the essentially unmixed nature of these two deeper levels across the units in the area, we can clearly define a Late Archaic analysis unit in the bottom two levels. However, note that only two units were hand-excavated in this area. Other samples from this area were collected from units excavated with a Gradall. As it is likely that these samples represent biased collections when compared both to the hand-excavated units from this area, as well as with other material at this site, we proposed to limit any detailed consideration of the material from these two units. Levels 2 and 3 from excavation unit $1+95 / \mathrm{S}+0$ and unit $2+00 / \mathrm{S}+00$ will, then, form our Late Archaic analytical unit in Area E.

As discussed in the previous chapter, Area E also had extensive modern/historic debris present, including metal and glass fragments down to Level 3 (1.0-1.5 feet). However, a review of the distribution of these items in the two hand-excavated squares shows that this historic/modern material is limited to Level 1. Levels 2 and 3 have no such material recorded. Furthermore, note that a single radiocarbon sample (UGA \#12308, Table 5-4 and Appendix C) was collected from this area. The sample, from Level 1,

Table 6-4. Projectile Point Distribution by Unit and Level, Area E

\begin{tabular}{|c|c|c|c|c|c|c|c|c|c|c|c|c|c|}
\hline Unit & Level & 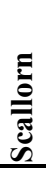 & $\bar{\Xi}$ & 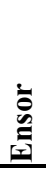 & 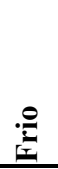 & $\begin{array}{l}\bar{\Xi} \\
\stackrel{\Xi}{\Xi}\end{array}$ & 莺 & 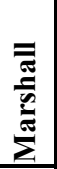 & 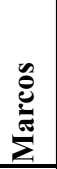 & \begin{tabular}{l}
$\stackrel{8}{\infty}$ \\
\multirow{\Xi}{*}{}
\end{tabular} & 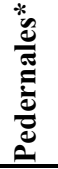 & 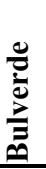 & Total \\
\hline $1+70 / \mathrm{N}+2.50$ & I & & & & & & & & & 2 & & & 2 \\
\hline $1+80 / \mathrm{N}+2.50$ & I & & & & & 2 & & & & & & & 2 \\
\hline $1+90 / \mathrm{N}+2.50$ & $\mathrm{I}$ & 1 & & & & 1 & & & & & & & 2 \\
\hline $1+95 / \mathrm{N}+5.00$ & I & 1 & & & & 1 & & & & & 1 & & 3 \\
\hline $1+95 / \mathrm{S}+0$ & I & 5 & & & & & 1 & & & & 1 & & 7 \\
\hline $2+00 / \mathrm{N}+5.00$ & I & & 1 & & & & & & & & & & 1 \\
\hline $2+05 / \mathrm{S}+0$ & I & 1 & & & & & & & & & 1 & & 2 \\
\hline $2+25 / \mathrm{S}+0$ & $\mathrm{I}$ & & 1 & & & & & & & & 1 & & 2 \\
\hline $2+10 / \mathrm{S}+0$ & $\mathrm{I}$ & & & & 1 & & 1 & & & & & & 2 \\
\hline Level 1 Total & & 8 & 2 & $\mathbf{0}$ & 1 & 4 & 2 & $\mathbf{0}$ & $\mathbf{0}$ & 2 & 4 & $\mathbf{0}$ & 23 \\
\hline $1+80 / \mathrm{N}+2.50$ & II & & & & & 1 & & & & & & & 1 \\
\hline $1+85 / \mathrm{N}+2.50$ & II & & & & & & & & & & 1 & & 1 \\
\hline $1+90 / \mathrm{N}+2.50$ & II & & & & & & & & & & 3 & 1 & 4 \\
\hline $1+95 / \mathrm{N}+5.00$ & II & & 1 & & & & 1 & & & & 3 & & 5 \\
\hline $1+95 / \mathrm{S}+0$ & II & & & & & 1 & & & & 1 & 1 & & 3 \\
\hline $2+00 / \mathrm{N}+5.00$ & II & & & & 1 & & & & & 2 & & & 3 \\
\hline $2+00 / \mathrm{S}+00$ & II & & & & & & & & & & 1 & & 1 \\
\hline $2+05 / \mathrm{S}+0$ & II & & & & & 1 & & 1 & 1 & 1 & 1 & & 5 \\
\hline $2+10 / \mathrm{S}+0$ & II & & & & & & & & & & 1 & & 1 \\
\hline Level 2 Total & & $\mathbf{0}$ & 1 & $\mathbf{0}$ & 1 & 3 & 1 & 1 & 1 & 4 & 11 & 1 & 24 \\
\hline $1+85 / \mathrm{N}+2.50$ & III & & & & & & & & & & 2 & & 2 \\
\hline $1+95 / \mathrm{S}+0$ & III & & & & & & & & & & 2 & & 2 \\
\hline $2+00 / \mathrm{N}+5.00$ & III & & & & & & & & & & 1 & & 1 \\
\hline $2+05 / \mathrm{S}+0$ & III & & & 1 & & 1 & & & & 1 & & & 3 \\
\hline $2+10 / \mathrm{S}+0$ & III & & & & & 1 & & & & & & & 1 \\
\hline $2+15 / \mathrm{S}+10$ & III & & & & & & 1 & & & & & & 1 \\
\hline $2+20 / S+0$ & III & & & & & & & & & & & 1 & 1 \\
\hline Level 3 Total & & $\mathbf{0}$ & $\mathbf{0}$ & 1 & $\mathbf{0}$ & 2 & 1 & $\mathbf{0}$ & $\mathbf{0}$ & 1 & 5 & 1 & 11 \\
\hline
\end{tabular}

* One surface find not included. 
produced a modern date. This sample was, however, located in $1+70 / \mathrm{N}+2.50$, over 20 feet away from the two handexcavated units that form our Late Archaic AU.

\section{Area F}

While the sample of diagnostic points from this area is small, Early Archaic points account for six of the seven points recovered from excavations in this area. The six points consist of three Early Split Stem, two Uvalde, and one Martindale. One Andice point, which Collins (1995:376) places at the beginning of the Middle Archaic, is the only point that does not reflect an Early Archaic production date. Area F, then, seems to be predominately Early Archaic. Like Area E, however, only a small portion of this area was excavated by hand. Other samples were collected from units excavated with a Gradall. As these samples are probably biased relative to hand-excavated units, we will define a single Early Archaic analytical unit focused only on the handexcavated sample. This Early Archaic AU consists of all levels from excavation units $2+70 / \mathrm{S}+5.50,2+75 / \mathrm{S}+5.50$, and $2+77.5 / \mathrm{S} 5.50$.

\section{Summary of Analytical Units}

Excavations at 41TV163 produced abundant remains. Our review of the projectile point assemblage clearly indicates that the material from the site has been generated over thousands of years. Archaic presence is shown in every area excavated. Early Archaic diagnostics are found in Area F. Middle Archaic occupation of the site is represented in Areas $A$ and $B$ and, to a minimal extent, Area F. The most intensive period of site occupation appears to be during the Late Archaic, with some material from this time period present in most areas of the site. Finally, Late Prehistoric occupation is represented in both Areas $\mathrm{C}$ and $\mathrm{E}$. The long period of site use, coupled with the nature of some of that use, clearly has resulted in reduced integrity for portions of the assemblage. In addition, excavation procedures, including the use of arbitrary, six-inch levels and reliance on a Gradall to investigate two areas of the site, have compromised aspects of the collected assemblage. Finally, in the three decades since the work was conducted, documentation of aspects of the excavation has been lost. Despite these problems, we have isolated a series of analytical units that have good temporal integrity. Specifically, we can isolate analytical units representing the Early (Area F), Middle (Area B), and Late Archaic (Areas B, C, and E), as well as the Late Prehistoric (Area C) material at site 41TV163. Radiocarbon dates from the site tend to support these temporal assignments, though samples were not directly available from most of the AUs identified by clusters of points.

Table 6-5 summarizes the available data, by temporal period, for the various analytical units. These data will be used in subsequent chapters to investigate two diachronic research issues. The AUs designated for 41TV163, and which will be used to investigate diachronic changes in both subsistence and lithic technology, are at the period level (e.g., Late Prehistoric). While a review of the history of the period, as well as the phase concepts, is clearly beyond the present chapter, it is the case that these have grown out of a need to have some temporal order to the record at a large scale. While several researchers recognized a clear distinction between what has become known as the Late Prehistoric and the Archaic based, in part, on the presence of ceramics and arrow points (e.g., Kelley 1947, 1959; Wilson 1930), Kelley's $(1947,1959)$ Edwards Plateau Aspect, which was essentially equivalent with the Archaic, defied attempts at more detailed divisions (see Suhm 1960). Johnson et al. (1962) proposed one of the earliest divisions of the Archaic by suggesting an Early, Middle, Late, and Transitional Archaic distinction (see also Johnson 1964). A variety of finer-scale classifications followed over the next few decades. These were primarily attempts to define more limited spatially and temporally constricted units designed to isolate cultural traditions in a restricted area (see Prewitt 1981, 1985; Sorrow et al. 1967; Weir 1976). As perhaps most explicitly stated in Weir (1976:106-118), these early attempts at division of the record were clearly tied to cultural historical concerns, with different projectile point types, and associated artifacts, being equated with different cultural groups. More recently, several researchers have attempted

Table 6-5. Artifact Types by Analytical Unit for 41TV163

\begin{tabular}{|c|c|c|c|c|c|}
\hline Type & Early Archaic & Middle Archaic & Late Archaic & Late Prehistoric & Totals \\
\hline Faunal Remains & n/a & 7 & 252 & 577 & 836 \\
\hline Debitage & 225 & 1975 & 3696 & 2751 & 8647 \\
\hline Cores & 3 & 9 & 13 & 13 & 38 \\
\hline Bifaces & 20 & 39 & 72 & 67 & 198 \\
\hline Other Tools & 8 & 21 & 33 & 18 & 80 \\
\hline
\end{tabular}


to more explicitly link archeological periods with alterations in climate. For example, Johnson and Goode (1994) have divided the central Texas record into six broad periods or "eras," including four in the Archaic, that are linked, to some degree, to changes in Holocene climate (see also Collins 1995).

\section{Investigating Subsistence Change}

These recent schemes have the potential to more clearly focus research into hunter-gatherer subsistence. Many of these climatic changes, such as the potential alterations between woodland/shrub and grasslands outlined in Chapter 2, directly impact the resource base available to hunters and gatherers. For example, there is ample evidence (see Collins 1995; Dillehay 1974; Johnson and Goode 1994) that the abundance of large grazers, such as bison, fluctuated dramatically through time. This fluctuating resource base should have implications both for subsistence, as well as aspects of lithic technology directly involved with subsistence acquisition.

As these large, potentially high-return animals moved in and out of the diets of hunter-gatherers, it is probable that the use of other, potentially lower-return plants and animals, also fluctuated in complex ways. For example, there is evidence that during much of the Late Archaic, bison were available in central Texas. Conversely, during the early part of the Late Prehistoric, the period apparently covered by our Late Prehistoric AU, bison were not in the region (see Collins 1995). Given the high return rates on bison, we would expect that when encountered, they would be pursued. During bison absence, conversely, we would expect that a wider variety of species would enter the diet. We might expect, for example, hunters to shift toward deer as a replacement for bison, as well as the use of smaller animals and increased dependence on plants. Overlain on these longterm changes in resource structure are short-term changes, including yearly and seasonal changes in resource availability and quality, that will further complicate patterns at many sites. We also expect spatial variability in resource structure as a function of differential climatic regimes. These yearly or seasonal fluctuations, as well as spatial variability in resources, clearly mean that subsistence during any one period will certainly vary between sites. For example, Late Archaic sites will not necessarily have bison present, but many probably will, and the presence of these high-return resources should result in a reduction in diet breadth relative to the early Late Prehistoric.
Investigating the subsistence resources at a period level, then, involves both the recognition that long-term changes in resources impact overall subsistence, such as obvious examples like the presence or absence of bison in a region, as well as the recognition that short-term variation at a variety of smaller spatial and temporal scales will produce variability in subsistence remains. The site of 41 TV163 was occupied, as some level, throughout much of the prehistoric sequence, with the earliest point types suggesting that occupation may have begun roughly 8,000 years ago. The occupation length assures that the inhabitants of the site were involved with dramatically different subsistence regimes through time. The site, then, potentially provides the opportunity to document the long-term changes in subsistence while holding the site location constant. That is, in these situations it can be assumed that whatever differences are seen in subsistence when comparing material from distinct analytical units is likely due to different adaptive strategies rather than simply changes in site location. While short-term fluctuations can certainly complicate any direct interpretation, we can hold spatial variability relatively constant.

We previously proposed that two data sets, faunal material and ethnobotanical remains, could be used in such an investigation of subsistence (Mahoney et al. 2003a). Unfortunately, reference to Table 6-5 will demonstrate that for the Early and Middle Archaic AUs we lack several sets of critical subsistence data. There are, for example, no faunal remains from the Early Archaic, and the Middle Archaic sample size is extremely small. In addition, only eight flotation samples and a single macrobotanical sample exist from the site. As presented in Appendix D, these produced only a single burned item, a geophyte. While the recovery of this bulb, which is probably associated with the burned rock midden in Area A, expands the number of sites at which this apparently important resource has been documented, the low frequency of recovery renders this data class virtually useless for comparative purposes.

We are left, then, with faunal material from both the Late Archaic and Late Prehistoric analytical units. Recall that bison were present in central Texas during much of the Late Archaic, and absent during the early portion of the Late Prehistoric period (see Collins 1995). We would expect these two AUs to have different faunal sets represented, with a wider diversity of species and smaller body sized species present in the Late Prehistoric relative to the Late Archaic. We also expect that the Late Prehistoric material might 
evidence higher rates of bone processing relative to the Late Archaic assemblage. In Chapter 5, we noted that our initial inspection of the fauna from 41TV163 indicated that butchering and impact marks, probably derived from bone breakage, were common in the sample, especially on the shafts of long bones of deer-sized animals. Many of the deersized remains are splinters of long bone diaphyses, with the bone broken while it was fresh. This splintering suggests intensive processing of the long bones of deer-sized mammals. Our initial impressions of the faunal assemblage as a whole, then, suggests that some level of subsistence stress may be indicated. We suggest that the level of stress is likely to be more acute during the Late Prehistoric.

Our analysis of the Late Archaic and Late Prehistoric faunal assemblages from the selected analytical units, presented in Chapter 7, was designed to gather information on the species represented as well as on processing methods. Unfortunately, the highly fragmented assemblages from the site are not easily classified to the species level. Nevertheless, we focus on a series of faunal attributes that are designed, to the degree possible, to illicit information on the range of animals used and information on processing methods. Specifically, we focus on the identification of each faunal element to the most detailed taxonomic unit possible. While we can, on occasion, identify a specific order (e.g., Artiodactyla) or genus (e.g., Odocoileus), often we are only able to place remains into groups based on animal body size (e.g., bisonsized, deer-sized, rabbit-sized). Nevertheless, these body size groups permit the identification of the most likely animals represented in the faunal collections from the two time periods. Second, we consider several variables designed to monitor, in part, processing of animals as well as discard and post-depositional damage to faunal material. These include traditional measures such as butchering marks and burning. We also monitored the frequency and potential causes of bone breakage. The examination of bone breakage was specifically concerned with identifying butchering or consumption activities, as well as monitoring the damage unrelated to dietary bone modification. We recorded if a given bone was likely broken while fresh or after it was dry. We also recorded obvious excavator breaks. In conjunction with the bone breakage assignment, we also recorded the maximum bone length and the weight of each fragment. Size was compared with other observations of bone damage as an additional measure of the degree of processing.

Finally, as a complementary aspect to the site-specific subsistence patterns analysis, we compare the information gleaned from the 41TV163 analytical units to 18 components from 13 other Texas sites containing Late Archaic and Late Prehistoric faunal remains.

\section{Changes in Lithic Technology}

Since we perceive the technological aspects of a cultural system to be directly involved in cultural adaptation, we expect that any changes in the land-use strategies and subsistence practices of a group will be reflected in the technological organization of the group. By technological organization we mean the combination of how peoples organize, in space and time, activities associated with the manufacture, repair and replacement of tools and weapons, and how the design of tools and weapons is conditioned by such factors as tool function, raw material availability, and reliability and maintainability considerations. In Chapter 8 we investigate three specific aspects of lithic technology using the analysis units defined earlier in this chapter. These topics are (1) changes in raw material procurement and reduction strategies; (2) changes in tool assemblage composition; and (3) changes in projectile point technology. The importance of these research issues as well as the data types employed to answer them are developed below.

The significant paleoenvironmental chances outlined in Chapter 2 clearly resulted in changes in the resources available for exploitation by hunters and gatherers. We expect that these changes should be reflected not only in subsistence data, but also in some aspect of the technological organization of the hunter-gatherers that visited 41TV163. It is probable that during the lengthy use of this location, aspects of the surrounding landscape such as raw material quality, abundance, and distribution remained relatively constant. If our assumption that these aspects of the lithic resource base remained constant is correct, then any changes in technological organization through time should be related to other conditioning factors such as changes in prey species and their distribution or changes in the organization of procurement strategies. Reference to Table 6-5 will suggest that unlike the faunal data, a relatively large assemblage of chipped stone material, including adequate samples from all AUs, are present. The period-level AUs from 41TV163 are potentially well suited for the investigation of the three topics noted previously.

To investigate raw material procurement practices through time, we focused on categorizing the cherts into color and texture groupings. The color/texture categories were defined based on the debitage since this data type is likely to contain examples of all raw materials brought onto and reduced at 
the site. Twenty-five different categories of chert were defined. Lacking details on the distribution of these raw materials in the natural environment, we rely primarily on a theoretical argument to examine this variable. The comparative sample of chert categories was used to classify all chipped lithics from the analytical units. The comparison of the color texture categories within the tools and the debitage provides a good indication of which categories are present in what chipped lithic artifact group. We suggest that color-texture categories represented only by formal tools (i.e., projectile points) or small numbers of only decorticate debitage are likely to be non-local in origin. Conversely, color-texture categories represented in both the tools and the debitage are likely to be of local origin as long as the debitage contains moderate to high proportions of corticated specimens.

Lithic reduction strategies may also vary in response to changes in organizational aspects of technology including raw material distribution and the need for retooling. For instance, it has been suggested that raw material availability will influence raw material reduction strategies (Andrefsky 1994a, 1994b; Parry and Kelly 1987). In addition, the bulk procurement and processing of seasonally available resources should favor the manufacture of formal tools preceding the actual need of these tools (see Hayden and Gargett 1988; Tomka 2001). With this in mind, we proposed to define the reduction strategies represented in the defined analytical units by establishing the stages of reduction represented in each chert color-texture category to relate reduction processes to raw material procurement strategies (see Mahoney et al. 2003b). To accomplish this aspect of the analysis, we recorded two attributes - cortex and sizeon each piece of debitage. Estimates of dorsal cortex on debitage were made and grouped for analysis into four categories: (1) no cortex; (2) $1-50 \%$ cortex; (3) $51-99 \%$ cortex; and (4) $100 \%$ cortex. Size of debitage was measured by maximum dimension with a digital caliper. Patterns in cortex categories within small and large debitage classes within each color-texture category should be a good indicator of whether the debitage derives from the reduction of decorticate-stage reduced raw materials (i.e., artifacts) or from the reduction of locally available unprepared resources (see Tomka and Fields 1990). We expected that some variability in reduction strategies should be apparent given the reduction of a mix of what we think are local and nonlocal raw materials. Unfortunately, we lack any independent measure of the local and non-local tool stone.

As part of the investigation of lithic reduction strategies, we also studied the cores present in the five analytical units and quantified both the type of reduction they represent (i.e., unidirectional, multi-directional, bifacial) and their degree of reduction. While the type of reduction is easily monitored on a given core by investigating the flaking patterns, the degree of reduction is more difficult to quantify. We monitored the number of flake scars, the maximum size $(\mathrm{mm})$, the weight (grams), and the presence/absence of cortex in order to provide some quantifiable measure of the degree of core reduction.

One of the more promising aspects of the lithic assemblages from the analytical units is the large number of chipped stone tools. Both expediently made tools (i.e., use-modified flakes) as well as formal tools (i.e., bifacial knives, unifacial scrapers) are present. Parry and Kelly (1987) have proposed that whether tools are expediently made or represent the products of extensive labor input is conditioned by degree of mobility. Conversely, Hayden and Gargett (1988) and Tomka (2001) have suggested that the design of tools is influenced more directly by expected processing requirements. The observation that the exploited resource base shifted between the Early Archaic and the Late Prehistoric, and in particular that bison may have been a significant resource during the Late Archaic, suggests that differences in resource procurement existed during the use of the site. At the same time, the mobility of the hunter-gatherer groups should have remained relatively high while the raw material landscape in the vicinity of the site should have remained constant. Given these aspects of land use, subsistence, and material availability, we investigate whether the tool assemblages from the five AUs reflect changes in the proportion of formal and expediently manufactured tools over time. We would expect a higher proportion of formal tools during the Late Archaic than the Early and Middle Archaic. Formal tool use may also have been dominant during the Late Prehistoric period if bison hunting was replaced by the intensive hunting of deer. However, if subsistence emphasis shifted to the procurement of plant resources, the frequencies of formal tools related to hunting and game processing should have decreased.

To investigate these suggestions, we first scanned all debitage from the analytical units and removed all usemodified tools. All chipped lithic tools were categorized into formal and expedient functional varieties (i.e., formal knife, expedient knife, etc.). All tools that represent the product of extensive chipping to achieve either a desired shape for hafting or a specific working edge shape were categorized as formal tools. All tools that exhibit little flaking to achieve a working edge have been classified as minimally retouched. All tools that represent flakes modified simply 
by use (i.e., no retouch) were categorized as expedient. Ratios of these three categories were then used to investigate changes through time.

Projectile point technology, including the design characteristics of a specimen and the refurbishing strategies followed by the users of the weapon systems, are critical aspects of technological organization since they are responsive to overall conditioning factors such as prey type, subsistence strategies, and raw material availability. The large sample of projectile points offers an excellent opportunity to investigate aspects of projectile technology, and specifically the reasons for projectile point discard, and the strategies of projectile point refurbishing. Given that points frequently can be classified into periods regardless of the context of recovery, all typed points are used in this analysis.

In order to investigate the manufacture, use, rejuvenation, and discard of projectile points, a systematic classification of projectile point types into categories of discard (i.e., use breakage, manufacture failure, postdepositional breakage) and the measurement of the remnant blade length and remnant blade width were made. The use of these attributes, in combination, can suggest the different causes of discard and remnant use-lives still present on discarded projectile points.

\section{Synchronic Research Issues: Investigating Feature 3}

The final area of investigation that we conducted with the 41TV163 data is more synchronic in nature. This analysis, discussed in Chapter 9, concerns the investigation of the possible Late Prehistoric structure at Millican Bench. As noted in the previous chapter, excavations in Area $\mathrm{C}$ at 41TV163 produced evidence, associated with Levels 1 and 2, of a possible ephemeral structure, Feature 3. Though bisected by a backhoe trench, the possible structure is primarily confined to four excavation units. If Feature 3 does represent a structure, the character of the Late Prehistoric period at this site is clearly distinct from the preceding occupations. The archeological evidence for prehistoric structures among central Texas hunter-gatherer groups is limited. Ethnohistoric data from Texas document that ephemeral structures, essentially consisting of pole frameworks covered with matting and hides, were built by native inhabitants in the central part of the state (Campbell 1983; Foster 1998). Feature 3 possibly represents such a structure.
As outlined in Chapter 9, we used a combination of ethnohistoric and ethnographic sources to explore what either documented or suspected structures would look like. This exploration included investigating the conditions of structure use. We also conducted a comparative study of sites in central Texas with known or suspected structures reported in the archeological record. We used these sources to define possible direct and indirect archeological evidence of structures among hunter-gatherers. Finally, we looked at the archeological evidence from 41TV163 in order to clarify the nature of this feature. While critical data are lacking to definitively classify the feature as a structure, we focused on both distributional data and artifact size in the immediate area of the feature to investigate the likelihood that the feature represented a maintained space. 


\title{
Chapter 7: Late Prehistoric and Late Archaic Subsistence Practices A Comparative Analysis
}

\author{
Steve A. Tomka, Raymond P. Mauldin, and Russell D. Greaves
}

In the original research design that accompanied the assessment of the Millican Bench archeological collection (Mahoney et al. 2003a), we proposed to compare bone assemblages from Middle and Late Archaic contexts with a Late Prehistoric assemblage to identify trends in subsistence strategies, seasonality, butchering and processing trajectories through time. We proposed to study two specific aspects of the faunal collections: (1) the identification of taxa and broad body size of the animals harvested; and (2) butchering practices, as they were manifested in bone breakage patterns. We also proposed to investigate the use of plants as exemplified within macrobotanical samples derived from distinct analytical units within the site. Unfortunately, flotation of soil samples from the site returned minimal results (see Appendix D). Consequently, in this chapter we focus primarily on faunal material. We demonstrate that within 41 TV163 there are differences in subsistence between the Late Archaic and Late Prehistoric analytical units. We then consider faunal material from a variety of other sites throughout the state in order to explore spatial and temporal variability in subsistence at different scales.

\section{Fluctuating Climates, Resources and Subsistence Strategies}

Based on the paleoenvironmental reconstructions for Texas, it is clear that climatic conditions fluctuated in broad terms between cool and moist and warm and dry environments during the past 12,000 years (Bousman 1998; Johnson and Goode 1994). These climatic fluctuations, some of which were explored in Chapter 2, are likely to have affected the types and structure of the resources across the state both in terms of primary as well as secondary biomass. One of the major impacts of these fluctuations in terms of resources available to hunters and gatherers is likely to have been the fluctuations in bison population. Although there is some disagreement regarding what climatic conditions drove bison oscillations in Texas, it is clear that bison densities fluctuated through time in Texas (see Bousman 1998; Collins 1995; Dillehay 1974; Huebner 1991; Johnson and Goode 1994). Dillehay's (1974) research identifies clear periods of bison presence and absence in the state. Collins (1995:Table 2) revised Dillehay's scheme. Collins suggests the following:
Presence Period I: 10,000 B.C. to 7000 B.C.

Absence Period I: 7000 B.C. to 4000 B.C.

Presence Period II: 4000 B.C. to 3000 B.C.

Absence Period II: 3000 B.C. to 2000 B.C. with a gradual increase until 1000 B.C.

Presence Period III: 2000 B.C. to A.D. 800

Absence Period III: A.D. 800 to A.D. 1300

Presence Period IV: A.D. 1300 to A.D. 1650

The first presence period occurs during the Paleoindian period, while the second occurs during the first half of the Middle Archaic period. The third presence period spans the Late Archaic period, while the fourth begins during the Late Prehistoric Toyah Phase and extends into the Historic period.

The degree of involvement and the strategies used to hunt bison would depend on whether bison migrations brought varying densities of these animals into the vicinity of huntergatherer territories. The distribution of bison is conditioned by the availability and distribution of favorable grass species and water. According to Johnson (1951), in the Great Plains bison are adapted to a shortgrass environment. A number of authors indicate that bison prefer $\mathrm{C} 4$ grasses in all seasons, except in the spring when $\mathrm{C} 4$ grasses are not actively growing (Peden et al. 1974; Schwartz and Ellis 1981). Shortgrass species, well adapted to arid and semi-arid settings, tend to consist of $\mathrm{C} 4$ grasses. Currently in Texas, approximately $68 \%$ of the grass species have $\mathrm{C} 4$ pathways of photosynthesis (Terri and Stowe 1976). In such shortgrass prairies, roughly $80 \%$ of the diet of bison consists of $\mathrm{C} 4$ grasses. Species of shortgrasses are common on the mixed prairies of the Edwards Plateau, the Rolling Plains, and the subtropical savannas of South Texas. The Blackland and the Coastal Prairies are tallgrass prairies consisting of a mix of shortgrass and tallgrass species dominated by the latter. At least in terms of grass species, much of the state, with the possible exception of the oak woodlands of East Texas, may have provided abundant food resources for bison.

Water is another critical resource among ruminants. As bison have to drink on a daily basis, water availability is a key 
limiting factor in the distribution of bison populations. A large portion of south Texas between the Nueces River and the Rio Grande currently has few perennial streams. Although it is likely that in prehistoric times water tables were higher, it is not expected that this would have substantially increased the number of perennial streams in the region. While bison may have moved into these areas on a limited or seasonal basis, the scarcity of predictable perennial water in south Texas would have been a significant hindrance to the migration, and by extension, the exploitation of bison. Based on the distribution of shortgrass species and water within the state, then, it is possible that when bison herds were in Texas, they would have been present throughout much of the state, with the possible exception of the east Texas Post Oak Woodlands and a portion of south Texas between the Rio Grande and the Nueces River drainages. This pattern seems to be reflected in the distribution of bison in the state between 1830 and 1860 , noted by Weniger (1997:Map 1).

While these general expectations are of some use, they do not provide a framework for considering specific ways in which changes in the presence, absence, and density of bison may have influenced subsistence strategies. Several specific suggestions can be made regarding the potential impact of bison population distributions across the state and changes in bison population densities through time. Following theoretical expectations derived from Optimal Foraging Theory, we suggest that the presence or absence of bison within the state would have significantly affected subsistence strategies. It is also likely that even when bison populations were present, seasonal or spatial fluctuations in their densities within a region would have impacted the subsistence and land-use strategies employed by huntergatherers exploiting the resources of that region.

As a result of their larger body size, we suggest that when bison were encountered, they would have been pursued. Specifically, we propose that:

1) Extended periods of bison availability would narrow diet breadth, measured in terms of number of species used, among central Texas hunter-gatherers;

2) The diet breadth of south and east Texas hunter gatherers may have remained relatively broad even during periods of bison presence because low bison population densities would result in low encounter rates;
3) Seasonal fluctuations in bison population densities lead to seasonal changes in diet breadth among central Texas hunter-gatherers;

4) Seasonal availability of bison, if documented, may have promoted the extensive processing of skeletal remains as a form of seasonal storage of excess nutrients and to reduce subsistence stress; such processing may be reflected in the form of bone grease rendering and predominance of small $(<3 \mathrm{~cm})$ bone fragments within the assemblage; This need for extensive processing may have been lessened in areas with year-round availability of deer and antelope; and

5) Absence of bison within the state would result in increased reliance on the next highest ranked prey, which is probably deer/antelope-sized animals, and a widening of the diet breadth with the inclusion of lower ranked species.

To address these research issues, we begin with the bone assemblage and macrobotanical samples from the Late Prehistoric Austin Phase and the Late Archaic analytical units from 41TV163 (see Chapter 6). Because plant remains are less likely to preserve in archeological deposits and macrobotanical sampling has become a standard archeological practice only relatively recently, the discussion will focus primarily on patterns identified in faunal assemblages.

At some point after the completion of the field work and prior to the arrival of the materials at CAR, Billy Davidson of TxDOT compiled a list of the numbers and types of skeletal elements by species identified in the Millican Bench collection. This list is curated with the site documentation. To ensure analytical consistency, the faunal collection that could be attributed to specific analytical units was reanalyzed by CAR personnel.

\section{The Faunal Assemblage from 41TV 163}

Table 7-1 presents the breakdown of the Millican Bench faunal material by class and analytical unit. The largest sample derives from the Late Prehistoric AU, and sample sizes decrease with increasing assemblage age. This pattern may be the result of differential preservation. The breakdown of the sample by class indicates that deer-sized specimens constitute the highest proportion of both the Late Prehistoric 
Table 7-1. Breakdown of Faunal Assemblage by Class and Analytical Unit

\begin{tabular}{|l|c|c|c|c|}
\hline \multicolumn{1}{|c|}{ Class } & $\begin{array}{c}\text { Late Prehistoric } \\
\text { (Austin Phase) }\end{array}$ & Late Archaic & Middle Archaic & Grand Total \\
\hline Artiodactyl & 26 & 6 & & 32 \\
\hline Avian & 20 & 9 & 1 & 30 \\
\hline Canid & & 1 & & 1 \\
\hline Beaver & 1 & & & 1 \\
\hline Deer & 11 & 5 & & 16 \\
\hline Rabbit-sized & 4 & 1 & & 5 \\
\hline Rodent-sized & 5 & & & 5 \\
\hline Cottontail Rabbit & 7 & & & 7 \\
\hline Turtle & 2 & & & 2 \\
\hline Deer-sized & 187 & 111 & 1 & 299 \\
\hline Bison-sized & & 8 & & 8 \\
\hline Dog-sized & 4 & 2 & 1 & 7 \\
\hline Unidentified frags. & 310 & 109 & 4 & $\mathbf{8 3 6}$ \\
\hline Grand Total & $\mathbf{5 7 7}$ & $\mathbf{2 5 2}$ & 7 & 723 \\
\hline
\end{tabular}

(34\%) and Late Archaic (46\%) assemblages. The higher proportion of deer in the Late Archaic sample may be the indirect result of the differential preservation of skeletal elements from deer compared to smaller body sized species in this older period. Both rabbit-sized animals and birds appear to have played a role in the diet of the Late Prehistoric inhabitants of the site. Birds are also present in the Late Archaic sample but an added aspect of this collection is the presence of bison-sized bones. Eight long bone pieces were identified as having the cortical bone thickness characteristic of bison. These specimens come from Area E, where one of the more common projectile points recovered was the Pedernales type. While we lack information on the number of individual animals represented, deer and deer-sized bones constitute $74 \%$ of all bone identified to class $(n=267)$ within the Late Prehistoric collection. Eighty-one percent of the identifiable bone $(n=143)$ from the Late Archaic assemblage consists of deer-sized specimens. Overall, eight classes of animals are present in the Late Prehistoric Austin Phase assemblage while only five are present in the Late Archaic assemblage.

Considering deer-sized elements, only $14(2.4 \%)$ of the Late Prehistoric specimens exhibited butchering marks, a level equal to the five (2\%) Late Archaic pieces that retain such indicators. Cut marks are present on two Late Prehistoric items and one Late Archaic specimen. Four Late Prehistoric pieces have cut marks derived from chopping while eight others have impact scars. Two Late Archaic bone fragments have chopping scars and two others have been fragmented through impact. Although butchering marks are uncommon in the two samples, it is likely that bone grease rendering or bone marrow extraction may have been responsible for the small mean size of the 41 TV163 bone samples.

The breakdown of the deer-sized skeletal elements by analytical unit (Table 7-2) indicates that long bone fragments are the most common in both samples. This pattern may also be the result of differential preservation given that such cortical bones are significantly denser than cancellous fragments. While a similar pattern may be obtained from off-site butchering and the transport of high meat utility elements to the site, such a pattern would be likely to introduce complete long bones into the assemblage and would also yield cancellous fragments. Unfortunately, the cancellous bone fragments that would need to be present to investigate this procurement strategy are the ones that would be removed by rapid degradation.

To investigate our suggestion that during periods of bison absence, inhabitants of central Texas may have experienced periods of dietary stress, we recorded the maximum dimension and weight of each bone recovered from the Late Prehistoric and Late Archaic analytical units. We also recorded breakage patterns on the remains. Bone breakage was classified into one of four types. There were (1) breakage while the bone was fresh, (2) dry breaks, (3) recent breaks, and (4) indeterminate breaks. Note also that a small number of bones were not fractured. Breakage on fresh bone probably indicates processing for either marrow or bone grease. Dry breaks, occurring well after the bone has lost grease, reflect postdepositional damage. Excavators 
Table 7-2. Breakdown of Deer-sized Elements by Analytical Unit

\begin{tabular}{|l|c|c|c|c|}
\hline \multicolumn{1}{|c|}{ Element } & $\begin{array}{c}\text { Late Prehistoric } \\
\text { (Austin Phase) }\end{array}$ & Late Archaic & Middle Archaic & Grand Total \\
\hline astragalus & 2 & & & 2 \\
\hline atlas & 1 & & & 1 \\
\hline caudal vertebra & 1 & 1 & & 2 \\
\hline unid. cancellous bone & 2 & 1 & & 3 \\
\hline cranium & 1 & & & 1 \\
\hline unid. flat bone & 7 & 4 & & 11 \\
\hline unid. long bone & 146 & 103 & & 250 \\
\hline mandible & 1 & 1 & & 2 \\
\hline metatarsal & 1 & 2 & & 3 \\
\hline maxilla & 1 & & & 1 \\
\hline 1st phalanx & 1 & & & 1 \\
\hline 3rd phalanx & 1 & & & 1 \\
\hline rib & & & & 1 \\
\hline radius & 1 & 1 & & 1 \\
\hline scapula & 1 & & & 1 \\
\hline fused tarsals & 30 & & & 33 \\
\hline unspec. segment & $\mathbf{1 9 8}$ & $\mathbf{1 1 6}$ & & $\mathbf{1}$ \\
\hline Grand Total & & & & \\
\hline
\end{tabular}

Table 7-3. Late Prehistoric and Late Archaic Fresh-broken Deer Bone Size*

\begin{tabular}{|l|c|c|}
\hline \multicolumn{1}{|c|}{ Statistics } & Late Prehistoric & Late Archaic \\
\hline Mean & 32.45 & 28.97 \\
\hline Median & 30 & 25 \\
\hline Mode & 21 & 21 \\
\hline Standard Deviation & 12.84 & 14.15 \\
\hline Range & 72 & 56 \\
\hline Minimum & 14 & 16 \\
\hline Maximum & 86 & 72 \\
\hline Count & 78 & 29 \\
\hline
\end{tabular}

* Includes specimens identified as deer-sized and deer.

probably caused recent breaks. Note that more than one type of breakage is sometimes present on a given specimen. To ensure that we were gauging prehistoric behavior rather than postdepositional factors and/or excavator induced size reduction, we first sought to define patterns only among specimens broken during butchering and food processing.

Table 7-3 presents descriptive statistics for fresh-broken deer-sized bones recovered from the Late Prehistoric and Late Archaic analytical units. A review of the data will show that Late Prehistoric deer bone fragments are on the average slightly larger $($ mean $=32.4 \mathrm{~mm})$ than their Late Archaic counterparts (mean $=28.9 \mathrm{~mm}$ ). This pattern is also reflected in the mean weight of the bone fragments with Late Prehistoric specimens being slightly heavier (mean $=1.5 \mathrm{~g}$ ) than the Late Archaic pieces (mean=1.3 g). The mean size of all deer-sized bones within the two collections is very similar (LP mean $=27.5 \mathrm{~mm}$; LA mean $=26.9 \mathrm{~mm}$ ) regardless of break cause. Both the length and the weight are similar, suggesting that in the case of deer-sized fragments, there is no significant difference between the degree of bone processing as indicated by size. 
Table 7-4. Bone Breakage by Analytical Unit

\begin{tabular}{|l|l|c|c|c|}
\hline Break Type & & Late Archaic & Late Prehistoric & Total \\
\hline Recent or not broken & Count & 18 & 16 & 34 \\
& Adjusted Residual & 2.92 & -2.92 & \\
\hline & & & & 205 \\
\hline Fresh Break Present & Count & 71 & 2.07 & \\
& Adjusted Residual & -2.07 & & 156 \\
\hline & & & 118 & \\
\hline Indeterminate & Count & 38 & & \\
& Adjusted Residual & -1.82 & 238 & 363 \\
\hline & & & -2.23 & \\
\hline Dry break & Count & 125 & & \\
\hline & Adjusted Residual & 2.23 & 577 & \\
\hline Total & & & & \\
\hline
\end{tabular}

Table 7-4 presents a comparison of the frequency of break types for the two AUs using all available specimens. Note that we have combined the small number of recent and not broken specimens in the table. Below each count we present standardized adjusted residuals for the cell. As discussed by several authors (see Everitt 1977; Haberman 1973), standardized adjusted residuals provide information on the contribution of the individual cell to the overall chi-square total. Standardized adjusted residuals are analogous to $\mathrm{Z}$ scores such that an adjusted residual score exceeding an absolute value of 1.96 suggests that the cell difference is significant at a probability beyond the level of .05 . Within Table 7-4, there are several significant cells. Of specific note is that fresh breaks are significantly over-represented in the Late Prehistoric cell relative to the Late Archaic. The increased frequency of bone breakage in the Late Prehistoric is consistent with our expectations that higher frequencies of processing should be occurring in assemblages during this period were bison are absent. Finally, note that indeterminate breaks are also over-represented in the Late Prehistoric. While not significant at the .05 level, the standardized adjusted residual value of 1.82 has a probability of .069. These are extremely small fragments as is evidenced by the mean weight of only 0.36 grams. It is possible that these specimens are the result of processing to a point where identification is no longer possible. The observation that they are also more frequent in the Late Prehistoric is consistent with greater degrees of processing of faunal material during this period.

\section{Regional Comparisons}

To define broad trends in subsistence practices and investigate the suggestions presented earlier, we compiled comparable data on 18 archeological components from 14 archeological sites (Table 7-5). The Toyah Phase is represented by six components, while the Austin Phase by two components, and the Late Archaic by nine components. Finally, while the 41TV163 Middle Archaic sample is very small and not discussed, we included a faunal assemblage representative of this period as a point of reference. Seven of the sites are from central Texas and three are from the southern edge of central Texas (Table 7-6). The remaining four sites are peripheral to the region, with one each from west-central Texas, east-central Texas, south Texas, and the Panhandle. The locations of the 14 sites are shown in Figure 7-1. The raw data, including the number of skeletal elements within each genus by site, is provided in Appendix A (Table A-1).

Before engaging in this comparative analysis, several cautionary notes are warranted. Differences in bone density will significantly impact not only the representation of different species within an assemblage but will also influence the survivability of different elements within the skeletal remains of a single species. In general, the bones of smallersized animals are less dense than larger animals. Similarly, the ribs and vertebrae are less dense than humeri mid-shaft bone within a single skeleton. Therefore, it is likely that differential preservation will tend to decrease the number 
Table 7-5. The Ages of Archeological Components with Bone Assemblages Used for Regional Comparison

\begin{tabular}{|c|c|c|c|c|}
\hline & \multicolumn{4}{|c|}{ Time Periods } \\
\hline Sites & Toyah & Austin & Late Archaic & Middle Archaic \\
\hline 41 TV163 & & 1 & 1 & \\
\hline $41 \mathrm{WM} 230$ & & & 1 & \\
\hline $41 \mathrm{WM} 267$ & & & 1 & \\
\hline 41WM56 & & & 1 & \\
\hline 41HY209-T & 1 & 1 & 1 & \\
\hline 41HY209-M & 1 & & & \\
\hline 41HY202-A & 1 & & 1 & \\
\hline $41 \mathrm{MM} 340$ & & & 1 & \\
\hline 41 TG346 & 1 & & & \\
\hline 41HF128 & & & 1 & \\
\hline 41BX228 & & & 1 & \\
\hline 41LK28 & & & & 1 \\
\hline 41LK201 & 1 & & & \\
\hline 41JW8 & 1 & & & \\
\hline Total & 6 & 2 & 9 & 1 \\
\hline
\end{tabular}

Table 7-6. Archeological Sites with Bone Assemblages Used for Regional Comparison

\begin{tabular}{|c|c|c|c|c|c|c|}
\hline \multirow[b]{2}{*}{ Sites } & \multicolumn{6}{|c|}{ Geographic Region } \\
\hline & $\begin{array}{c}\text { Central } \\
\text { Texas }\end{array}$ & $\begin{array}{c}\text { West-central } \\
\text { Texas }\end{array}$ & $\begin{array}{c}\text { East-central } \\
\text { Texas }\end{array}$ & $\begin{array}{c}\text { South-central } \\
\text { Texas }\end{array}$ & South Texas & Panhandle \\
\hline $41 \mathrm{TV} 163$ & 1 & & & & & \\
\hline 41WM230 & 1 & & & & & \\
\hline 41WM267 & 1 & & & & & \\
\hline 41WM56 & 1 & & & & & \\
\hline 41HY209-T & 1 & & & & & \\
\hline 41HY209-M & 1 & & & & & \\
\hline 41HY202-A & 1 & & & & & \\
\hline $41 \mathrm{MM} 340$ & & & 1 & & & \\
\hline $41 \mathrm{TG} 346$ & & 1 & & & & \\
\hline 41HF128 & & & & & & 1 \\
\hline $41 \mathrm{BX} 228$ & & & & 1 & & \\
\hline 41LK28 & & & & 1 & & \\
\hline 41LK201 & & & & 1 & & \\
\hline 41JW8 & & & & & 1 & \\
\hline Total & 7 & 1 & 1 & 3 & 1 & 1 \\
\hline
\end{tabular}




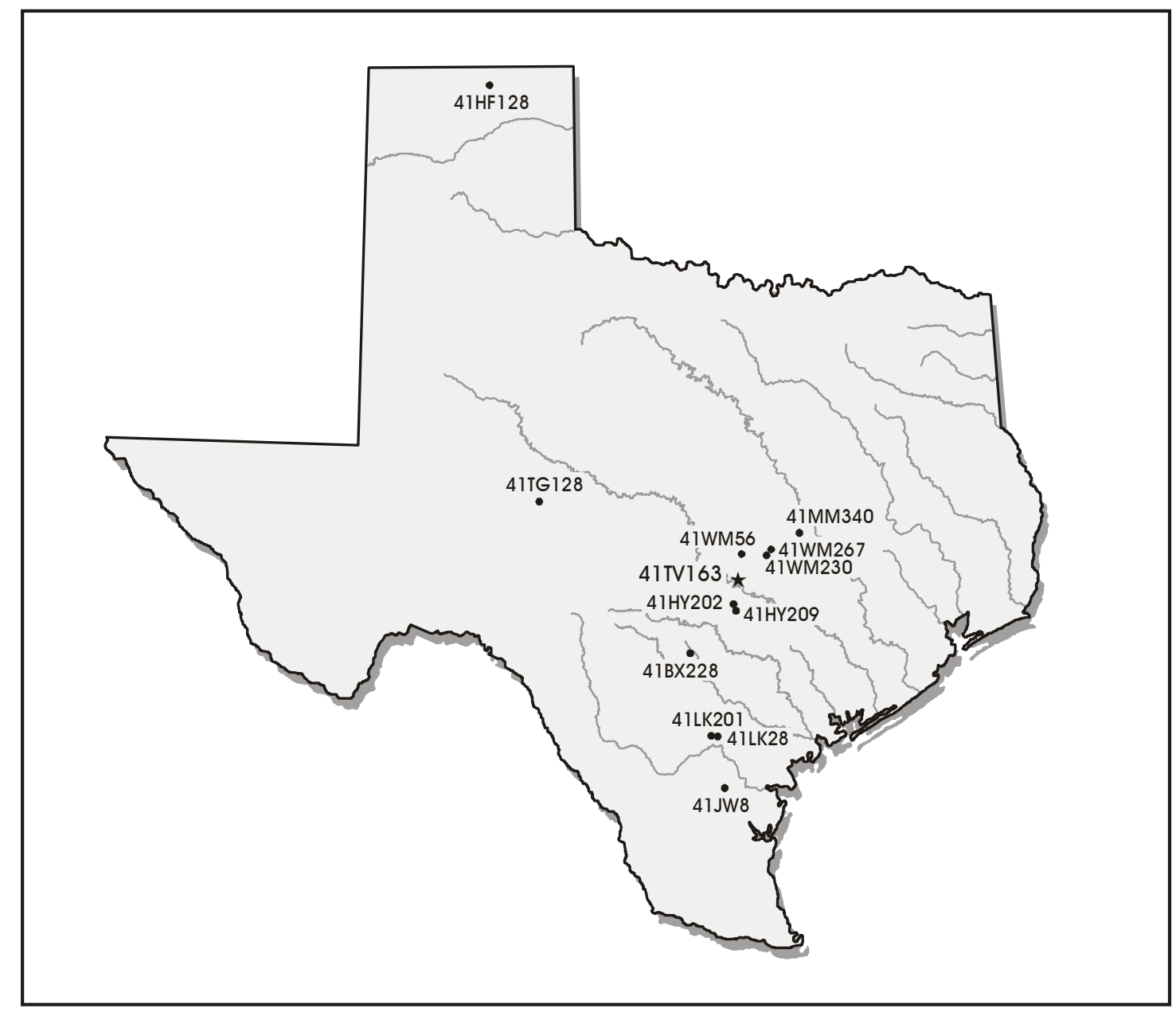

Figure 7-1. Location of archeological sites mentioned in the comparative faunal analysis discussion.

of softer bones within the same skeleton and/or species with less dense bone. Different climatic and soil conditions will also impact the survival of faunal elements as will the age of the assemblage. Finally, we lack data on the number of individual animals represented by the faunal material for most cases. Note also that faunal sample sizes vary dramatically between assemblages ranging from a high of 24,448 bones in the case of the Middle Archaic 41LK28 sample to a low of 149 in the case of the Toyah Phase materials from 41HY202-A (Table 7-7). The variable sample sizes further complicate the interpretations, as we would expect that larger sample sizes would contain more species simply as a function of their larger size. The relationship between number of faunal remains and number of genera is further complicated by differences in the body size of the animals represented. As many of the assemblages are highly fragmented, those assemblages with bison present will tend to have increased numbers of items as a function of the significant body size of the animal. Given the variable nature of the data, as well as the potential for differential impacts on faunal elements, and the different contributions of animals of various body sizes to the overall number of bone present, we are forced to essentially use presence/absence data of genera as a measure of diet breadth.

As shown in Table 7-7, the average number of genera for the six Toyah Phase components, a period of bison presence, is 19 , though a wide range of from 5 to 36 genera is present during this time period. The two Austin Phase components, representing a period when bison is absent or at very low densities, average 12 genera. The nine Late Archaic components, a period where bison is again present, have a mean of 17 genera, but a wide range is again present with a low of only 2 and a high of 34 . The single Middle Archaic 
Table 7-7. Number of Genera Identified by Component within the Comparative Faunal Assemblage

\begin{tabular}{|l|l|c|c|}
\hline \multicolumn{1}{|c|}{ Age of Component } & \multicolumn{1}{c|}{ Site/Component } & Sample size & \# of Genera \\
\hline Toyah & $41 \mathrm{TG} 346$ & 11197 & 7 \\
\hline Toyah & $41 \mathrm{HY} 209-\mathrm{T}$ & 14234 & 24 \\
\hline Toyah & $41 \mathrm{HY} 209-\mathrm{M}$ & 4334 & 12 \\
\hline Toyah & $41 \mathrm{HY} 202-\mathrm{A}$ & 149 & 5 \\
\hline Toyah & $41 \mathrm{JW} 8$ & 3041 & 29 \\
\hline Toyah & $41 \mathrm{LK} 201$ & 9650 & 36 \\
\hline Austin & $41 \mathrm{HY} 209-\mathrm{T}$ & 265 & 16 \\
\hline Austin & $41 \mathrm{TV} 163$ & 577 & 8 \\
\hline Late Archaic & $41 \mathrm{TV} 163$ & 252 & 5 \\
\hline Late Archaic & $41 \mathrm{HY} 209-\mathrm{T}$ & 468 & 13 \\
\hline Late Archaic & $41 \mathrm{HF} 128$ & 20295 & 4 \\
\hline Late Archaic & $41 \mathrm{MM} 340$ & 3378 & 22 \\
\hline Late Archaic & $41 \mathrm{HY} 202-\mathrm{A}$ & 315 & 2 \\
\hline Late Archaic & $41 \mathrm{WM} 230$ & 1852 & 34 \\
\hline Late Archaic & $41 \mathrm{WM} 267$ & 1625 & 32 \\
\hline Late Archaic & $41 \mathrm{WM} 56$ & 463 & 19 \\
\hline Late Archaic & $41 \mathrm{BX} 228$ & 19,795 & 21 \\
\hline Middle Archaic & $41 \mathrm{LK28}$ & 24448 & 19 \\
\hline
\end{tabular}

sample, created during a period when bison may have been present, has 19 genera represented. While the number of components in our comparative data set is small, and while we lack comparative data on plant remains, these data do not support our suggestions that wider diet breadth should be reflected when bison are absent.

To explore this pattern further, we attempt to more clearly define the presence of bison in a component by considering components that are dominated by bison remains. We realize, as noted earlier, that body size will certainly impact this measure, and that the "dominance" of bison in a given assemblage may only reflect a small number of animals. Nevertheless, the faunal samples by genus and species within each site and/or component are presented in Appendix A (Table A-1). It is evident from that table that deer and deer/ antelope-sized faunal remains dominate the majority of the collections regardless of the age and location of the site. Two sites, 41TG346 (Late Prehistoric) and 41HF128 (Late Archaic), do not fit this pattern in that both assemblages are overwhelmingly composed of bison remains. Both are located on the Llano Estacado. No other sites exist in our sample that have large faunal assemblages dominated by bison remains. However, at least two additional sites have small to moderate sample sizes dominated by bison,
41HY202-A ( $\mathrm{n}=232)$ with $99 \%$ bison, and the Toyah component at $41 \mathrm{HY} 209-\mathrm{M}(\mathrm{n}=1,066)$ with $68 \%$ bison. Both of these are in central Texas. Deer and deer-sized faunal remains tend to dominate the majority of the other assemblages throughout the state, regardless of the age of the components. However, there are at least three sites in central Texas, 41WM230, 41WM267, and 41WM56, where rodents tend to outnumber deer, antelope, and similarly sized species.

Among the faunal assemblages dominated by bison bones (41TG346, 41HF128, 41HY202-A Late Archaic, and 41HY202-A Toyah; see Table A-1), the number of species represented ranges between 2 and 7, with a mean of 4.5 species (see Table 7-7). The only assemblage that does not fit this pattern is $41 \mathrm{HY} 209-\mathrm{M}$ where bison bones are relatively common (68\%) but 12 genera are present. Including all five components where bison is frequent, the average number of genera is 6 . In contrast, for the remaining 13 sites that are not dominated by bison, the average number of genera represented is 21.4 , with a range from a low of 8 to a high of 36. These patterns suggest that when bison skeletal elements dominate the faunal assemblage, overall diet breadth, as indicated by the presence of skeletal remains of other genera, is narrower when contrasted to assemblages when bison is not the dominant species. 
As a final component of the investigation into faunal remains, we further explore this pattern by combining the generalevel faunal data for each site into three body size categories. The body size classifications for each genus present within the faunal collections are presented in Appendix A, Table A-2. Table 7-8 shows the breakdown of the faunal assemblages by body size category within each site. Note that the samples sizes are reduced from the Table 7-7 totals as not all fragments could be assigned to a body size group. The results of this analysis parallel those discussed previously. Within three sites (41TG346, 41HF128, and 41HY202-A Late Archaic), large body sized prey constitute $99 \%$ of the skeletal elements recovered, and in two other instances (41HY209-M Toyah and 41HY202-A Toyah) large body sized animals (i.e., bison) constitute more than $50 \%$ of the fragments. Note that these are the same five sites discussed previously, and they had an average number of six genera. Within five sites/components (41HY209-T Toyah, 41TV163 Austin, 41TV163 Late Archaic, 41MM340, and 41LK28), the medium body sized prey contributes more than $50 \%$ of the skeletal elements (Table 7-8). The number of genera for these sites is $24,8,5,22$, and 19 , respectively, with an average of 15.6. Finally, four sites (41HY209-T Austin, 41WM230, 41WM267, and 41WM56) have faunal assemblages within which small to very small body sized species constitute the largest percentage of the skeletal remains. The genus richness of these faunal assemblages is $16,34,32$, and 19 , with an average of 25.25. Assemblages dominated by bison elements have the lowest number of genera. Those dominated by deer and deer/antelope-sized elements have moderate numbers of genera. Finally, those dominated by small to very small sized bone have the highest mean number of genera.

These patterns in body size, as well as those discussed previously, are consistent with our expectations that diet breadth would be relatively narrow in situations where bison are present, and wide in situations where bison are absent. While the period-level comparisons are not supported, these site-specific patterns reflect relationships between prey size and diet breadth at the site component level. It is likely, then, that while the faunal assemblage at one Toyah Phase site may be dominated by bison and the diet breadth may be very narrow (i.e., $41 \mathrm{TG} 346$ and 41HF128), at another Toyah Phase site, occupied at a different time of the year or within a different ecological setting, the assemblage may be dominated by medium body sized animals and may have a higher number of genera (i.e., 41JW8 and 41HY209-T). Such variability is to be expected as hunter-gatherers reposition themselves constantly across the landscape in search of resources.

Table 7-8. Breakdown of Faunal Assemblages by Phase/Time Period and Body Size

\begin{tabular}{|c|c|c|c|c|c|c|c|c|}
\hline \multirow[b]{2}{*}{ Phase/Period } & \multirow[b]{2}{*}{ Site } & \multicolumn{2}{|c|}{ Large } & \multicolumn{2}{|c|}{ Medium } & \multicolumn{2}{|c|}{ Total Small-Very Small } & \multirow[b]{2}{*}{ Total } \\
\hline & & Count & Percent & Count & Percent & Count & Percent & \\
\hline Toyah & $41 \mathrm{TG} 346$ & 11,022 & 98.6 & 53 & 0.5 & 104 & 0.9 & 11,179 \\
\hline Toyah & 41HY209-T & 1770 & 19.6 & 6031 & 66.8 & 1227 & 13.6 & 9,028 \\
\hline Toyah & 41HY209-M & 729 & 68.4 & 290 & 27.2 & 47 & 4.4 & 1,066 \\
\hline Toyah & 41HY202-A & 83 & 55.7 & 52 & 34.9 & 14 & 9.4 & 149 \\
\hline Austin & $41 \mathrm{TV} 163$ & 0 & 0.0 & 203 & 84.2 & 38 & 15.8 & 241 \\
\hline Austin & 41HY209-T & 61 & 31.1 & 55 & 28.1 & 80 & 40.8 & 196 \\
\hline Late Archaic & $41 \mathrm{TV} 163$ & 8 & 5.8 & 119 & 86.9 & 10 & 7.3 & 137 \\
\hline Late Archaic & 41HY209-T & 103 & 37.7 & 88 & 32.2 & 82 & 30.0 & 273 \\
\hline Late Archaic & 41HF128 & 20,160 & 99.3 & & 0.0 & 135 & 0.7 & 20,295 \\
\hline Late Archaic & $41 \mathrm{MM} 340$ & 315 & 9.9 & 2308 & 72.5 & 560 & 17.6 & 3,183 \\
\hline Late Archaic & 41HY202-A & 230 & 99.1 & 2 & 0.9 & 0 & 0.0 & 232 \\
\hline Late Archaic & $41 \mathrm{WM} 230$ & 5 & 0.3 & 311 & 16.8 & 1536 & 82.9 & 1,852 \\
\hline Late Archaic & $41 \mathrm{WM} 267$ & 0 & 0.0 & 215 & 6.8 & 2946 & 93.2 & 3,161 \\
\hline Late Archaic & 41WM56 & 8 & 1.7 & 172 & 37.1 & 283 & 61.1 & 463 \\
\hline Middle Archaic & 41LK28 & 0 & 0.0 & 15,314 & 71.4 & 6141 & 28.6 & 21,455 \\
\hline
\end{tabular}




\section{Plant Remains and their Role in Subsistence}

Although we have focused on faunal remains in the previous sections of this chapter, it cannot be ignored that plant remains were probably a significant element of the prehistoric hunter-gatherer diet. Based on the general ethnographic and ethnoarcheological literature and ethnohistoric accounts from Texas, it is clear that resources such as nuts (walnuts, pecans, acorns), tubers and bulbs (sotol, camas, wild onions), and prickly pear leaves and fruit played an important role in hunter-gatherer diet. It is likely that it was the distribution and variability in plant resources that most directly conditioned hunter-gatherer mobility much of the time, especially when groups were not involved in pursuing bison.

Unfortunately, of the nine macrobotanical samples submitted for analysis, only one (Cat. No. 333-001) from unit S175/ E200, Zone III-B, a Late Archaic analytical unit, returned evidence of a potentially edible plant species, an onion bulb (Allium sp.). The results of the macrobotanical analysis are described in detail in Appendix D, authored by Dr. Phil Dering.

The recovery of a single onion bulb is not much on which to base a reconstruction of the role of plant resources in Late Prehistoric and Late Archaic diets. Nonetheless, recently unearthed evidence from a series of archeological sites with burned rock middens (see Brownlow 2003; Mauldin et al. 2003; Mehalchick et al. 2003) strongly suggests that bulbs and other plant resources that needed long periods of cooking to render them digestible by humans were extensively exploited by prehistoric groups. Even more intriguing than the finds of charred plant remains are the radiocarbon dates that have been obtained from numerous middens. Numerous dates compiled on middens from a number of projects (i.e., see Black and Creel 1997:Figure 134, 135; Mauldin et al. 2003:Figure 7-2) suggest that even if rock oven technology had an early beginning, the use of these cooking features seemed to have flourished during the Late Prehistoric period, and in particular during the Austin Phase (A.D. 700-1250).

The use of high carbohydrate plant resources increases at the end of the Late Archaic and during the Transitional Archaic as indicated by midden use dates. Rock oven cooking flourished during the Austin Phase, as bison is a lesser component of the diet and medium body sized animals are more intensively hunted. Interestingly, rock oven cooking continues well into the Toyah Phase, if the series of late dates actually indicate oven use rather than an overprinting of Toyah materials and organics onto abandoned facilities and features.

\section{Summary and Conclusions}

We began this chapter noting that differences in subsistence between major periods of bison presence or absence could be expected. We suggested several patterns that might be anticipated, including a reduction in diet breadth when bison were abundant, and a widening of diet breadth when bison were absent or at extremely low densities. We also suggested that increased processing of bone might be anticipated under conditions of bison absence. Using data from 41TV163, our contrast between the Late Prehistoric Austin Phase analytical unit and assemblages from the Late Archaic found evidence consistent with those expectations. While the numbers of genera present in the assemblages are only slightly increased in the Late Prehistoric Austin Phase analytical units relative to those of the Late Archaic, bone processing seems to have been more frequent in the Late Prehistoric material. While the 41TV163 macrobotanical samples yielded only one edible plant species, an onion that may have come from a Late Archaic context, plant resources were probably a significant dietary component. The rapid increase in rock oven cooking facilities during the Late Archaic and their fluorescence during the Austin Phase and through the Toyah Phase suggests that plant resources that required lengthy cooking times may have been regular components of the diet.

We then conducted a regional comparison using faunal material from a number of sites. We had suggested that bison availability will impact the diet breadth of hunter-gatherers and expected a narrowing of diet breadth when bison were present. While hampered by the quality of available data, our analysis shows that when bison constitutes a large proportion of the faunal remains within an assemblage, the number of genera represented tends to be low. When medium body sized species dominate the faunal collections, more genera are present. Finally, the highest number of genera tends to be noted in assemblages dominated by elements derived from small to very small prey species. That analysis also suggests that variation rather than homogeneity characterized any given period. For example, the comparison of Toyah Phase faunal assemblages shows that they vary within central Texas as a group both in terms of genera richness, as well as in terms of the proportional contribution of large body sized mammals to the diet. Interestingly, there 
are two large archeological faunal assemblages that are composed nearly entirely of bison remains. Both of these assemblages, 41TG346 and 41HF128, are outside of central Texas. They reflect an adaptive stance similar to central and northern plains bison hunters. Toyah Phase faunal assemblages from central Texas tend to have moderate numbers of species/genus represented. This may reflect diversification of hunting strategies rather than specialization on bison. The two Toyah Phase assemblages from southcentral (41LK201) and south Texas (41JW8) have high numbers of genera reflecting extreme hunting diversification. The Hinojosa Site (41JW8) is particularly interesting in that it is found south of the riverine portion of south Texas, in an area that is assumed to have been somewhat marginal to bison. The high number of genera of that assemblage may be reflective of this marginal location. The trend may also reflect an emphasis on plant resources as suggested by historic accounts of prickly pear exploitation in portions of south Texas (Campbell 1988:50). Variability in subsistence strategies also seems to be exemplified in the two Austin Phase assemblages but the small sample sizes make it difficult to rely too heavily on the results. The presence of the large body sized fauna within one assemblage suggests that the Austin Phase was a time of bison scarcity rather than total absence, although some degree of mixing of materials from other components may also account for the pattern. Late Archaic faunal assemblages also show a great degree of subsistence variability. The assemblage from $41 \mathrm{HF} 128$ is similar to $41 \mathrm{TG} 346$ and indicates a high degree of specialization in bison procurement. Whether this occurred on a seasonal basis or throughout the year is difficult to tell, although the kill site appears to have been used in March (Quigg 1997:118). With the exception of 41HF128, only one other Late Archaic site (41HY202-A) has a faunal assemblage dominated by large body sized prey species. Even within the remainder of the components, however, subsistence variability exists as noted by the fact that some site faunal assemblages are dominated by medium body sized prey (i.e., deer/antelope; 411MM340), while other assemblages are dominated by small to very small body sized species.

The results of these comparative analyses suggest that productive research may be pursued with existing faunal assemblages even when the original analyses are decades old and fragmentary in nature. The research highlighted one critical aspect of previously analyzed faunal assemblages: the variability in what and how it was analyzed. A number of other faunal assemblages exist curated in various facilities across the state. Some of these assemblages could not be used either because reporting was inadequate or only a small sample of the specimens was analyzed. A great deal more could have been done at the regional scale if some of the temporally isolable assemblages could have been more fully analyzed. Given the critical importance of reconstructing and understanding variability in hunter-gatherer subsistence practices across the state, it is suggested that the many existing faunal collections from isolable sites be re-analyzed to increase sample sizes and standardize analysis attributes and reporting criteria. It is also recommended that minimal analysis standards be sought and adopted to ensure that future faunal analyses record a set of usable attributes in identical manner so that the data resulting from multiple disparate projects can be comparable with other analyses and used for regional-scale investigations. 



\title{
Chapter 8: Technological Organization at 4ITV163
}

\author{
Raymond P. Mauldin, Steve A. Tomka, Harry J. Shafer, and Jason D. Weston
}

In this chapter we investigate selected aspects of technological organization. Technological organization concerns how people organized activities associated with the design, manufacture, repair, and replacement of tools, and how these activities may have been conditioned by factors such as the availability and form of tool stone, as well as reliability and maintainability considerations of the tool itself. The chapter contains two primary sections. The first section is concerned with how raw material was acquired and used at the site. Using the lithic material from the six analytical units (AUs) that represent four temporal periods (see Chapter 6), we use several measures to identify raw materials that may have been locally obtained and distinguish these from stone that may have been brought to 41TV163. We then consider what these local and non-local material types were used to produce. Finally, we investigate changes between the four temporal periods in raw material procurement, aspects of reduction strategies, and tool assemblages. The second section of this chapter focuses on changes in aspects of projectile point technology. The design characteristics of projectile points, as well as refurbishing strategies, are critical aspects of technological organization because they are responsive to factors such as available prey type, mobility strategies, and raw material access. Relying on data collected from 428 projectile points, 212 of which can be assigned to one of the four temporal periods, this second section investigates categories of discard (e.g., use breakage, manufacture failure, postdepositional breakage), as well as measures of remnant use life (i.e., blade length and width).

\section{Raw Material Acquisition and Use at 41 TV163}

The six analytical units at 41TV163 will form the initial data set used in this discussion. As outlined in Chapter 6, the AUs contain 8,647 pieces of lithic debitage, 38 cores, 103 projectile points, and 198 bifaces. In addition, 80 other chipped stone tools, including 52 items that we suggest were used as scrapers, three battered/chopping tools, eight knives, a drill, four multifunction tools, and 12 gravers, several of which are on bifaces or points, are present. The AUs represent roughly $20 \%$ of the debitage collected from the site, $18 \%$ of all cores, $24 \%$ of the projectile points, $21 \%$ of the bifaces, and $17 \%$ of the other tools. All four temporal periods are represented in the sample, with the smallest samples sizes coming from the Early Archaic period, with 256 chipped stone items. While petrified wood and quartzite are present in the sample, over $99 \%$ of all material in the AUs was classified as chert.

\section{Identifying Local and Non-Local Material Groups}

The initial aspect of technological organization investigated in this chapter concerns the acquisition of chert by the inhabitants of 41TV163. Like many areas along the Balcones Escarpment, 41TV163 appears to have been located with access to a variety of abundant, good-quality chert sources. As discussed in Chapter 2, the geology within the general area of $41 \mathrm{TV} 163$ is dominated by a variety of chalk, limestone, marl, and dolomite deposits, including deposits associated with the Fredericksburg Group. These Fredericksburg deposits contain abundant white to gray colored chert nodules (see Barnes 1974). During the various occupations of $41 \mathrm{TV} 163$, then, we assume that raw material was abundant, and that while the distribution and quality of stone may have varied from source to source on a small scale, good-quality cherts were probably consistently available to the occupants of the site. As good-quality cherts are still common in this area today, this assumption seems reasonable. The vast majority of stone found at the site, then, was probably acquired locally.

A cursory review of the site level assemblage clearly suggests that a few chert colors, falling within the gray and white color ranges of the Fredericksburg deposits, dominate the assemblage. However, other chert colors are also represented in small quantities that are not within this color range. This appears to especially be the case with the projectile points. While it is certainly possible that some of these chert colors are local, their presence suggests that some component of the tool stone may have been transported to the site from outside of the immediate area. If groups of materials that are likely to be local and non-local can be identified, and given the assumption that local material access was relatively constant, changes in the percentage of non-local stone through time may provide a rough measure of changes in the way that raw material acquisition was organized. 
As it is explained in more detail below, our distribution between local and non-local raw materials is established on patterning in the debitage in terms of both variability in size range and corticate/decorticate specimens. Therefore, the derived patterns will reflect differences in what degree of reduction do raw materials arrive at the site and the length of the reduction sequence carried out on site. As long as variability in these two aspects of raw material reduction are conditioned by distances of raw material from 41TV163, the patterns will reflect differences in the procurement of local versus non-local materials. In a more theoretical sense, we expect that local materials may be thought of as those that can be accessed with one day's foraging distance while those resources falling outside of this may be considered non-local. However, there may be situations when some degree of raw material field-reduction may occur prior to transport even when the resource is found within the limits of one day's foraging distance.

To investigate raw material procurement practices through time we focused on categorizing the cherts into color and texture groupings. The color/texture categories were defined based on the debitage within the AUs because this data type is likely to contain examples of all raw materials brought onto and reduced at the site. Initially, 26 different categories of chert were defined for the 8,647 pieces of debitage, though several of the 26 categories were represented by only a handful of items. After an examination of the number of items in each group, these 26 categories were reduced to 14 by combining 13 groups with small samples (min. $=1$; max. $=34$ ) into a single category. Table 8-1 presents the raw material group numbers, a brief color description of the material, and information on the number and relative frequency of these materials in the combined AU debitage. The combined material category is material Group 8 . The scheme in Table 8-1 was used to classify all chipped lithics from the analytical units. The comparison of the material groups within the tools and the debitage provides a good indication of which categories are present in what chipped lithic artifact group.

Unfortunately, we lack details on the distribution of these raw material groups in the natural environment. That is, while we suspect that the majority of debitage in a given white or gray chert is local, and that at least some of the other materials are not local, we lack any samples from the environment that would allow us to verify these suspicions. We rely, then, primarily on theoretical argument to begin to explore local materials relative to non-local materials at 41TV163. Specifically, we suggest that locally available materials would tend to be used primarily to produce new tools, as well as bifaces and points for use away from 41TV163. Local materials would, then, be subject to longer manufacture sequence potentially involving decortication of nodules, thinning, and shaping of a variety of different tools. Debitage from local materials should be characterized by large numbers of items and, as a group, should have high variability in debitage size. While all cortex categories should be present in local material groups, the debitage is likely to be dominated by non-cortical flakes, especially in situations with long reduction sequences and large nodule sizes. Cores should be frequently represented among local materials, and reflect a variety of sizes. Conversely, material categories overly represented primarily by formal tools,

Table 8-1. Raw Material Groups Represented in Debitage.

\begin{tabular}{|c|c|c|c|}
\hline Material Group No. & Color Description & Debitage Sample Size & Percent of Sample \\
\hline 1 & pale to light gray & 1195 & 13.8 \\
\hline 2 & brownish-gray & 1202 & 13.9 \\
\hline 3 & dark gray to black & 320 & 3.7 \\
\hline 4 & dark brown & 114 & 1.3 \\
\hline 5 & dark gray-brown & 690 & 8.0 \\
\hline 6 & gray-brown & 1766 & 20.4 \\
\hline 7 & light brown & 65 & 0.8 \\
\hline 8 & various & 186 & 2.2 \\
\hline 10 & pinkish-beige & 194 & 2.2 \\
\hline 11 & beige & 1489 & 17.2 \\
\hline 12 & pinkish-gray & 202 & 2.3 \\
\hline 15 & dark-beige & 723 & 1.2 \\
\hline 17 & gray-red to beige-red & 106 & 4.6 \\
\hline 18 & light-beige & 395 & \\
\hline & & & \\
\hline
\end{tabular}


bifaces, and/or having low numbers of debitage, are likely to be non-local in origin. The rejuvenation of tools made of these non-local materials, and transported to Millican Bench in a more finished form, would represent much shorter reduction sequences relative to the sequences characteristic of local materials. These sequences should produce fewer numbers of debitage and debitage with a more limited size range. Primary flakes should be infrequent, especially in larger size ranges, though, like the local materials, tertiary flakes will dominate non-local debitage. Non-local cores should be infrequent, and when present, should be small.

In order to investigate these suggestions, we first focus on debitage. We recorded two attributes on all debitage within the AUs. Estimates of dorsal cortex on debitage were made and grouped for analysis into four categories: (1) no cortex; (2) $1-50 \%$ cortex; (3) $51-99 \%$ cortex; and (4) $100 \%$ cortex. Size of debitage was measured by maximum dimension with a digital caliper.

Figure 8-1 presents an initial consideration of the 14 raw material groups using two debitage attributes designed to measure overall raw material size and variability in debitage size. On the Y-axis is the range (maximum size - minimum size) of debitage in a given raw material group. While the $1 / 4$-inch screens used on the project limit the minimum size, the maximum size of a flake is probably limited by core size. Larger ranges, then, probably reflect larger initial core or biface size. On the $\mathrm{X}$-axis, we plot the coefficient of variation for flakes in a material group. The coefficient of variation (C.V.) measures the variability in the size of flakes and is calculated as mean flake size divided by the standard deviation of the group.

Several different clusters are apparent in Figure 8-1. There is a group of four materials $(4,8,12,17)$, designated by triangles, which have low variability and are probably produced from smaller parent pieces given the low ranges. Reference to Table 8-1 will suggest that these four material types all have lower numbers of items, with an average sample size of 152 pieces. Referencing our previous discussion, these four types have characteristics consistent with groups dominated by non-local materials. A second cluster of seven materials $(1,2,3,5,6,10,18)$ has higher variability. Flakes in these groups probably come from larger cores and/ or bifaces. Sample sizes for these materials are much higher,

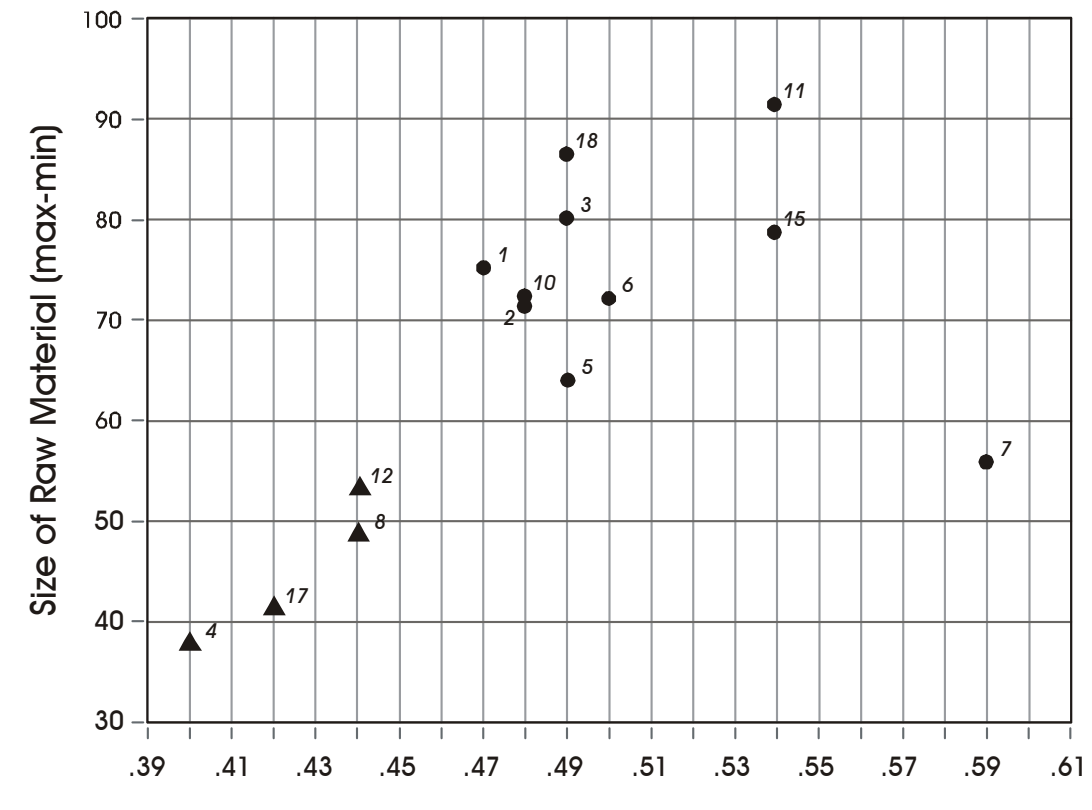

C.V. on Flake Size

Figure 8-1. Range of raw material groups and the coefficient of variation on flake size. 
with an average of 823 items per group (Table 8-1). Two other raw material types, numbers 11 and 15 , could be collapsed into the a third group as they have similar size ranges, but slightly higher variability than Group 2 . These two cases have samples sizes of 1,489 (Group 11), and 723 (Group 15). All of these nine cases (Groups 1, 2, 3, 5, 6, 10, $11,15,18)$ are consistent with our initial expectations for local materials. Finally, raw material Group 7, with only 65 cases, has high variation in flake size, but comes from smaller cores or bifaces (Figure 8-1). This material group has characteristics of both a local raw material (high variability) and non-local source (small size, smaller numbers).

At a group level, we can contrast cortex occurrence and percentage for those raw material types suspected to be dominated by non-local stone (Groups 4, 8, 12, 17, and 7) with those that are thought to be primarily local (Groups 1 , $2,3,5,6,10,11,15$, and 18). Recall that we suggested that while non-cortical flakes should dominate both non-local and local materials, non-local raw materials should lack large primary flakes, while local materials should contain these specimens. In order to consider this suggestion, we broke up maximum flake length of all 8,647 items into roughly equal size groups. The largest size group contains 1,730 items, all of which exceed $26.8 \mathrm{~mm}$ in size. Table 8-2 presents these 1,730 items. Included are the number of primary flakes $(100 \%$ dorsal cortex $)$, the percentage of primary flakes, and the number of flakes by raw material group. The materials are ranked by suspected core size based on the Y-axis in Figure 8-1. As such, the top four cases are those material groups that we suspect are dominated by nonlocal raw materials, while the fifth case, material type 7 , is thought to contain some non-local tool stone.
Examination of the table will show that of these top five cases, large primary flakes are rare. Only one (20\%) of the five groups has primary flakes present, and although just 106 large items are in these five cases, the percentage of primary flakes is only $1.89 \%$ for all five cases. Seven of the remaining nine types $(77.8 \%)$ have large primary flakes. While this fits our overall expectations regarding the presence of large primary flakes in local raw materials, the percentage of large primary flakes within the 1,624 items in these nine groups, $1.85 \%$, is virtually identical to the $1.89 \%$ of the flakes in the previous five groups. This is not consistent with our expectations.

One possibility is that we have dramatically different core sizes and reduction trajectory lengths in these two groups. That is, if the types dominated by local material are significantly larger to start with, then the percentage of large primary flakes should be quite low. In situations with high availability of large local materials, then, the percentage of large primary flakes may not be a useful measure in considering material origin. Nonetheless, it is the cases that these data are only partially consistent with our expectations.

As a final exploration of this question within the debitage, we constructed Table 8-3. Here, we grouped those types that potentially contain high frequencies of non-local materials (Groups 4, 7, 8, 12, and 17) and contrasted them to a group containing the remaining nine material types. These two groups contained 675 and 7,972 pieces of debitage, respectively. We then contrasted the number of items per pieces of debitage for bifaces $(\mathrm{n}=198)$, points $(n=108)$, and other tools $(n=80)$ by raw material group. For the three ratios in the table, the frequency of local debitage

Table 8-2. Primary Flakes by Raw Material Type for Large Debitage

\begin{tabular}{|c|c|c|c|}
\hline Raw Material Type & Primary Flakes & Total Large Flakes & Percent Primary Flakes \\
\hline 4 & 0 & 11 & $0 \%$ \\
\hline 17 & 0 & 15 & $0 \%$ \\
\hline 8 & 2 & 39 & $5.10 \%$ \\
\hline 12 & 0 & 30 & $0 \%$ \\
\hline 7 & 0 & 11 & $0 \%$ \\
\hline 5 & 0 & 110 & $1.53 \%$ \\
\hline 2 & 3 & 196 & $1.28 \%$ \\
\hline 6 & 4 & 313 & $2.86 \%$ \\
\hline 10 & 1 & 35 & $0.33 \%$ \\
\hline 1 & 1 & 304 & $1.75 \%$ \\
\hline 15 & 2 & 114 & $0 \%$ \\
\hline 3 & 0 & 36 & $4.59 \%$ \\
\hline 18 & 5 & 109 & $3.71 \%$ \\
\hline 11 & 14 & 377 & $1.88 \%$ \\
\hline Total & 32 & 1700 & \\
\hline & & & \\
\hline
\end{tabular}


Table 8-3. Comparison of Potentially Non-local and Local Stone Debitage to Tools and Cores

\begin{tabular}{|l|c|c|}
\hline Ratios & Non-local Materials & Local Materials \\
\hline Debitage / Other Tools & $27.0 / 1$ & $144.95 / 1$ \\
\hline Debitage / Cores & n/a & $209.79 / 1$ \\
\hline Debitage / Misc. Bifaces & $8.04 / 1$ & $69.9 / 1$ \\
\hline Debitage / Points & $17.78 / 1$ & $135.12 / 1$ \\
\hline
\end{tabular}

per other tool, biface, and point always dramatically outnumbered the ratios for non-local materials. That is, nonlocal materials are over-represented in bifaces, points, and other tools relative to the number of non-local debitage. These patterns are consistent with the importation of nonlocal materials in an already reduced or finished form (i.e., bifaces, points, finished tools). Though not shown in Table 8-3, only a single core from non-local materials was present among the 38 cores in the four AUs. There were, then, roughly 675 pieces of non-local debitage per core, compared to 215 pieces of debitage for local cores. Given that we suggested that local cores are likely to be substantially larger, these ratios further suggest that much of the non-local debitage is being produced from the reduction or rejuvenation of bifaces and projectile points. Although this pattern may also be interpreted as reflecting longer reduction sequences among non-local materials compared to local ones, it is more likely to be due to the fact that non-local materials were rarely introduced to 41TV163 in the form of cores, but more likely as finished tools.

\section{Debitage in Analytical Units}

While the precise designation of local and non-local raw materials remains unconfirmed given that we lack independent geological information on the distribution of the materials, much of the previous analysis of the raw material groups is consistent with our expectations for what local and non-local material should look like within this site. We will assume, then, that non-local stone dominates material types $4,7,8,12$, and 17 , while the remaining types represent primarily local stone sources. Using these designations, as well as information on cortex percentages and flake size, we now turn to summarizing the changes in raw material use through time at 41TV163.

Table 8-4 presents a breakdown of the percentage of cortex by temporal period. For this table we have combined all primary flakes (100\% cortex) and those flakes with between $51 \%$ and $99 \%$ cortex into a single category. With the possible exception of the Early Archaic, the percentages are quite similar. Non-cortical flakes are highest in the Late Archaic, though the differences between the three late periods are minimal.

Finally, Table $8-5$ presents the distribution of debitage by local and non-local raw material types for the four temporal periods. Note that in both the Early and Middle Archaic, the contribution of the non-local materials hovers around $4 \%$ of the total raw materials. In the Late Archaic, $8.1 \%$ of the material in use has been classified as non-local, while this figure climbs to almost $10 \%$ during the Late Prehistoric. The increasing use of probable non-local materials late in the sequence may reflect changes in the level of mobility, the way that mobility was organized, or changes in the nature of site use at 41TV163. While we currently lack methods to identify which of these suggestions should be pursued in future research, the patterns in Table 8-5 suggest that material acquisition patterns varied through time at 41TV163.

Table 8-4. Percentage of Cortex Groups for Four Temporal Periods at 41TV163

\begin{tabular}{|l|c|c|c|c|}
\hline Analytical Unit & No Cortex & $\mathbf{1 - 5 0 \%}$ Cortex & $\mathbf{5 1 - 1 0 0 \%}$ & Total Number of Items \\
\hline Early Archaic & $77.33 \%$ & $18.67 \%$ & $4.00 \%$ & 225 \\
\hline Middle Archaic & $84.76 \%$ & $12.96 \%$ & $2.28 \%$ & 1975 \\
\hline Late Archaic & $85.50 \%$ & $11.66 \%$ & $2.84 \%$ & 3696 \\
\hline Late Prehistoric & $82.99 \%$ & $13.92 \%$ & $3.09 \%$ & 2751 \\
\hline Total Number of Items & 7291 & 1112 & 244 & 8647 \\
\hline
\end{tabular}


Table 8-5. Frequency of Debitage by Raw Material Groups for Four Temporal Periods at 41TV163

\begin{tabular}{|l|c|c|c|c|c|}
\hline Analytical Units & Local Materials & Percentage & Non-local Materials & Percentage & Total \\
\hline Early Archaic & 216 & $96.0 \%$ & 9 & $4.0 \%$ & 225 \\
\hline Middle Archaic & 1903 & $96.4 \%$ & 72 & $3.6 \%$ & 1975 \\
\hline Late Archaic & 3398 & $91.9 \%$ & 298 & $8.1 \%$ & 3696 \\
\hline Late Prehistoric & 2478 & $90.1 \%$ & 273 & $9.9 \%$ & 2751 \\
\hline Totals & 7995 & $92.5 \%$ & 652 & $7.5 \%$ & 8647 \\
\hline
\end{tabular}

\section{Cores in Analytical Units}

As part of the investigation of lithic reduction strategies we also studied the cores present in the analytical units and quantified both the type of reduction they represent (i.e., unidirectional, multidirectional, bifacial) and their degree of reduction. To monitor degree of reduction, we counted the number of flake scars, recorded the weight (grams) of cores, and noted the presence/absence of cortex on cores. Only a single core was made on a non-local material group. No comparisons are made, then, between local and nonlocal patterns.

Overall, most cores were classified as multidirectional, with this group making up $60.5 \%$. Bidirectional cores were the second most common type, with nine cases. The average core weight of the 38 specimens was 53.3 grams, with a range of between 6.1 grams and 202.4 grams. Cortex was present on $42.1 \%(n=16)$ of the cores, and those cores with cortex were substantially heavier (mean wt. $=73.1 \mathrm{~g}$ ) than those without cortex (mean=38.9 g). The number of flake scars ranged from 1 to 29 , with most cores having less than 10 scars present.

Figure 8-2, a histogram of the number of scars per core, clearly suggests that three groups are present. The first group, with a mode of three scars and a range of from 1 to 7 , consists of 24 of the 38 cores. A second group, with a mode at 11 scars and a range of between 8 and 14, contains 12 cores. Finally, two cores, designated Group 3, have more than 17 scars. Initially, we suspected that the number of scars would be inversely related to core weight. That is, the more scars present on a core, the more flake removals and the lighter the core. Figure 8-3, a box plot of the weights of cores by the three groups, suggests that this is not the case. In fact, those cores with less than eight flake scars are substantially smaller than the two cores in Group 3, the latter having more than 17 scars present.
Figure 8-4 suggests a possible reason for this unexpected relationship. We suggest that, initially, this relationship holds as suggested by the upper part of the curve. However, at some point, new removals begin to take off previous removals. That is, new removals, at some point, will contain previous removals on their dorsal surface. This should result in both a reduction of weight and a reduction of flake scars, as more removals occur. As indicated in the graphic, if this is the case, we should expect that multidirectional cores, defined as cores with removals from several different directions, should increasingly characterize the Groups 2 and 3 cores shown in Figure 8-2. Of the 24 cores within Group 1, multidirectional cores make up 42\%. For the 14 cores classified as Groups 2 and 3, multidirectional cores make up $93 \%$. Note that in situations with low raw material availability, most cores will probably end up near the bottom of the reduction trajectory shown in Figure 8-4. That is, most cores should be multidirectional, have small weights, and have a moderate number of flake scars. Only in situations with high raw material availability, such as 41TV163, might we have the opportunity to more clearly define this core reduction trajectory.

Table 8-6 presents summary data on cores by the four temporal periods. Note that for all four cases, sample sizes are small. This is especially the case for the Early Archaic, were only three cores are present. In addition, given the discussion in the previous paragraph, the number of flake scars is difficult to interpret clearly in terms of reduction. However, note that most other indicators suggest that cores were more completely reduced in the Late Prehistoric. It is during this period that we have the highest percentage of cores with no cortex, the highest percentage of multidirectional cores, and the lowest median core weight. This period is clearly different from the three earlier periods. 


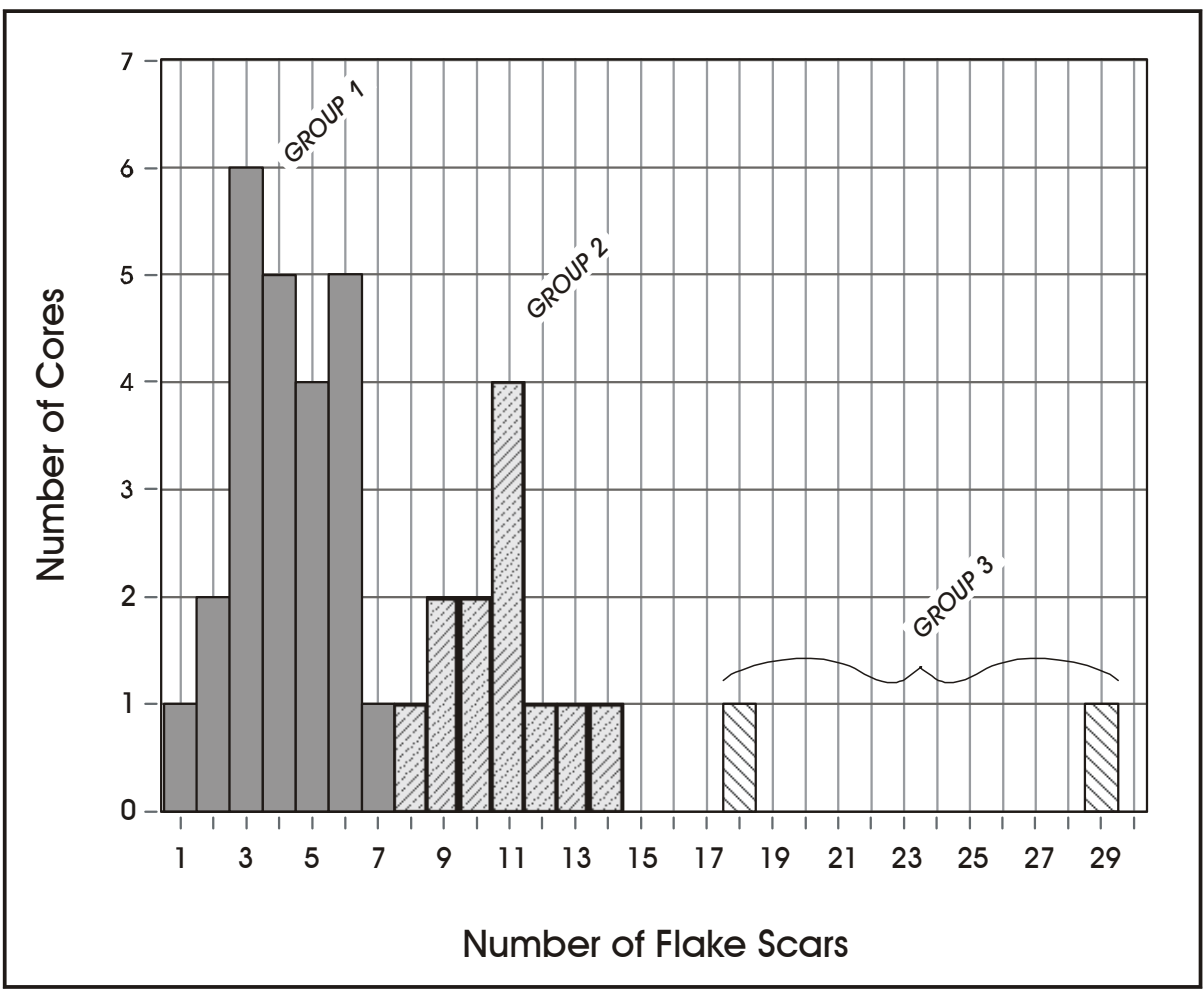

Figure 8-2. Number of flake scars on cores.

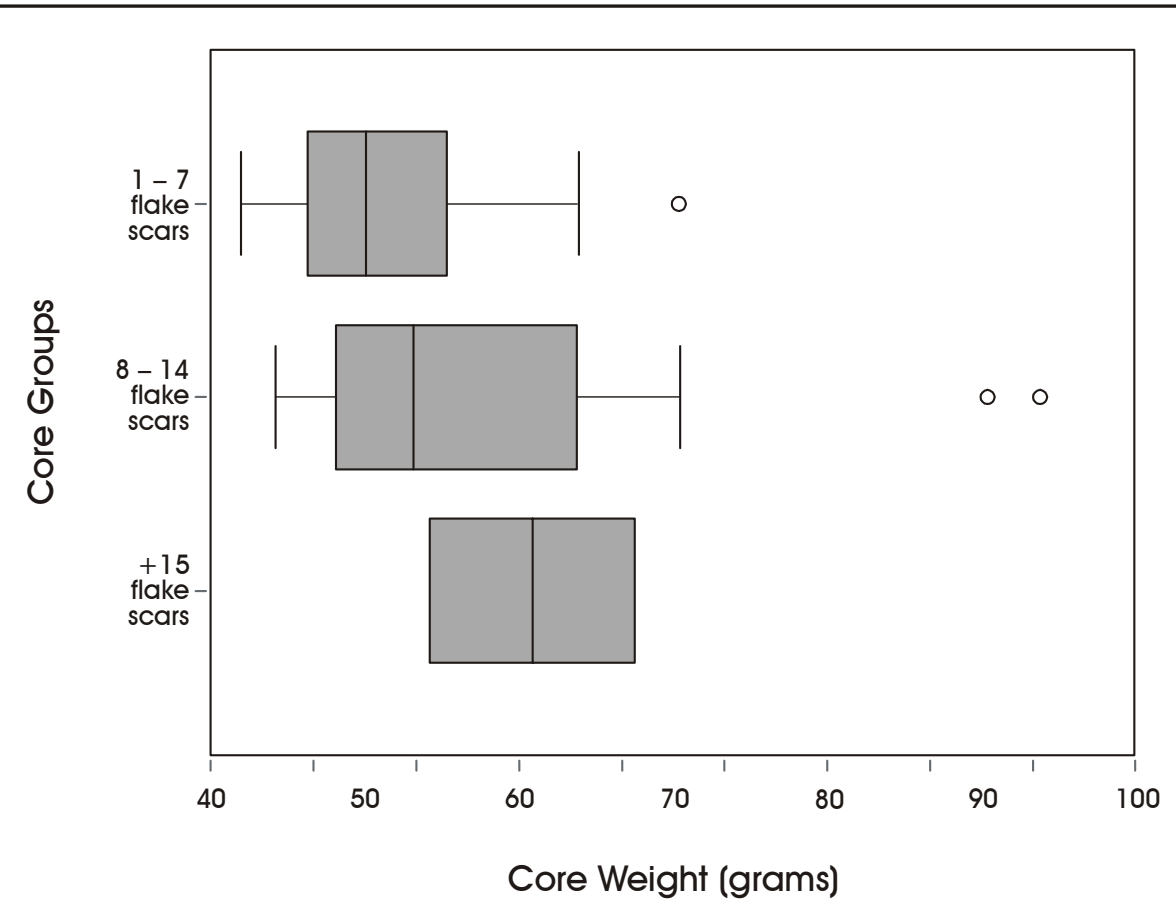

Figure 8-3. Weight of cores by flake scar group. 


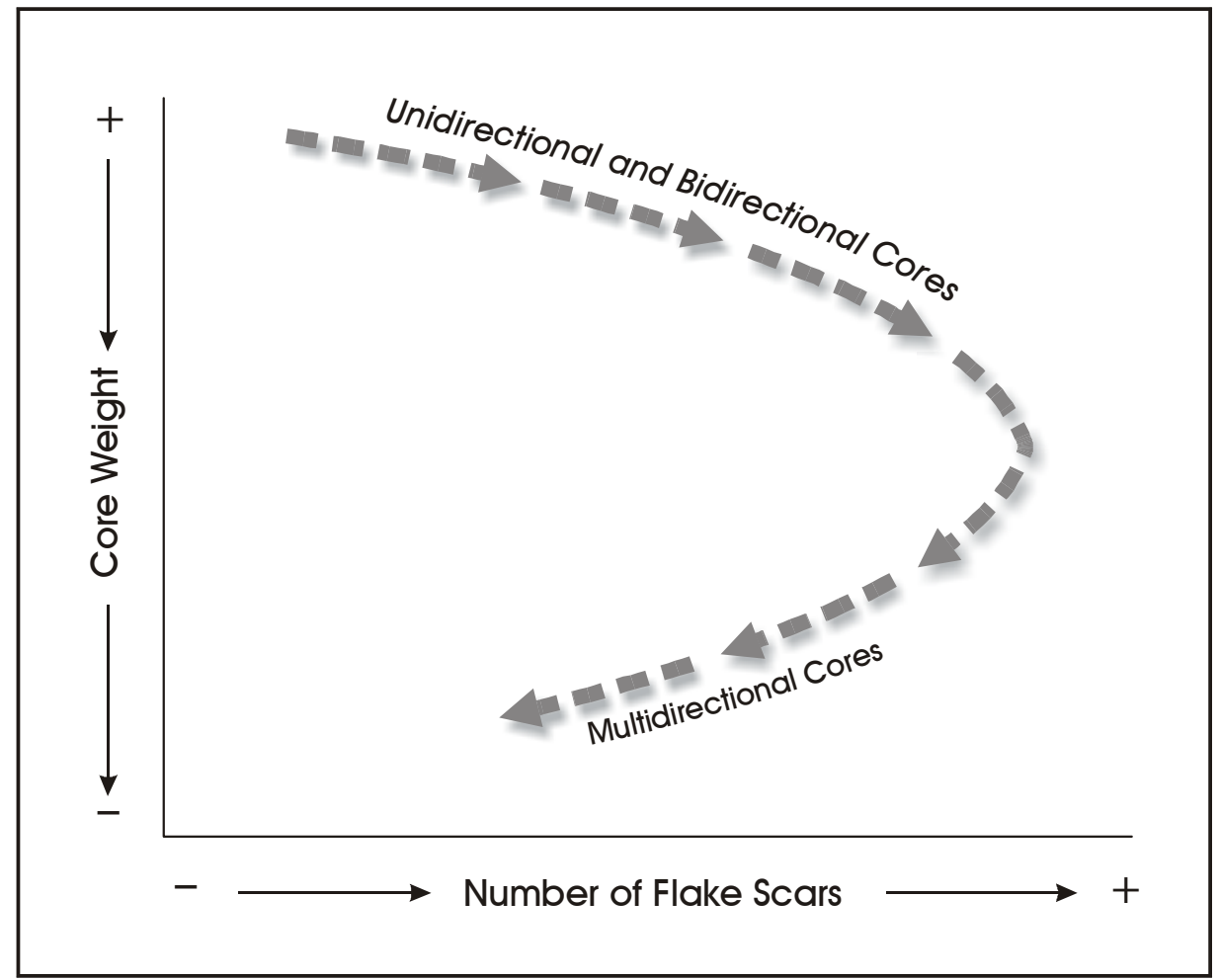

Figure 8-4. Suggested relationship between core weight and number of flake scars.

\section{Technological Organization: Tool Design and Projectile Point Technology at 41TV163}

The resources exploited by hunter-gatherers and the strategies employed are in part conditioned by the primary and secondary biomass productivity of the environment and the structure and distribution of resources. The success with which hunter-gatherers exploit these resources depends in part on the strategies employed in their procurement and the effectiveness of the weapons and tools used in procurement and processing activities and tasks. A number of factors may constrain tool manufacture and morphology including function, raw materials, manufacture technology, and the economics of production and use (Hayden et al. 1996). Desired improvements in labor efficiency also can lead to the adoption of new or improved tool forms (Aldenderfer 1990:63-65).

Parry and Kelly (1987) have previously suggested that the manufacture of tools is in part conditioned by raw material availability and group mobility. They have argued, however, that once raw material availability is not a constraining factor, the more mobile a group is the more likely that it will be equipped with formal tool forms and the less mobile, the more likely that expedient tool forms will dominate its tool assemblages. Tomka (2001) on the other hand, suggested that the design of a tool is most likely conditioned

Table 8-6. Core Attributes by Four Temporal Periods at 41TV163

\begin{tabular}{|l|c|c|c|c|c|}
\hline Analytical Unit & \% Non-cortical & \% Multidirectional & Median Wt. (gr.) & Median \# of Scars & Number of Cores \\
\hline Early Archaic & $33 \%$ & $66 \%$ & 51.8 & 11 & 3 \\
\hline Middle Archaic & $22 \%$ & $44 \%$ & 41.1 & 4 & 9 \\
\hline Late Archaic & $46 \%$ & $46 \%$ & 49.3 & 4 & 13 \\
\hline Late Prehistoric & $54 \%$ & $85 \%$ & 35.7 & 8 & 13 \\
\hline
\end{tabular}


not by mobility per say but the amount of work that needs to be carried out with the tool and the time constraints within which these activities have to be carried out. That is, low to moderate levels of activities that occur on a daily basis (i.e., food processing) and have no time constraints can be carried out with expedient tools that are in many instances very effective in short duration tasks. The performance of repetitive tasks for an extended time is more effectively carried out with hafted tools that allow exertion of greater force for longer periods and with less hand/finger strain.

The two theoretical approaches have different implications for interpreting hunter-gatherer mobility, labor organization, and subsistence strategies based on the ratios of formal versus expedient tool forms noted in archeological assemblages. In the first instance (Parry and Kelly 1987), and assuming readily available raw materials, high proportions of expedient tool forms should suggest a high degree of sedentism, while a high proportion of formal tools would indicate high rates of mobility (i.e., distance and number of moves). In the second instance (Tomka 2001), high proportions of expedient tools would suggest low processing rates that are dispersed over time, while high numbers of formal tool forms would indicate increased levels of activity and greater temporal constraints.

Artifact discard and replacement strategies represent an additional aspect of technological organization that is conditioned by broader aspects of land use. Binford (1979) has suggested that within contexts of bulk resource procurement constrained by the temporary seasonal availability of high ranking resources, there is such a premium on resource acquisition that hunter-gatherers will gear up, that is, manufacture replacement gear, in advance of the need for this gear to allow greater expenditure of time and energy into resource acquisition rather than tool repair and/or replacement. Such a strategy manifests not only in terms of the timing of the manufacture and repair activities but also the design of the tools and tool repair strategies such as the use of over-designed reliable tools and tools composed of multiple modular components that facilitate the removal and replacement of failed components (Bleed 1986). In contrast, in contexts where resource procurement occurs on a daily basis, in part because the resources being procured are not seasonal and acquisition is not concentrated into a single season, there are ample opportunities to repair and/or replace failed weapon parts at the end of each day's hunt. These two approaches to tool replacement and repair should have dramatically different archeological manifestations, particularly in terms of projectile point technology since these artifacts/components are the ones that are most likely to fail within compound weapon systems.

Based on these general propositions, we assume that under conditions of time stress, tool repair will consist of the discard of failed points and their replacement with new specimens rather than the rejuvenation of failed specimens. It is also possible that under these circumstances, some degree of preventive tool replacement may also be practiced. That is, tools that are already heavily rejuvenated and/or near "exhaustion" may be replaced even if they have not yet failed in order to prevent their failure at a time when their repair and/or replacement takes away time from more important activities such as resource procurement. In contrast, within the context of daily procurement of resources available year-round, we assume that it is likely that failed components such as projectile points will be rejuvenated rather than discarded. Therefore, we would expect that under the first instance, we should recover projectile points with longer remaining use life as well as heavily rejuvenated but complete projectile points discarded prior to failure. In the second instance, we expect to recover projectile points with shorter remaining use lives (i.e., heavily rejuvenated) and fewer complete points discarded before failure.

To investigate the aforementioned aspects of technological organization and projectile technology, we first categorized all chipped lithic tools identified within the lithic collections from the analytical units into functional (i.e., projectile point, chopper, drill, graver, knife, scraper, multi-functional) and formal (i.e., bifaces, cores) categories. The classification of the sample into functional categories was based on a combination of macroscopic and low-power (20X-40X) microscopic analysis. Use-modified flakes (i.e., some expedient tools) were categorized into scrapers, knives, and/ or gravers based on the location of edge modification and characteristics of microflake scarring (Tringham et al. 1974). Retouched tools (i.e., unifacial and bifacial knives, scrapers) were classified into functional categories following the detailed scan of the working edges of the tools under 20X and 40X magnification. A Southern Precision Instruments binocular microscope (Model 1892-TL) was employed. On incomplete specimens, break cause was also assessed and considered as an indicator of whether a tool had been used or not. Break cause (i.e., use break, manufacture break, postdepositional break) was assessed through a comparison of the archeological specimens with a comparative collection.

Table 8-7 presents the composition of the lithic assemblages within the four analytical units (AUs) defined in Chapter 6. 
Miscellaneous bifaces are the single most common artifact category in each analytical unit. Dart points are the second most common tool type in all analytical units except AU 4 (Early Archaic) where scrapers are more common than projectile points. Scrapers are the third most numerous artifact category in all AUs except AU 1 (Late Prehistoric) where cores are slightly more common. With the exception of gravers that occur in three of the four AUs, other tool categories are infrequent. Overall, the diversity of functional classes is very limited although the overall sample sizes of chipped lithic artifacts is relatively small within the AUs.

To address issues of technological organization, next we categorized each tool into one of three categories reflective of the degree of reduction of the parent material or core used in tool manufacture. Formal tools are made through the extensive retouch of parent materials or cores. Minimally retouched tools are made by the removal of few flakes from and minimal alteration of the parent material or core. Expedient tools represent the use of unmodified lithic debitage. All projectile points are classified as formal tools; the classification of all other tools recovered from the site is presented in Table 8-8.

A look at the table indicates that formal tools are absent from AU 1 and are infrequent in the collections from the other AUs. The majority of the few formal tools are scrapers. Minimally retouched tools outnumber all other forms in AU 1, while expedient tools outnumber all others in AU 3. In contrast, minimally retouched and expedient tools occur in equal or nearly equal frequencies in AUs 2 and 4. These figures seem to suggest some changes in the amount of time and energy invested in non-projectile point tool manufacture through time, especially as it involved the making of scrapers. The sample size in the earliest of the analytical units (AU 4, Early Archaic) is too small for adequate interpretation, however, it appears that during the Middle Archaic (AU 3) the emphasis was on the use of unmodified debitage for expedient tools. During the Late Archaic (AU 2) nearly as many tools were made through minimal retouch as expedient tools being used. By the Late Prehistoric period, minimally retouched tools (i.e., scrapers) were fulfilling most tool needs, at least in terms of scraping tasks. Although formal tools are infrequent, the aforementioned pattern does suggest a trend through time of greater investment in tool manufacture during the Late Archaic and Late Prehistoric periods compared to preceding times.

To further explore these patterns, we calculated ratios for several artifact categories by analytical unit (Table 8-9). The ratio of expedient to formal tools, not including projectile points, ranges from a low of 1.5:1 in AU 4 to a high of 15:1 in AU 3 (Table 8-9). The Middle Archaic assemblage has the highest expedient to formal tool ratio, although AU 1, the Late Prehistoric unit, has no formal tools other than projectile points. The trend in expedient and minimally retouched tools was mentioned above and is reaffirmed in the ratio of expedient and minimally retouched tools by analytical unit. The ratio of projectile points to other formal tools is highest in the Middle Archaic analytical unit (AU 3) but projectile points significantly outnumber other formal tools in all AUs except AU 4. This predominance of projectile points suggests heavy emphasis on hunting activities or at least the discard of failed components of the hunting weaponry while at the site. The ratio of miscellaneous bifaces to cores is indicative of the proportion of bifacial reduction versus core reduction at the site. As indicated earlier (Table 8-6), the majority of the core reduction is multidirectional. It is clear from the ratios that bifacial core reduction, or the manufacture of bifaces, was

Table 8-7. Lithic Assemblage Composition by Analytical Unit

\begin{tabular}{|l|c|c|c|c|c|}
\hline $\begin{array}{c}\text { Artifact Class } \\
\text { (Late Prehistoric) }\end{array}$ & $\begin{array}{c}\text { AU 2 } \\
\text { (Late Archaic) }\end{array}$ & $\begin{array}{c}\text { AU 3 } \\
\text { (Middle Archaic) }\end{array}$ & $\begin{array}{c}\text { AU 4 } \\
\text { (Early Archaic) }\end{array}$ & Total \\
\hline Projectile Points & 30 & 40 & 30 & 3 & 103 \\
\hline Other Tools & & & & & \\
\hline choppers & 2 & 1 & & & 3 \\
\hline drill & & 1 & & & 1 \\
\hline graver & 5 & 2 & 5 & & 12 \\
\hline knives & & 4 & 3 & 1 & 8 \\
\hline scraper & 11 & 23 & 12 & 6 & 52 \\
\hline multi-functional & & 2 & 1 & 1 & 4 \\
\hline Misc. Bifaces & 67 & 72 & 39 & 20 & 198 \\
\hline Cores & 13 & 13 & 9 & 3 & 38 \\
\hline
\end{tabular}


Table 8-8. Breakdown of Non-projectile Point Tools by Manufacture Type within Analytical Units

\begin{tabular}{|c|c|c|c|c|c|c|c|}
\hline AU/Manufacture Type & Chopper & Graver & Scraper & Knife & Drill & $\begin{array}{c}\text { Multi- } \\
\text { functional }\end{array}$ & Total \\
\hline \multicolumn{8}{|l|}{ AU 1 (Late Prehistoric) } \\
\hline Formal & & & & & & & 0 \\
\hline Minimally Retouched & 2 & 1 & 10 & & & & 13 \\
\hline Expedient & & 4 & 1 & & & & 5 \\
\hline \multicolumn{8}{|l|}{ AU 2 (Late Archaic) } \\
\hline Formal & & & 3 & & 1 & & 4 \\
\hline Minimally Retouched & 1 & 1 & 11 & & & 1 & 14 \\
\hline Expedient & & 1 & 9 & 4 & & 1 & 15 \\
\hline \multicolumn{8}{|l|}{ AU 3 (Middle Archaic) } \\
\hline Formal & & & 1 & & & & 1 \\
\hline Minimally Retouched & & 1 & 3 & 1 & & & 5 \\
\hline Expedient & & 4 & 8 & 2 & & 1 & 15 \\
\hline \multicolumn{8}{|l|}{ AU 4 (Early Archaic) } \\
\hline Formal & & & 2 & & & & 2 \\
\hline Minimally Retouched & & & 1 & 1 & & 1 & 3 \\
\hline Expedient & & & 3 & & & & 3 \\
\hline Total & 3 & 12 & 52 & 8 & 1 & 4 & 80 \\
\hline
\end{tabular}

Table 8-9. Selected Artifact Ratios by Analytical Units

\begin{tabular}{|l|c|c|c|c|}
\hline Artifact/Tool Category & AU 1 & AU 2 & AU 3 & AU 4 \\
\hline expedient : formal tools & - & $3.75: 1$ & $15: 1$ & $1.5: 1$ \\
\hline expedient : minimally retouched tools & $.38: 1$ & $1.1: 1$ & $3: 1$ & $1: 1$ \\
\hline projectile points : formal tools & - & $10: 1$ & $30: 1$ & $1.5: 1$ \\
\hline miscellaneous bifaces : cores & $5.2: 1$ & $5.5: 1$ & $4.3: 1$ & $6.7: 1$ \\
\hline miscellaneous bifaces : projectile points & $2.2: 1$ & $1.8: 1$ & $1.3: 1$ & $6.7: 1$ \\
\hline
\end{tabular}

much more common than the reduction of cores for the production of flake blanks. This pattern may be explainable for the Archaic analytical units since most of the projectile points are made through bifacial reduction of nodular or flake cores. However, the arrow points that make up the bulk of the Late Prehistoric (AU 1) projectile points could be made on flake blanks removed from multidirectional cores. Therefore, the high ratio of bifaces to cores suggests that the miscellaneous bifaces recovered in AU 1 may represent the manufacture of large bifacial tool forms such as knives. However, no bifacial knives have been recovered from this AU.

Even more interesting is the pattern in the miscellaneous biface to projectile point ratios (Table 8-9). Miscellaneous bifaces (i.e., those that broke during manufacture and/or could not be classified into a functional category) outnumber projectile points in all analytical units. The ratio of bifaces to projectile points is highest in AU 4 where nearly seven bifaces are present for every projectile point. The ratio of bifaces to points is only slightly in favor of bifaces in AU 3 , however, bifaces outnumber points almost 2:1 in AU 2 and more than 2:1 in AU 1.

To further investigate this pattern, we sought to classify the miscellaneous biface sample into stages of reduction based on width/thickness (w/t) ratios and mean edge angle measurements (Callahan 1979). Only 131 of the 198 miscellaneous bifaces from AUs were sufficiently complete to measure maximum width and thickness and both edge angles (right and left edges). Of these, 10 came from AU 4, 26 came from $\mathrm{AU}$ 3, 49 were from $\mathrm{AU}$ 2, and 46 were from $\mathrm{AU} 1$. Based on patterning within the width/thickness ratio and the mean of the two edge angles, the 131 bifaces were grouped into early, middle, and late reduction stage specimens. The early reduction stage specimens have $\mathrm{w} / \mathrm{t}$ ratios of less than 3 and mean edge angles that are greater than or equal to 40 . Middle reduction stage specimens have mean edge angles that are less than 40 and $w / t$ ratios from 3-4.4. Late reduction stage specimens have $\mathrm{w} / \mathrm{t}$ ratios that exceed 4.5 . 
Table 8-10 presents the breakdown of the bifaces into reduction stages by analytical unit. It also compares the distributions using adjusted residuals (Everitt 1977). Adjusted residual values that are higher than 1.96 or lower than -1.96 are statistically significant at the .05 level of significance and appear in bold in the table. It is evident that early reduction stage bifaces are over-represented in AU 4 indicating that more than expected early reduction stage bifaces were discarded in this analytical unit. Recall that bifaces outnumber projectile points more than $6: 1$ in this AU. On the other hand, fewer than expected late reduction stage bifaces were discarded in AU 3, the Middle Archaic analytical unit. Here the number of miscellaneous bifaces is only slightly more than the number of projectile points (39 to 30). Finally, in contrast to AU 3, late reduction stage bifaces are over-represented in AU 2, the Late Archaic analytical unit, where nearly two bifaces are present for every projectile point (72 to 40 ).

Given that no formal bifacial knives have been recovered from the AUs examined, could it be that all miscellaneous bifaces represent the replacement of failed projectile points or is their numeric abundance an indicator of gearing up manufacture for future use? The answer to this question is difficult to determine. However, when we consider that in AUs 1 and 2 nearly twice as many bifaces are being manufactured than points, it is likely that many more points are being made than necessary for projectile point replacement. We cannot determine the reason for the large number of bifaces, however, it is likely that while some were intended to replace failed points, others were likely taken off site either in the form of curated projectile points or some other bifacial tool form.

We mentioned earlier that the strategies employed in tool replacement and rejuvenation, and specifically projectile point rejuvenation and replacement, may be related to broader aspects of land use and subsistence. To investigate this possibility, we measured the blade length and maximum blade width of each projectile point that could be assigned to a specific period. Blade length was measured on both complete and fragmentary specimens to ascertain how much of the blade was present on the specimen at the time of discard. Maximum blade width also was measured on each specimen. It was assumed that points broken during seasonal bulk procurement hunts would not be refurbished but rather discarded and replaced with new specimens. On the other hand, we assumed that other points broken on day-to-day hunts would be refurbished daily so that when finally discarded, such points would have both shorter and narrower blades.

Table 8-11 shows the mean remnant blade length and mean remnant blade width of projectile points by analytical unit. It is evident that Middle Archaic points have the longest remnant blade lengths, while not surprisingly, that Late Prehistoric arrow points have the shortest remnant blade lengths. Middle and Late Archaic points have the broadest remnant blades at discard, while arrow points have the narrowest blades at the time of discard. The longer remnant blade length and wider remnant blade of Middle Archaic points suggests that they were discarded without extensive rejuvenation perhaps in the context of rapid replacement of failed specimens. On the other hand, the significantly shorter-bladed Late Archaic specimens suggests that these points were rejuvenated repeatedly to reduce their remnant blade length.

Because several distinct projectile point types are lumped as Late Archaic, we decided to explore remnant blade lengths at the type level to establish any differences between types. Table 8-12 lists mean remnant blade length and mean remnant blade width for several of the Late Archaic and two Middle Archaic types found at 41TV163. It is clear that the three youngest point types (Darl, Ensor, and Fairland) have the shortest combined remnant blade lengths $(19.4 \mathrm{~mm})$. The seven next oldest Late Archaic points (Marcos-Bulverde) have a combined mean remnant blade

Table 8-10. Breakdown of Bifaces by Reduction Stage and Adjusted Residual Values

\begin{tabular}{|l|c|c|c|c|c|c|c|c|c|}
\hline & \multicolumn{2}{|c|}{ Late Prehistoric } & \multicolumn{2}{c|}{ Late Archaic } & \multicolumn{2}{c|}{ Middle Archaic } & \multicolumn{2}{c|}{ Early Archaic } & $\begin{array}{c}\text { Adjusted } \\
\text { Residual }\end{array}$ \\
\cline { 2 - 11 } Reduction Stage & Count & $\begin{array}{c}\text { Adjusted } \\
\text { Residual }\end{array}$ & Count & $\begin{array}{c}\text { Adjusted } \\
\text { Residual }\end{array}$ & Count & $\begin{array}{c}\text { Adjusted } \\
\text { Residual }\end{array}$ & Count \\
\hline Early & 9 & -1.23 & 11 & -0.71 & 8 & 0.63 & 6 & $\mathbf{2 . 5 6}$ & 34 \\
\hline Middle & 25 & 1.31 & 19 & -1.38 & 15 & 1.27 & 2 & -1.75 & 61 \\
\hline Late & 12 & -0.26 & 19 & $\mathbf{2 . 2 4} *$ & 3 & $\mathbf{- 2 . 0 3}$ & 2 & -0.55 & 36 \\
\hline Total & 46 & & 49 & & 26 & & 10 & & 131 \\
\hline
\end{tabular}

* Bolded values are statistically significant at the .05 level of significance. 
Table 8-11. Mean Blade Length and Blade Width by Temporal Period

\begin{tabular}{|l|c|c|c|c|}
\hline Period & $\begin{array}{c}\text { Mean Remnant } \\
\text { Blade Length }\end{array}$ & Sample Size & $\begin{array}{c}\text { Mean Remnant } \\
\text { Blade Width }\end{array}$ & Sample Size \\
\hline Early Archaic & 33.9 & 11 & 25.5 & 11 \\
\hline Middle Archaic & 40.5 & 39 & 28.1 & 37 \\
\hline Late Archaic & 30.7 & 189 & 28 & 184 \\
\hline Late Prehistoric & 14.6 & 85 & 14.2 & 72 \\
\hline
\end{tabular}

length of $32.8 \mathrm{~mm}$. The two Middle Archaic points (Nolan and Travis) have a combined mean remnant blade length of $40.2 \mathrm{~mm}$. The mean remnant blade width of the three youngest types (Darl, Ensor, and Fairland) is $21.6 \mathrm{~mm}$, while the seven next oldest Late Archaic points (MarcosBulverde) have a combined mean remnant blade width of $31.7 \mathrm{~mm}$. Finally, the two Middle Archaic points in the table have a combined mean remnant blade length of $27.6 \mathrm{~mm}$. Again, the combined pattern obtained from the mean remnant blade lengths is that Middle Archaic as well as early Late Archaic points in general are discarded while retaining longer use lives than their later counterparts. Although early Late Archaic specimens are generally discarded with narrower blade lengths than their later counterparts, Middle Archaic specimens in general have broader blades at the time of discard than at least some of their Late Archaic counterparts. While the broad-bladed point types such as Marshall, Montell, Castroville, and Marcos have longer and broader blades than the later Late Archaic types (i.e., Ensor), we do not see a technological or functional reason why they would not be reduced to the same degree as the smaller types, especially since the presence of the smaller forms demonstrate that they also were effective weapon components. Rather, we assume that the differences in remnant blade lengths and widths indicates different approaches to projectile point rejuvenation conditioned by differences in resource availability and structure.

The final two aspects of projectile technology concern the proportion of complete projectile points and stem fragments being discarded by time period and within selected point types. Table 8-13 shows the breakdown of complete specimens and stem fragments by time period. The first aspect bespeaks of the rate of preventive discard that may be practiced by a group, while the second aspect documents a design weakness in a projectile point (i.e., the neck). It is evident that the Middle Archaic has the highest rates of complete point discard, while Late Archaic and Late Prehistoric collections retain the lowest rates among the three largest samples. The small Early Archaic collection has no stem fragments but the percentage of stem fragments increases in each of the subsequent time periods.

Table 8-12. Mean Blade Length and Blade Width for Selected Point Types

\begin{tabular}{|l|c|c|c|c|}
\hline Type & $\begin{array}{c}\text { Mean Remnant } \\
\text { Blade Length }\end{array}$ & Sample Size & $\begin{array}{c}\text { Mean Remnant } \\
\text { Blade Width }\end{array}$ & Sample Size \\
\hline Darl & 22.7 & 42 & 18.3 & 39 \\
\hline Ensor & 22 & 13 & 24.2 & 12 \\
\hline Fairland & 13.4 & 23 & 22.2 & 16 \\
\hline Marcos & 35.3 & 4 & 33.8 & 4 \\
\hline Castroville & 35.5 & 7 & 37.8 & 7 \\
\hline Montell & 35.7 & 11 & 29 & 11 \\
\hline Marshall & 28.4 & 6 & 28.9 & 4 \\
\hline Lang & 33.5 & 23 & 32.4 & 23 \\
\hline Pedernales & 34.4 & 50 & 31.7 & 46 \\
\hline Bulverde & 26.8 & 13 & 28.7 & 11 \\
\hline Nolan & 44.1 & 24 & 29.5 & 24 \\
\hline Travis & 36.3 & 14 & 25.8 & 13 \\
\hline
\end{tabular}


Table 8-14 presents the numbers and percentages of complete points and stem fragments within selected Late Archaic (Darl, Ensor, Fairland, Marcos, Castroville, Montell, Marshall, Lange, Pedernales, and Bulverde) and Middle Archaic (Nolan and Travis) points. An examination of the table will show that, on average, few complete specimens are discarded among the three youngest Late Archaic point types (mean=9\%). On the other hand, among the next seven Late Archaic types (Marcos-Bulverde), an average of $16 \%$ of the specimens discarded are complete. The highest percentages occur among the Marcos and Pedernales points. Finally, among the Middle Archaic points, an average of $26 \%$ of the projectile points are complete at the time of discard. The pattern of projectile point failure at the neck suggests that Darl and Fairland points tend to be structurally weak at the neck with $7 \%$ to $30 \%$ of these points, respectively, failing at the neck during use. The neck failure rates among older Late Archaic points tend to be similar to Darl points.
Overall, the study of remnant blade lengths at discard, as well as the percentages of discarded points suggests that younger Late Archaic points tend to be discarded more heavily reduced than older Late Archaic types, which in turn tend to be complete or to have longer blade remnants than their Middle Archaic counterparts. This pattern matches expectations within the Late Archaic sample since we tend to see a correlation between the exploitation of medium body sized animals during the later part of the Late Archaic correlating with well-used (i.e., reduced, rejuvenated) projectile points and less rejuvenation of projectile points and preventive maintenance through the discard of complete points earlier in the Late Archaic when bison were present within the state. However, the fact that Middle Archaic points show an even higher degree of preventive discard of complete points and have higher mean remnant blade lengths than all Late Archaic types suggests that tool replacement strategies may have had a gearing up component and, therefore, animal procurement may have had a seasonal component not hitherto suspected.

Table 8-13. Complete Specimens and Stem Fragments by Time Period

\begin{tabular}{|l|c|c|c|c|c|}
\hline Period & $\begin{array}{c}\text { Number of } \\
\text { Complete Points }\end{array}$ & $\begin{array}{c}\text { Percent of Total } \\
\text { Sample }\end{array}$ & $\begin{array}{c}\text { Number of Stem } \\
\text { Fragments }\end{array}$ & $\begin{array}{c}\text { Percent of Total } \\
\text { Sample }\end{array}$ & $\begin{array}{c}\text { Total } \\
\text { Sample Size }\end{array}$ \\
\hline Early Archaic & 1 & 9.1 & 0 & 0.0 & 11 \\
\hline Middle Archaic & 10 & 25.6 & 2 & 5.1 & 39 \\
\hline Late Archaic & 25 & 12.3 & 16 & 7.8 & 204 \\
\hline Late Prehistoric & 12 & 14.3 & 12 & 14.3 & 84 \\
\hline
\end{tabular}

Table 8-14. Number and Percent of Complete Points and Stem Fragments for Selected Point Types

\begin{tabular}{|l|c|c|c|c|c|}
\hline Type & $\begin{array}{c}\text { Number of } \\
\text { Complete Points }\end{array}$ & $\begin{array}{c}\text { Percent of Total } \\
\text { Sample }\end{array}$ & $\begin{array}{c}\text { Number of Stem } \\
\text { Fragments }\end{array}$ & $\begin{array}{c}\text { Percent of } \\
\text { Total Sample }\end{array}$ & $\begin{array}{c}\text { Total Sample } \\
\text { Size }\end{array}$ \\
\hline Darl & 7 & 16.7 & 3 & 7.1 & 42 \\
\hline Ensor & 0 & 0.0 & 0 & 0.0 & 13 \\
\hline Fairland & 0 & 0.0 & 7 & 30.4 & 23 \\
\hline Marcos & 1 & 25.0 & 0 & 0.0 & 4 \\
\hline Castroville & 1 & 14.3 & 0 & 0.0 & 7 \\
\hline Montell & 2 & 18.2 & 0 & 0.0 & 11 \\
\hline Marshall & 1 & 16.7 & 0 & 0.0 & 6 \\
\hline Lange & 1 & 4.3 & 0 & 0.0 & 23 \\
\hline Pedernales & 11 & 22.0 & 4 & 8.0 & 50 \\
\hline Bulverde & 1 & 7.7 & 1 & 7.7 & 13 \\
\hline Nolan & 8 & 33.3 & 0 & 0.0 & 24 \\
\hline Travis & 2 & 14.3 & 1 & 7.1 & 14 \\
\hline
\end{tabular}




\section{Summary and Conclusions}

In this chapter, our goal was to examine two aspects of the chipped lithic technology in the large collection of unmodified debitage, tools, and projectile points identified in the 41TV163 collection: raw material procurement and technological organization. To reconstruct raw material procurement strategies, we first defined local versus nonlocal materials based a series of attributes and broad debitage size classes in the 14 raw material groups represented in the debitage. Five raw material groups $(4,7,8,12$, and 17) appear to primarily represent non-local materials. An additional nine raw material groups $(1,2,3,5,6,10,11,15$, and 18) are of probable local origin. In general, the raw material procurement patterns indicate that non-local materials are over-represented in bifaces, points, and other tools relative to the number of non-local debitage. These patterns are consistent with the importation of non-local materials in an already reduced or finished form (i.e., bifaces, points, finished tools). In addition, the use of non-local materials also changes through time. Relatively low percentages of non-local materials are noted in the Early and Middle Archaic analytical units (4\% and 3.6\%, respectively). In contrast, the percentage of non-local materials more than doubles during the Late Archaic and Late Prehistoric periods.

The study of technological organization focused on two aspects of lithic technology, the composition of the tool assemblages and projectile point technology. Overall, expedient and minimally retouched tools dominate the tool assemblages. Formal tools, with the exception of projectile points, are infrequent. This aspect of the assemblage may be conditioned by the abundant availability of local materials and the even distribution of resource processing tasks within the broad-spectrum generalized foraging system practiced by the site's inhabitants. The large number of miscellaneous bifaces in contrast to the cores and projectile points present within the analytical units suggests that some tool manufacture may have been intended for purposes other than the on-site replacement of failed bifacial tools.

The analysis of the projectile technology indicates that there are significant differences in mean remnant blade length and the percentages of complete specimens within the Late Archaic and between the Late Archaic and Middle Archaic. Projectile point use tends to be relatively intensive around the end of the Late Archaic but it tends to exhibit a move toward greater preventive maintenance and less intensive rejuvenation during the earlier portion of the Late Archaic and the Middle Archaic. These patterns suggest that projectile technology and hunting patterns were changing through time, likely in response to changes in resource type and structure.

Finally, while the lithic assemblages discussed here derive from a type of site that is notorious for mixed contexts, and the materials were excavated over three decades ago, this analysis shows that productive research and new insights into prehistoric technology and human behavior can be gained from working with such materials. 



\title{
Chapter 9: Exploration of Feature 3 A Possible Late Prehistoric Structure at Millican Bench
}

\author{
Harry J. Shafer, Steve A. Tomka, and Raymond P. Mauldin
}

In summarizing the data recovered from Millican Bench in Chapter 5, we briefly reviewed the characteristics of Feature 3, the possible Late Prehistoric structure. A more detailed consideration and analysis of the evidence will be presented in the second part of this chapter. However, because the excavations occurred more than 30 years ago, we felt that relying purely on the archeological evidence at hand may severely limit the analytical potential of this possible structure. In consultation with TxDOT staff archeologists, it was decided that a more fruitful approach would consist of first summarizing the available ethnohistoric descriptions of residences and/or structures noted by early travelers among hunter-gathers inhabiting Texas and the surrounding regions. This information would, in turn, be used to define potential archeologically visible indicators of structures. Following the consideration of these two topics, we then summarize the existing evidence for archeologically excavated features interpreted as structures in the state. In the last section of the chapter, we review the characteristics of Feature 3 to ascertain whether it could represent the remains of a habitation structure.

\section{Dwellings among Hunter-Gatherers}

\section{Theory and Expectations}

What kinds of land-use and subsistence strategies practiced among traditional societies result in the construction and use of features and facilities that can be interpreted as residences? In pursuing answers to this question, Flannery (1972, 2002) defined three general patterns within the ethnographic record: (1) hunter-gatherers that built circular huts; (2) horticulturalists that also built circular huts; and (3) horticulturalists that built and resided in rectangular structures. Interestingly, these three patterns appear to be exemplified within the Texas ethnohistoric record. Cabeza de Vaca describes the use of circular huts among some of the highly mobile groups he encountered in south Texas, while the southern and prairie Caddo horticulturalists were using more substantial circular huts at the time of the Spanish entradas and first French contacts (Martin and Bruseth 1987; Perttula 1999; Peter and McGregor 1988). Finally, the Pueblo-like horticulturalist societies in the Jornada (Whalen 1980) and La Junta regions (Kelley 1986:72-77) constructed rectangular dwellings.
Although a multitude of constructed and naturally occurring facilities are likely to be used among hunter-gatherers as shelters, how substantial and durable a structure is may depend on the anticipated length of time the structure is to be used (Kent 1991:42; Smith 2003). Anticipated mobility may in turn be influenced by several factors including the abundance of foods within the area and perhaps factors such as group size and composition (Diehl and Gilman 1996). Therefore, it is likely that the architecture of highly mobile people exploiting a broad spectrum of low-productivity seasonal resources may be virtually invisible archeologically. However, the presence of highly productive r-selected resources (see Pianka 1970) and/or new technological means to intensively exploit such resources may lead to longer periods of seasonal sedentism within certain resource patches (c.f. Flannery 1969, 1986; Henry 1985), construction of more durable architecture, and greater archeological visibility. We would expect shelter use to be ubiquitous among huntergatherers. However, if the above generalizations are applicable, we would expect shelters to be more durable and of higher archeological visibility in regions of the state characterized by highly-productive r-selected resources (e.g., acorns, pecans) and succulents (prickly pears), and/or in areas where a variety of resources co-occur to form highly varied but productive resource patches. Portions of central Texas, south-central Texas, and perhaps the Lower Pecos may have offered such resources or combinations of resources as suggested by the apparent "broad spectrum" adaptation (Collins 1995:387-389) and of incipient territoriality characteristic in these regions (Hall 1998).

\section{The Ethnohistoric Evidence: Texas and the Surrounding Region}

While we offer some general expectations related to the use and archeological visibility of structures across the state, the primary archeological challenge of recognizing what archeological features represent shelters as opposed to other facilities (e.g., windbreaks, outdoor activity areas) still remains. In this section we provide an overview of ethnohistoric mentions of structures among hunter-gatherers in Texas and surrounding regions. From this overview, we derive a summary of the potential archeological indicators of structures that may aid in identifying the nature of Feature 3 at 41 TV 163. 
Fleeting references to architecture among hunter-gatherers of Texas and adjacent regions to the south and west provide only a hint of how these people lived (Berlandier 1969; Campbell 1988; Foster 1998; Griffen 1968; John 1989; Newcomb 1961; Ricklis 1988, 1994b; Wade 2003). For example, in the north-central Texas prairies, substantial circular structures with implanted posts were constructed in historic times among Caddoan speaking Wichita groups (Berlandier 1969:42-47; Davis et al. 1967; Newcomb 1961: 255; Smith et al. 1993). These structures, grouped into small villages, were occupied by groups who practiced mixed hunting and gardening subsistence (Newcomb 1961:253, 254). The mobility practiced by such groups constrained them to fixed residences that in turn were linked to productive garden patches of domesticated resources.

In contrast to these residentially constrained mobile groups (Graham 1994), it is likely that the structures constructed and used by hunter-gatherers not dependent on domesticated resources were much less durable. Based on the earlier generalizations, it is possible that at least in certain seasons mobile hunting and gathering groups in Texas and adjacent areas in northern Mexico may have not constructed structures when establishing encampments, but rather simply used the shade of trees (Fowler and Fowler 1971:Figures 12 and 21; Griffen 1968:106, 107). This would be especially true for groups who occupied an encampment for only a few days. Temporary structures involving hardly more than pole frameworks arranged in a semi-circle and covered with brush, mats, or hides have been described ethnographically for many groups in Texas, the Southwest, and northern Mexico (Berlandier 1969:42, 43; Campbell 1988; Griffen 1968:106-107; John 1989:58; Newcomb 1961:43; 68; and illustrated by Fowler and Fowler 1971:Figures 12 and 21; see Figure 9-1). In some instances, these structures were collapsible and moved from camp to camp (Newcomb 1961:43, 68). In others, the ends of poles were stuck in the ground, bent, and tied with thongs (Newcomb 1961:68). Interiors were variously floored with mats, Spanish moss (where available), and skins. Hearths for warming and heating were placed in the approximate center or toward the entrance. Trash was discarded and apparently accumulated directly on the floors (De Mésières' description of Wichita houses in Bolton 1914:294; Dyer 1917 cited in Newcomb 1961:325).

Griffen (1968:106) reports on the various tribes and bands of seventeenth- and early-eighteenth-century Native Americans living in present-day states of Nuevo León, Coahuila, and Chihuahua. Apparently little information on specific house types is contained in the various Spanish archives reviewed by Griffen (Archivo General de la Nación, México, D.F.; Archivo de Hidalgo del Parral, Parral, Chihuahua; and Documentos para la Historía de México). Brief descriptions include skin-covered huts (jacales) of the Cocoyomes and Sisimbles, "little" huts (jacalillos) of the Salineros, and "small huts in the form of caves" (chosuelas a manera de cuebas) of an unnamed band (Griffen 1968:106). Kirchhoff (1944:138) similarly indicates that some hunter-gatherer groups in northern Mexico did not construct shelters but slept in the open or in caves. At least some hunter-gathers in Nuevo León erected beehive-shaped shelters covered with grass and these huts were grouped in semi-circles within camps. Saldivar (1943:12) also describes Tamaulipan hunter-gatherers as having no built shelters.

\section{Diagnostic Indicators of Prehistoric Structures}

Based on the preceding review of the meager evidence, and supplemented by additional observations on hunter-gatherer site structure from the general hunter-gatherer literature, we may surmise that a mobile hunter-gatherer structure may possess one or more of the following elements: postholes or other indicators of superstructure elements; central hearths; wattle-impressed daub; burials; differential distributions of artifacts within and outside structures; activity area maintenance; and distinct household trash/ midden deposits. Any one of these elements could alert the archeologist to the possible presence of a structure.

\section{Postholes and Other Indicators of Superstructure}

It is possible that dome-shaped huts constructed by the bending of poles together at the center of the hut may require the placement of poles into the ground or may require securing of the poles since lateral tension may otherwise force these poles apart. Such constraints may result in postholes and concentrations of support rocks encircling each post. The groupings of postholes and/or support rocks would tend to form an oval pattern. However, the poles of A-frame structures may be placed on the surface of the ground because little lateral tension exists on these elements to separate them under the weight of covers. In this case, at best only concentrations of support rocks may exist in association with each pole. The support stones may form a circular pattern. Exceptions to this pattern may exist under windy conditions since without the stabilization of support poles heavy winds may push over A-frame conical structures.

In addition, superstructure elements that consist of skins may require the support of the bottoms of the hides at ground 
level. This may be best accomplished by a series of rocks placed at regular distances from each other around the outer edge of the structure. Conversely, such support may be provided by a ring of soil piled on the skins around the outside of the structure.

Although the construction of windbreaks and "lean-to" facilities can result in postholes, it is likely that the arrangement of the holes and/or support rocks will not be in full circles and oval shapes but would rather be semi-circular in arrangement.

\section{Central Hearth Features}

Although by no means a universal pattern (Yellen 1977), hearth features often occur within shelters built and used by huntergatherers (Fisher and Strickland 1991). Interior hearths may be necessary to keep warm during inclement weather and/or for food preparation when this cannot be accomplished outdoors. Depending on the extent of indoor activities, interior hearths may be rather small and circumscribed either within basins or stone-lined depressions to confine ash and charcoal and reduce the chances of accidental fires and injury. Because of frequent use, these interior hearths often contain white wood ash that is regularly cleaned and removed to refuse middens often located on the perimeter of camps (Fisher and Strickland 1991).

It is assumed that because these hearths are within circumscribed intensively used spaces, they would be systematically maintained and the space around them would be kept relatively free of refuse, charcoal and ash. Conversely, isolated outdoor hearths or hearths associated with windbreaks tend to be larger in size and use-related refuse tends to be less systematically removed due to less interference with hearth-associated and other activities. Because such hearths would tend to be the focal points for many activities including food preparation, consumption, and tool repair, it is likely that artifacts associated with these activities would be commonly found in the immediate vicinity of such outdoor hearths. A variant of outdoor hearths was described by Berlandier (1969) in proximity to structure entrances. These hearths were used during the summer to control insects.

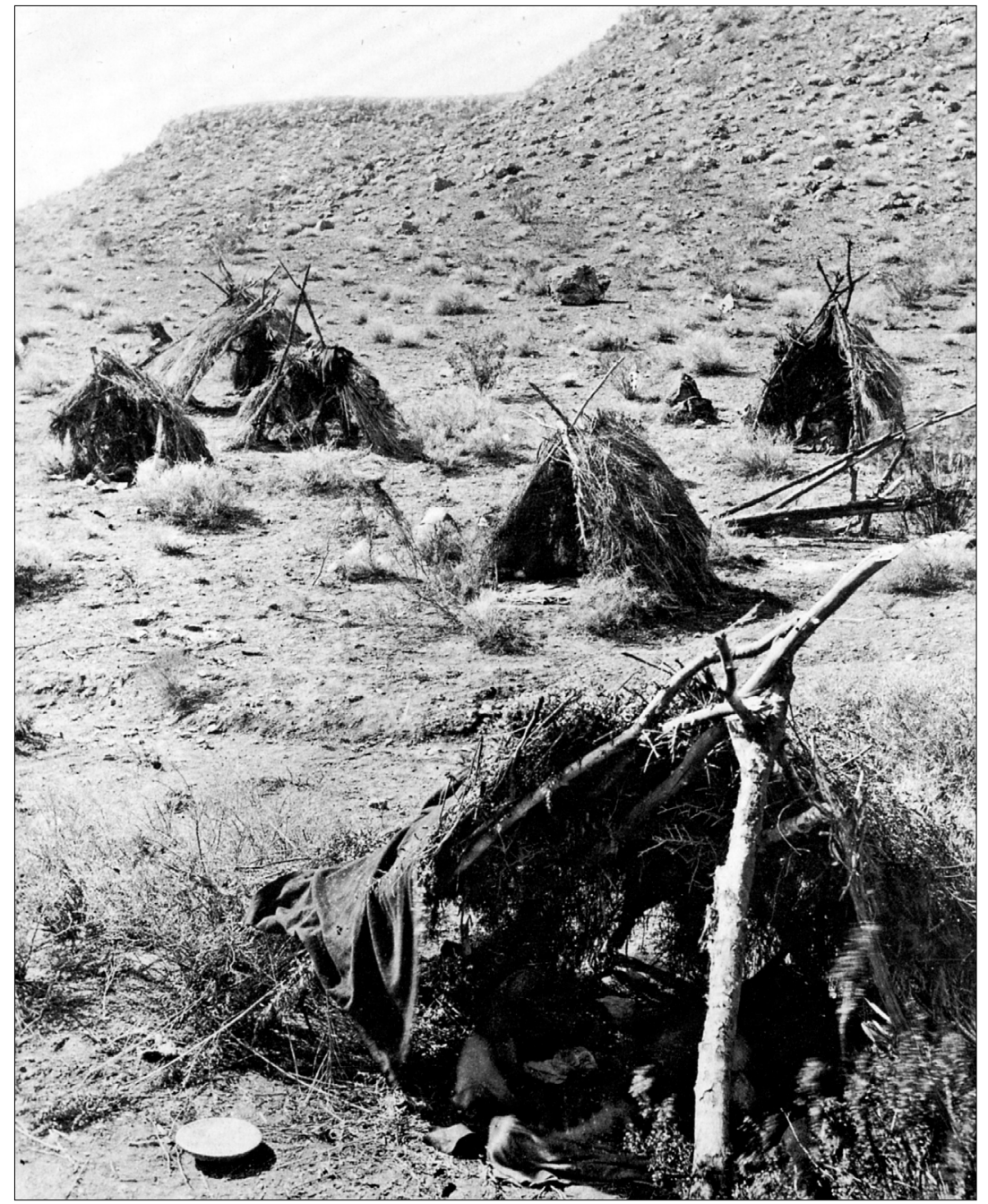

Figure 9-1. Numa encampment of brush shelters near St. George, Utah, 1873. (J. K. Hillars photograph, 1873; Smithsonian Institution, National Anthropological Archives, George V. Allen Photographic Collection, Photo Lot 90-1, No. 279.)

Finally, indoor hearths may be distinguished from outdoor features based on their white ash content. It is suggested that indoor hearths provide a slow, complete combustion and reduce the fuel to a white ash. Outdoor fires, fed with ample oxygen, burn quicker and are more likely to leave dark ash and charcoal residue.

\section{Wattle-impressed Daub}

It is not expected that highly mobile hunter-gatherers constructed shelters with wattle insulated walls unless they operated within a residentially constrained land-use system. Such labor output would be out of line with the length of anticipated site use under most subsistence strategies reliant on wild resources. It should, therefore, not be surprising 
that the use of clay as insulation in brush and grass-covered structures is documented ethnohistorically only among east Texas horticulturalists (Bell et al. 1967:320). When such structures burn, the clay is fired to create daub with stick and grass impressions. The existence of a structure is suggested by the presence of wattle-impressed daub (Brewington et al. 1995:54-56; Story 1965). Wattleimpressed daub was recovered at the Baylor Site in McClennen County (Story and Shafer 1965), and Shafer (personal notes) recorded a burned daub structure exposed in the bank of Elm Creek east of Troy, Texas in northern Bell County. La Harpe, in 1719, described Wichita houses constructed of grass and reeds and plastered with earth (Margry 1888:Part 6, 294-295, cited in Bell et al. 1967:320). De Mésières also mentions Wichita houses as being made of earth (Bolton 1914:294).

\section{Burials}

Burials have not been characteristically associated with habitation space in central Texas except for rockshelters. The Late Prehistoric mortuary pattern generally involves isolated interments placed beneath rock cairns in a flexed or semi-flexed position in rockshelters or open-air sites. Formal open-air cemeteries were excavated at Loeve-Fox (Prewitt 1974) and Pat Parker (Greer and Benfer 1975). Sinkholes also were apparently extensively used throughout the karstic limestone region of the Edwards Plateau (Bement 1994; Benfer and Benfer 1981). Burials do occur within round structures in the southern Caddo area (e.g., Brewington et al. 1995; Good 1982; Kelley 1994).

\section{Differential Patterns in Artifact Distributions Within and Outside Structures}

Because a variety of activities may be carried out within the confined space of a shelter, it is assumed that the floor surface is regularly maintained or swept to remove refuse that may interfere with the performance of activities. Whether such maintenance is simply the picking up of the larger trash by hand or the sweeping of the floor, it is likely that it will tend to result in the removal of the majority of the larger size classes of refuse. Either practice may leave behind the majority of a wide variety of small refuse that escapes notice or may be buried in the soft matrix of the floor. In addition, areas adjacent the wall of the structure may be incompletely cleaned because of interference from temporarily stored items. Therefore, it is expected that interior spaces surrounding hearths should be relatively free of large refuse and dominated by small debris. A range of debris sizes may be present at some distance from the central hearth indicative of debris accumulated against the wall of the shelter.
Outdoor activity areas immediately adjacent to structures should exhibit a wide variety of refuse, a range of refuse sizes, and general lack of maintenance, depending on the length of occupation and the nature of that outside use. Outdoor activity areas with hearths may exhibit a drop zonetoss zone refuse distribution pattern with minimal formal activity area maintenance (Binford 1978).

\section{Household Middens or Sheet Scatters}

The patterns of household trash disposal vary according to site type and socio-cultural complexity. These patterns range from formally depositing trash in specifically designated midden deposits, informally sweeping trash off of residential platforms, to merely tossing trash adjacent to the activity area.

For hunters and gatherers, however, the situation is much different. Campsites are often temporary, and disposal of household trash and garbage is casual and in the immediate vicinity of the activity (Binford 1983:144-192). In outdoor activity areas, debris resulting from household activities is tossed away from the seated activity area forming a semicircular or circular toss zone. When indoor or outdoor activity areas and/or facilities are maintained, the resulting debris is disposed of in proximity of the dwellings and on the perimeter of the camp (Fisher and Strickland 1991:Figure $2,220)$. For rockshelters, this deposition often occurred out in front of the shelter, but not always (e.g., Henderson 2001). At Hinds Cave, extensive latrine deposits were found inside the sheltered area downslope from the main habitation area. Grass beds and white ash deposits were found in the main habitation area (Shafer 1986:97, 98; Shafer and Bryant 1977). Midden accumulations would be concentrated in the vicinity of the dwellings and at the periphery of the camp. With the absence of physical evidence for dwellings, the location of dwellings can be inferred by the presence and distribution of household trash, especially bone scraps, formal and expedient tools, and evidence of tool refurbishing (broken and discarded points and retouch debitage).

\section{Archeological Examples of Structures}

Archeological evidence for hunter-gatherer structures is found across several areas of the state, from north-central Texas (Peter and McGregor 1988), the southern Plains (Boyd 1993), and the Trans-Pecos region (Mallouf 1999; Ohl and Cloud 2001; Seymour 2003; Turpin 1995). Unequivocal evidence from central Texas, however, is elusive. Features interpreted as structures have been documented at the Lion Creek Site (Johnson 1997), the Graham/Applegate Site (Hixson 2003), the Slab Site 
(Patterson 1987), and the Turkey Bend Site (Lintz et al. 1995). Ash-filled central hearth features, postholes, and debris patterns were interpreted as evidence for structures at the Longhorn Site (Boyd 1993). Patterns of midden accumulation also have been used to argue the presence of structures at Buckhollow (Johnson 1994), Rowe Valley and Loeve-Fox sites (Prewitt 1982:188-208, 1984).

Johnson (1997) and Lintz et al. (1995) have provided summaries of extant data on possible house structures in central Texas and in the surrounding region. The summary of archeological examples of house structures follows the outline provided by Lintz et al. (1995). These authors define four types of archeological signatures indicative of structures. Type 1 structures lack physical evidence such as postholes, central hearth features, and cobble alignments. Instead, Type 1 structures are inferred on the basis of artifact and material distributions. Type 2 structures have posthole patterns, wall trenches, and central hearth features with ash. Type 3 structures consist of circular alignments of cobbles consistent with tipi or wiki-up rings documented historically. Type 4 structures consist of rock-paved central hearth features surrounded by rock piles or clusters. Archeological examples of each of these proposed structure types will now be presented.

\section{Type 1}

Artifact scatters on possible living surfaces presumed to be the locations of structures have been posited by Johnson (1994) at Buck Hollow and Prewitt $(1982,1984)$ at Rowe Valley and Loeve-Fox sites. In each case, the assumption is based on the distribution or scatter of bone, debitage, and ceramic sherds in proximity to large, stone-paved hearths. At the Currie Site, Treece et al. (1993a) describe five "family" hearths located near a large, stone-paved hearth. Johnson (1994:264) interprets this as indicative of five family occupied structures sharing a large communal hearth feature. Type 1 structures might simply include brush arbors or shade trees used for summer camps. Examples of these types of warm-season camps are documented by J. E. Powell among the Kiabab Paiute and illustrated in Figures 12 and 21 in Fowler and Fowler (1971; Figure 9-2).

\section{Type 2}

Evidence in the form of postholes, wall trenches, ash-filled central hearth features, and wattle-impressed daub identify Type 2 structures. Postholes have been documented at the Cobb-Pool (Peter and McGregor 1988), Bird Point Island (Martin and Bruseth 1987), and Hurricane Hill sites (Perttula
1999). Wall trenches were documented at the Rocky Branch (Treece et al. 1993b) and Currie (Treece et al. 1993a) sites at O.H. Ivie Reservoir. Also, postholes that may be associated with structures have been recorded at the Zapotec Site (41HY163; Garber 1987), the Means Site (41NU82; Ricklis and Gunter 1986), the McKenzie Site (41NU221; Ricklis 1988), and the Longhorn Site (41KT53; Boyd 1993). Only at Lake Joe Pool and Cooper Reservoir did these postholes form circular patterns identifiable as houses (Peter and McGregor 1988).

\section{Type 3}

Circular alignments of cobbles or tipi rings marking the location of structures have been documented at the Squawteat Peak Site, Pecos County (Young 1981), in the lower Pecos River region (Turpin 1995), and in the upper Colorado River area of west-central Texas (Shafer 1967:Figure 5). Infierno Complex structures are described as "tipi rings" (Turpin 1995), and consist of circular or oval rings of cobbles, sometimes paired. Only one structure has been excavated, and was found to contain no internal features. In each case, the structures are located on promontories located near a water source, with as few as one to over 100 structures. A tipi ring was recorded at $41 \mathrm{CK} 65$ in the Robert Lee Reservoir basin during the course of an archeological survey (Shafer 1967:Fig. 5).

\section{Type 4}

Two Late Prehistoric, and possibly related, archeological complexes were defined for this cultural pattern. The Cielo Complex is defined west of Big Bend (Mallouf 1999; Ohl and Cloud 2001) and the Cerro Rojo site is in the Hueco Mountains (Seymour 2003). As with the Infierno Complex, these sites also are located on promontories near water.

Cielo Complex structures occur singly or in clusters of 20 or more. These structures are small with circular to oval stacked stone house foundations with interior diameters varying from $1.7 \mathrm{~m}$ to $3.4 \mathrm{~m}$. No preparation was evident in shaping the stone used in construction. Presumably the purpose of the stones was two-fold: to anchor the pole framework on a landscape devoid of soil, and to aid in deflecting the wind when the structures were occupied. In each case, the settlements were established on elevated landforms with extended views of the horizon. Such locations were windy, and some effort was made to anchor the base of the structures for stability. Cielo Complex site material culture includes Perdiz arrow points, ceramics, end scrapers, and beveled knives. 


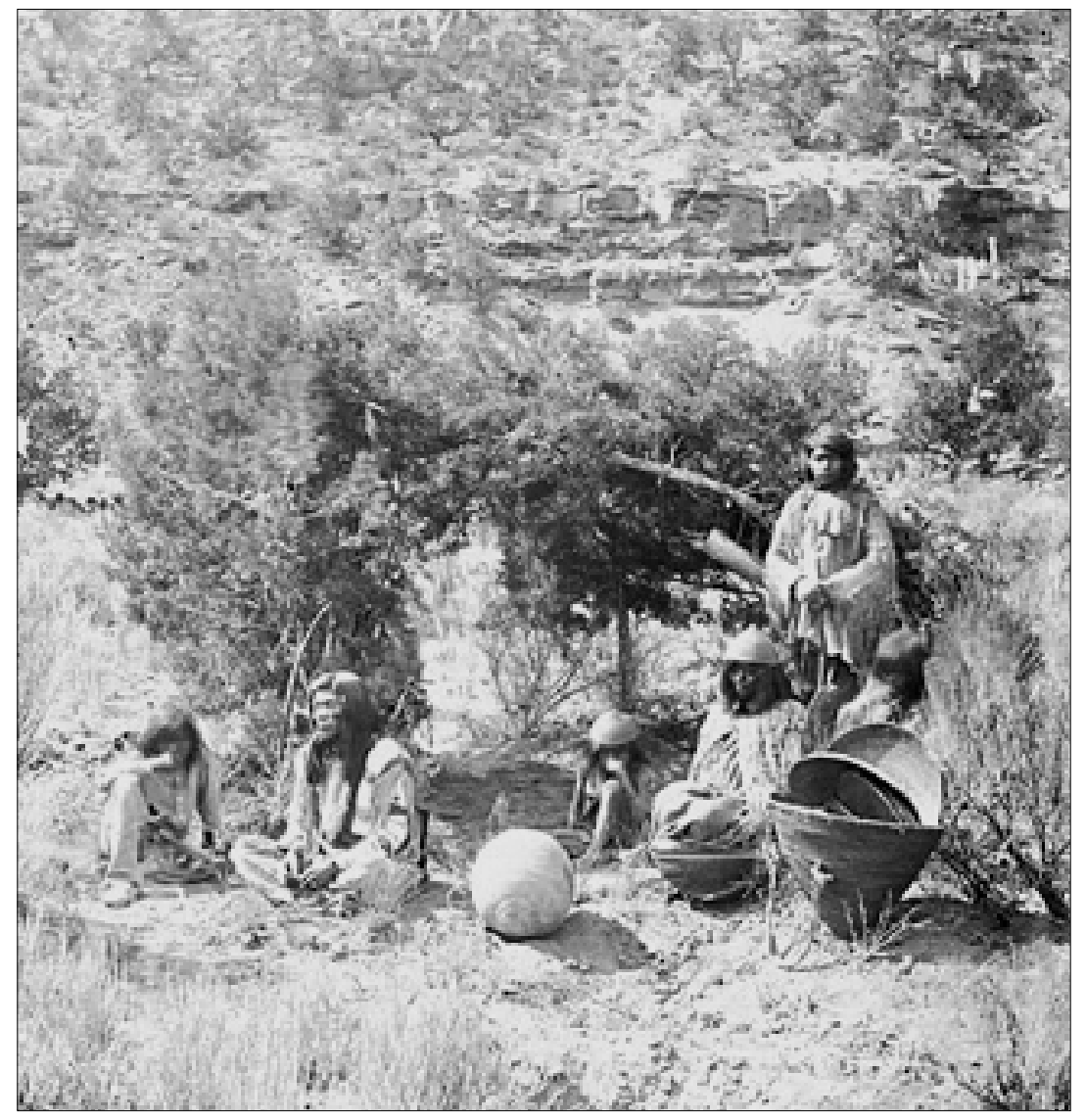

Figure 9-2. Southern Paiute encampment near Kanab, Utah, in 1873, showing the use of a shade tree for a temporary encampment. The image is from Fowler and Fowler 1971:Figure 21 and entitled "Summer Home Under a Cedar Tree."

(J. K. Hillars photograph, 1873; Smithsonian Institution, National Anthropological Archives, Bureau of American Ethnology Collection, BAE GN 10600A 06279100.)

are described as structures, and date anywhere from the Early Archaic to the Late Prehistoric, a brief overview of this feature type is provided.

Johnson (1997) describes one possible and two suspected prehistoric structures at the Lion Creek site in Burnet County. "House 1" consisted of a very large rocklined thermal feature approximately $2 \mathrm{~m}$ in diameter surrounded by a cleared space approximately $1 \mathrm{~m}$ wide. The cleared space was defined by an oval concentration of stones measuring approximately $5 \mathrm{~m}$ in diameter. The oval concentration was not a continuous line of stones, but rather was a series of clusters arranged in an oval pattern. The clusters measured up to a meter across in places. This structure was dated to the Late Archaic (Pedernales interval) based on diagnostics associated with the feature.

"House 2" was less well-defined in Johnson's view, but was very similar to "House 1." This feature was smaller that "House 1" as was its central hearth feature. The central hearth feature was basin-shaped and lined with sandstone slabs; it measured from $1.0 \mathrm{~m}$ to $1.2 \mathrm{~m}$ in diameter, and was again surrounded by an open space averaging about $1 \mathrm{~m}$ wide. A circular arrangement of some eight

Cerro Rojo is an unusually large promontory that contains 275 structural features. These range from circles of stacked slabs, circles of cobbles or small boulders, circles of smaller stones resembling tipi rings, and structure clearings. The material culture associated with these structures includes Soto, Harrell, and triangular arrow points, bi-pointed bifacial knives, flake awls, and various plain wares (Seymour 2003). The structures at Cerro Rojo occurred isolated and in clusters, but no particular village pattern was observed. These material assemblages did vary from one part of the promontory to another, suggesting to Seymour (2003) that the site was multiethnic, occupied by both Apache and Manso.

None of the examples reviewed above describe the kinds of features documented at Lion Creek (Johnson 1997), Slab (Patterson 1987), and Turkey Bend Ranch sites (Lintz et al. 1995). Because these interesting and perplexing features clusters of stones surrounded the open space. Johnson was unable to provide a convincing date for the feature, but assigned it to the Middle Archaic Nolan interval based on a preponderance of Nolan points from the matrix surrounding the feature.

"House 3" yielded the only radiocarbon date from any of the suspected house features. This one-sigma date was A.D. 982-1045, consistent with the Scallorn arrow points associated with the structure. This feature, like those mentioned above, consisted of a large, rock-lined central thermal feature surrounded by an open space. The open space was defined by an oval pattern of 11 rock clusters, with an additional rock-lined thermal feature and rock clusters north of the main feature. The central hearth feature measured about 1.5 $\mathrm{m}$ in diameter. The feature, or house outline, was slightly under $5 \mathrm{~m}$ east-west and slightly over $5 \mathrm{~m}$ north-south. 
A similar feature, albeit Early Archaic in age, also interpreted as a structure, was recorded at the Turkey Bend Ranch Site (41CC112) by Lintz et al. (1995). This feature measured approximately $5 \mathrm{~m}$ by $6 \mathrm{~m}$ and consisted of a very large rockpaved hearth feature surrounded by a 1-m-wide, donut-shaped path containing at least two small rock concentrations. Beyond this path was a circular pattern of intermittent clusters which Lintz et al. (1995) took to be anchors for posts.

Recent investigations at the Graham/Applegate Site (41LL419) conducted by the Llano Uplift Archeological Society (Hixson 2003) revealed four features similar to those reported at the Lion Creek and Turkey Bend Ranch sites. Hixson follows the lead of Johnson and Lintz and classified these features as "houses," and concludes that they fit Lintz et al.'s (1995) Type 4 structure. The features at Graham/ Applegate probably date to the Late Prehistoric.

Patterson (1987) has argued that features at the Slab Site, similar to those at Lion Creek and Turkey Bend, also were the remains of structures. Other similar features have been documented at Lake Buchanan in Llano County (Johnson 1997:58, 59).

A common element to each of these donut-shaped features and presumed structures at the Slab Site, Lion Creek, Turkey Bend, Graham/Applegate, and Lake Buchanan sites is a large, slab-lined central rock feature. The central rock features are surrounded by a cleared space outlined by clusters of rock concentrations or smaller thermal features. Lintz et al. (1995) argue that these cobble concentrations were placed to anchor posts. Alternatively, these may have been work stations used by various family groups involved in the use of a communal central rock feature (Johnson 1997:32). The pattern of these structures is certainly intriguing. That such a pattern occurred over such a long period of time (from the Early Archaic at the Turkey Bend Site to the Late Prehistoric - "House 1"- at the Lion Creek Site) suggests that these features were the result of rather highly structured behaviors that must have provided some adaptive advantages. However, they can hardly be interpreted as structures for the simple reason that the heat from such large thermal features would preclude human presence when activated, especially if it was used as an earth oven as Johnson $(1997: 32,33)$ hinted.

Instead, the donut-shaped features fit precisely the structure of the "outside hearth model" for hunter-gatherers described by Binford (1983:Figure 89, 158). In each of these cases, the hearth feature was surrounded by a cleared space that was used as the work area. A toss zone lay outside of the cleared area, creating a donut-shaped concentration. If indeed these central rock features were fired up within an enclosed brush structure, the structure would surely burn and anyone inside would be charred from the heat generated, a point that apparently bothered Johnson (1997:32, 33). In all likelihood, the donut-shaped thermal features are the foundations or centers for burned rock middens. Many burned rock middens have large, central hearth features identical to those reported in each of the donut-shaped features as a central or underlying element. The Higgins Site is an excellent example (Black et al. 1998a:Figure 61a). Features at Lion Creek, Turkey Bend Ranch, Graham/Applegate, and other reported sites may be single-use localities for the same structured activities that were repeated and resulted in burned rock middens at other localities such as Higgins Site.

\section{Feature 3: The Possible Structure at $41 \mathrm{TV} 163$}

As outlined in Chapter 5, Feature 3 was a possible structure located in excavation Area $\mathrm{C}$. The feature was marked by a roughly circular pattern of medium-sized cobbles. The circular pattern was roughly $2.4-3 \mathrm{~m}(8-10 \mathrm{ft}$. $)$ in diameter. As shown in Figure 9-3, the feature was bisected with the excavation of the backhoe trench through this area. The pattern of stone did not become apparent until manual excavations exposed the cobbles in Level $2(0.5-1.0 \mathrm{ft}$. below surface). The feature was encountered in portions of units S185/E155, S185/E160, S175/E155, and S175/E160, with the approximate center of the proposed structure at S183/E155.

The pattern of cobbles appeared intact and no evidence of significant disturbance was noted according to Frank Weir (personal communication 2002). A cobble scree deposit (Feature 4), originating from the bench above the terrace, caps the back part of the terrace that contained the feature. In pursuit of the possibility that the cobble alignment may be fortuitous and part of this scree deposit, photographic archives were examined closely along with an interview with Weir regarding his recollections. Weir recalled that the area of the alignment was suspicious because the area appeared to have been cleared of cobbles. In Weir's opinion, the pattern was not fortuitous. As discussed in Chapter 5, two additional features, numbers 7 and 9, may represent the continuation of the scree deposit to the east.

The deposits that contained the possible structure yielded predominately Late Prehistoric Scallorn arrow points, though some Late Archaic materials, including Darl and 


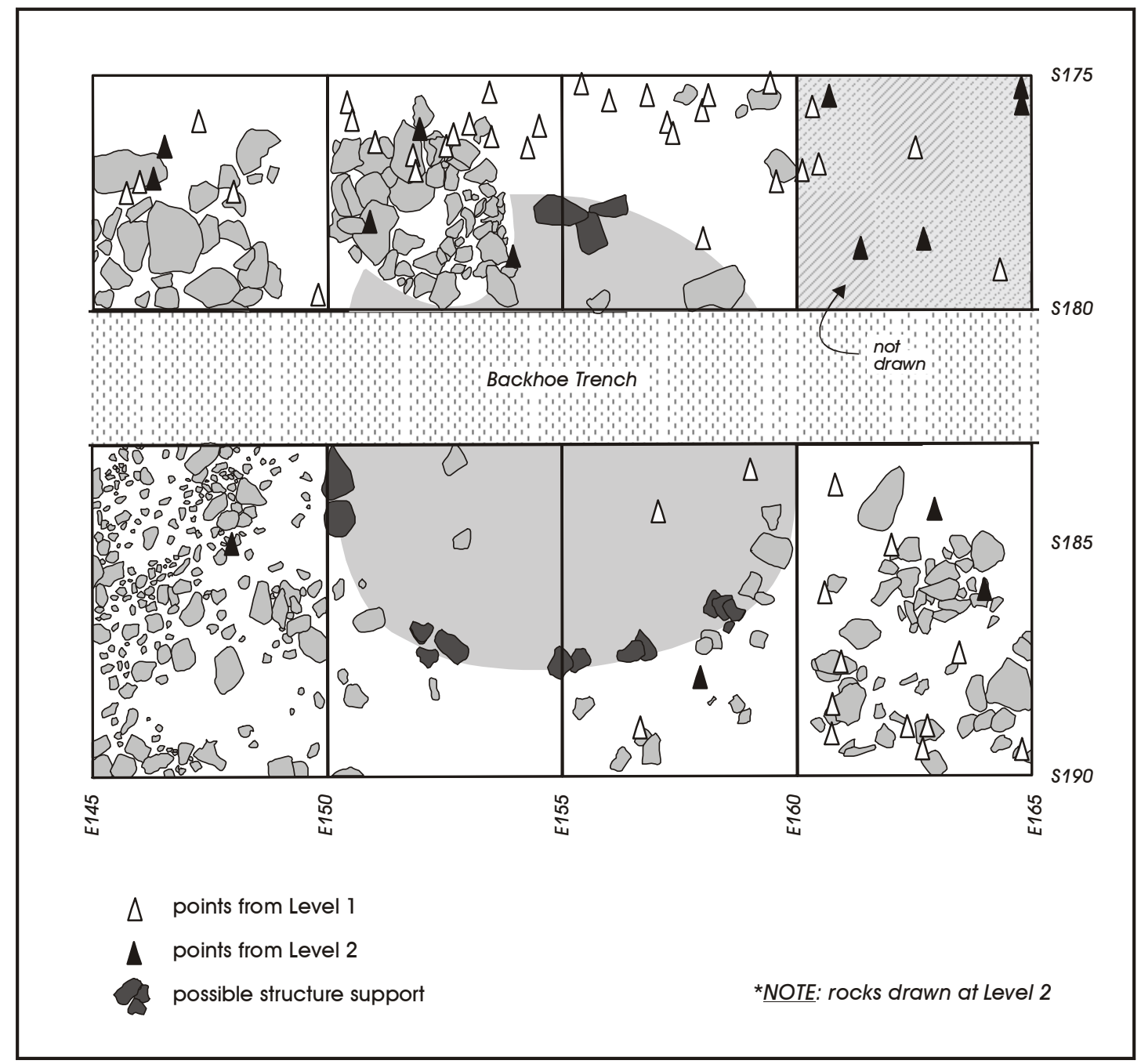

Figure 9-3. Feature 3 at $41 T V 163$.

Fairland dart points, were also recovered. A radiocarbon date obtained soon after the 1970-1971 excavation, TX \#1511, was from a sample collected just outside of this structure at Level 2 in unit S175/E155. This uncorrected date calibrates to A.D. 1310-1490. As discussed in Chapter 5 , CAR obtained an additional date, from Level $1(0-0.5$ ft.) of square S175/E160 (see Table 5-4; UGA \#12305). That calibrated, corrected date had a two-sigma range of A.D. 1300-1430. A second CAR obtained date, UGA\#12306 from Level 1 of S185/E160 returned a modern date. The within-unit provenience of these two dates, however, is not known, and it is unclear if either the modern date, or the A.D. 1300-1430 date, was from within the structure. Nevertheless, two Late Prehistoric dates, along with the predominance of Late Prehistoric points, suggests that the feature was probably used during the Late Prehistoric period, although earlier dart points are present at low frequencies.

\section{Evidence of a Structure}

Does this feature represent the remains of a structure? As outlined previously in this chapter, our review of ethnographic, ethnohistoric, and archeological occurrences of structures suggests several elements that might be expected to be present in some situations with structures. In the case of the hunting and gathering adaptation represented at 41TV163, we expect that a structure, if present, would be circular in form. In specific structures, and depending on 
the season of occupation, environmental conditions, and abandonment context, we might also expect one of more of the following elements: (1) postholes or rock supports; (2) a central hearth, possibly with distinctive ash deposits; (3) presence of chunks of wattle and daub; (4) a maintained living surface within the structure; (5) higher artifact densities around the structure; (6) presence of burials associated with the structure; (7) associated trash midden deposits; and (8) associated outside features or activity areas. We briefly consider each of these below in the context of Feature 3.

Feature 3 does have several of these attributes. The feature is round, and was defined on the basis of an apparently cleared area of stone. This suggests some potential for a maintained surface. In addition, while no postholes or floors were defined during excavation, the feature may have evidence of rock supports, suggested by several smaller concentrations of stone (shown in black on Figure 9-3) that outline the feature. A human burial, Feature 10, was beneath the feature. There was a dense concentration of debris, including bone, charcoal, and stone, in the immediate area of the feature, along with several additional features that could represent an outside activity area.

The feature also lacks several of these attributes, including wattle and daub remains and evidence of postholes. There was no central hearth feature, though the backhoe trench, which destroyed a significant section of the central area, could have removed all evidence of such a central feature. A closer look at those attributes that are present also suggests that the evidence for their association with Feature 3 is tenuous. Feature 10, the burial, probably predates the possible structure by roughly 800 years suggesting that at least two overlapping activity episodes may be responsible for the spatial patterns. Based on the radiocarbon dates and the distribution of diagnostic points, all of the associated features, as well as much of the accumulated trash midden deposits, seems to predate the feature. When seen in full, we are primarily left with two sets of remains - the clustering of rocks along the feature outline that may reflect supports for posts and the apparent cleared area within the feature.

While we are unable to assess the validity of the post supports, additional information on the maintained surface is available from two sources, the point-provenienced information on some artifacts and the size of artifacts recovered in squares that are predominantly inside and outside the feature. Figure 9-3 shows the distribution of projectile points in Level 1 (white) and Level 2 (black) for the four squares containing the feature, as well as four squares surrounding the feature. These data were taken from a drawing and notes on the artifact bags. While not all points were recorded in this manner, the distribution does suggest that most points from both levels were located outside of the structure. Within the confines of Feature 3, only three points were present, and the drawing suggests clusters of points to the north and southeast of the feature. This pattern is consistent with the idea of the feature area representing a maintained space, with larger artifacts removed to the boundaries of the feature.

Additional information on this topic is presented in Table 9-1. Here we present information on the number and size of artifacts in Levels 1 and 2 for the eight units shown in Figure 9-3. For the purpose of this discussion, squares are either assigned to outside of the feature $(n=4)$ or inside of the feature $(n=4)$. That is, no designation of within feature was made for the artifacts collected. Consequently, even though, as shown in Figure 9-3, much of S175/E160 is outside of the structure, we consider all artifacts from this square as being within Feature 3. Artifact size was obtained by using a series of nested screens with $1 / 4^{-}, 1 / 2-$, and 1 -inch mesh. Over 8,900 items were present in the two levels from these eight squares. We suggest that if the area of Feature 3 represents a maintained surface, then (1) squares classified as being within the proposed structure should have lower artifact frequencies relative to the surrounding squares; (2) artifacts in the two largest size grades ( $>/=1$ inch, $1 / 2-1$ inch) should have a much lower frequency within the feature relative to surrounding squares, and this should especially be the case for the larger size grade; and (3) items in the smallest size grade which consisted of small flakes that passed through the $1 / 4$-inch mesh after several minutes of shaking the screen, should have either a lower frequency within the possible structure, or a roughly equivalent density, when compared to outside units. That is, we expect that these smaller flakes would be increasingly likely to be missed by maintenance activities.

Turning first to overall frequency, the external squares have 4,758 items, a density of roughly 1,196 items per square. Within-structure frequency is lower, with an overall total of 4,148 items and a density of 1,037 items per square. While these differences are slight, they do trend in the anticipated direction. Artifacts in the $1 \mathrm{inch}$ or greater size range also are more common outside of the feature with a density of 14.75 per square compared to 12 within the feature. Artifacts in the $1 / 2-1$ inch size range also pattern as anticipated, with an average of just over 113 items per external square, and 
Table 9-1. The Distribution of Artifacts, by Size, In and Around Feature 3

\begin{tabular}{|c|c|c|c|c|c|c|c|}
\hline South & East & Level & Total Artifacts & $\geq 1$ inch & 0.5-1 inches & $<1 / 4$ inch & Location \\
\hline 175 & 150 & 1 & 992 & 28 & 203 & 105 & out \\
\hline 175 & 150 & 2 & 289 & 15 & 98 & 14 & out \\
\hline 175 & 165 & 1 & 696 & 20 & 156 & 57 & out \\
\hline 175 & 165 & 2 & 412 & 12 & 77 & 28 & out \\
\hline 185 & 150 & 1 & 446 & 13 & 123 & 37 & out \\
\hline 185 & 150 & 2 & 128 & 1 & 19 & 13 & out \\
\hline 185 & 165 & 1 & 1216 & 20 & 173 & 340 & out \\
\hline 185 & 165 & 2 & 579 & 9 & 58 & 175 & out \\
\hline 175 & 155 & 1 & 1194 & 26 & 177 & 173 & in \\
\hline 175 & 155 & 2 & 610 & 14 & 133 & 88 & in \\
\hline 175 & 160 & 1 & 1164 & 24 & 201 & 138 & in \\
\hline 175 & 160 & 2 & 371 & 10 & 131 & 25 & in \\
\hline 185 & 155 & 1 & 192 & 6 & 56 & 11 & in \\
\hline 185 & 155 & 2 & 74 & 3 & 14 & 2 & in \\
\hline 185 & 160 & 1 & 451 & 11 & 103 & 47 & in \\
\hline 185 & 160 & 2 & 92 & 2 & 28 & 5 & in \\
\hline
\end{tabular}

105 items per internal square. However, the density of smaller items does not follow the anticipated pattern. In this size grade, just over 96 items per square were present outside of the feature, while 61 items per square were present within the feature. While several of the data sets trend as predicted, the overall pattern is not strong, and the patterning in the smallest size range is counter to expectation.

Does Feature 3 reflect a structure? We do not know. No direct evidence for a superstructure, in the form of postholes or pieces of wattle and daub, are present. And, while the concentrations of rock may reflect post supports, it is just as probable that they do not. A central hearth could have been present, but given the location of the backhoe trench, we cannot confirm that it was, or was not, there. We can suggest that there is a moderate possibility, based on the lack of large cobbles, the projectile point distributions, the lower overall artifact densities, and the lower densities of larger-sized items, that the area identified as Feature 3 represents some sort of maintained space. This suggestion is of some interest, in that maintenance of space certainly suggests that occupation at 41TV163 during the Late Prehistoric period was probably of a different character than earlier use of the site.

\section{Summary}

The archeological evidence that Feature 3 was, in fact, the outline of a structure is inconclusive. As both the ethnographic and ethnohistorical overviews suggest, it is likely that hunters and gatherers occupying sites such as 41TV163 had structures, at least during some portion of the year. However, the archeological visibility of these features would have been extremely low. Our review of the evidence does suggest that it is possible that Feature 3 represented some sort of maintained location. This, in itself, is of interest, for this suggests that either the length of occupation or perhaps the nature of the occupation at site 41TV163 during the Late Prehistoric was substantially different than during earlier uses of the site. 


\title{
Chapter 10: Summary and Conclusions
}

\author{
Steve A. Tomka and Raymond P. Mauldin
}

\section{Report Summary}

The Center for Archaeological Research (CAR) at The University of Texas at San Antonio, under contract with the Texas Department of Transportation (Work Authorization \#57014PD004), conducted an inventory and assessment of the archeological collections and documentation associated with site 41TV163, located in north-central Travis County, Texas. The excavations at the site were conducted between September of 1970 and February of 1971 under the direction of Frank Weir, then of the Texas Highway Department. The excavation is of historical interest, as 41TV163 was the first archeological site excavated by the then Texas Highway Department (THD) under their archeological program established in 1970 in an effort to comply with the National Environmental Protection Act (NEPA).

The inventory of collections, and the assessment of the documentation were conducted in 2002 (Mahoney et al. 2003a). Based on that assessment, and in consultation with TxDOT Environmental Division staff, a series of possible research questions were developed that could be pursued with the site data. Following agreement on the general research directions and specific analyses, CAR was instructed to produce a final report and to prepare the project material for permanent curation. This document constitutes the final report on the TxDOT work at 41TV163. Included in this report are a description of the site, excavation procedures, and an analysis of cultural materials collected from selected components.

The initial three chapters of this document provided background to the project, including an overview of the physical and cultural setting of the site. Chapter 4 outlined the field and laboratory methods used in 1970-1971 and 2002-2003, and Chapter 5 provided a summary of the data recovered in 1970-1971. Chapter 6, which summarized aspects of the research perspective, also identified several analytical units. Based on the distribution and clustering of diagnostic projectile points, and supported by recently acquired radiocarbon dates, four different analytical units were identified. These analytical units covered four temporal periods, spanning much of the known prehistoric sequence from Early Archaic through the Austin Phase of the Late Prehistoric. While the quantity and type of data varied, these analytical units were subsequently used to address a series of contemporary research questions. Chapters 7 and 8 addressed two diachronic research topics, changes in subsistence practices and changes in chipped stone technology. Chapter 9 addressed a synchronic research topic, the evaluation of Feature 3, a possible structure within the Late Prehistoric analytical unit defined at the site.

Chapter 7 used primarily faunal data from the Late Prehistoric Austin Phase analytical unit and assemblages from the Late Archaic analytical units to investigate changes in subsistence. Operating from the perspective of optimal foraging theory, we outlined a series of expectations regarding the potential impact of changes in the availability and density of higher-ranked bison on the diet. These expectations were partially supported by the 41TV163 data, as we found evidence for both a slight increase in the number of genera during the Late Prehistoric Austin Phase, when bison were absent or at low densities, and the Late Archaic, when bison were more common. We also found some support for differences in the frequency of fresh bone breakage, with bone processing occurring more often in the Late Prehistoric material. We then conducted a regional comparison using faunal material from a number of sites. While hampered by the quality of available data at this regional scale, our analysis shows that when bison constitutes a large proportion of the faunal remains within an assemblage, the number of genera represented tends to be low. Conversely, when assemblage elements are primarily derived from small to very small prey species, the numbers of genera tends to be high. These patterns are consistent with our expectation, but they do not seem to hold for the period level (e.g., Early Archaic, Late Archaic). That is, the analysis suggests that variation rather than homogeneity in subsistence characterized any given period.

In Chapter 8, we examined several aspects of chipped stone technology. Using data from the Early, Middle, and Late Archaic, along with information from the Late Prehistoric, we focused on documenting two aspects of the lithic technology, raw material procurement and technological organization. To reconstruct raw material procurement strategies, we attempted to identify local relative to nonlocal tool stone based on a series of variables. While hampered by the lack of a geological survey, we suggested 
that five raw material types, identified primarily on the basis of color, appear to represent primarily non-local stone. Nine other raw material types appear to be dominated by local stone. The raw material patterns indicate that non-local materials are over-represented in bifaces, points, and other tools relative to the number of non-local debitage. These patterns are consistent with the importation of non-local materials in an already partially reduced or finished form (i.e., bifaces, points, finished tools). In addition, relatively low percentages of non-local materials were noted in the Early and Middle Archaic analytical units, while relatively high percentages of non-local materials were present during the Late Archaic and Late Prehistoric periods. The study of technological organization focused on two aspects of the assemblage, the composition of the tools and an investigation into projectile point technology. Overall, expedient and minimally retouched tools dominate the tool assemblages. Formal tools, with the exception of projectile points, are infrequent. We suggested that these patterns may be conditioned by the abundant availability of local materials and the even distribution of resource processing tasks. We also suggested that some on-site production of tools was probably intended for purposes other than the on-site replacement of failed bifacial tools. Finally, the analysis of the projectile technology indicates that there are significant differences in mean remnant blade length and the percentages of complete specimens within the Late Archaic and between the Late Archaic and the Middle Archaic. Projectile point use tends to be relatively intensive around the end of the Late Archaic but it tends to exhibit a move toward greater preventive maintenance and less intensive rejuvenation during the earlier portion of the Late Archaic and the Middle Archaic. These patterns suggest that projectile technology and hunting patterns were changing through time in likely response to changes in resource type and structure.

In Chapter 9, we investigated the possibility that Feature 3 was a house structure. After a review of both the ethnographic and ethnohistorical discussions of structures, we outlined several characteristics that hunting and gathering structures might possess. We then assessed the Feature 3 data in that context. While we were unable to confirm that the feature was a structure, we can suggest that the feature may represent some sort of maintained area. The presence of this maintained area suggests that either the length of occupation, or the nature of the occupation, at site 41TV163 during the Late Prehistoric may have been substantially different than use of the site during earlier periods.

\section{Conclusions}

In each of the three analytical chapters, we struggled with using old data, collected for different purposes and collected with different methods, to address modern questions. For example, our investigation into subsistence in Chapter 7 was limited primarily to faunal remains as flotation samples were not routinely collected in Texas in the early 1970s. Our investigation of lithic technology necessarily operated at the period (e.g., Early Archaic, Late Archaic) level as the collection of data in six-inch levels simply did not allow us to more finely separate these long blocks of time into finer units. The resulting conclusions of this investigation, then, were somewhat limited due, in part, to the fact that the site was excavated some three decades ago.

The age of the excavations provided two different yet related challenges. On the one hand, we were faced with the challenge of compiling and reviewing all of the artifacts and records produced by the excavations to reconstruct what was done at the site, what had been recovered, how it was recovered, and where it was recovered. This challenge is not unlike that faced by any project archeologist returning from a field season full of notes, photographs, profiles, and boxes of artifacts and samples. What compounded this first challenge for us is that the field methods employed were unlike those in use today and would not be appropriate for addressing fine-scale research issues. This was further complicated by the fact that many of the detailed field notes were lost shortly after the completion of the excavation.

Perhaps the more interesting challenge was that of defining research topics that were relevant to contemporary huntergatherer investigations while using collections excavated for the purpose of investigating culture historical concerns of the late 1960s and early 1970s. In our initial assessment of the excavations, we were overly critical of the methods employed. Fortunately, two of the collaborators on this project, Dr. Shafer and Dr. Weir, quickly helped us realize that in the 1960s and early 1970s, six-inch levels and large mechanical excavations were a proven standard in Texas. Many of these methods grew out of the large-scale excavation projects sponsored by the WPA. It was, after all, these excavation projects that provided a wealth of material that laid the foundation for subsequent archeological studies in the state. Finally, we should recall that while current archeological investigations are research design oriented and data recovery plans dictate the kinds 
and quantities of artifacts to be recovered to address specific research questions, the excavations of the 1960s and early 1970s in the state clearly had different goals. Archeologists working in Texas were wrestling with issues of chronology and culture history building, and gathering the basic building blocks of this framework. Radiocarbon dating was not widely used and one of the biggest challenges faced by archeologists in this period was to define some temporal framework that would allow the ordering of the large quantity of materials. In that context, it is no surprise that the principal goal of the Millican Bench excavations was to confirm the broad outlines of the regional chronology and perhaps even help divide it into finer units through the excavation of a deeply stratified central Texas site. In the end, we used their data for a different purpose than they intended. While limited at times, our results do suggest that old collections, collections gathered under different theoretical goals and using different methods, can be used to successfully investigate current research questions. 


\section{References Cited}

Aldenderfer, M. S.

1990 Defining Lithic-Using Craft Specialization in Lowland Maya Society through Microwear Analysis: Conceptual Problems and Issues. Aun 14:53-70.

Andrefsky, Jr., W.

1994a Raw-Material Availability and the Organization of Technology. American Antiquity 59:21-34.

1994b The Geological Occurrence of Lithic Material and Stone Tool Production Strategies. Geoarcheology 9:345-362.

Aveleyra Arroyo de Anda, L., M. Mardonado-Koerdell, and P. Martinez del Rio

1956 Cueva de la Candelaria. Memoria No. 5. Instituto Nacional de Anthropología e Historia. Mexico.

Barnes, V. E.

1974 Geologic Atlas of Texas: Austin Sheet. Bureau of Economic Geology, The University of Texas at Austin.

Bell, R. E., E. B. Jelks, and W. W. Newcomb (assemblers)

1967 A Pilot Study of Wichita Indian Archaeology and Ethnohistory. Final Report for Grant GS-964, National Science Foundation, Austin.

Bement, L. C.

1994 Hunter-Gatherer Mortuary Practices during the Central Texas Archaic. The University of Texas Press. Austin.

Benfer, R., and A. Benfer

1981 The Mason Ranch Burial Cave, Uvalde County, Texas. La Tierra 8(3):16-26.

Berlandier, J. L.

1969 The Indians of Texas in 1830, edited by J. Ewers. Smithsonian Institution Press. Washington D.C.

Binford, L. R.

1978 Dimensional Analysis of Behavior and Site Structure: Learning from an Eskimo Hunting Stand. American Antiquity 43:330-361.

1979 Organization and Formation Processes: Looking at Curated Technologies. Journal of Anthropological Research 35:255-306.

1983 In Pursuit of the Past: Decoding the Archaeological Record. Thames and Hudson. New York.

Black, S. L.

1995 Texas Archeology 1995. Bulletin of the Texas Archeological Society 66:17-45.

Black, S. L., and D. G. Creel

1997 The Central Texas Burned Rock Midden Reconsidered. In Hot Rock cooking on the Greater Edwards Plateau: Four Burned Rock Midden Sites in West Central Texas, edited by S. L. Black, L. W. Ellis, D. G. Creel, and G. T. Goode, pp. 446-515. Studies in Archeology 22. Texas Archeological Research Laboratory, The University of Texas at Austin. 
Black, S. L., K. Jolly, C. D. Frederick, J. R. Lucas, J. W. Karbula, P. R. Takac, and D. R. Potter

1998a Archaeology along Wurzbach Parkway, Module 3. Investigations and Experimentation at the Higgins Site (41BX184): Vol. 1. Studies in Archaeology 27, Texas Archeological Research Laboratory, The University of Texas at Austin.

1998b The Central Texas Burned Rock Midden Reconsidered. In Hot Rock Cooking on the Edwards Plateau: Four Burned Rock Midden Sites in West Central Texas, by S. L. Black, L. W. Ellis, D. G. Creel, and G. T. Goode, pp. 269-305. Studies in Archaeology 22. Texas Archeological Research Laboratory, The University of Texas at Austin. Archeology Studies Program Report 1, Environmental Affairs Division, Texas Department of Transportation, Austin.

Black, S. L., and A. J. McGraw

1985 The Panther Springs Creek Site: Cultural Change and Continuity within the Upper Salado Creek Watershed, South-Central Texas. Archaeological Survey Report, No. 100. Center for Archaeological Research, The University of Texas at San Antonio.

Bleed, P.

1986 The Optimal Design of Hunting Weapons Maintainability or Reliability. American Antiquity 51:737-747.

Bolton, H. E.

1914 The Expedition of 1772 from Natchitoches to the Nations of the Upper Trinity and Brazos River, Athanase de Mésières and the Lousiana-Texas Frontier 1768-1770 (2 vols):283-351. Cleveland.

Bomar, G. W.

1995 Texas Weather. Second edition, revised. University of Texas Press, Austin.

Bousman, C. B.

1998 Chapter 8: Late Paleoindian Archeology. In Wilson-Leonard: An 11,000-year Archeological Record of HunterGatherers in Central Texas: Volume I: Introduction, Background, and Synthesis, edited by M. B. Collins, pp. 161-210. Studies in Archeology 31, Texas Archeological Research Laboratory, The University of Texas at Austin, and Archeology Studies Program, Report 10. Texas Department of Transportation, Environmental Affairs Division, Austin.

Boyd, D. K.

1993 Cultural Features at 41KT53. In Data Recovery at Justiceburg Reservoir (Lake Alan Henry), Garza and Kent Counties, Texas: Phase III, Season 2, edited by D. K. Boyd, J. Peck, S. A. Tomka, and K. W. Kibler, pp. 101-130. Reports of Investigations Number 88, Prewitt and Associates, Inc., Austin.

Brewington, R. L., J. E. Dockall, and H. J. Shafer

1995 Archaeology of 41MX5: A Late Prehistoric Caddoan Hamlet in Morris County, Texas. Reports of Investigations No. 1. Center for Environmental Archaeology, Texas A\&M University, College Station.

Brownlow, R. K.

2003 Archeological Investigations at 41WM815 A Blackland Prairie Site Williamson County, Texas. Archeology Studies Program Report, No. 23. Environmental Affairs Division, Texas Department of Transportation, Austin.

Buikstra, J. E., and D. H. Ubelaker

1994 Standards for Data Collection from Human Skeletal Remains. Research Series No. 44. Arkansas Archeological Survey, Fayetteville. 
Callahan, E.

1979 The Basics of Biface Knapping in the Eastern Fluted Point Tradition A Manual for Flintknappers and Lithic Analysts. Archaeology of Eastern North America 7:1-180.

Campbell, T. N.

1983 Espinosa, Olivares, and the Colorado River Indians, 1709. Sayersville Historical Association Bulletin 3:2-6, 1516.

1988 Espinosa, Olivares, and the Colorado River Indians, 1709. In The Indians of Southern Texas and Northeastern Mexico: Selected Writings of Thomas N. Campbell, by T. N. Campbell, pp 61-70. Published by the Texas Archeological Research Laboratory with the cooperation of the Department of Anthropology, The College of Liberal Arts, and the Institute of Latin American Studies, Austin.

Camper, H. A.

1991 Pollen Analysis of Patschke Bog. Unpublished M.S. thesis, Department of Botany, Texas A\&M University, Bryant. Data archived at the World Data Center for paleoclimatology data. NOAA/NGDC Paleoclimatology Program, Boulder.

Coffman, R. J., M. C. Trachte, and M. B. Collins

1986 Cultural Ecology of the Kenyon Rockshelter and the Cunningham Site, Canyon Creek Development, Travis County, Texas. Reports of Investigation 53. Prewitt and Associates, Inc., Austin.

Collins, M. B. (editor)

1998b Wilson-Leonard: An 11,000-year Archeological Record of Hunter-Gatherers in Central Texas: Volume I: Introduction, Background, and Synthesis, Studies in Archeology 31, Texas Archeological Research Laboratory, The University of Texas at Austin, and Archeology Studies Program, Report 10. Environmental Affairs Division, Texas Department of Transportation, Austin.

Collins, M. B.

1972 The Devil's Hollow Site, A Stratified Archaic Campsite in Central Texas. Bulletin of the Texas Archeological Society 43:77-100.

1994 Chapter 6: Late Archaic Evidence in the Project Area. In Archaic and Late Prehistoric Human Ecology in the Middle Onion Creek Valley, Hays County, Texas, edited by R. A. Ricklis and M. B. Collins, pp. 101-189. Studies in Archeology No. 19. Texas Archeological Research Laboratory. The University of Texas at Austin.

1995 Forty Years of Archaeology in Central Texas. Bulletin of the Texas Archeological Society 66:361-400.

1998a Chapter 4: Background to the Archeological Investigations. In Wilson-Leonard: An 11,000-year Archeological Record of Hunter-Gatherers in Central Texas: Volume I: Introduction, Background, and Synthesis, edited by M. B. Collins, pp. 55-68. Studies in Archeology 31, Texas Archeological Research Laboratory, The University of Texas at Austin, and Archeology Studies Program, Report 10. Environmental Affairs Division, Texas Department of Transportation, Austin.

1998c Chapter 7: Early Paleoindian Components. In Wilson-Leonard: An 11,000-year Archeological Record of HunterGatherers in Central Texas: Volume I: Introduction, Background, and Synthesis, edited by M. B. Collins, pp. 123-160. Studies in Archeology 31, Texas Archeological Research Laboratory, The University of Texas at Austin, and Archeology Studies Program, Report 10, Environmental Affairs Division, Texas Department of Transportation, Austin.

1999 Clovis Blade Technology. The University of Texas Press, Austin.

Collins, M. B., B. Ellis, C. Dodt-Ellis

1990 Excavations at the Camp Pearl Wheat Site (41KR243): An Early Archaic Campsite on Town Creek, Kerr County, Texas. Studies in Archaeology No. 6. Texas Archeological Research Laboratory, The University of Texas at Austin. 
Collins, M. B., J. Guy, and S. W. Dial

1998 The Archaic Period: 8800-1300 B.P. In Wilson-Leonard: An 11,000-year Archeological Record of HunterGatherers in Central Texas: Volume 1: Introduction, Background, and Synthesis, edited by M. B. Collins, pp. 211-270. Studies in Archaeology 31, Texas Archeological Research Laboratory, The University of Texas at Austin.

Crawford, D.

1963 The Granite Beach Site, Llano County, Texas. Bulletin of the Texas Archeological Society 36:71-98.

David, B.

1990 How was this bone burnt? In Problem Solving in Taphonomy: Archaeological and Palaeontological Studies from Europe, Africa and Oceania, edited by S. Soloman, I Davidson and D. Watson, pp. 65-79. Anthropology Museum, the University of Queensland, St. Lucia.

Davis, E. M., K. Gilmore, L. Harper, R. K. Harris, E. B. Jelks, and B. Yancy

1967 The Site. Bulletin of the Texas Archeological Society 37:1-17.

Davis, W. B., and D. J. Schmidly

1994 The Mammals of Texas. Texas Parks and Wildlife, Austin.

Dering, J. P.

2000 Appendix II: Macrobotanical Remains from Soil Flotation Samples from the Bessie Kruze Site, with Thoughts about the Blackland Prairie. In Life and Death as Seen at the Bessie Kruze Site (41WM13) on the Blackland Prairie of Williamson County, Texas, by L. Johnson, pp. 213-220. Archaeology Studies Program, Report 22. Environmental Affairs Division, Texas Department of Transportation, Austin.

2003 Appendix C: Plant Remains from Rice's Crossing (41WM815). In Archeological Investigations at 41 WM815 A Blackland Prairie Site Williamson County, Texas, by R. K. Brownlow, pp. 115-120. Archaeology Studies Program, Report 23. Environmental Affairs Division, Texas Department of Transportation, Austin.

Diehl, M., and P. A. Gilman

1996 Implications from the Designs of Different Southwestern Architectural Forms. In Interpreting Southwestern Diversity: Underlying Principles and Overarching Patterns. Arizona State University Anthropological Papers. Tempe.

Dillehay, T.

1974 Late Quaternary Bison Population Changes on the Southern Plains. Plains Anthropologist 19(64):180-196.

Diamond, D. D., D. H. Riskind, and S. L. Orzell

1987 A Framework for Plant Community Classification and Conservation in Texas. The Texas Journal of Science 39(3):203-221.

Everitt, B. S.

1977 The Analysis of Contingency Tables. Chapman and Hall, London.

Ezzo, J. A.

1992 A refinement of the adult burial chronology of Grasshopper Pueblo. Journal of Archaeological Science 19:445457. 
Ferring, C. R.

2001 The Archaeology and Paleoecology of the Aubrey Clovis Site (41DN479), Denton County, Texas. Center for Environmental Archaeology, Department of Geography, University of North Texas, Denton.

Fisher, J. W., Jr., and H. C. Strickland

1991 Dwellings and fireplaces: keys to Efe Pygmy campsite structure. In Ethnoarchaeological Approaches to Mobile Campsites. Hunter-Gatherer and Pastoralist Case Studies, edited by C. S. Gamble and W. A. Boismier, pp. 215236. Ethnoarchaeological Series 1. International Monographs in Prehistory, Ann Arbor.

Flannery, K. V.

1969 Origins and Ecological Effects of Early Domestication in Iran and the Near East. In The Domestication and Exploitation of Plants and Animals, edited by P. Ucko and G. Dimbleby, pp. 73-100. Duckworth, London.

1972 The Origins of the Village as a Settlement Type in Mesoamerica and the Near East: A Comparative Study. In Man, Settlement, and Urbanism, edited by P. J. Ucko, R. Tringham, and G. W. Dimbleby, pp. 23-53. Duckworth, London.

1986 The Research Problem. In Guila Naquiz: Archaic Foraging and Early Agriculture in Oaxaca, Mexico, edited by K. V. Flannery, pp. 501-507. Academic Press, New York.

2002 The Origins of the Village Revisited. American Antiquity 67(3):417-433.

Foster, W. C. (editor)

1995 Spanish Expeditions into Texas, 1689-1768. University of Texas Press. Austin.

1998 The La Salle Expedition to Texas: The Journal of Henri Joutel 1684-1687. Texas Historical Association. Austin.

Fowler, D. D., and C. S. Fowler

1971 Anthropology of the Numa: John Wesley Powell's Manuscripts on the Numic Peoples of Western North America, 1868-1880. Smithsonian Contribution to Anthropology 14. Washington D.C.

Garber, J. F.

1987 Transitional Archaic Structure and Activity Area at the Zatopec Site, San Marcos, Texas. La Tierra 14(2):19-30.

Gilmore, K.

1969 The San Xavier Missions: A Study in Historical Site Identification. Report No. 16. State Building Commission, Austin.

Givens, R. D.

1968 A Preliminary Report on Excavations at Hitzfelder Cave. Bulletin of the Texas Archeological Society 38:47-50.

Good, C. E.

1982 Analysis of Structures, Burials, and Other Cultural Features. In The Deshazo Site, Nacogdoches County, Texas, Volume 1, edited by D. A. Story, pp. 51-112. Texas Antiquities Permit Series, No. 7. Texas Antiquities Committee, Austin.

Graham, M.

1994 Mobile Farmers: An Ethnoarchaeological Approach to Settlement Organization among the Raramuri of Northwestern Mexico. Ethnoarchaeological Series No. 3. International Monographs in Prehistory, Ann Arbor.

Greer, J. W., and R. A. Benfer

1975 Austin Phase Burials at the Pat Parker Site, Travis County, Texas. Bulletin of the Texas Archeological Society 46:189-216. 
Gregory, D., and M. R. Schurr

2000 Fluoride Dating within an Early Agricultural Period Settlement in the Tucson Basin. Poster presented at the Society for American Archaeology 65th Annual Meeting, Philadelphia, Pennsylvania.

Griffen, W. B.

1968 Culture Change and Shifting Populations in Central Northern Mexico. Anthropological Papers of the University of Arizona 13. The University of Arizona Press, Tucson.

Haberman, S. J.

1973 The Analysis of Residuals in Cross-classified Tables. Biometrics 29:205-220.

Hall, G. D.

1998 Prehistoric Human Food Resource Patches on the Texas Coastal Plain. Bulletin of the Texas Archeological Society 69:1-10.

Hayden, B., and R. Gargett

1988 Rooms, Roofs, Rims, and Resources: The Anatomy of Interior Housepits. Paper presented at the annual meeting of the Canadian Archaeological Association, Whistler, British Columbia.

Hayden, B., N. Franco, and J. Spafford

1996 Evaluating Lithic Strategies and Design Criteria. In Stone Tools: Theoretical Insights into Human Prehistory, edited by G. H. Odell, pp. 9-50. Plenum Press, New York.

Henderson, J., and G. T. Goode

1991 Pavo Real: An Early Paleoindian Site in South-Central Texas. Current Research in the Pleistocene 8:26-28.

Henry, D. O.

1985 Preagricultural Sedentism: The Natufian Example. In Prehistoric Hunter-Gatherers, pp. 365-384. Academic Press, New York.

Hester, T. R.

1978 Notes on the Edwards Arrow Point Type. La Tierra 5(4).

1990 Notes on South Texas Archaeology: 1991-2: The Plainview Points from the St. Mary's Hall Site, South-Central Texas. La Tierra 18(2):1-4.

1995 The Prehistory of South Texas. Bulletin of the Texas Archeological Society 66:427-460.

Hester, T. R., and M. B. Collins

1969 Burials from the Frisch Auf! Site: 41FY42. Texas Journal of Science 20(3):261-272.

Hixson, C.

2003 Horizontal Stratigraphy at the Graham/Applegate Site (41LL419). CTA Newsletter 27(2):12-16.

Huebner, J. A.

1991 Late Prehistoric Bison Populations in Central and Southern Texas. Plains Anthropologist 36(137):343-358.

Jackson, A. T.

1938 The Fall Creek Sites. In University of Texas Anthropological Papers Volume III, No. 1, edited by J. E. Pearce, pp. 11-118. The University of Texas at Austin. 
Jelks, E. B.

1962 Site: The Kyle Stratified Central Texas Aspect Site in Hill County, Texas. Archaeology Series 5. Department of Anthropology, The University of Texas at Austin.

John, E. A. H. (editor)

1989 Views from the Apache Frontier, Report on the Northern Provinces of New Spain. By José Cortés. Translated by J. Wheat. University of Oklahoma Press, Norman.

Johnson, C. W.

1951 Protein as a Factor in the Distribution of the American Bison. Geographical Review 41:330-331.

Johnson, L.

1964 The Devil's Mouth Site: A Stratified Campsite at Amistad Reservoir, Val Verde County, Texas. Archeology Series, No. 6. Department of Anthropology, The University of Texas at Austin.

1991 Early Archaic Life at the Sleeper Archeological Site, 41BC65, of the Texas Hill County, Blanco County, Texas. Publications in Archeology, Report 39. Texas Department of Transportation, Austin.

1994 The Life and Times of Toyah-Culture Folk, The Buckhollow Encampment Site 41KM16, Kimble County, Texas. Office of the State Archeologist Report 38. Texas Department of Transportation and Texas Historical Commission, Austin.

1995 Past Cultures and Climates at Jonas Terrace, 41ME29, Medina County Texas. Office of the State Archeologist Report 40. Texas Historical Commission, Austin.

1997 The Lion Creek Site (41BT105): Aboriginal Houses and Other Remains at a Prehistoric Ranceria in the Texas Hill County (Burnet County). Archeology Studies Program, Report 1. Environmental Affairs Division, Texas Department of Transportation, Austin. And Office of the State Archeologist, Report 41.

2000 Life and Death as Seen at the Bessie Kruze Site (41WM13) on the Blackland Prairie of Williamson County, Texas. Archaeology Studies Program, Report 22. Environmental Affairs Division, Texas Department of Transportation, Austin.

Johnson, L., Jr., and G. T. Goode

1994 A New Try at Dating and Characterizing Holocene Climates, as well as Archeological Periods, on the Edwards Plateau. Bulletin of the Texas Archeological Society 65:1-51.

Johnson, L., Jr., D. A. Suhm, and C. D. Tunnell

1962 Salvage Archaeology of Canyon Reservoir: The Wunderlich, Footbridge, and Oblate Sites. Bulletin No. 5. Texas Memorial Museum, The University of Texas at Austin.

Kelley, D. B.

1971 Indian Tribes of Texas, edited by D. H. Winfrey. Texian, Waco.

1994 The McLelland and Joe Clark Sites: Protohistoric-Historic Caddoan Farmsteads in Southern Bossier Parish, Louisiana. Report submitted to the U.S. Army Corps of Engineers by the Coastal Environments, Inc., Baton Rouge.

Kelley, J. C.,

1947 The Lehmann Rock Shelter: A Stratified Site of the Toyah, Uvalde, and Round Rock Foci. Bulletin of the Texas Archeological and Paleontological Society 118:115-128.

1959 The Desert Cultures and the Balcones Phase: Archaic Manifestations in the Southwest and Texas. American Antiquity 24:276-288.

1986 Jumano and Patarabueye: Relations at La Junta de los Rios. University of Michigan Museum of Anthropology Papers 77. Ann Arbor. 
Kelley, J. C., and T. N. Campbell

1942 What are the Burnt Rock Mounds of Texas? American Antiquity 7(3):319-323.

Kelly, T. C.

1961 The Crumley Site: A Stratified Burnt Rock Midden, Travis County, Texas. Bulletin of the Texas Archeological Society 31:239-272.

Kent, S.

1991 The Relationship between Mobility Strategies and Site Structure. In The Interpretation of Archaeological Spatial Patterning, edited by E. M. Kroll and T. D. Price, pp. 33-60. Plenum Press, New York.

Kibler, K. W., and A. M. Scott

2000 Archaic Hunters and Gatherers of the Balcones Canyonlands: Data Recovery from the Cibola Crossing Site (41BX377), Camp Bullis Military Reservation, Bexar County, Texas. Reports of Investigations, Number 126. Prewitt \& Associates, Inc., Austin.

Kirchhoff, P.

1944 La Unidad Basica de la Cultura de los Recolectores-Cazadores del Norte de Mexico. In El Norte de Mexico y el Sur de Estados Unidos, pp. 133-144. Sociedad Mexicana de Antropologia. Castillo de Chapultepec, Mexico.

Lintz, C., A. Treece, and F. Oglesby

1995 The Early Archaic Structure at the Turkey Bend Ranch Site (41CC112), Concho County. In Advances in Texas Archeology, Contributions from Cultural Resource Management, edited by J. E. Bruseth and T. K. Perttula, pp. 155-185. Cultural Resource Management Report 5. Texas Historical Commission, Department of Antiquities, Austin.

Lukowski, P.

1988 Archaeological Investigations at 41BX1, Bexar County, Texas. Archaeological Survey Report, No. 135. Center for Archaeological Research, The University of Texas at San Antonio.

1994 A New Try at Dating and Characterizing Holocene Climates, as well as Archeological Periods, on the Eastern Edwards Plateau. Bulletin of the Texas Archeological Society 65:1-51.

Mahoney, R. B., H. J. Shafer, and F. A. Weir

2003a An Assessment of 41TV163, a Multicomponent Site in Travis County, Texas. Manuscript on file Center for Archaeological Research, The University of Texas at San Antonio.

Mahoney, R. B., H. J. Shafer, S A. Tomka, L. C. Nordt, and R. P. Mauldin

2003b Royal Coachman (41CM111): An Early Middle Archaic Site along Cordova Creek I Comal County, Texas. Archaeological Survey Report, No. 332, Center for Archeological Research, The University of Texas at San Antonio; Archeological Studies Program, Report. 49, Environmental Affairs Division, Texas Department of Transportation, Austin.

Mallouf, R. J.

1999 Comments on the Prehistory of Far Northeastern Chihuahua, the La Junta District, and the Cielo Complex. Journal of Big bend Studies. Sul Ross State University, Alpine.

Margry, P.

1875-1888 Découvertes et éstablishssements des Francis dans l'ouest et dans le sud de l'Amérique Septentrionale (1614-1754). Mémoires et documents inedits, 6 vols. Paris. 
Martin, W. A., and J. E. Bruseth

1987 Description and Analysis of Cultural Features. In The Bird Point Island and Adams Ranch Sites: Methodological and Theoretical Contributions to North Central Texas Archaeology, edited by J. Bruseth and W. Martin, pp. 127142. Richland Creek Technical Series, Volume II. Archaeology Research Program, Southern Methodist University, Dallas.

Mauldin, R. P., D. L. Nickels, and C. J. Broehm

2003 Archaeological Testing to Determine the National Register Eligibility Status of 18 Prehistoric Sites on Camp Bowie, Brown County, Texas. 2 volumes. Archaeological Survey Report, No. 334. Center for Archaeological Research, The University of Texas at San Antonio.

Mehalchick, G., D. K. Boyd, K. W. Kibler, and C. Ringstaff

2003 Shifting Sands and Geophytes: Geoarcheological Investigations at Paluxy Sites on Fort Hood, Texas. Archeological Resource Management Series Research Report No. 48, United States Army, Fort Hood. (Draft)

National Climate Data Center (NCDC)

2003 Online Climate Data for Austin, Texas. Available at <http://lwf.ncdc.noaa.gov/ oa/climate/climatedata.html $>$

Newcomb, W. W., Jr.

1961 Indians of Texas: From Prehistoric to Modern Times. The University of Texas Press, Austin.

Nickels, D. L., C. B. Bousman, J. D. Leach, and D. A. Cargill

2001 Test Excavations at the Culebra Creek Site, 41BX126, Bexar County, Texas. Archaeological Survey Report, No. 265. Center for Archaeological Research, The University of Texas at San Antonio. Archeological Studies Program, Report 3. Environmental Affairs Division, Texas Department of Transportation, Austin.

Nickels, D. L., and R. P. Mauldin

2001 An Archaeological Survey of Twin Buttes Reservoir, Tom Green County, Texas. Archaeological Survey Report, No. 300. Center for Archaeological Research, The University of Texas at San Antonio.

Ohl, A. J., and W. A. Cloud

2001 Archeological Survey of Select Boundary and Power Line Segments, Big Bend Ranch State Park, Presidio County, Texas. Reports in Contract Archaeology No. 3. Center for Big Bend Studies, Alpine.

Parry, W. J., and R. L. Kelly

1987 Expedient Core Technology and Sedentism, In The Organization of Core Technology, edited by J. K. Johnson and C. A. Morrow, pp. 285-304. Westview Press, Boulder.

Patterson, P. E.

1987 Archaeological Excavations at 41LL78, The Slab Site, Llano County, Texas. Publications in Archaeology Report 34. State Department of Highways and Public Transportation, Highway Design Division, Austin.

Peden, D. G., G. M. Van Dyne, R. W. Rice, and R. M. Hanson

1974 The Trophic Ecology of Bison bison on Shortgrass Plains. Journal of Applied Ecology 11:489-497.

Perttula, T. K.

1997 The Caddo Nation: Archaeological and Ethnographic Perspectives. University of Texas Press, Austin. 
Perttula, T. K. (editor)

1999 The Hurricane Hill Site (41HP106): The Archaeology of a Late Archaic/Early Ceramic and Early-Middle Caddoan Settlement in Northeast Texas. 2 Vols. Special Publication No. 4. Friends of Northeast Texas Archaeology, Pittsburgh and Austin.

Perttula, T. K., R. C. Fields, J. E. Corbin, and N. A. Kenmotsu

1993 The Emergence of Sedentism in Northeast Texas, ca. 500 B.C to A.D. 1000. In Archeology in the Eastern Planning Region, Texas: A Planning Document, edited by N. A. Kenmotsu and T. K. Perttula. Cultural Resource Management Report 3. Department of Antiquities Protection, Texas Historical Commission, Austin.

Peter, D. E., and D. E. McGregor

1988 Site 41DL148: Cobb-Pool. In Late Holocene Prehistory of the Mountain Creek Drainage: Joe Pool Lake Archaeological Project, Volume 1, edited by D. E. Peter and D. E. McGregor, pp. 131-198. Archaeology Research Program, Institute for the Study of Earth and Man, Southern Methodist University, Dallas.

Pianka, E. R.

1970 On r and K Selection. American Naturalist 100:592-597.

Potzger, J. E., and B. C. Tharp

1943 Pollen records of Canadian Spruce and Fir from a Texas Bog. Science 98:584.

1947 Pollen Profile from a Texas Bog. Ecology 28:274-280.

Prewitt, E. R.

1974 Archeological Investigations at the Loeve-Fox Site, Wliamson County, Texas. Research Report 49. Texas Archeological Survey, The University of Texas at Austin.

1981 Culture Chronology in Central Texas. Bulletin of the Texas Archeological Society 52:65-89.

1982 Archaeological Investigations at the Loeve-Fox, Loeve, and Tombstone Bluff Sites in the Granger Reservoir Lake District of Central Texas. In Archaeological Investigations at the San Gabriel Reservoir Districts, Central Texas (Volume 4), assembled by T. R. Hays, pp 188-208. Institute of Applied Sciences, North Texas State University, Denton.

19841984 TAS Field School, Rowe Valley Site, June 9-17. Texas Archeology 28(2):14-17.

1985 From Circleville to Toyah: Comments on Central Texas Chronology. Bulletin of the Texas Archeological Society 54:201-238.

n.d. The Rogers Springs Site: 1974 Investigations. Research Report 54. Unpublished manuscript on file at Texas Archeological Research Laboratory, The University of Texas at Austin.

Quigg, J. M.

1997 Bison Processing at the Rush Site, 41TG346, and Evidence for Pemmican Production in the Southern Plains. Southern Plains Bison Procurement and Utilization from Paleoindian to Historic, edited by L. C. Bement and K. J. Buehler, pp. 145-161. Plains Anthropologist 42(159), Memoir 29.

Ramsey, C. B.

2000 OxCal Program Version 3.5. Radiocarbon Accelerator Unit, University of Oxford, Oxford, UK.

Ricklis, R. A.

1988 Archeological Investigations at the McKenzie Site (41NU221), Nueces County, Texas: Descriptions and Contextual Interpretations. Bulletin of the Texas Archeological Society 58:1-76. 
1994a Toyah Components: Evidence for Occupation in the Project Area during the Latter Part of the Late Prehistoric Period. In Archaic and Late Prehistoric Human Ecology in the Middle Onion Creek Valley, Hays County, Texas, by R. A. Ricklis and M. B. Collins, pp. 191-205. Studies in Archaeology 19. Texas Archeological Research Laboratory, The University of Texas at Austin.

1994b Aboriginal Life and Culture on the Upper Texas Coast: Archaeology at the Mitchell Ridge Site, 41GV66, Galveston Island. Coastal Archaeological Research, Inc., Corpus Christi.

Ricklis, R. A., and M. B. Collins

1994 Archaic and Late Prehistoric Human Ecology in the Middle Onion Creek Valley, Hays County, Texas. Studies in Archaeology 19. Texas Archeological Research Laboratory, The University of Texas at Austin.

Ricklis, R. A., and R. R. Gunter

1986 Archaeological Investigations at the Means Site (41NU184), Nueces County, Texas. La Tierra 13(1):15-32.

Riskind, D. H., and D. D. Diamond

1988 An Introduction to Environments and Vegetation. In Edwards Plateau Vegetation: Plant Ecological Studies in Central Texas, edited by B. B. Amos and F. R. Gehlbach, pp. 1-15. Baylor University Press, Waco.

Saldivar, G.

1943 Los Indios de Tamaulipas. Instituto de Geografia e Historia. Mexico.

Schwartz, C., and J. E. Ellis

1981 Feeding Ecology and Niche Separation in Some Native and Domestic Ungulates on the Shortgrass Prairie. Journal of Applied Ecology 18:343-353.

Schurr, M. R.

1989 Fluoride dating of prehistoric bones by ion selective electrode. Journal of Archaeological Science 16:265-270.

Seymour, D. J.

2003 A Rancheria in the Gran Apacheria: Evidence of Intercultural Interaction at the Cero Rojo Site. Unpublished manuscript on file with H. J. Shafer.

Shafer, H. J.

1963 Test Excavations at the Youngsport Site: A Stratified Terrace Site in Bell County, Texas. Bulletin of the Texas Archeological Society 34:57-81.

1967 An Archeological Survey of Robert Lee Reservoir, Coke County, Texas. Texas Archeological Salvage Project Survey Reports 4. The University of Texas at Austin.

1977 Art and Territoriality in the Lower Pecos Region. Plains Anthropologist 22:13-22.

1986 Ancient Texans: Art and Lifeway of the Lower Pecos. Texas Monthly Press.

Shafer, H. J., and V. M. Bryant

1977 Archeological Investigations at Hinds Cave (41VV435), Val Verde County, Texas. Report submitted to the National Science Foundation by the Department of Anthropology, Texas A\&M University, College Station.

Shafer, H. J., and M. R. Waters

2001 Clovis Archaeology at the Gault Site, Texas: Texas A\&M University Excavations. Paper presented at the $66^{\text {th }}$ Annual Meeting of the Society for American Archaeology, New Orleans. 
Shaw, R. B., K. C. Volman, and F. E. Smeins

1980 Modern Pollen Rain and Vegetation on the Edwards Plateau. Palynology 4:205-213.

Shipman, P., G. Foster, and M Schoeninger

1984 Burnt Bones and Teeth: An Experimental Study of Color, Morphology, Crystal Structure and Shrinkage. Journal of Archaeological Science 11:307-325.

Smith, C. S.

2003 Hunter-gatherer Mobility, Storage, and Houses in a Marginal Environment: An Example from the Mid-Holocene of Wyoming. Journal of Anthropological Archaeology 22:162-189.

Smith, J. E., II, J. C. Blaine, K. Gilmore, R. K. Harris, and I. M. Harris.

1993 The Vinson Site (41LT1): A Norteno Focus Indian Village in Limestone County, Texas. Bulletin of the Texas Archeological Society 64:65-162.

Sollberger, J. B.

1978 A New Type of Arrow Point with Speculations as to its Origin. La Tierra 5(4):13-20.

Sorrow, W. M.

1969 Archeological Investigations at the John Ischy Site: A Burned Rock Midden in Williamson County, Texas. Papers of the Texas Archeological Salvage Project, No. 18. The University of Texas at Austin.

Sorrow, W. M., H. J. Shafer, and R. E. Ross

1967 Excavations at Stillhouse Hollow Reservoir. Papers No. 11. Texas Archeological Survey, The University of Texas at Austin.

Southern Regional Climate Center (SRCC)

2003a Normal Daily Minimum Temperature. $<$ http://www.srcc.lsu.edu/7100/tmin/USMap.html $>$ Accessed February 2003.

2003b Normal Daily Maximum Temperature. <http://www.srcc.lsu.edu/7100/tmax/TX.html > Accessed February 2003.

2003c Normal Monthly Precipitation. <http://www.srcc.lsu.edu/7100/prcp/TX.html>Accessed February 2003.

Steele, D. G., and B. W. Olive

1989 Bioarcheology of the Region 3 Study Area. In From the Gulf to the Rio Grande: Human Adaptation in Central, South, and Lower Pecos Texas, by T. R. Hester, S. L. Black, D. G. Steele, B. W. Olive, A. A. Fox, K. J . Reinhard and L. C. Bement, pp. 93-114. Arkansas Archeological Survey Research Series No. 33. Fayetteville.

Story, D. A.

1965 The Archeology of Cedar Creek Reservoir, Henderson and Kaufman Counties. Texas. Bulletin of the Texas Archeological Society 36:163-257.

Story, D. A., and H. J. Shafer

19651964 Excavations at Waco Reservoir, McLennan County, Texas: The Baylor and Britton Sites. Miscellaneous Papers No. 6. Texas Archeological Salvage Project, University of Texas at Austin.

Suhm, D. A.

1955 Excavations at the Collins Site, Travis County, Texas. Bulletin of the Texas Archeological Society 26:7-54.

1957 Excavations at the Smith Rockshelter, Travis County, Texas. Texas Journal of Science 9(1):26-58.

1959 The Williams Site Central Texas Archeology. Texas Journal of Science 11(2):218-250.

1960 A Review of Central Texas Archaeology. Bulletin of the Texas Archeological Society 28:63-108. 
Swanson, E. R.

1995 Geo-Texas. A Guide to the Earth Sciences. Texas A\&M University Press, College Station, Texas.

Terri, J. A., and L. G. Stowe

1976 Climatic Patterns and the Distribution of C4 Grasses in North America. Oecologia 23:1-12.

Texas Parks and Wildlife Department (TPWD)

1984 TPWD GIS Data. On file Center for Archaeological Research, The University of Texas at San Antonio.

2003 Hill Country Wildlife Management: Vegetation. <http://tpwd.state.tx.us/conserve/wildlife_ management/ hillcountry/vegetation/> Accessed August 21.

Thoms, A. V., D. D. Kuehn, B. W. Olive, J. E. Dockall, P. A. Clabaugh, and R. D. Mandel

1996 Early and Middle Holocene Occupations at the Richard Beene Site: The 1995 Southern Texas Archaeological Association Field School Project. La Tierra 23(4):8-36.

Tomka, S. A.

2001 The Effect of Processing Requirements on Reduction Strategies and Tool Form: A New Perspective. In Lithic Debitage Context, Form, Meaning, edited by W. Andrefsky, Jr., pp. 207-223. The University of Utah Press, Salt Lake City.

Tomka, S. A., and R. C. Fields

1990 Chapter 9: Chipped Stone Artifacts, 41LN29A and 41LN106. In Excavations at the Charles Cox, Lambs Creek Knoll, and Buffalo Branch Sites, Jewett Mine Project, Leon and Freestone Counties, Texas, Volume I, edited by R. C. Fields, pp. 141-287. Report of Investigations, No. 70. Prewitt and Associates, Inc., Austin.

Toomey, R. S.

1993 Late Pleistocene and Holocene Faunal Environmental Changes at Hall's Cave, Kerr County, Texas. Ph.D. dissertation, The University of Texas at Austin. University Microfilms, Ann Arbor.

Toomey, R. S., M. D. Blum, and S. Valastro, Jr.

1993 Late Quaternary Climates and Environments of the Edwards Plateau, Texas. Global and Planetary Change 7:299320.

Treece, A. C., J. M, Quigg, C. Lintz, and K. Miller

1993a Rocky Branch Site (41RN169). In Cultural Resource Investigations in the O. H. Ivie Reservoir, Concho, Coleman, and Runnels Counties, Texas. Volume IV: Data Recovery Results from Ceramic Sites, by A. C. Treece, C. Lintz, W. N. Trierweiler, J. M. Quigg, and K. A. Miller, pp. 31-118. Technical Report No. 346-IV. Mariah Associates, Inc., Austin.

Treece, A. C., J. M. Quigg, K. Miller, and P. L. O’Neill

1993b Currie Site, 41CC131. In Cultural Resoruce Investigations in the O. H. Ivie Reservoir, Concho, Coleman, and Runnels Counties, Texas. Volume IV: Data Recovery Results from Ceramic Sites, by A. C. Treece, C. Lintz, W. N. Trierweiler, J. M. Quigg, and K. A. Miller, pp. 119-306. Technical Report No. 346-IV. Mariah Associates, Inc., Austin.

Tringham, R., G. Cooper, G. Odell, and B. Voytek

1974 Experimentation in the Formation of Edge of Damage: A New Approach to Lithic Analysis. Journal of Field Archaeology 1:171-195. 
Turner, E. S., and T. R. Hester

1999 A Field Guide to Stone Artifacts of Texas. Gulf Publishing Co., Houston.

Turpin, S. A.

1995 The Lower Pecos Region of Texas and Northern Mexico. Bulletin of the Texas Archeological Society 66:541560 .

Fish and Wildlife Service (FWS)

2003 Balcones Canyonlands National Wildlife Refuge. U.S. Fish and Wildlife Service $<$ http://southwest.fws.gov/refuges/ texas/balcones/index.htm> Accessed August 23.

Wade, $\mathrm{M}$.

2003 The Native Americans of the Texas Edwards Plateau, 1582-1799. The University of Texas Press, Austin.

Weir, F. A.

1976 The Central Texas Archaic. Unpublished Ph.D. dissertation. Anthropology Department, Washington State University.

1979 Grenhaw: An Archaic Site in Central Texas. Bulletin of the Texas Archeological Society 50:5-67.

2004 Comments on the Draft Report of the Millican Bench Site: 41TV163. March 26, 2004. Unpublished document on file Center for Archaeological Research, The University of Texas at San Antonio.

Weniger, D.

1997 The Explorers' Texas: The Animals They Found. Eakin Press, Austin.

Werchan, L. E., A. C. Lowther, and R. N. Ramsey

1974 Soil Survey of Travis County, Texas. United States Department of Agriculture, Soil Conservation Service; In cooperation with the Texas Agricultural Experiment Station. U.S. Government Printing Office, Washington, D.C.

Wesolowski, A. B., T. R. Hester, and D. R. Brown

1976 Archeological Investigations at the Jetta Court Site (41TV51), Travis County, Texas. Bulletin of the Texas Archeological Society 47:25-88.

Whalen, M. E.

1980 The Pueblo Period in South-Central New Mexico. In An Archeological Synthesis of South-Central and Southwestern New Mexico, by S. A. LeBlanc and M. E. Whalen, pp. 388-448. Office of Contract Archaeology, University of New Mexico, Albuquerque.

Wilson, E. W.

1930 Burned Rock Mounds of Southwest Texas. Bulletin of the Texas Archeological and Paleontological Society 2:59-63.

Woolsey, A. M.

1938 Additional Buchanan Lake Sites. In Anthropological Papers Volume III, No. 1, edited by J. E. Pearce, pp. 121145. The University of Texas at Austin.

Yellen, J.

1977 Archaeological Approaches to the Present: Models for Reconstructing the Past. Academic Press, New York. 
Young, D.

1988 An Osteological Analysis of the Paleoindian Double Burial from Horn Shelter Number 2. Central Texas Archeologist 11:13-115.

Young, W. C.

1981 Investigations at the Squawteat Peak Site, Pecos County, Texas. Publications in Archaeology Report 20. Highway Design Division, State Department of Highways and Public Transportation, Austin. 
Appendix A

\section{Vertebrate Faunal Remains}




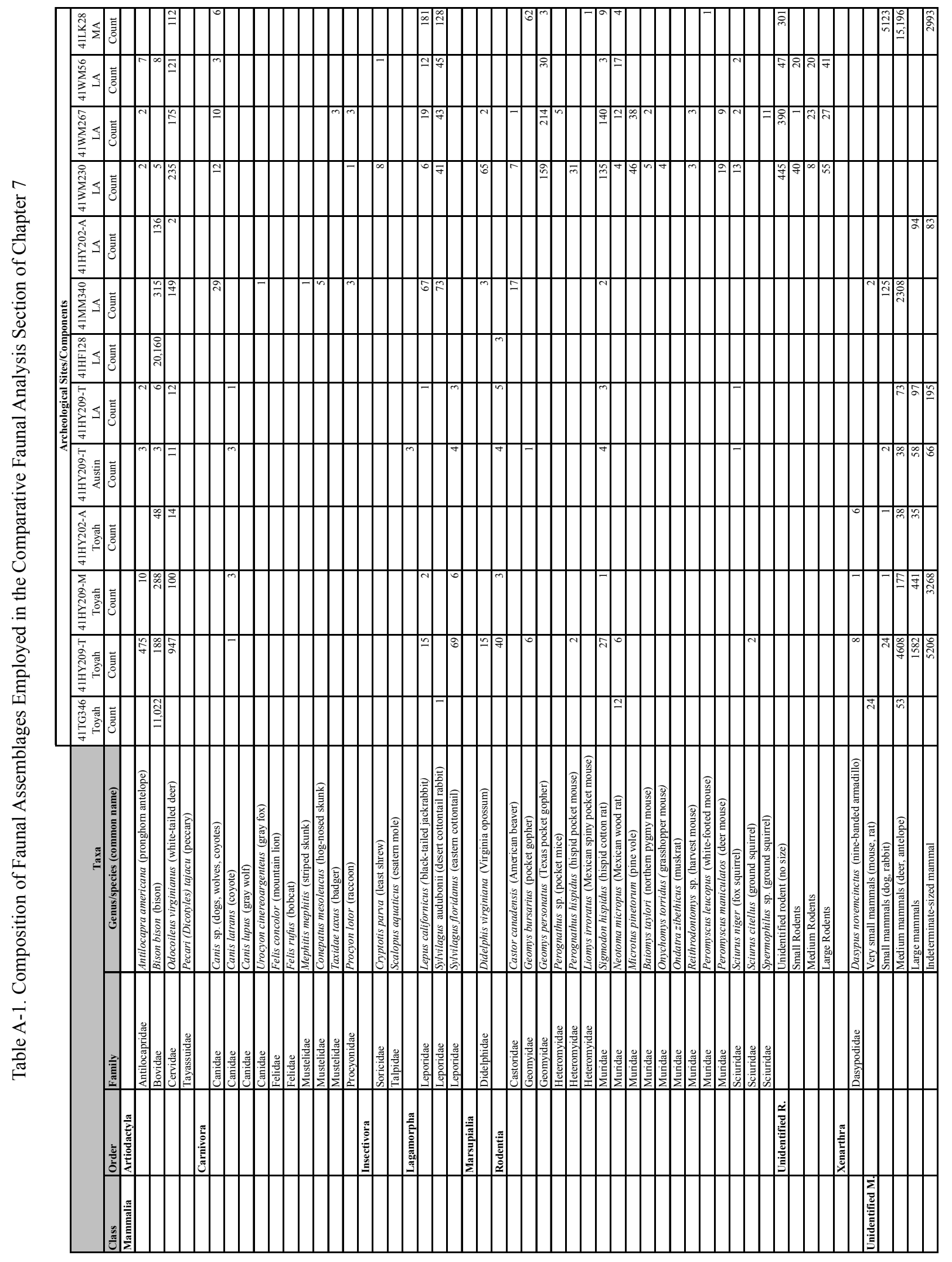




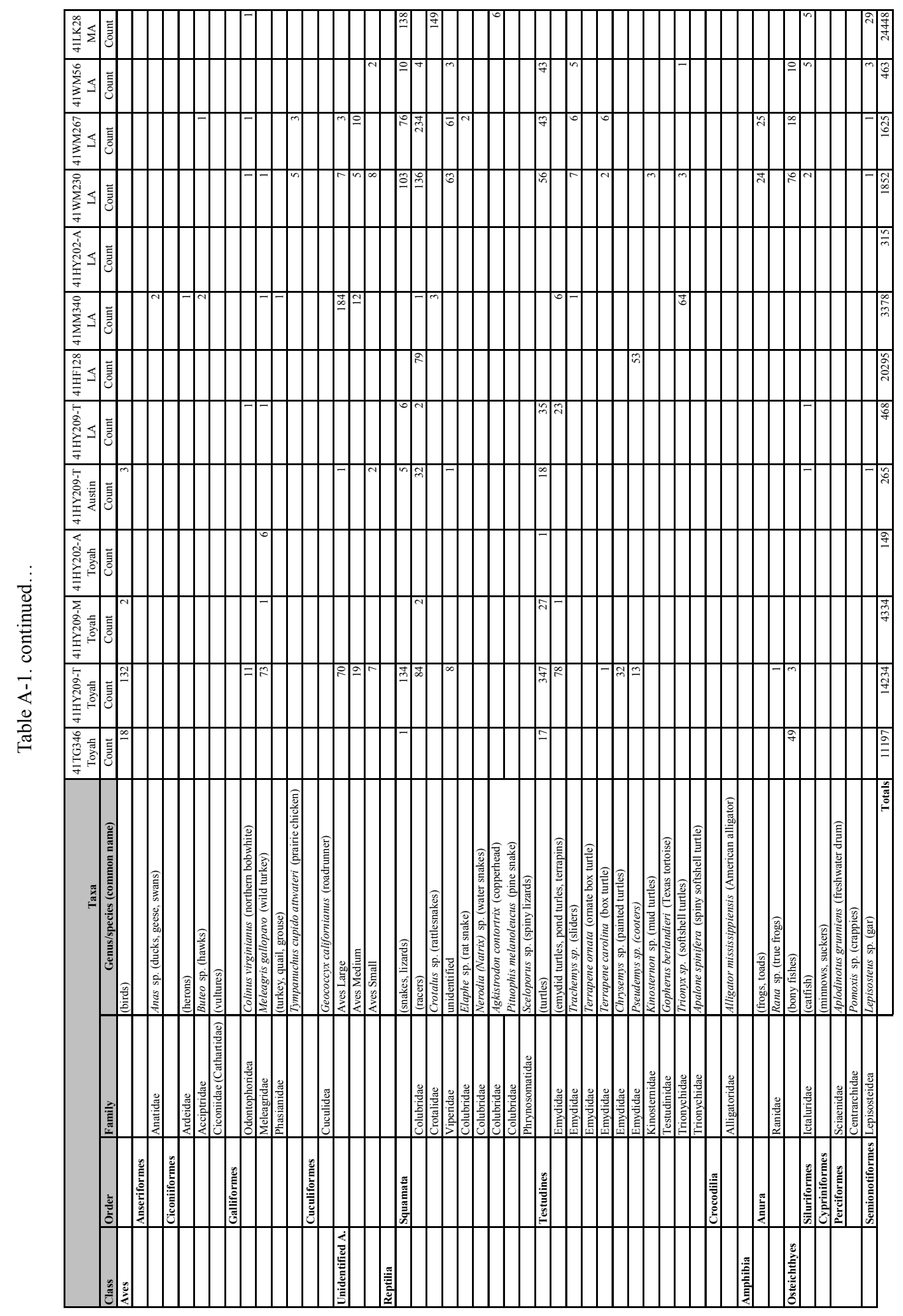


Table A-2. Size Classification of Animal Species Encountered in the Archeological Assemblage Consulted

\begin{tabular}{|c|c|c|c|}
\hline \multicolumn{3}{|r|}{ Taxa } & \multirow[b]{2}{*}{ Body Size } \\
\hline Order & Family & Genus/species (common name) & \\
\hline \multicolumn{4}{|c|}{ Artiodactyla } \\
\hline & Antilocapridae & Antilocapra americana (pronghorn antelope) & $\mathrm{M}$ \\
\hline & Bovidae & Bison bison (bison) & $\mathrm{L}$ \\
\hline & Cervidae & Odocoileus virginianus (white-tailed deer) & $\mathrm{M}$ \\
\hline & Tayassuidae & Pecari (Dicotyles) tajacu (peccary) & $\mathrm{M}$ \\
\hline \multicolumn{4}{|c|}{ Carnivora } \\
\hline & Canidae & Canis sp. (dogs, wolves, coyotes) & $\mathrm{M}$ \\
\hline & Canidae & Canis latrans (coyote) & $\mathrm{M}$ \\
\hline & Canidae & Canis lupus (gray wolf) & M \\
\hline & Canidae & Urocyon cinereoargenteus (gray fox) & $\mathrm{S}$ \\
\hline & Felidae & Felis concolor (mountain lion) & $\mathrm{L}$ \\
\hline & Felidae & Felis rufus (bobcat) & S \\
\hline & Mustelidae & Mephitis mephitis (striped skunk) & $\mathrm{S}$ \\
\hline & Mustelidae & Conepatus mesoleucus (hog-nosed skunk) & $\mathrm{S}$ \\
\hline & Mustelidae & Taxidae taxus (badger) & $\mathrm{S}$ \\
\hline & Procyonidae & Procyon lotor (raccoon) & $\mathrm{S}$ \\
\hline \multicolumn{4}{|c|}{ Insectivora } \\
\hline & Soricidae & Cryptotis parva (least shrew) & VS \\
\hline & Talpidae & Scalopus aquaticus (esatern mole) & VS \\
\hline \multicolumn{4}{|c|}{ Lagamorpha } \\
\hline & Leporidae & Lepus californicus (black-tailed jackrabbit) & $\mathrm{S}$ \\
\hline & Leporidae & Sylvilagus audubonii (desert cottontail rabbit) & $\mathrm{S}$ \\
\hline & Leporidae & Sylvilagus floridanus (eastern cottontail) & $\mathrm{S}$ \\
\hline \multicolumn{4}{|c|}{ Marsupialia } \\
\hline & Didelphidae & Didelphis virginiana (Virginia opossum) & $\mathrm{S}$ \\
\hline \multicolumn{4}{|c|}{ Rodentia } \\
\hline & Castoridae & Castor canadensis (American beaver) & $\mathrm{M}$ \\
\hline & Geomyidae & Geomys bursarius (pocket gopher) & $\mathrm{VS}$ \\
\hline & Geomyidae & Geomys personatus (Texas pocket gopher) & VS \\
\hline & Heteromyidae & Perognathus sp. (pocket mice) & VS \\
\hline & Heteromyidae & Perognathus hispidus (hispid pocket mouse) & VS \\
\hline & Heteromyidae & Liomys irroratus (Mexican spiny pocket mouse) & VS \\
\hline & Muridae & Sigmodon hispidus (hispid cotton rat) & VS \\
\hline & Muridae & Neotoma micropus (Mexican wood rat) & VS \\
\hline & Muridae & Microtus pinetorum (pine vole) & VS \\
\hline & Muridae & Baiomys taylori (northern pygmy mouse) & VS \\
\hline & Muridae & Onychomys torridus (grasshopper mouse) & VS \\
\hline & Muridae & Ondatra zibethicus (muskrat) & $\mathrm{S}$ \\
\hline & Muridae & Reithrodontomys sp. (harvest mouse) & $\mathrm{VS}$ \\
\hline & Muridae & Peromyscus leucopus (white-footed mouse) & VS \\
\hline & Muridae & Peromyscus maniculatos (deer mouse) & VS \\
\hline & Sciuridae & Sciurus niger (fox squirrel) & S \\
\hline & Sciuridae & Sciurus citellus (ground squirrel) & $\mathrm{S}$ \\
\hline & Sciuridae & Spermophilus sp. (ground squirrel) & $\mathrm{S}$ \\
\hline
\end{tabular}


Table A-2. continued...

\begin{tabular}{|c|c|c|c|}
\hline \multicolumn{3}{|r|}{ Taxa } & \multirow[b]{2}{*}{ Body Size } \\
\hline Order & Family & Genus/species (common name) & \\
\hline \multirow[t]{4}{*}{ Unidentified $\mathrm{R}$. } & & Unidentified rodent (no size) & \\
\hline & & Small Rodents & VS \\
\hline & & Medium Rodents & $\mathrm{S}$ \\
\hline & & Large Rodents & $\mathrm{S}$ \\
\hline \multicolumn{4}{|l|}{ Xenarthra } \\
\hline & Dasypodidae & Dasypus novemcinctus (nine-banded armadillo) & $\mathrm{S}$ \\
\hline & & Very small mammals (mouse, rat) & VS \\
\hline & & Small mammals (dog-size) & $\mathrm{S}$ \\
\hline & & Medium mammals (deer/antelope) & $\mathrm{M}$ \\
\hline & & Large mammals & $\mathrm{L}$ \\
\hline \multicolumn{4}{|l|}{ Anseriformes } \\
\hline & Anatidae & Anas sp. (ducks, geese, swans) & $\mathrm{S}$ \\
\hline \multicolumn{4}{|l|}{ Ciconiiformes } \\
\hline & Ardeidae & (herons) & $\mathrm{S}$ \\
\hline & Acciptridae & Buteo sp. (hawks) & $\mathrm{S}$ \\
\hline & Ciconiidae (Cathartidae) & (vultures) & $\mathrm{S}$ \\
\hline \multicolumn{4}{|l|}{ Galliformes } \\
\hline & Odontophoridea & Colinus virginianus (northern bobwhite) & VS \\
\hline & Meleagridae & Meleagris gallopavo (wild turkey) & $\mathrm{S}$ \\
\hline & Phasianidae & (turkey, quail, grouse) & $\mathrm{S}$ \\
\hline & & Tympanuchus cupido attwateri (prairie chicken) & S \\
\hline \multicolumn{4}{|l|}{ Cuculiformes } \\
\hline & Cuculidea & Geococcyx californianus (roadrunner) & $\mathrm{VS}$ \\
\hline & & Aves Large & $\mathrm{S}$ \\
\hline & & Aves Medium & VS \\
\hline & & Aves Small & $\mathrm{VS}$ \\
\hline \multirow[t]{9}{*}{ Squamata } & & (snakes, lizards) & VS \\
\hline & Colubridae & (racers) & $\mathrm{VS}$ \\
\hline & Crotalidae & Crotalus sp. (rattlesnakes) & $\mathrm{VS}$ \\
\hline & Viperidae & unidentified & VS \\
\hline & Colubridae & Elaphe sp. (rat snake) & $\mathrm{VS}$ \\
\hline & Colubridae & Nerodia (Natrix) sp. (water snakes) & $\mathrm{VS}$ \\
\hline & Colubridae & Agkistrodon contortrix (copperhead) & $\mathrm{VS}$ \\
\hline & Colubridae & Pituophis melanoleucus (pine snake) & $\mathrm{VS}$ \\
\hline & Phrynosomatidae & Sceloporus sp. (spiny lizards) & VS \\
\hline \multirow[t]{11}{*}{ Testudines } & & (turtles) & $\mathrm{VS}$ \\
\hline & Emydidae & (emydid turtles, pond turles, terrapins) & $\mathrm{VS}$ \\
\hline & Emydidae & Trachemys sp. (sliders) & VS \\
\hline & Emydidae & Terrapene ornata (ornate box turtle) & $\mathrm{VS}$ \\
\hline & Emydidae & Terrapene carolina (box turtle) & $\mathrm{VS}$ \\
\hline & Emydidae & Chrysemys sp. (painted turtles) & VS \\
\hline & Emydidae & Pseudemys sp. (cooters) & $\mathrm{VS}$ \\
\hline & Kinosternidae & Kinosternon sp. (mud turtles) & $\mathrm{VS}$ \\
\hline & Testudinidae & Gopherus berlandieri (Texas tortoise) & VS \\
\hline & Trionychidae & Trionyx sp. (softshell turtles) & $\mathrm{VS}$ \\
\hline & Trionychidae & Apalone spinifera (spiny softshell turtle) & VS \\
\hline
\end{tabular}


Table A-2. continued...

\begin{tabular}{|c|c|c|c|}
\hline \multicolumn{3}{|r|}{ Taxa } & \multirow[b]{2}{*}{ Body Size } \\
\hline Order & Family & Genus/species (common name) & \\
\hline \multicolumn{4}{|l|}{ Crocodilia } \\
\hline & Alligatoridae & Alligator mississippiensis (American alligator) & $\mathrm{M}$ \\
\hline \multirow[t]{3}{*}{ Anura } & & (frogs, toads) & VS \\
\hline & Ranidae & Rana sp. (true frogs) & $\mathrm{VS}$ \\
\hline & & (bony fishes) & $\mathrm{VS}$ \\
\hline Siluriformes & Ictaluridae & (catfish) & VS \\
\hline Cypriniformes & & (minnows, suckers) & VS \\
\hline \multirow[t]{2}{*}{ Perciformes } & Sciaenidae & Aplodinotus grunniens (freshwater drum) & $\mathrm{S}$ \\
\hline & Centrarchidae & Pomoxis sp. (crappies) & $\mathrm{VS}$ \\
\hline Semionotiformes & Lepisosteidea & Lepisosteus sp. (gar) & $\mathrm{S}$ \\
\hline $\begin{array}{l}\mathrm{L}=\text { Large } \\
\mathrm{M}=\text { Medium }\end{array}$ & $\begin{array}{l}\mathrm{S}=\text { Small } \\
\mathrm{VS}=\text { Very } \mathrm{S}\end{array}$ & & \\
\hline
\end{tabular}


Appendix B

\section{Human Remains}




\title{
Appendix B: Human Remains
}

\author{
Richard B. Mahoney
}

The partial remains of a single burial were encountered in Area C (Feature 10) at 41TV163. The remains are represented primarily by fragmented elements of the skull and arms (see Figure 5-4). Specific cranial elements present include the frontal, both parietals, the temporals, the occipital, both malars, a portion of the palatine and maxilla, the left half of the mandible, two sphenoid fragments, and five teeth. Postcranial elements include both humeri, the left ulna, the left radius, 13 hand phalanges, four metacarpals of the left hand (MC-1 through MC-4), one metacarpal of the right hand (MC-1), two carpals of the right hand, 10 vertebral fragments, two rib fragments, and a portion of the right scapula. The feature notes and numerous photographs document that only the upper portion of the individual was well represented in the feature. Approximately 40 grams of small $(<1 \mathrm{~cm}$ in diameter) unidentifiable fragments comprise the balance of human skeletal material recovered. No duplication exists in the collection, and the remains appear to be from a single individual.

\section{Sex Determination}

Due to the lack of the more confident sexing pelvic elements, sex is based on non-metric traits of the partially reconstructed cranium. Six traits were used to determine the sex of this individual, including observations of the nuchal crest, mastoid processes, supraorbital margins, glabella, mental eminence, and zygomatic arches. Four of these observations indicate a probable female, one observation indicates ambiguous sex, and one observation indicates a probable male. As such, the sex of this individual cannot be determined with absolute certainty. However, given the greater number of observed female traits, this individual is classified as a probable female.

\section{Age Determination}

Specific age range determination was not possible due to the lack of requisite skeletal elements. Several morphologic traits were observed, however, to indicate that these remains are that of an adult. Specifically, the two long bone articular surfaces present (proximal left ulna and distal left humerus) exhibit complete epiphyseal fusion. Moreover, lipping and pitting along the ulna joint surface, indicative of osteoarthritis, is evident, further suggesting advanced adult age. Alveolar resorption of the posterior portion of the mandible in combination with the extreme dental attrition similarly suggests advanced adulthood.

\section{Biological Affiliation}

No skeletal elements outwardly signaling biological affiliation are contained in the human remains assemblage. The recovery of the remains in context with a prehistoric campsite in central Texas, however, demonstrates the remains are of Native American affiliation.

\section{Stature Estimation}

Estimation of stature is not possible due to the fragmented nature of the long bones.

\section{Circumstances Surrounding the Manner of Death}

Due to the fragmentary and incomplete nature of the remains, it is not possible to determine the circumstances surrounding the manner of death. All bone present was inspected for evidence of perimortem trauma or pathologies that may have contributed to the death of this individual, but none were indicated.

\section{Taphonomy}

Several natural, postdepositional factors have affected the human remains assemblage, including chemical, rodent, and carnivore activities. Chemical weathering has affected the cortical surfaces of the majority of the assemblage. Rodent gnawing is present on most of the long bones, most notable along the humeral diaphyses. Carnivore tooth marks are visible along the proximal portion of the left humerus and articular ends of the lone right metacarpal. It is possible that the latter natural force is responsible for the absence of the majority of the postcranial skeleton. 


\section{Pathology}

Two pathologies were noted during examination of the skeletal remains. Osteoarthritis, a relatively common degenerative bone disorder typically occurring in load bearing joints, was noted along the extant portion of the left ulna proximal articular surface. Lipping and pitting along this joint surface is evident, although no eburnation was present here or along the trochlea of the left humerus. Porotic hypertosis, a hematopoietic disorder wherein the diploë of the cranium becomes thickened and sponge-like, was noted on the posterior of the occipital, superior to the nuchal crest.

\section{Summary}

Age at Death: $>35$

Sex: Probable Female

Ethnicity: Native American

Manner of Death: Indeterminate

Temporal Affiliation: Late Archaic 


\section{INVENTORY RECORDING FORM FOR COMPLETE SKELETONS}

Site Name/Number Millican Bench/41TV163 Observer RB Mahoney

Feature/Burial Number $\quad 10 / 1$ Date 12-03

Burial/Skeleton Number $\quad 1 / 1$

Present Location of Collection UTSA-CAR

\section{CRANIAL BONES AND JOINT SURFACES}

Frontal

Parietal

Occipital

Temporal

TMJ

\begin{tabular}{l} 
R(right) \\
1 \\
\hline 1 \\
\hline 2 \\
\hline 2 \\
\hline 1
\end{tabular}

Sphenoid

Zygomatic

Maxilla

Palatine

Mandible

\begin{tabular}{c}
$\mathrm{L}$ \\
3 \\
\hline 2 \\
\hline 3 \\
\hline \\
\hline 1 \\
\hline
\end{tabular}

$\mathrm{L}$

$\mathrm{R}$

Os Coxae
Ilium

1schium

Pubis

Acetabulum

Auric. Surface

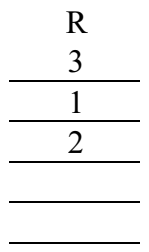

Clavicle

Glenoid f.

Patella

Sacrum

VERTEBRAE (individual)

C1

$\mathrm{C} 2$

C7

T10

T11

T12

L1

L2

L3

L4

L5

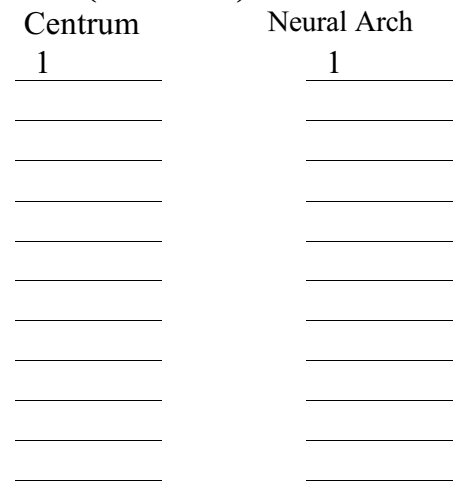

\section{RIBS (individual)}

L

$$
\begin{aligned}
& 1 \mathrm{St} \\
& 2 \mathrm{nd} \\
& 11 \mathrm{th} \\
& 12 \mathrm{th}
\end{aligned}
$$

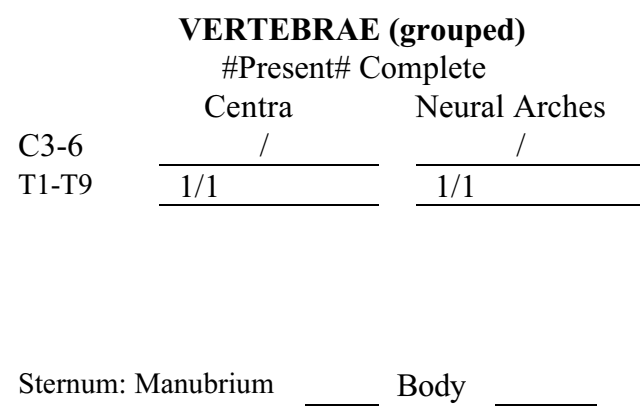

RIBS (grouped) \#Present/\# Complete

3-10

\begin{tabular}{lll}
$\mathrm{L}$ & $\mathrm{R}$ & $2^{\text {Unsided }}$ \\
1 & 1 \\
\hline
\end{tabular}




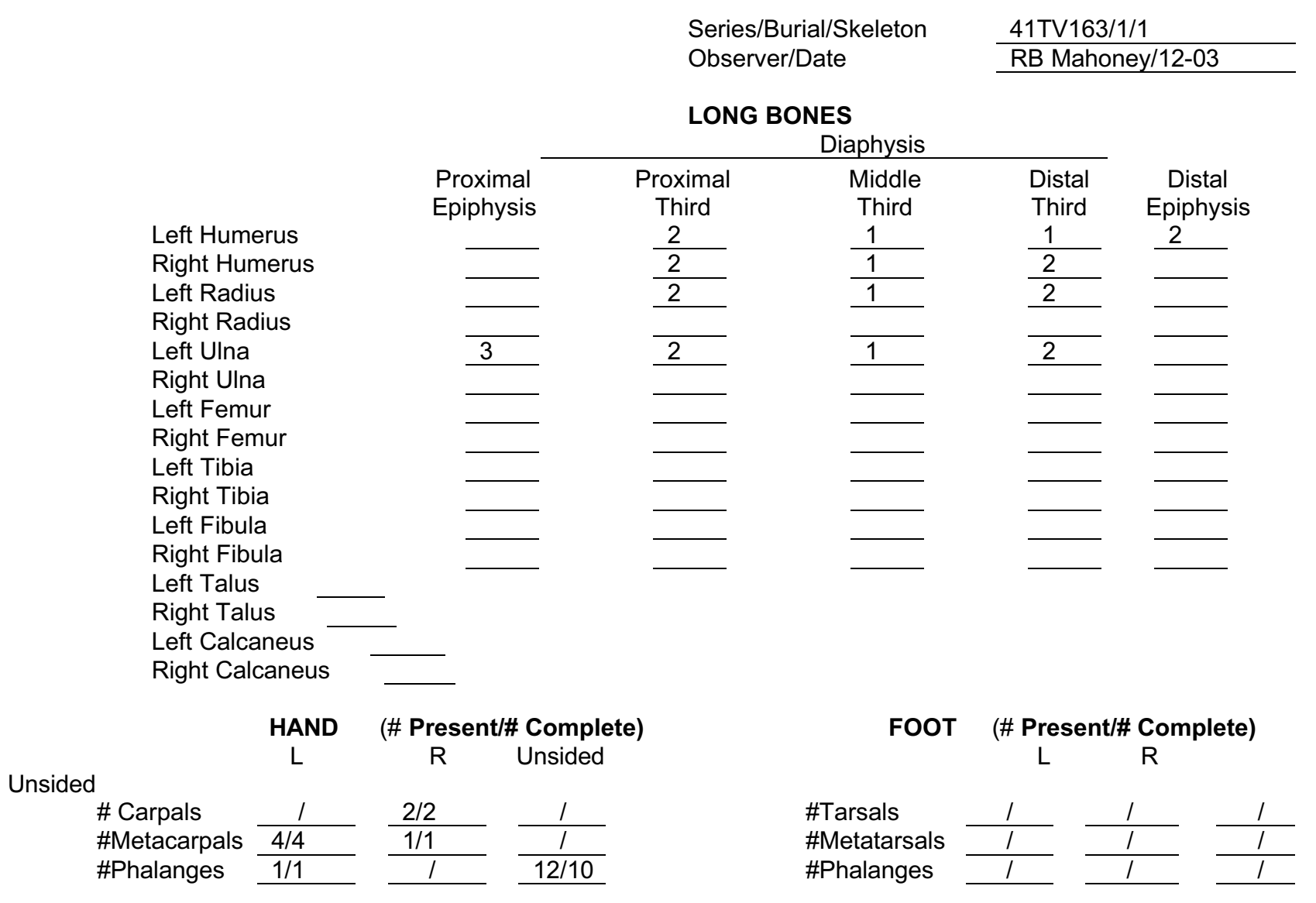

Comments: 


\section{ADULT SKELETON RECORDING FORM : ANTERIOR VIEW}

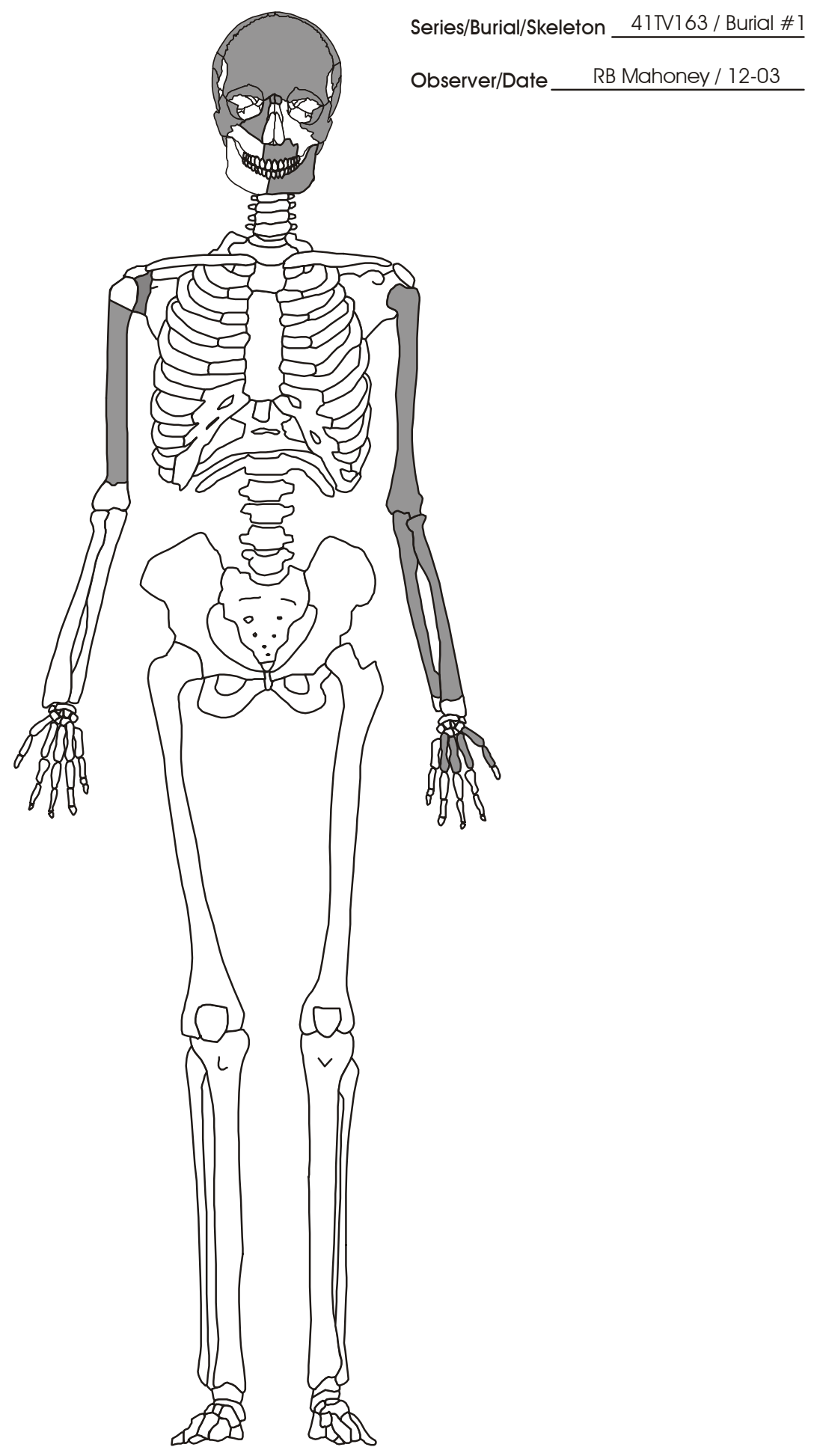




\section{ADULT SKELETON RECORDING FORM : POSTERIOR VIEW}
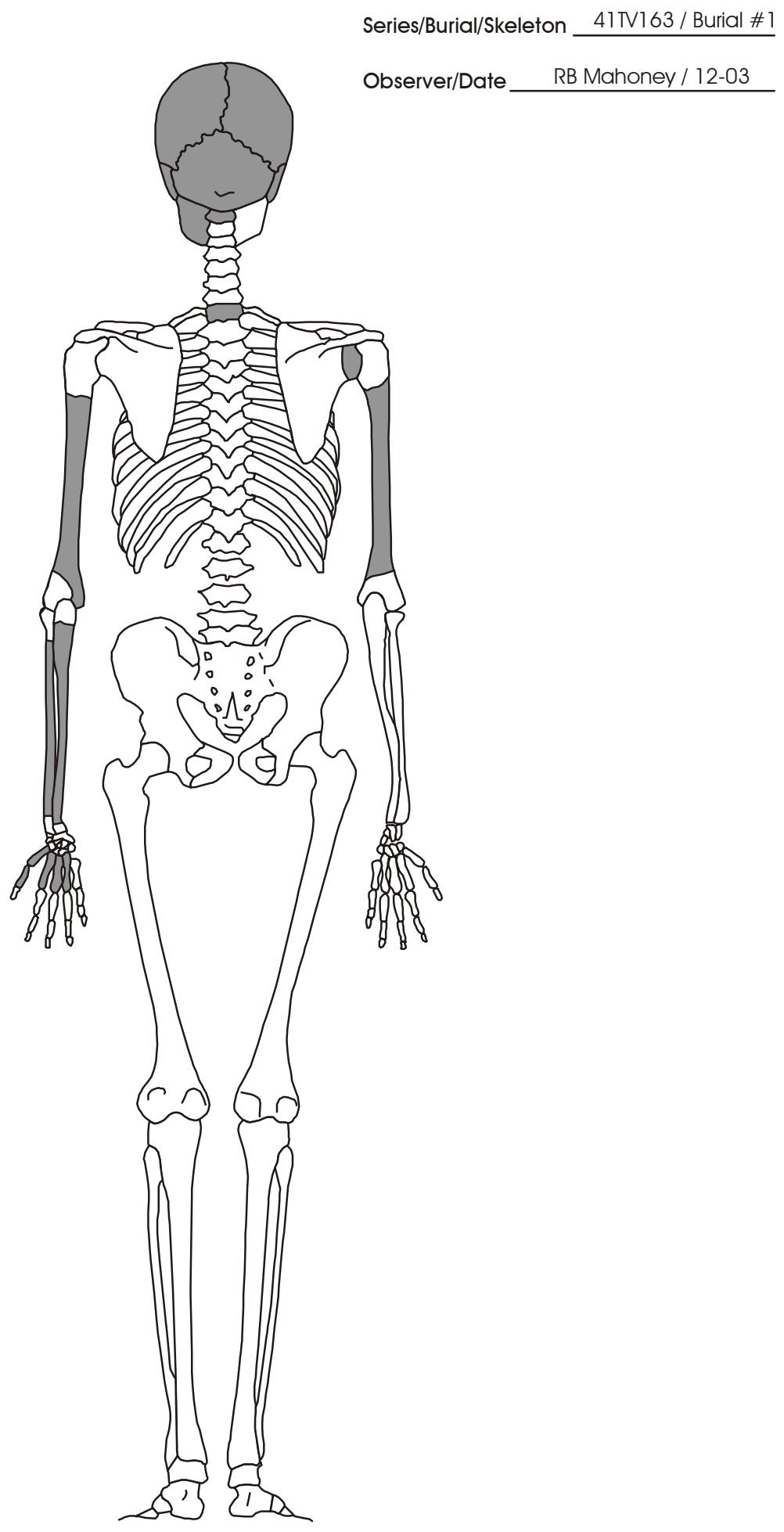


\section{ADULT SKELETON RECORDING FORM : RIGHT LATERAL VIEW}

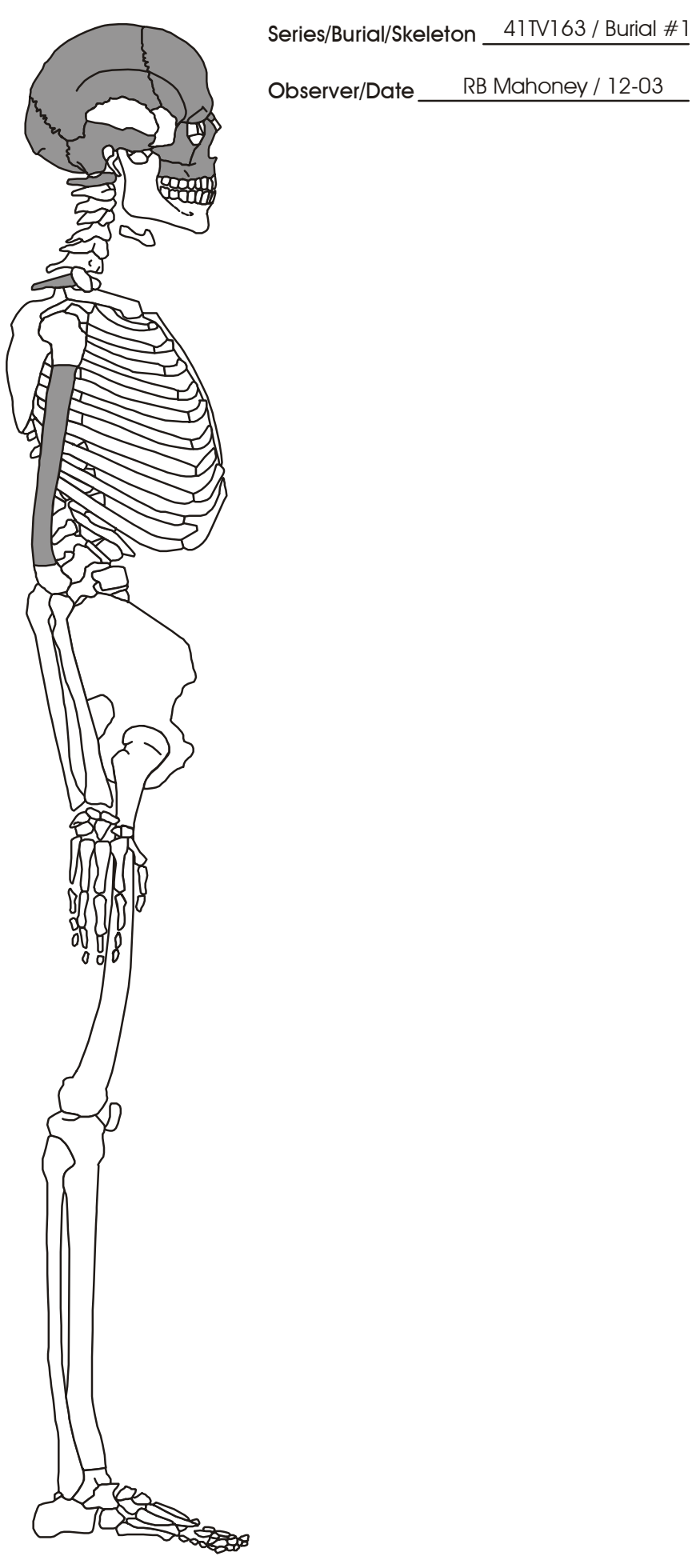




\section{ADULT SKELETON RECORDING FORM : LEFT LATERAL VIEW}
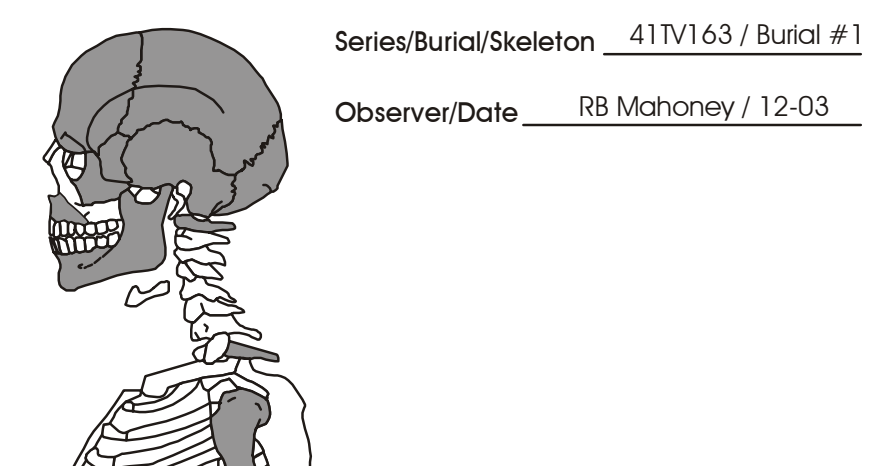


\section{SKULL RECORDING FORM : ANTERIOR VIEW}

Series/Burial/Skeleton 41TV163 / Burial \# 1

Observer/Date__ RB Mahoney / 12-03

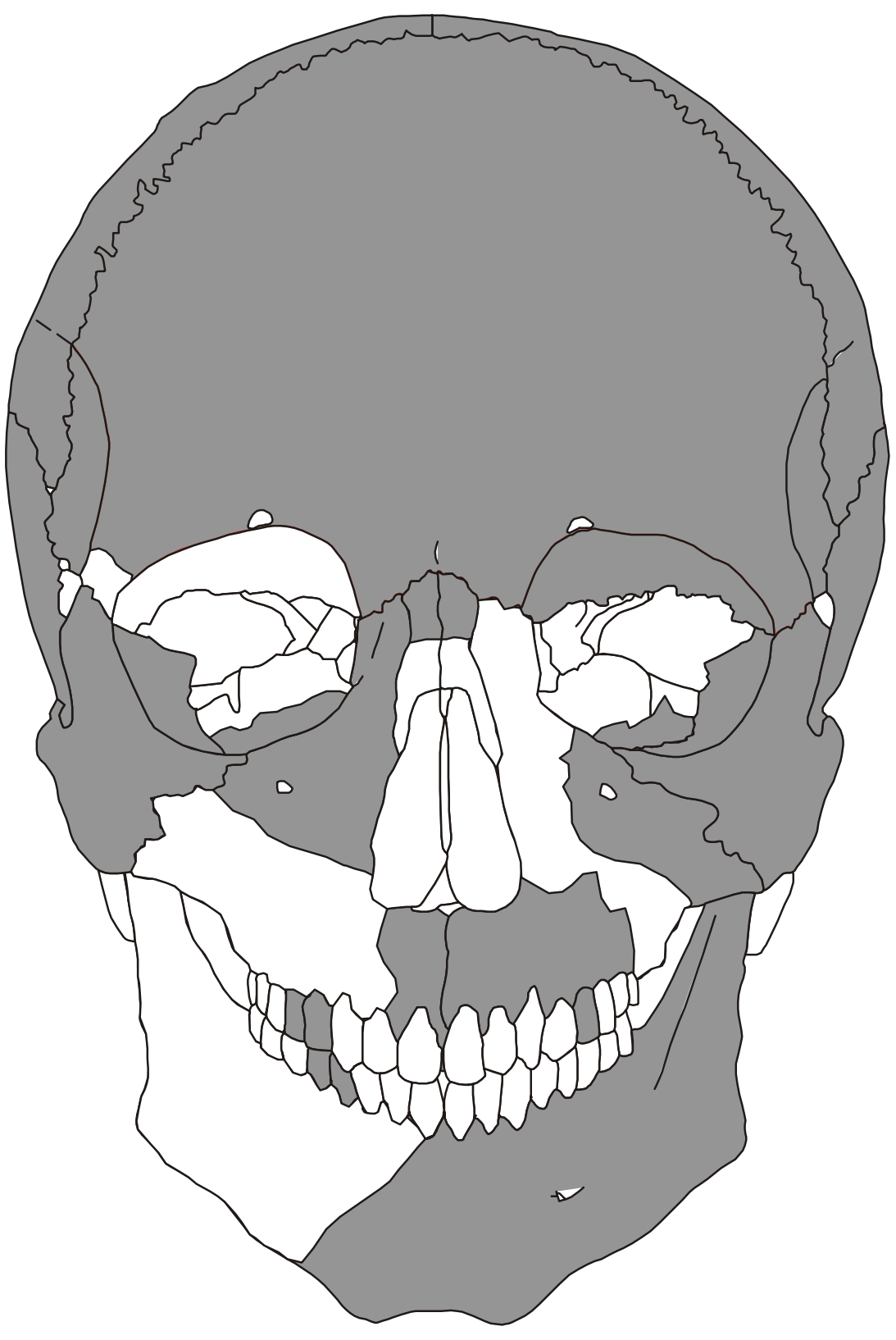




\section{SKULL RECORDING FORM : POSTERIOR VIEW}

Series/Burial/Skeleton 411V163 / Burial \#1

Observer/Date_ RB Mahoney / 12-03

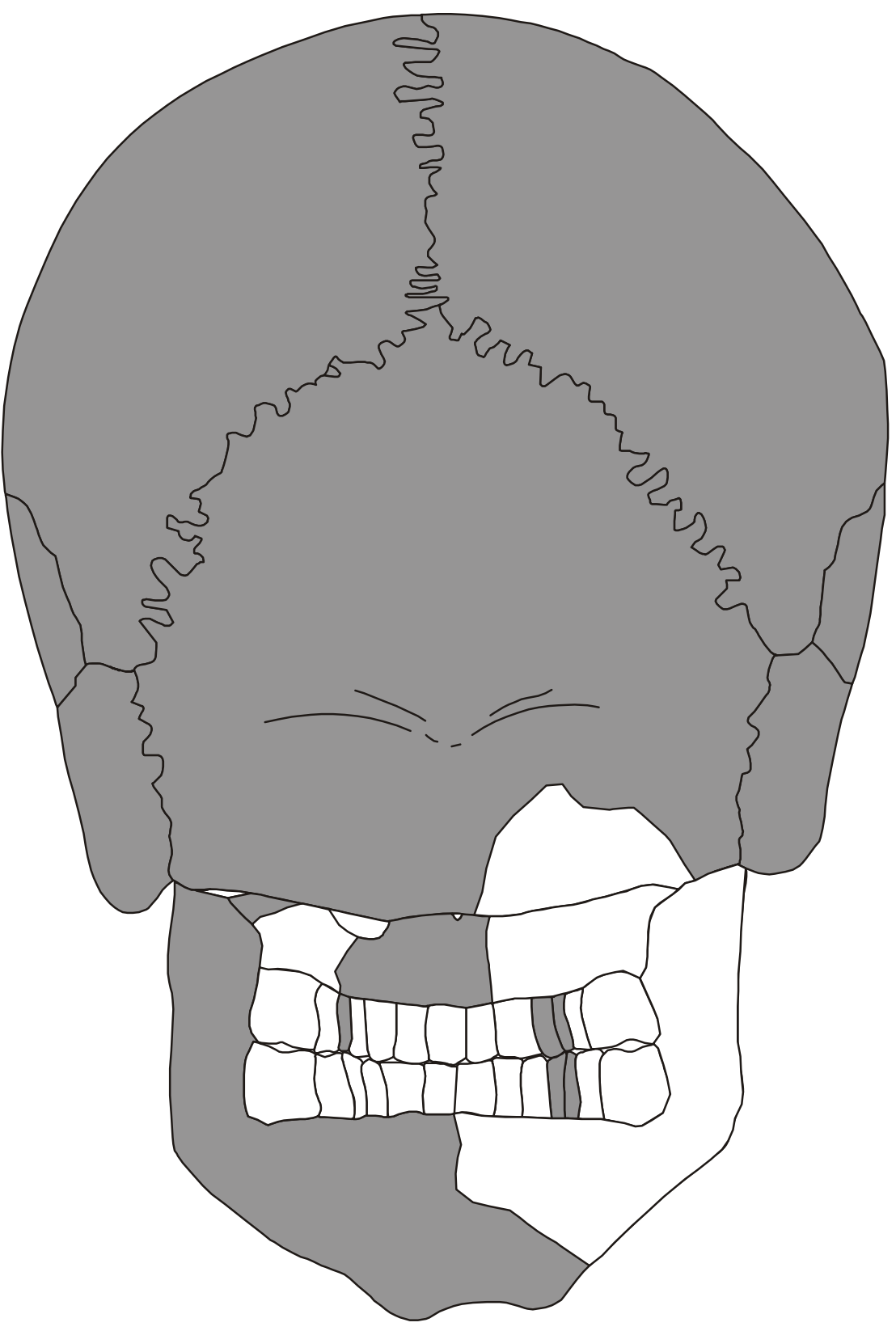




\section{SKULL RECORDING FORM : RIGHT LATERAL VIEW}

Series/Burial/Skeleton $41 \mathrm{TV} 163$ / Burial \# 1

Observer/Date _ RB Mahoney / 12-03

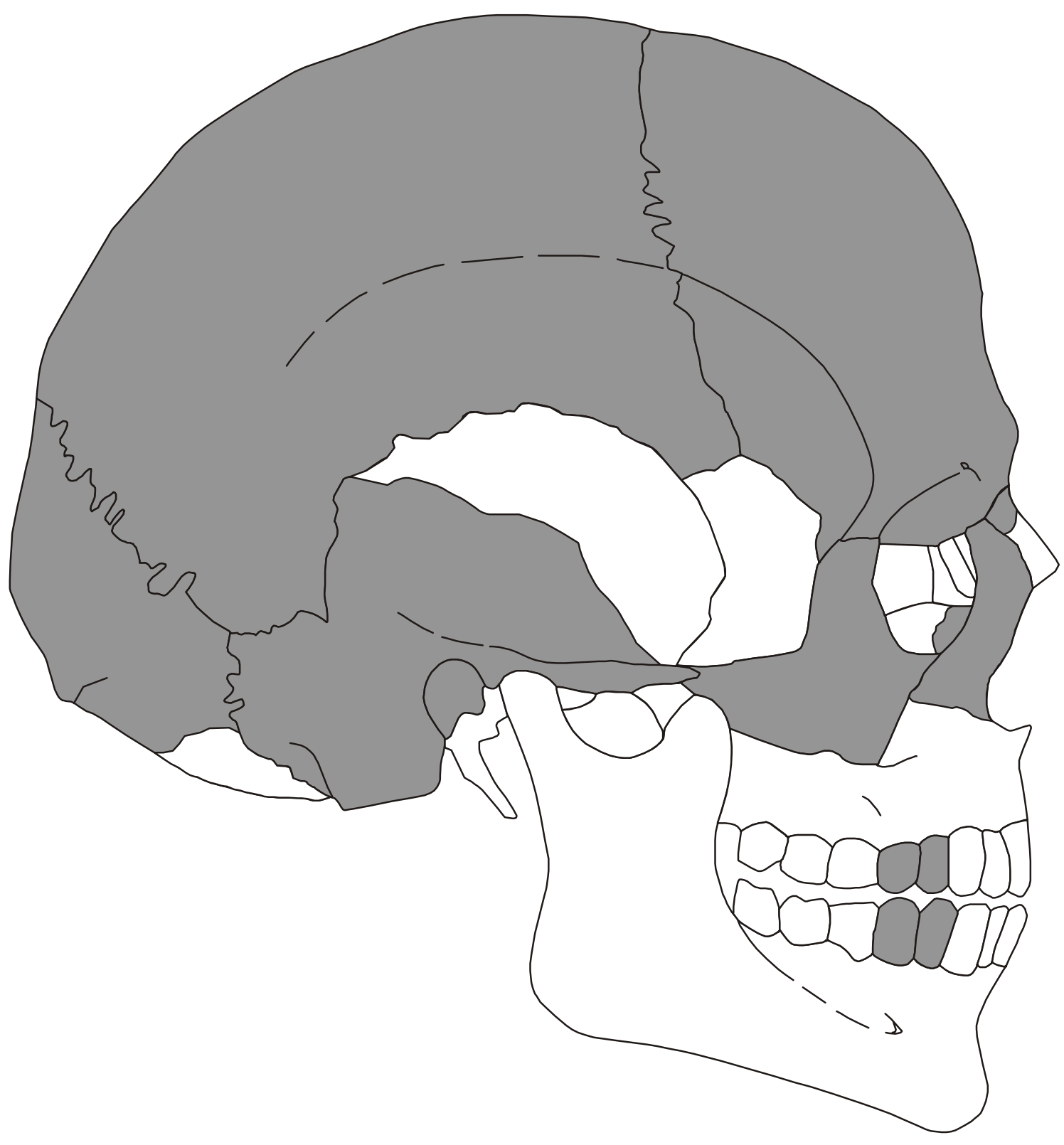




\section{SKULL RECORDING FORM : LEFT LATERAL VIEW}

Series/Burial/Skeleton 41TV163/Burial \#1

Observer/Date _ RB Mahoney / 12-03

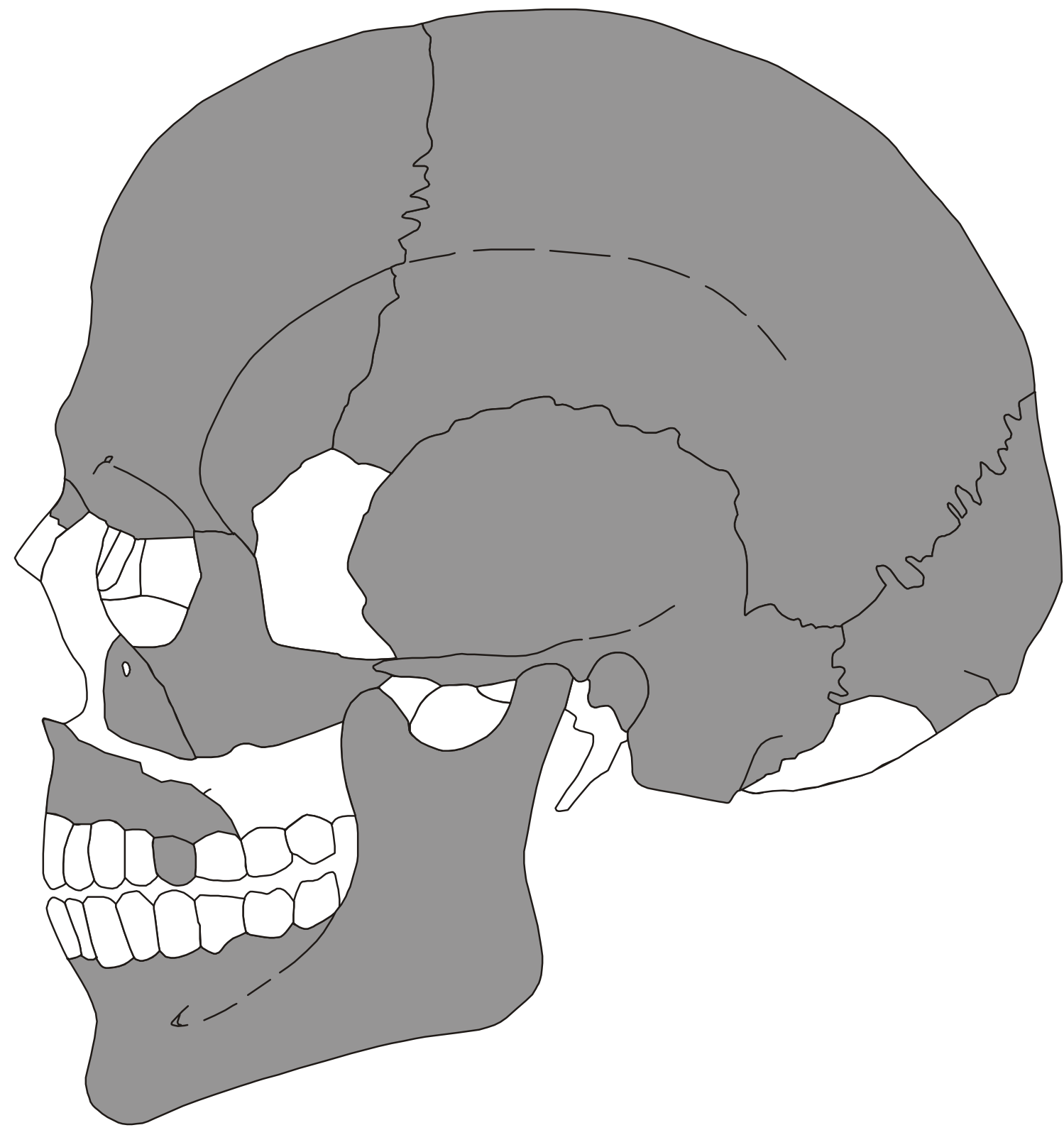




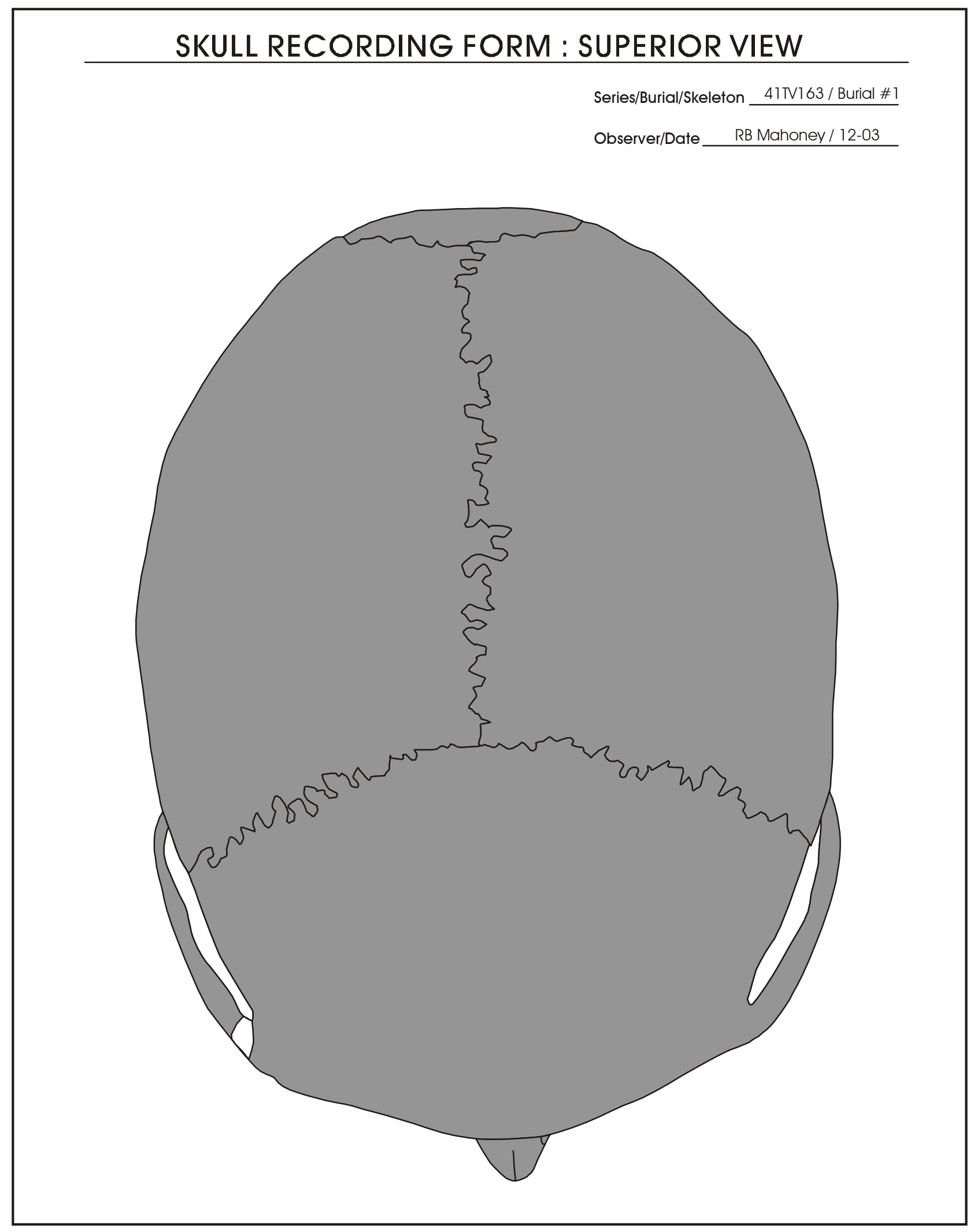




\section{SKULL RECORDING FORM : BASILAR VIEW}

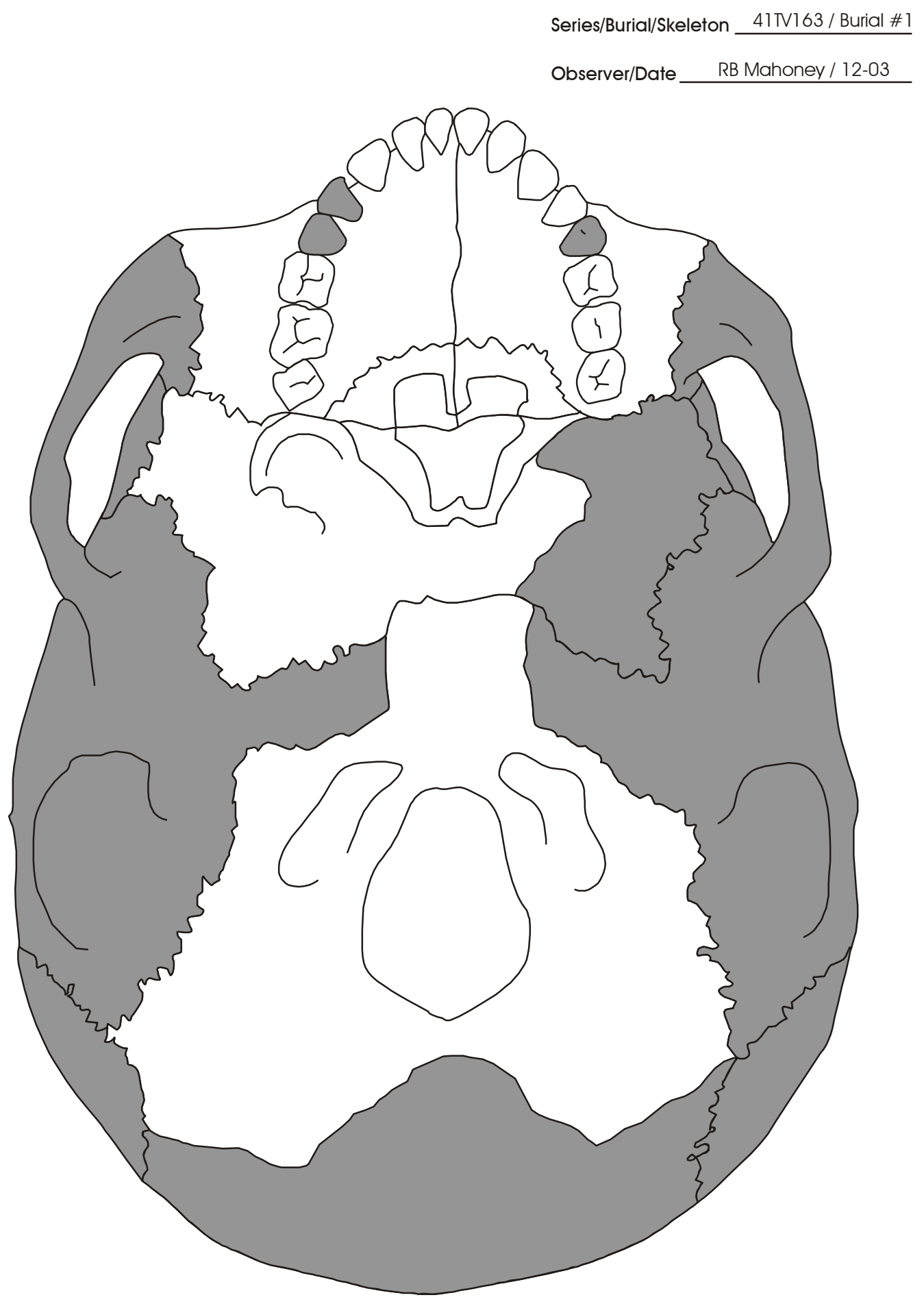




\section{POSTCRANIAL BONES VISUAL RECORDING FORM RIGHT OS COXAE, SCAPULA, CLAVICLE}

Series/Burial/Skeleton 41TV163/Burial \# 1

Observer/Date _ RB Mahoney / 12-03
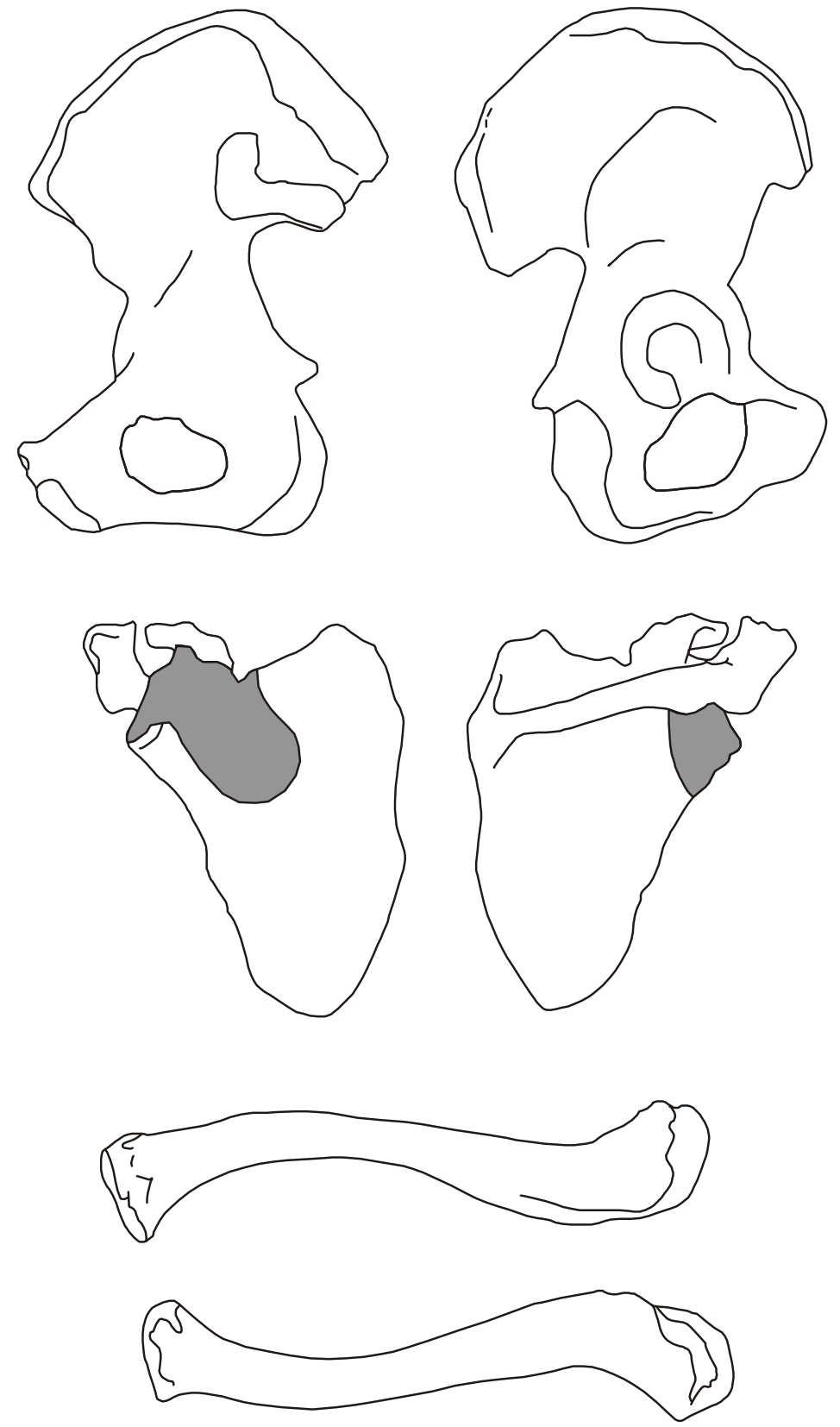


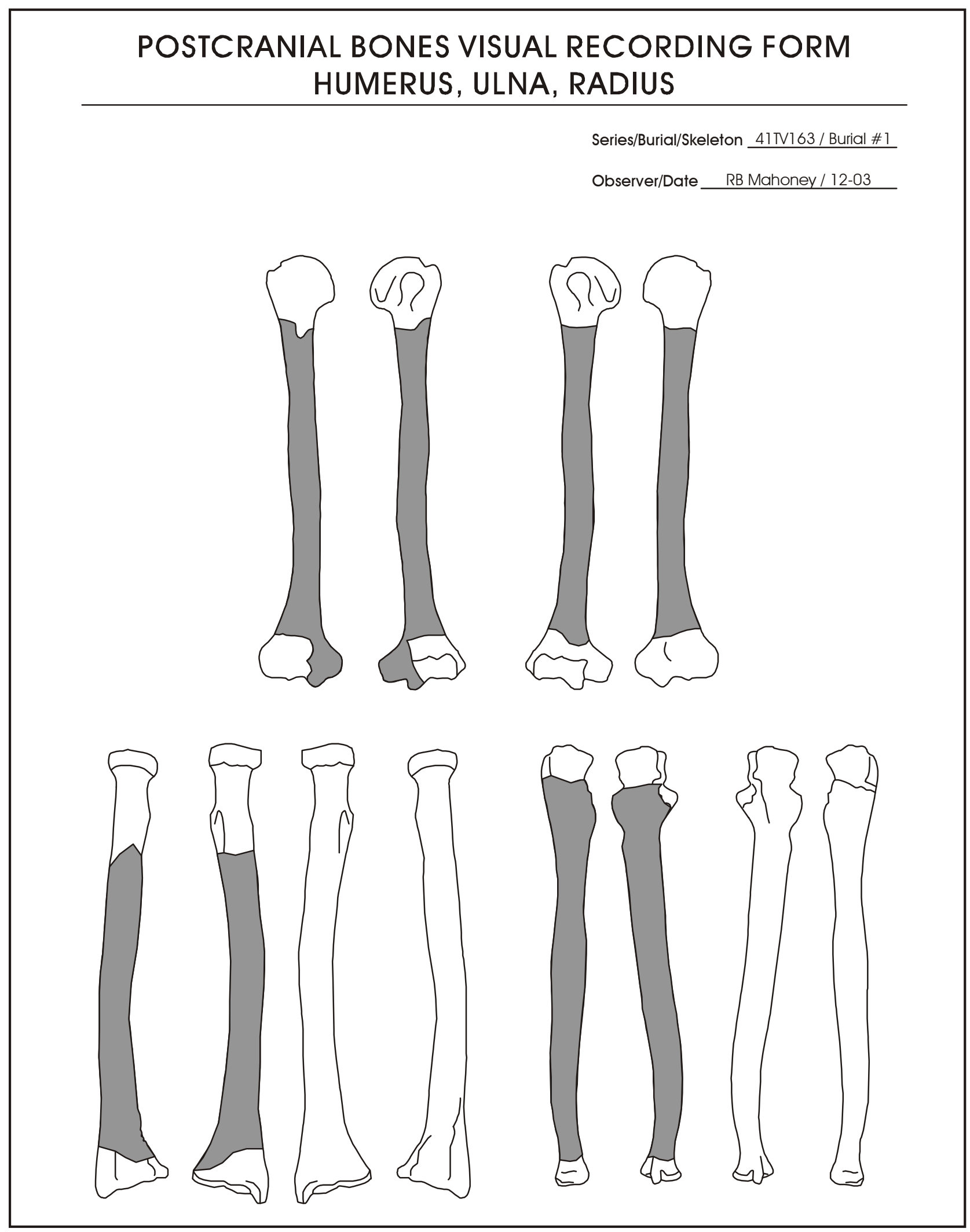




\section{ADULT SEX/AGE RECORDING FORM}

\begin{tabular}{|c|c|c|c|c|c|c|c|}
\hline Site Name/Number & \multicolumn{2}{|c|}{ Millican } & / 41TV163 & \multirow{4}{*}{$\begin{array}{l}\text { Observer } \\
\text { Date }\end{array}$} & \multicolumn{3}{|c|}{ RB Mahoney } \\
\hline Feature/Burial Number & 10 & $/ 1$ & & & \multicolumn{3}{|c|}{$12-03$} \\
\hline Burial/Skeleton Number & 1 & \multicolumn{2}{|l|}{$/ 1$} & & & & \\
\hline \multirow[t]{2}{*}{ Present Location of Collection } & UTS & & & & & & \\
\hline & \multicolumn{3}{|c|}{ SEX } & & & & \\
\hline $\begin{array}{l}\text { Pelvis } \\
\text { Ventral Arc }(1-3)\end{array}$ & $\mathrm{L}$ & $\mathrm{R}$ & $\begin{array}{l}\text { Skull } \\
\quad \text { Nuchal }\end{array}$ & rest $(1-5)$ & $\mathrm{L}$ & $2^{\mathrm{M}}$ & $\mathrm{R}$ \\
\hline Subpubic Concavity (1 -3) & & & Mastoi & rocess $(1-5)$ & 2 & & 2 \\
\hline Ischiopubic Ramus Ridge (1 -3) & & & Suprao & tal Margin (1-5) & 4 & & 4 \\
\hline Greater Sciatic Notch (1 -5) & & & Glabella & $(-5)$ & 2 & & 2 \\
\hline Preauricular Sulcus (0-4) & & & Mental & ninence $(1-5)$ & & 3 & \\
\hline Estimated Sex, Pelvis (0-5) & & & Estimat & Sex, Skull (0-5) & 3 & 3 & 3 \\
\hline
\end{tabular}


Series/Burial/Skeleton Millican Bench / $1 / 1$

Observer/Date RB Mahoney / 12-03

\section{Pubic Symphysis}

Todd (1-10)

Suchey-Brooks (1 -6)
$\mathrm{L}$

$\mathrm{R}$

AGE

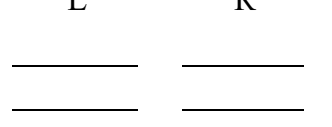

$\mathrm{L}$

$\mathrm{R}$

Suture Closure (blank $=$ unobservable; $0=$ open; $1=$ minimal; $2=$ significant; $3=$ complete $)$

External 1. Midlambdoid

Cranial 2. Lambda

Vault 3. Obelion

4. Anterior Sagittal

5. Bregma

6. Midcoronal

7. Pterion

8. Sphenofrontal

9. Inferior Sphenotemporal

10. Superior Sphenotemporal
Palate

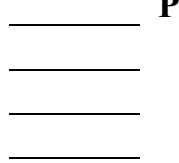

Internal Cranial Vault
11. Incisive

12. Anterior Median Palatine

13. Posterior Median Palatine

14. Transverse Palatine

15. Sagittal

16. Left Lambdoid

17. Left Coronal

Estimated Age: $\quad$ Young Adult (20-35 years) Middle Adult (35-50 years)

Old Adult (50+ years)

\section{Comments:}

Fragmentary condition of majority of cranial vault precluded observation of sutural closure. Specifically, taphonomic forces have fractured the vault into numerous pieces, and although the cranium has been partially recontructed, the fractures lines along the sutures have obscured the development of closure. The lack of the innominates in concert with only two scores for sutural closure have resluted in an indeterminate age using the above methods. 


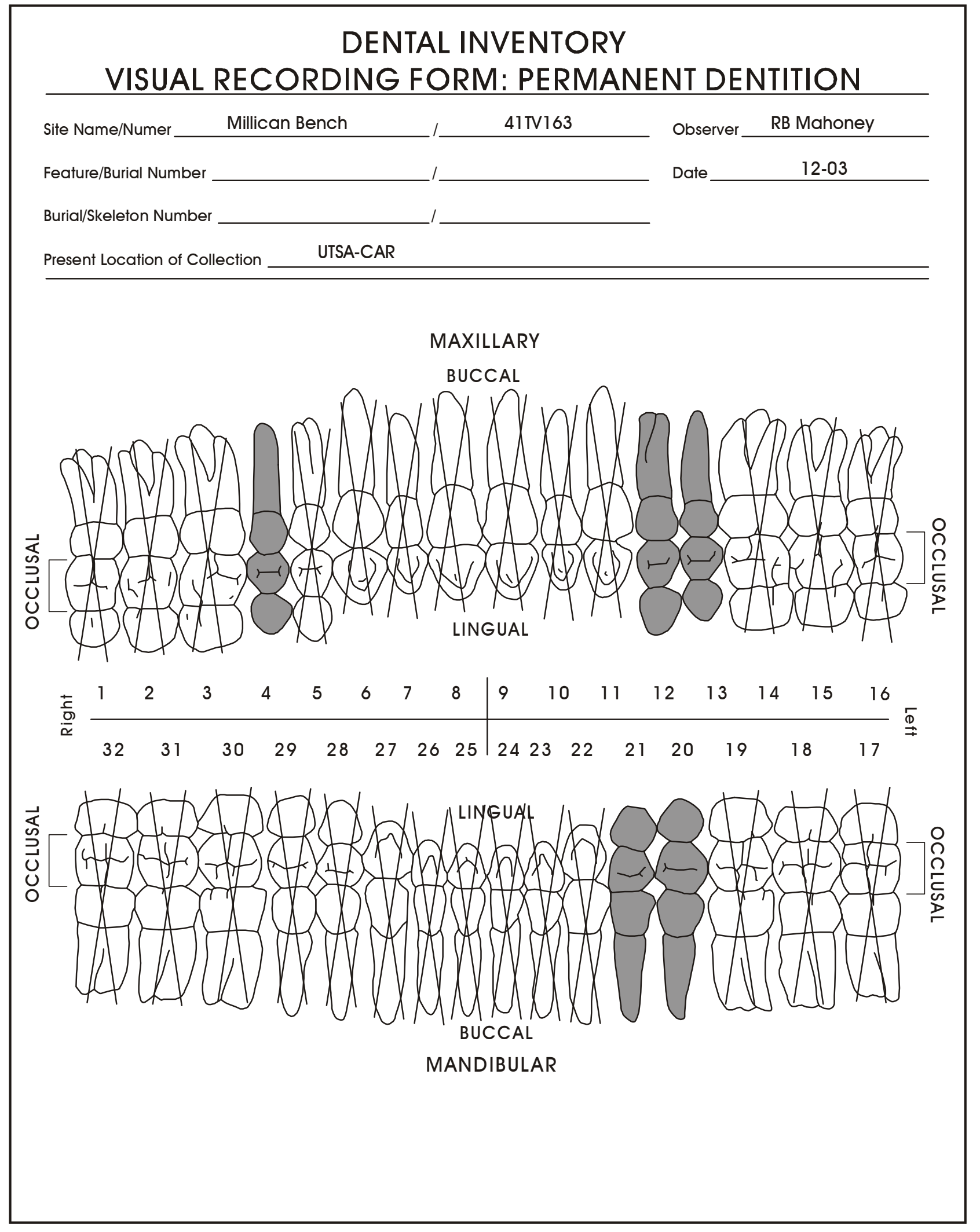




\section{DENTAL INVENTORY RECORDING FORM}

\section{DEVELOPMENT, WEAR, AND PATHOLOGY: PERMANENT TEETH}

\begin{tabular}{|c|c|c|c|c|}
\hline Site Name/Number & Millican & / 41TV163 & Observer & RB Mahoney \\
\hline Feature/Burial Number & 10 & & Date & $12-03$ \\
\hline Burial/Skeleton Number & $/ 1$ & & & \\
\hline Present Location of Collection & UTSA-CAR & & & \\
\hline
\end{tabular}

Tooth presence and development: code 1-8. For teeth entered as 'l" (present, but not in occlusion), record stage of crown/root formation under "Development." Occlusal surface wear: use left teeth, following Smith (1984) for anterior teeth (code 1-8) and Scott (1979) for molars (code O-10). If marked asymmetry is present, record both sides. Record each molar quadrant separate in the spaces provided $(+)$ and the total for all four quadrants under 'Total." Caries: code each carious lesion separately (1 -7); Abscesses: code location (1 -2). Calculus: code 0-3, 9. Note surface affected (buccal/labial or lingual).

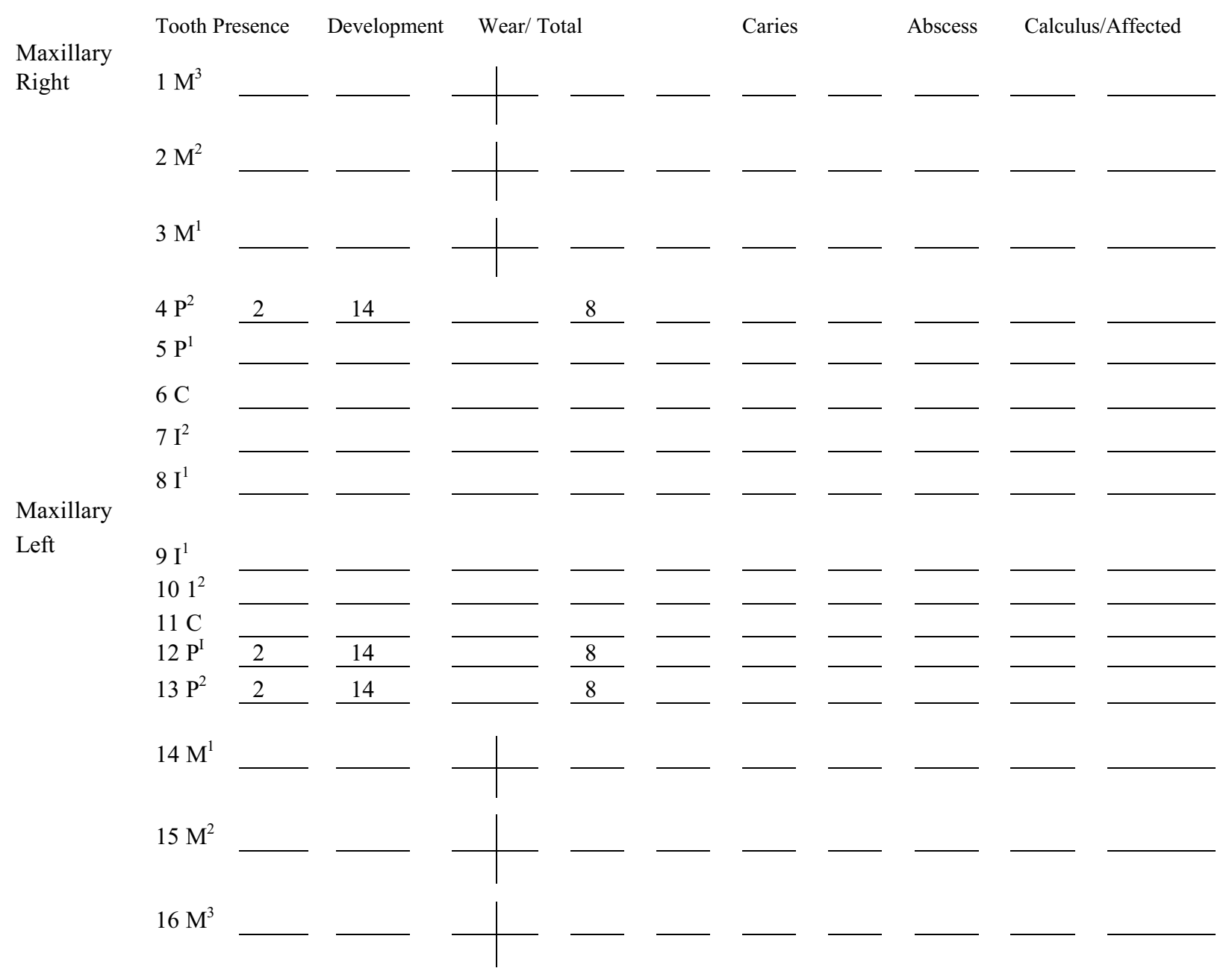


Series/Burial/Skeleton Observer/Date
41TV163/1/1

RB Mahoney/12-03

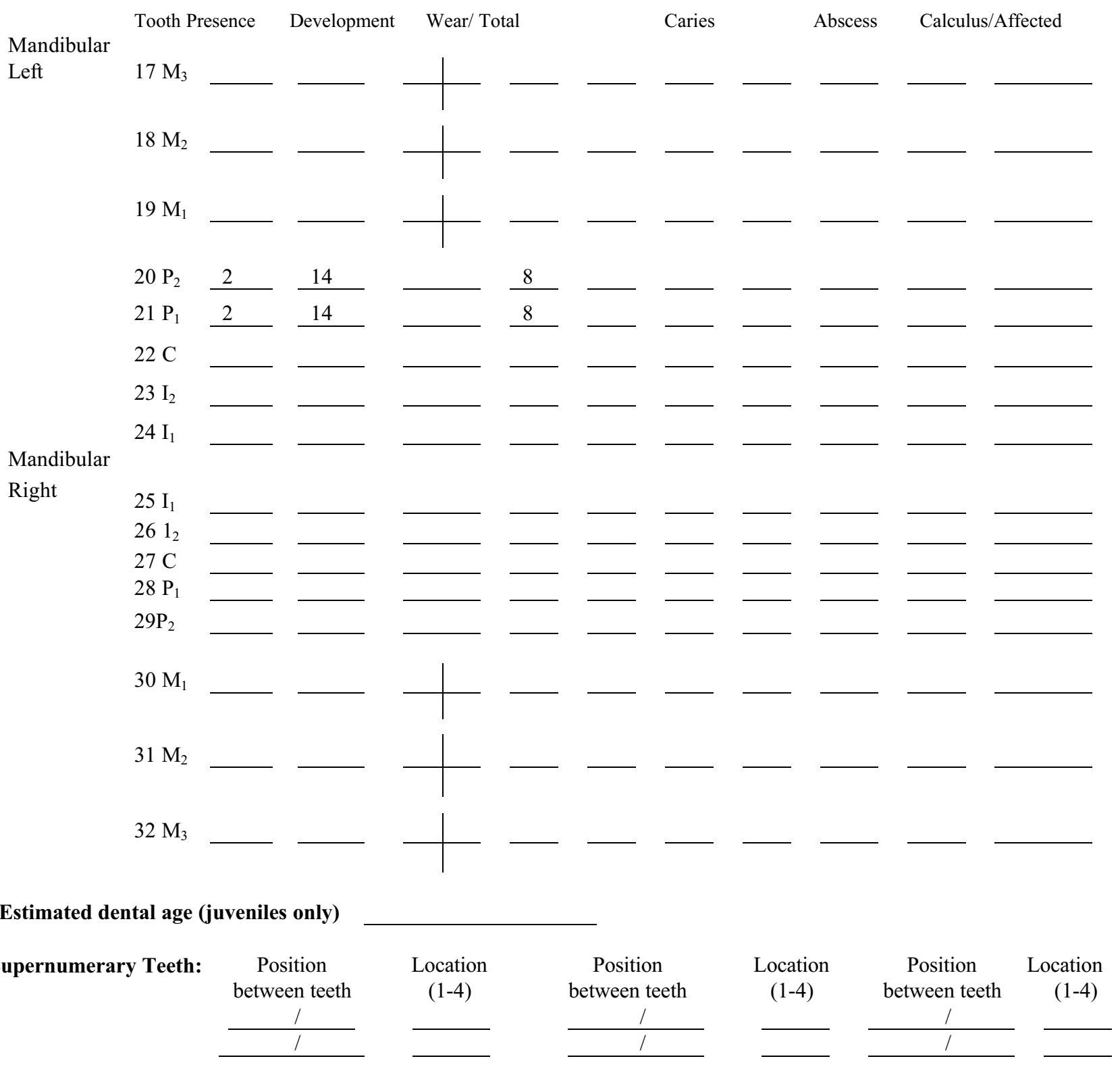

Comments:

Extreme dietary and probable nondietary wear along the occlusal and lingual surfaces has all but obliterated the crown in each of the five teeth present. The pulp cavity has been exposed in each 
Appendix C

\section{Radiocarbon Results}




\section{The University of Georgia}

Center for Applied Isotope Studies

Tel: $\quad$ (706) 542-1395

FAX: (706) 542-6106

\section{FAX TRANSMISSION COVER SHEET}

Date: $\quad$ August 22, 2003

Page 1 of 10

To: James T. Abbotr, PhD.

Cultural Resources Management, Texas DOT

FAX No: $\quad 512-416-2643$

From: John Noakes $9 M$

Center for Applied Isótope Studies

120 Riverbend Road

Athens, GA 30602

Re: W.A. \#57304SA004

Jim,

Here are the calibration sheets for seven of the nine radiocarbon analyses we faxed earlier today (UGA-12300 through 12305, and 12307). Results for two of the samples, 12306 and 12308 are not appropriate for a calendar calibration. We are also sending a corrected results letrer showing a correction to the result for UGA-12304 - the sigma $( \pm 100)$ is the same for the Radiocarbon Age as for the $8^{13} \mathrm{C}$ Corrected Age.

Included also is a calibration for UGA-12273, processed under W.A. \# 57302SA004. Of the three dates in that group, this is the only sample for which a calibrated date is appropriate. 


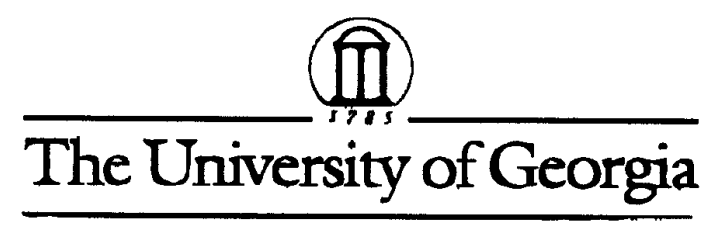

Center for Applied Isocope Studies

\section{RADIOCARBON AGE ANALYSIS REPORT}

August 22, 2003

Dr. James T. Abbott

Staff Geoarcheologist

Cultural Resources Management

Texas Department of Transportation

Dewitt C. Greer State Highway Bldg.

125 E. 11th Street

Austin, TX 78701-2483

Dear Dr. Abbott,

Enclosed please find the results for the Radiocarbon $\left({ }^{24} \mathrm{C}\right)$ analygis including Stable

Isotope Ratio analysis $\left(8^{13} \mathrm{C}\right)$ correction for the charcoal samples received by our laboratory on July 2, 2003.

\begin{tabular}{|c|c|c|c|c|}
\hline UGA\# & $\begin{array}{l}\text { Sample } \\
\text { I.D. }\end{array}$ & $\begin{array}{c}\text { Radiocarbon } \\
\text { Age } \\
\text { (XBP } \pm 10)\end{array}$ & $\begin{array}{l}\text { Radiocarbon } \\
\delta^{13} \text { C Corrected } \\
\text { Age ( } 1 \text { P } \pm 1 \sigma)\end{array}$ & $\begin{array}{c}\delta^{13} \mathrm{C} \\
\text { (Years } \\
\text { corrected) }\end{array}$ \\
\hline 12300 & Millican 175-009: & $3,040 \pm 80$ & $3,050 \pm 80$ & $-24.58(+7)$ \\
\hline 12301 & Millican 171-003: & $2,830 \pm 110$ & $2,840 \pm 110$ & $-24.25(+12)$ \\
\hline 12302 & Millican 316-003: & $1,270 \pm 40$ & $1,270 \pm 40$ & $-25.04(-1)$ \\
\hline 12303 & Millican 326-002: & $1,610 \pm 40$ & $1,520 \pm 40$ & $-24.38(+10)$ \\
\hline 12304 & Millican 332-001: & $1,630 \pm 100$ & $1,610 \pm 40$ & $-26.19(-19)$ \\
\hline 12305 & Millican 153-004: & $570 \pm 40$ & $580 \pm 40$ & $-24.36(+10)$ \\
\hline 12306 & Millican 188-004: & $40 \pm 40$ & $20 \pm 40$ & $-26.00(-16)$ \\
\hline 12307 & Millican 318-009: & $1,640 \pm 40$ & $1,590 \pm 40$ & $-27.80(-45)$ \\
\hline 12308 & Millican 202-003: & $60 \pm 40$ & $60 \pm 40$ & $-25.10(-2)$ \\
\hline
\end{tabular}

All the above listed samples were pretreated with acid, alkali and acid to remove potential contaminants from the surface and interior prior to processing for AMS dating.

If you have any questions, or need additional information, please do not hesitate to call.

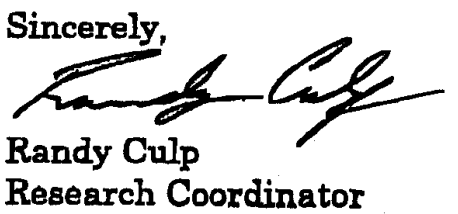

All dates are reporled in years before present ( $O$ YBPm1950 A.D.). By international convention, the half-life of radiocarban is taken to be 5568 years. Standardization is with the National Institute of Standards and Technology's Oxalic Acid SRM-1990C, which is taken to be 189\% modern (1950). The uncertainty in the reported age is at a one standard deviation confidence level (68\% probability). Stable carbon iootope ratios (OSC) ore given both as per mill $(' / 0)$ difference from PDB-I standard ratio and as the corrected radiocarbon age, in YBP. The corrected age facilitates the comparison of different materials which form in nalure with different carbon isotope ratios. To obtain a corrected date, this correction factor should be added to the reporled age (TBP). 
Radiocarbon determination

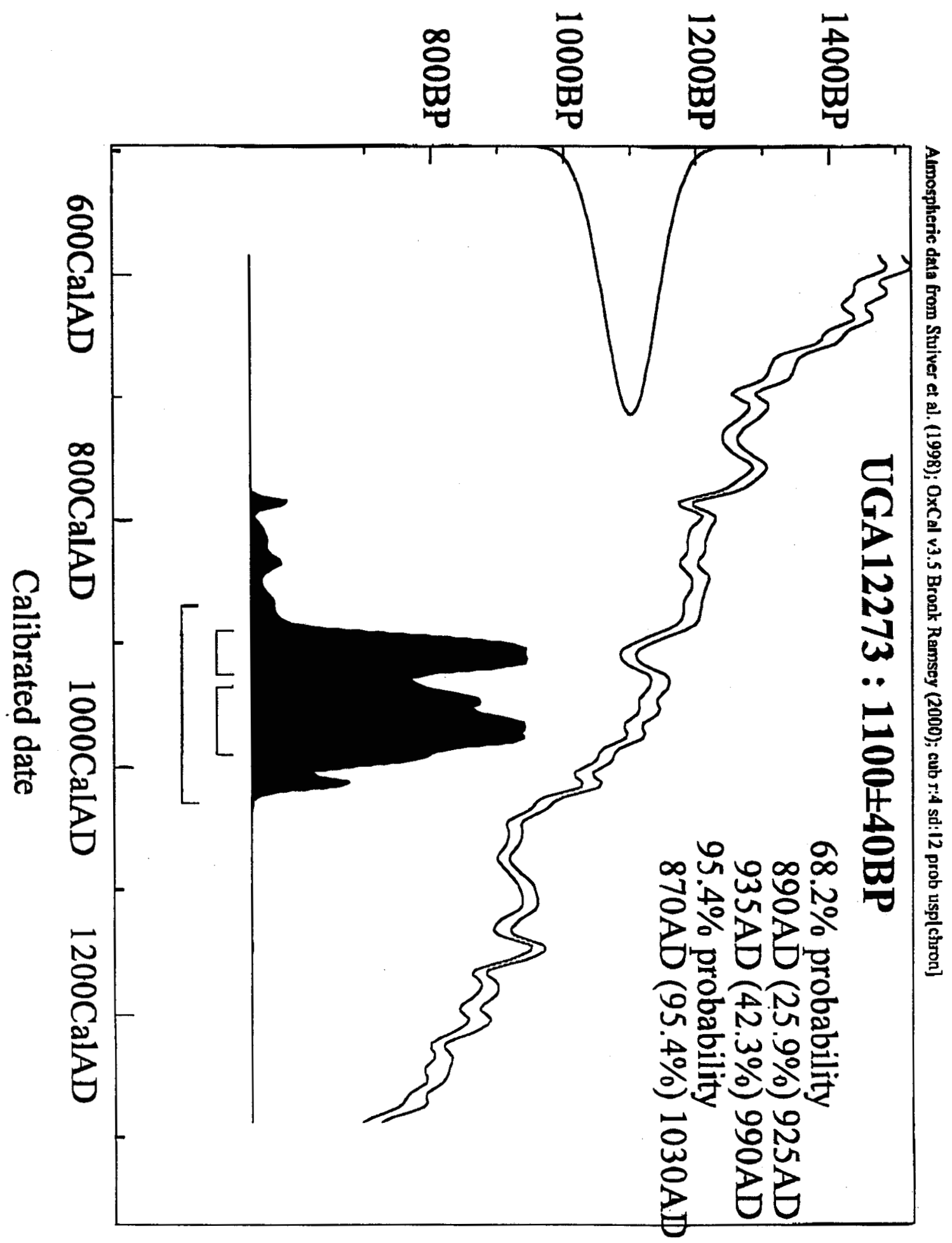




\section{Radiocarbon determination}

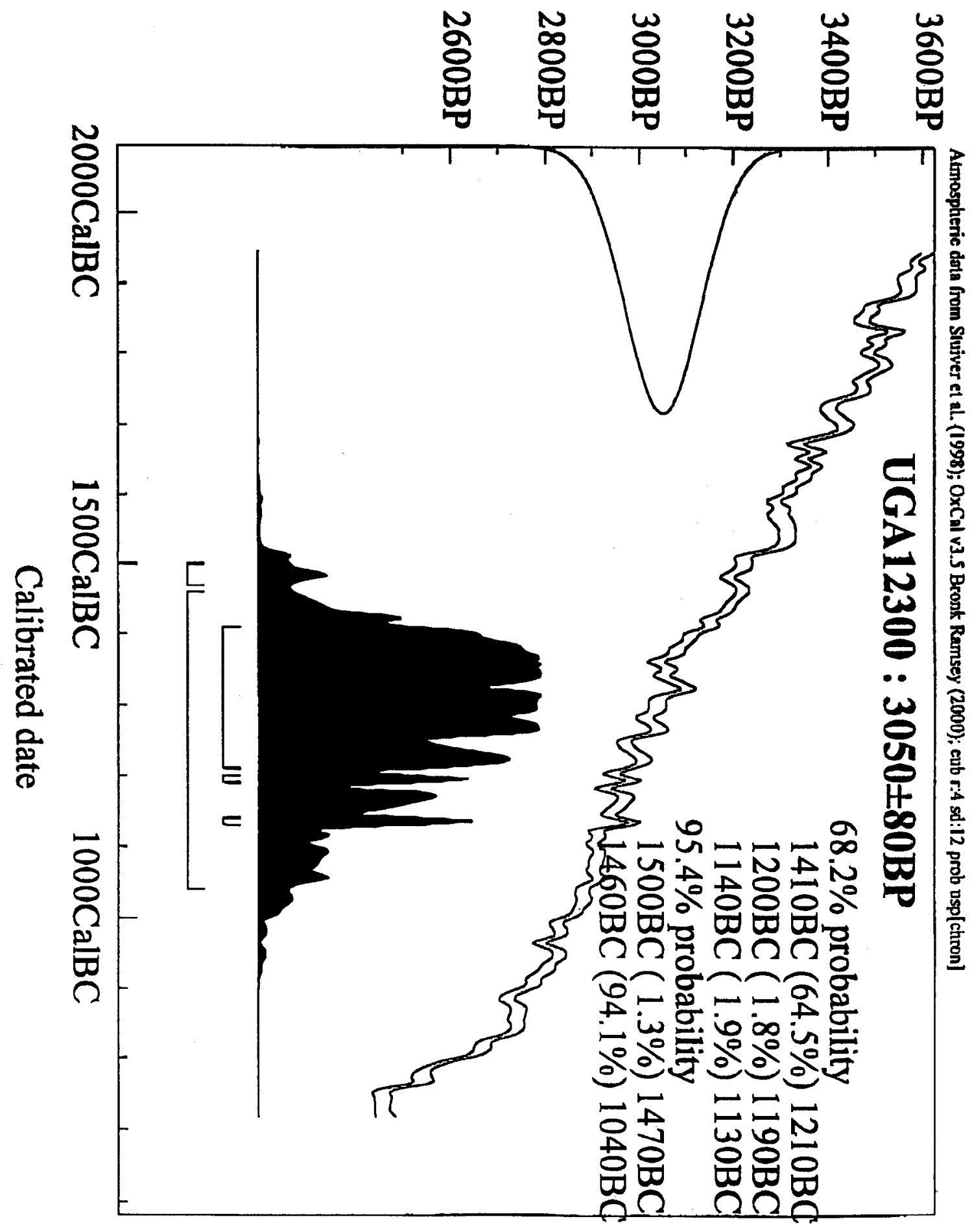




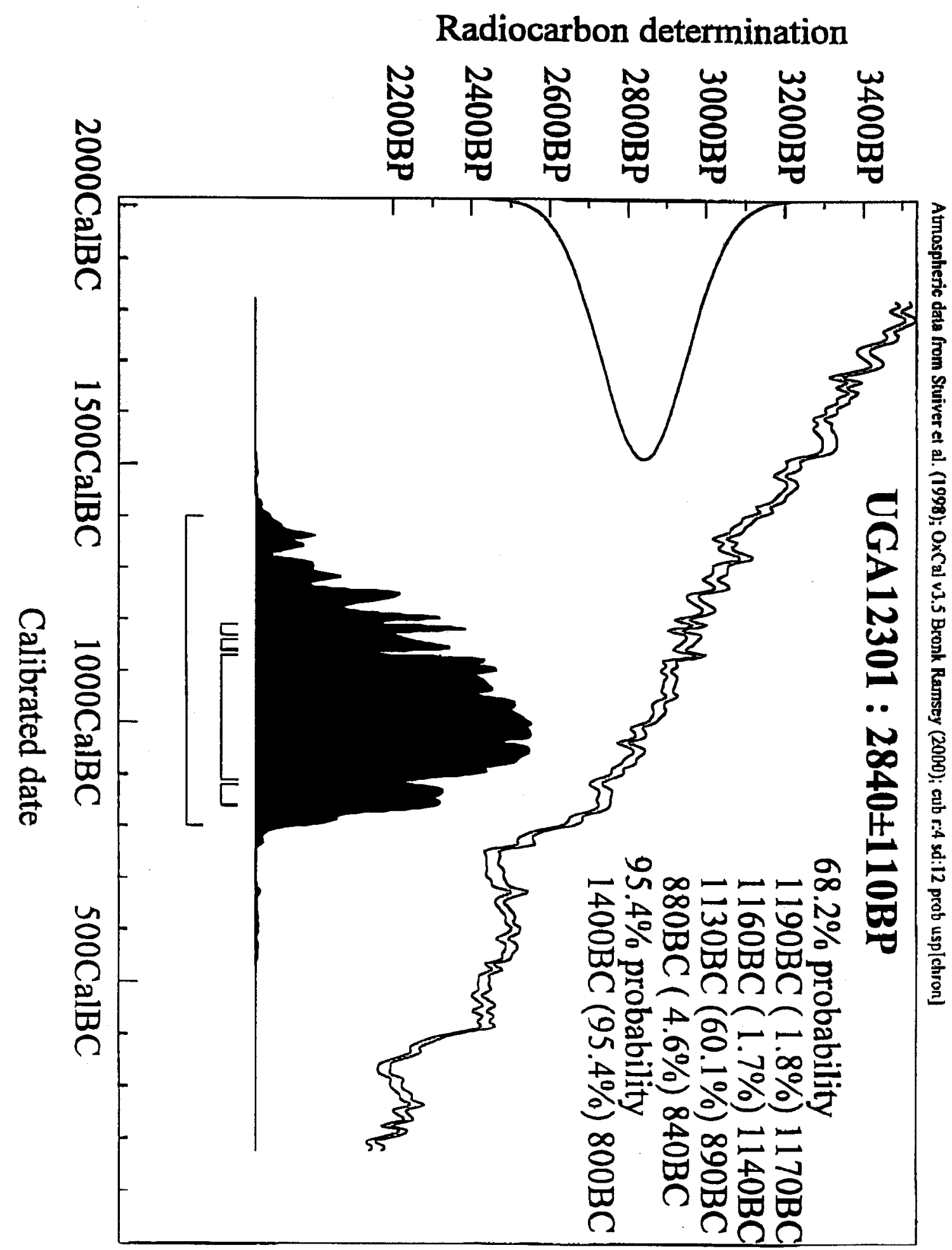


Radiocarbon determination

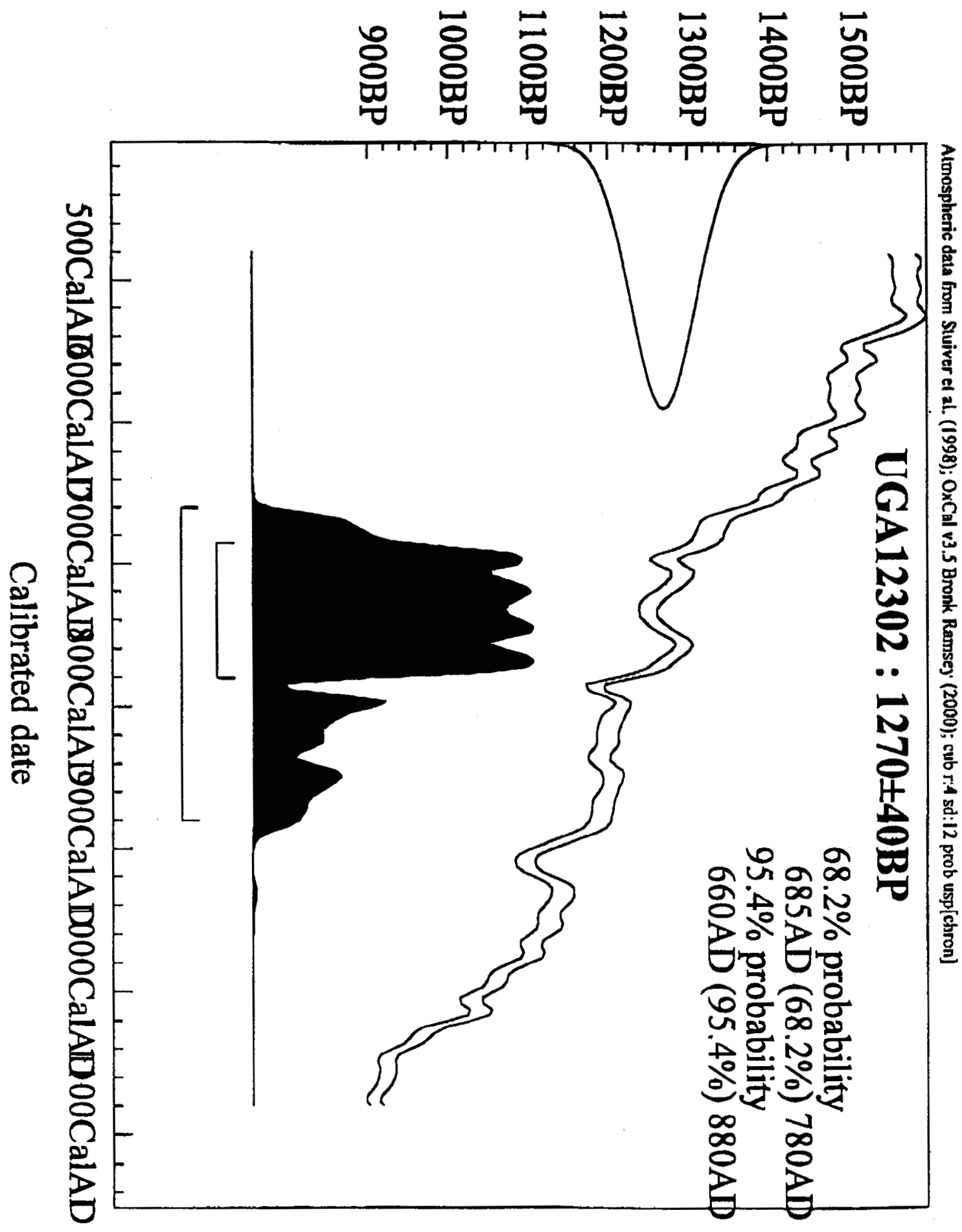




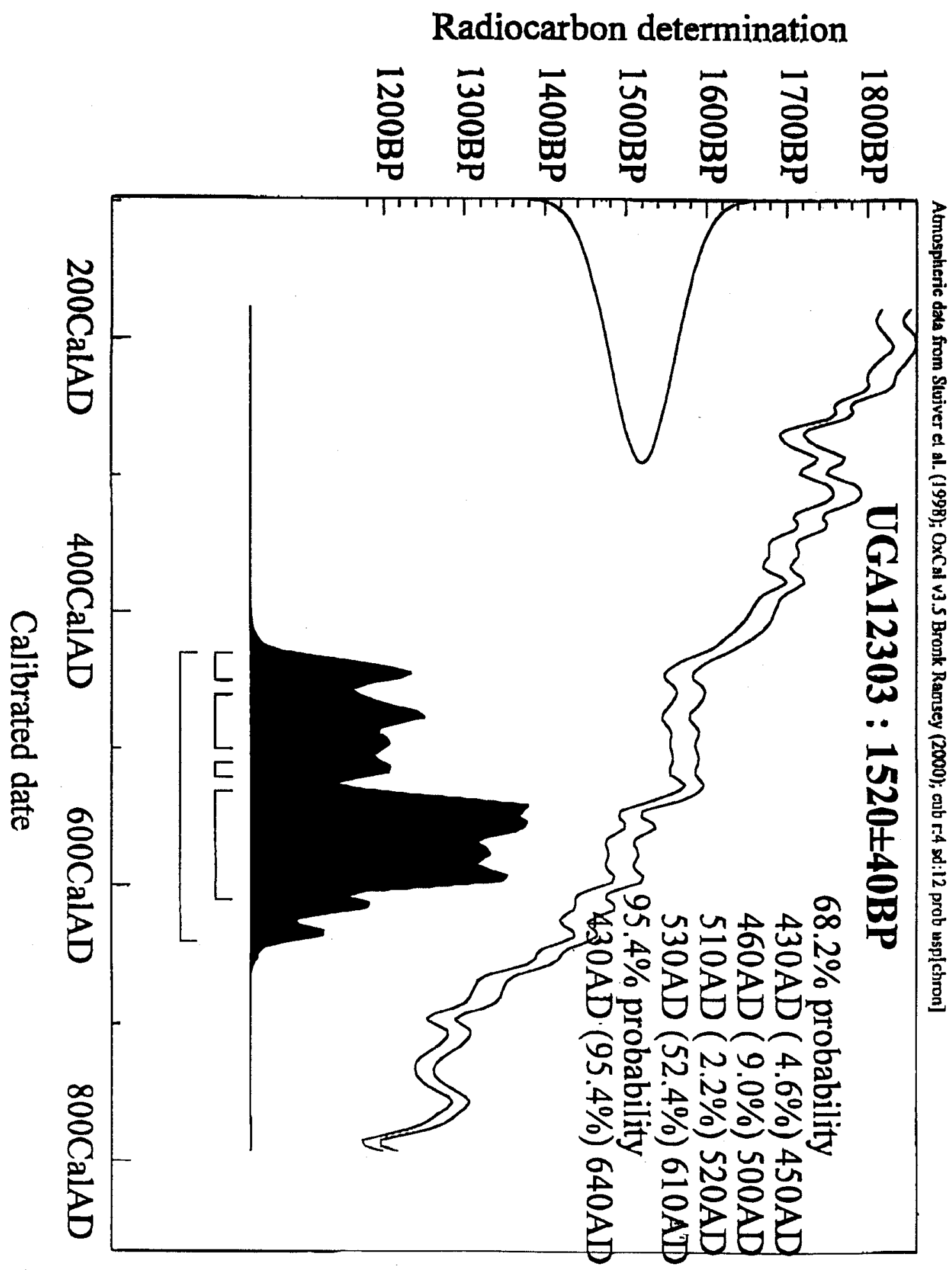




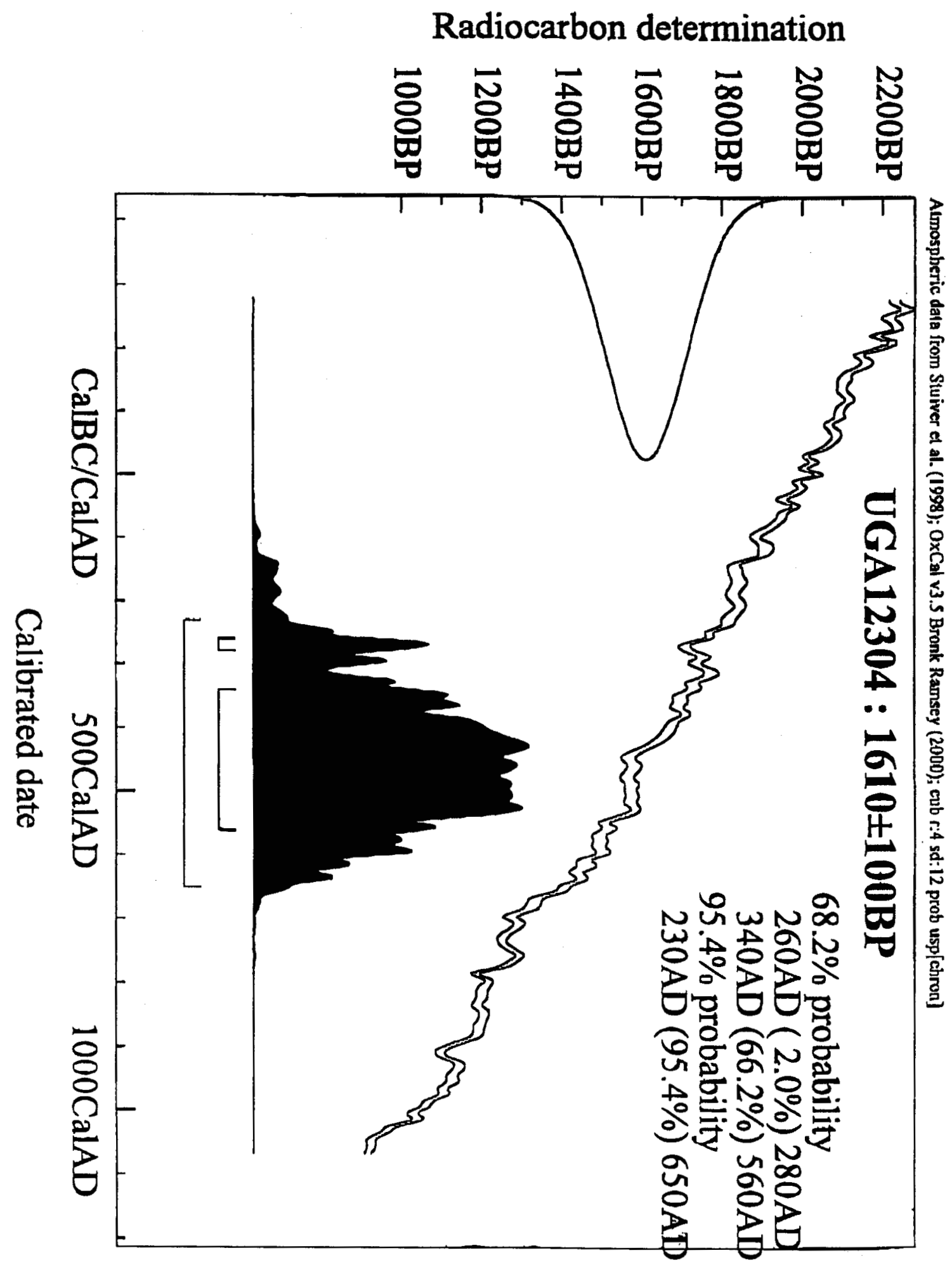




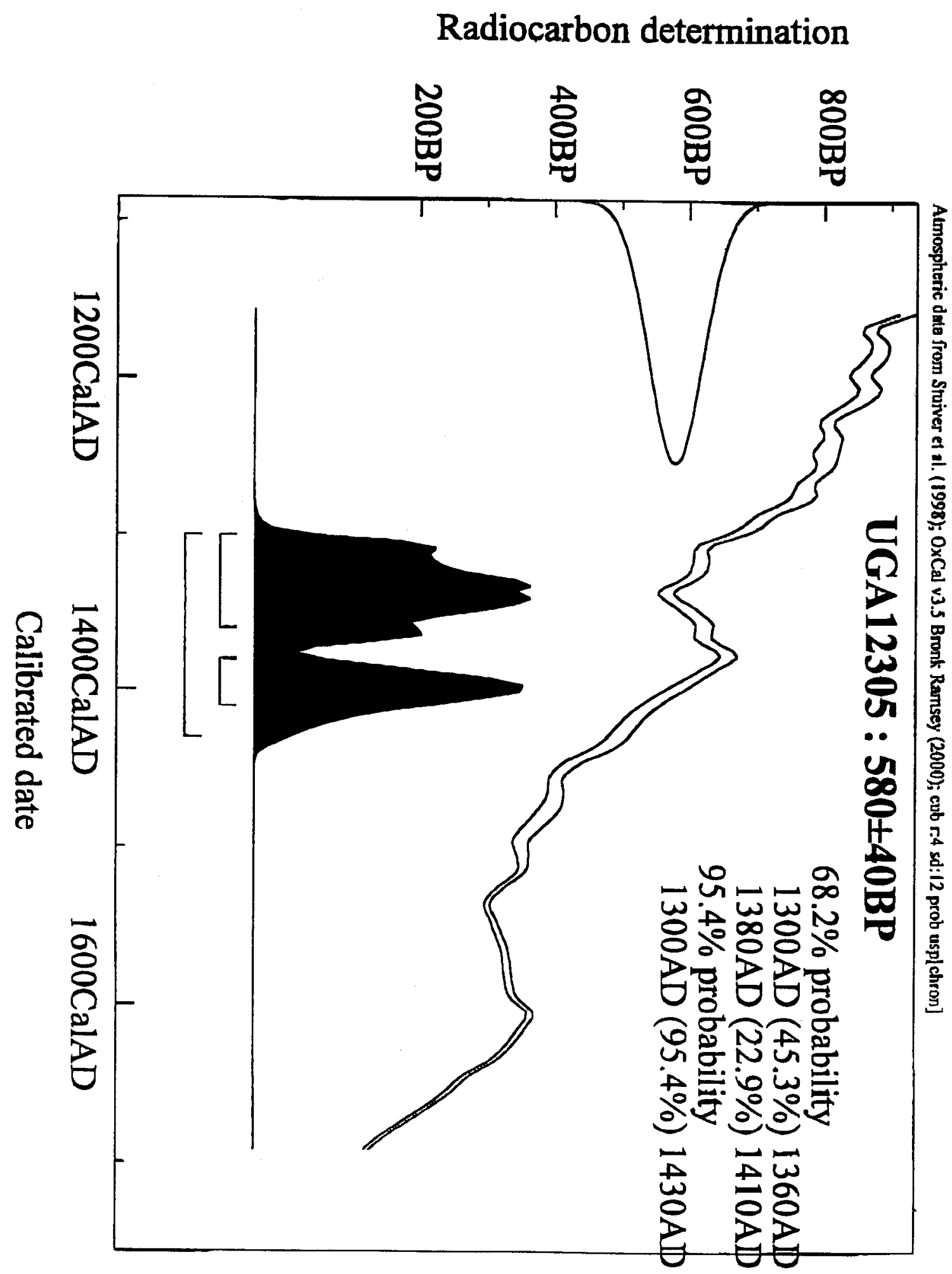




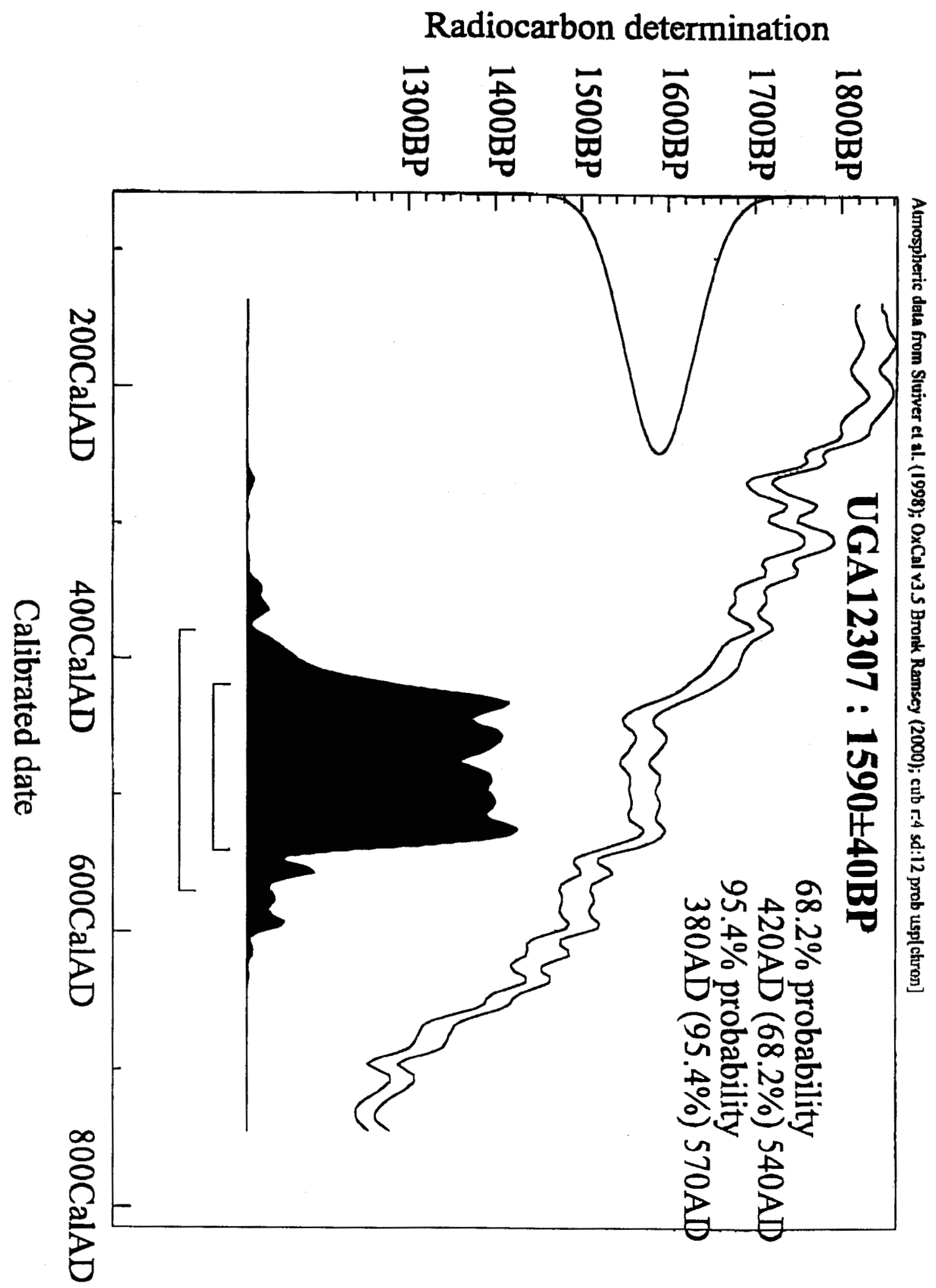



Appendix D

\section{Plant Remains from 41TV163}




\section{Appendix D: Plant Remains from 41TV163}

\section{J. Philip Dering}

The Center for Archaeological Research submitted nine flotation samples and one macrobotanical sample from 41TV163 to Shumla Archeobotanical Services for analysis. The nine samples were recovered during the 1970-1971 TxDOT sponsored excavations. The flotation samples varied in size from 0.05 liters to 8.0 liters, and totaled 35.15 liters.

\section{Methods}

There are two types of samples in the current studyflotation samples and macrobotanical samples. Flotation is a method of recovering organic remains from archeological sediments by using water to separate heavy or soluble inorganic particles from plant parts and small animal bone. The material floating to the surface is called the light fraction, and this is caught on a fine mesh screen or strainer. The material that sinks to the bottom is the heavy fraction and it is also caught on a fine mesh screen. Most of the soil, including clay and silt, is dissolved or suspended in the water that passes through the screens and is either recycled or discarded. In most cases, only the light fraction is submitted for analysis after the heavy fraction has been examined for plant materials.

Macrobotanical samples are carbonized plant remains that are separated from the rest of the archeological material by hand. Macrobotanical samples are collected either from an excavator's screen, are point-collected and plotted individually in the field, or picked from laboratory samples. They are often labeled ${ }^{14} \mathrm{C}$ or radiocarbon samples.

At the vast majority of open sites, only carbonized plant remains are considered to be potentially a part of the archeological record. In some rare cases, certain durable and easily identifiable wood types such as juniper may survive in a partially carbonized state, but only at younger sites in relatively dry conditions. Submerged sites in which deposits have remained in anaerobic conditions can also preserve uncarbonized plant remains quite well. Deposits in the current study have been exposed to the elements for a sufficient time period that, with few exceptions, only carbonized plant material is considered to be included in the archeological record.
The analysis followed standard archeobotanical laboratory procedures. The light fraction of each flotation sample was passed through a nested set of screens of 4-mm, 2-mm, $1-\mathrm{mm}$, and $0.450-\mathrm{mm}$ mesh and examined for charred material that was separated for identification. Carbonized wood from the 4-mm and 2-mm screens (smaller pieces are seldom identifiable) was separated in a 25-piece grab sample and identified. However, the charred material caught on all of the sieve levels, including the bottom pan, was scanned for floral parts, fruits, seeds, and other potentially edible plant parts such as bulb fragments, agave, or maize fragments. All of the potentially edible plant parts were counted and examined for identification. Screen- or pointcollected macrobotanical samples (radiocarbon samples, etc.) were also sorted, identified, counted, and weighed.

Identification of carbonized wood was accomplished by using the snap technique, examining them at 8 to 45 magnifications with a hand lens or a binocular dissecting microscope. Identifications were made using wood or seed identification manuals and wood, seed, and plant voucher reference collections in the laboratory at Shumla Archeobotanical Services.

Seeds and fruit fragments were identified using reference specimens in the Shumla Archeobotanical Services laboratory. Some seeds are so similar that they are grouped into types that include more than one taxonomic category. For example, the term cheno-am is used to refer to the charred seeds (achenes) of either the genus Chenopodium (goosefoot) or Amaranthus (pigweed). Although it may be possible to distinguish these seeds when they are fresh and uncharred, quite often they swell and distort when exposed to heat. Therefore, these are referred to as the seed type "cheno-am," which is a category that refers to both genera.

\section{Results}

The quantity of carbonized plant material from the 41TV163 samples was low. The archeobotanical assemblage consisted of 44 charred plant fragments weighing $1.55 \mathrm{~g}$. Carbonized plant materials were not recovered from the $4 \mathrm{~mm}$ screen, and all of the identified wood charcoal was picked from the 
2-mm screen. One bulb fragment and one seed (hackberry nutlet) were the only edible plant parts recovered from the samples. Wood charcoal fragments were identified as oak and juniper. Some of the fragments were not identifiable primarily because of their small size. Results of the analysis are presented in Table D-1.

Eight fragments of juniper weighing $0.3 \mathrm{~g}$ were recovered from four samples. Oak occurred in three samples, but in slightly greater abundance, totaling 28 fragments weighing $0.4 \mathrm{~g}$. Two types of potentially edible plant resources were identified in the samples. A hackberry nutlet was noted in Cat. \#120-027-1, a flotation sample recovered from Level 6 of S165/E200. Hackberry nutlets or seeds are often recovered from open archeological sites in North America, and because they are composed of calcium carbonate they resist deterioration. Therefore, hackberry nutlets have the potential to be part of the archeological record. Hackberry was consumed by Native Americans throughout its extensive range, especially the species Celtis laevigata, known as sugarberry. The small fruit was usually pounded or ground into sweet meal which was combined with other foods. For example, the Comanche combined the pulp of sugarberry with fat, rolled it into balls and roasted it (Carlson and Jones 1940:521).

The only macrobotanical sample submitted for analysis contained a fairly complete bulb fragment that compares favorably to an onion bulb. The bulb specimen (Cat. No. 333-001) measures $12.9 \mathrm{~mm}$ long by $8.6 \mathrm{~mm}$ and weighs $0.1 \mathrm{~g}$. Several other fragments that have separated from the specimen bring the total weight to $0.3 \mathrm{~g}$.
A bulb has a shortened stem termed a basal plate that has one or more apical meristems, and is enclosed by several fleshy scales, usually in a rosette pattern. The basal plate also contains adventitous root initials. The scales are the primary storage tissue in true bulbs. Depending on the species, scales consist of either modified leaves or leaf bases. Both types of structures are enlarged with fleshy tissue that stores food and water.

The specimen from 41TV163 consists of what appears to be a single relatively thick leaf scale encircled by thinner leaf scales. The central stem is missing, presumably it has broken away from the specimen, leaving a hollow space at the center of the specimen. This condition is not unusual in archeological material, but it does not make identification easy. The sample most closely resembles wild onion or Allium sp., which can have a relatively thick $(<2 \mathrm{~mm})$, spongy leaf scale surrounded by thinner leaf scales.

\section{Discussion and Conclusions}

Table D-2 lists the archeological sites along the northern, southern, and eastern and periphery of the Edwards Plateau from which onion remains have been identified. Onions have been recovered from at least five sites along the southern and eastern periphery of the Edwards Plateau, and from three sites in Brown County, located on the northern periphery.

In the Edwards Plateau region, there are over 30 prehistoric archeological sites from which all types of bulb remains have been recovered, including eastern camas, dog's-tooth

Table D-1. Plant Materials Recovered from 41TV163

\begin{tabular}{|l|l|l|l|l|l|l|l|c|c|}
\hline Cat \# & \multicolumn{1}{|c|}{ Unit } & Zone & Area & \multicolumn{1}{|c|}{ Level } & \multicolumn{1}{c|}{ Taxon } & \multicolumn{1}{c|}{$\begin{array}{c}\text { Common } \\
\text { Name }\end{array}$} & \multicolumn{1}{c|}{ Part } & Count & $\begin{array}{c}\text { Weight } \\
\text { (grams) }\end{array}$ \\
\hline $165-018-1$ & S175/E200 & B & -- & I/ II $(0-0.5)$ & Juniperus sp. & Juniper & Wood & 2 & 0.05 \\
\hline $167-010-1$ & S175/E200 & B & & II/III $(1.0-1.5)$ & Indeterminate & -- & Wood & 1 & 0.05 \\
\hline $116-012-1$ & S165/E200 & B & -- & II $(0.5-1.0)$ & Juniperus sp. & Juniper & Wood & 3 & 0.1 \\
\hline $120-027-1$ & S165/E200 & B & -- & IV/V $(2.5-3.0)$ & Quercus sp. & Oak & Wood & 1 & 0.05 \\
\hline $120-027-1$ & S165/E200 & B & -- & IV/V $(2.5-3.0)$ & Celtis sp. & Hackberry & Seed & 1 & - \\
\hline $117-025-1$ & S165/E200 & B & & II.III $(1.0-1.5)$ & Indeterminate & -- & Wood & 6 & 0.1 \\
\hline $150-061-1$ & S150/E200 & C & & I (0.0-0.5) & Quercus sp. & Oak & Wood & 1 & 0.05 \\
\hline $219-007-1$ & I+95/N5.0 & IIA & E & III $(1.0-1.5)$ & Juniperus sp. & Juniper & Wood & 2 & 0.1 \\
\hline $218-037-1$ & I+95/N5.0 & IIA & E & II $(0.5-1.0)$ & Juniperus sp. & Juniper & Wood & 1 & 0.05 \\
\hline $328-010-1$ & Burial F-10 & C & & III & Quercus sp. & Oak & Wood & 26 & 0.3 \\
\hline $333-001$ & S175/E200 & III & B & III & cf. Allium sp. & Onion & Bulb & 1 & 0.7 \\
\hline
\end{tabular}


Table D-2. Overview of Allium Finds from Sites Located along the Northern and Eastern Periphery of the Edwards Plateau

\begin{tabular}{|c|c|c|c|}
\hline County & Site Name (Number) & References & Est. Age of Bulb Remains (Years B.P.) \\
\hline Bosque & $\begin{array}{l}\text { Horn Shelter No. } 1 \\
(41 \mathrm{BQ} 47)\end{array}$ & $\begin{array}{l}\text { Phil Dering, personal communication 2001; } \\
\text { Watt } 1978\end{array}$ & $510+/-30$ \\
\hline Brown & $\begin{array}{l}\text { 41BR250, 41BR253, } \\
\text { 41BR493 }\end{array}$ & Dering 2003 & $\begin{array}{l}730+/-40 \text { to } 790+/-40(41 B R 250 \text { and } 41 B R 253) \\
220+/-40 \text { to } 970+/-40(41 B R 493) \\
\text { e.g., primarily Late Prehistoric }\end{array}$ \\
\hline Coryell & Firebreak Site (41CV595) & Dering 2002 & 2180 to $1050 ; 1910+/-70$ on Feature 15 \\
\hline Hays & Onion Creek (41HY209) & & $660+/-50$, to $790+/-50$ \\
\hline Travis & Toyah Bluff (41TV441) & Dering 2001 & 860 to 460 \\
\hline Williamson & $\begin{array}{l}\text { Block House Creek } \\
(41 \mathrm{WM} 632)\end{array}$ & Dering 1999 & $\begin{array}{l}1790 \text { to } 900 \\
1242 \text { to } 530\end{array}$ \\
\hline
\end{tabular}

violet, rain lily, and unidentified bulbs. All of the current finds are located within the context of burned rock features, and most are associated with burned rock middens. The number continues to grow annually.

The accumulating evidence points to the probability that root foods were one of the primary food resources prepared in earth ovens. Prior to these discoveries, the debate regarding the types of food prepared in earth ovens revolved around the possibility that acorns (Creel 1986, 1991) or sotol (Prewitt 1974) were the dominant resources prepared at these facilities. The list was expanded by Black and Creel (1997: 294) to include other resources such as prickly pear fruits and various types of bulbs. The authors maintain correctly that burned rock middens resulted from repeated earth oven use, and that earth ovens were facilities that did not represent "a single, functionally specific entity except in the general sense" (Black and Creel 1997:294). The facilities were instead utilized to prepare many types of food, including bulbs, prickly pear tunas, and perhaps even acorns.

Over the previous decade the importance of geophytes in prehistoric land-use strategies has been emerging slowly from the archeological record. It is becoming clear that geophytes ("root" foods), especially bulbs, may have constituted a very important part of prehistoric subsistence throughout central Texas, and perhaps throughout most of Texas. What is interesting is the lack of corroboration of the archeological record with early historic observations, which often provide details of hunting trips or use of other more easily observable resources, overlooking the lowly root.
Even more interesting is the fact that the utilization of root foods is described for southern Texas, where no remains of roots have been recovered. Campbell and Campbell (1981: 18) provide the best summary of the earliest European observations of the use of root foods. Cabeza de Vaca, who has given us the earliest accounts, noted two or three kinds of roots were dug in the region during winter months when other foods were not available. These roots did not occur in dense stands, were difficult to collect, and required fairly long foraging trips to secure sufficient quantities for daily subsistence. These roots were baked for two days in what was probably an earth oven. The description of the baking facility is poor, but an earth oven is the only type of facility in which such a process could take place.

However, I believe that the real picture, and the importance, of geophytes is beginning to emerge as flotation efforts have expanded. It is becoming apparent that the use of root foods not only was important within the range of burned rock midden sites, but also extended beyond the range of burned rock middens into areas in which smaller rock features are noted, but large accumulations are lacking. For example, onion bulbs were identified from burned rock features in Grimes County, far east of the Edwards Plateau (Dering 1994:D1). The current study contributes more evidence toward the argument that root foods were an important staple in for the forager in southern-central North America. 


\section{References Cited}

Black, S. L., and D. G. Creel

1997 The Central Texas Burned Rock Midden Reconsidered. In Hot Rock Cooking on the Greater Edwards Plateau, by S. L. Black, L. W. Ellis, D. G. Creel, and G. T. Goode, pp. 269-306. Studies in Archeology 22, Texas Archeological Research Laboratory, The University of Texas at Austin, and Archeology Studies Program, Report 2, Environmental Affairs Department, Texas Department of Transportation, Austin.

Campbell, T. N., and T. J. Campbell

1981 Historic Indians of the Choke Canyon Reservoir Surrounding Area, Southern Texas. Choke Canyon Series, No. 1. Center for Archaeological Research, The University of Texas at San Antonio.

Carlson, G., and V. H. Jones

1940 Some Notes on Uses of Plants by the Comanche Indians. Papers of the Michigan Academy of Science, Arts and Letters 25:517-542.

Creel, D. G.

1986 A Study of Prehistoric Burned Rock Middens in Western Central Texas. Unpublished Ph.D. Dissertation, The University of Arizona, Tucson.

1991 Assessing the Relationship Between Burned Rock Midden Distribution and Archaic Subsistence in West Central Texas. In The Burned Rock Middens of Texas: An Archeological Symposium, by T. R. Hester, pp. 33-44. Studies in Archeology 13, Texas Archeological Research Laboratory, The University of Texas at Austin.

Dering, J. P.

1994 Appendix D-Plant Remains from 41GM224, Grimes County, Texas. In Excavations at Site 41 GM224 in the Gibbons Creek Lignite Mine Permit 38A Area, Grimes County, Texas, by R. Rogers. Espey, Huston, and Associates, Inc., Austin.

1999 Flotation Sample Identifications and Counts. Appendix B in Archaeological Investigations at Block House Creek, Williamson County, Texas, edited by M. Bowden. Parsons Brinckerhoff Quade and Douglas, Inc., Austin.

2001 Macrobotanical Remains. In Appendix B of Changing Perspectives on the Toyah: Data Recovery Investigations of 41TV441, The Toyah Bluff Site, by J. W. Karbula, R. Feit, and T. B. Griffith, pp. B-9 to B-19. Archeology Series No. 94. Hicks and Company, Austin.

2002 Macrobotanical Analysis of Soil Flotation Samples. Appendix D in Geoarcheological Investigations and National Register Testing of 57 Prehistoric Archeological Sites on Fort Hood, Texas: The 1999 Season, by G. Mehalchick, K. Killian, S. C. Caran, K. W. Kibler, T. K. Perttula, S. Iruegas, and H. Neff, pp. 446-455. Fort Hood Archeological Resource Management Series, Research Report No. 44. United States Army, Fort Hood. (Draft)

2003 Botanical Perspectives on Land Use in the Cross Timbers and Prairies. In Archeological Testing to Determine the National Register Eligibility Status of 18 Prehistoric Sites on Camp Bowie, Brown County, Texas, by R. P. Mauldin, D. L. Nickels, and C. J. Broehm, pp. 58-78. Archeological Survey Report No. 334. Center for Archeological Research, The University of Texas at San Antonio.

Prewitt, E. R.

1974 The Rogers Springs Site. Unpublished manuscript on file at the Texas Archeological Research Laboratory, The University of Texas at Austin.

Watt, F.

1978 Radiocarbon Chronology of Sites in the Central Brazos Valley. Bulletin of the Texas Archeological Society 49:111138. 

Appendix E

Selected Projectile Points from 41TV163 


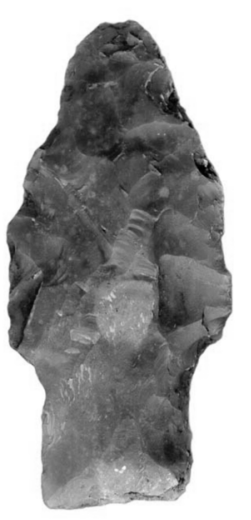

22

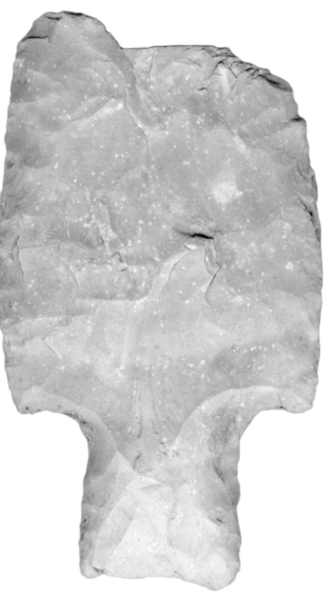

27

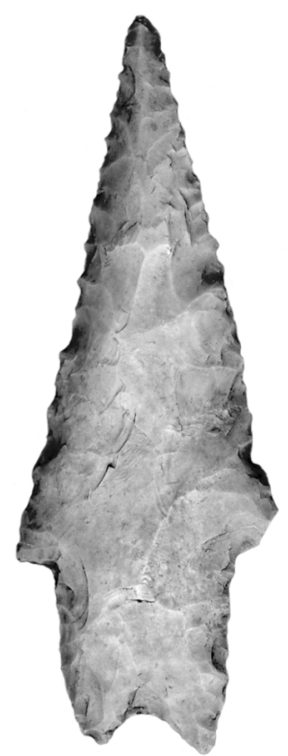

23

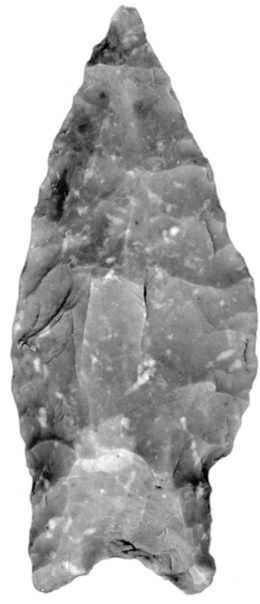

24

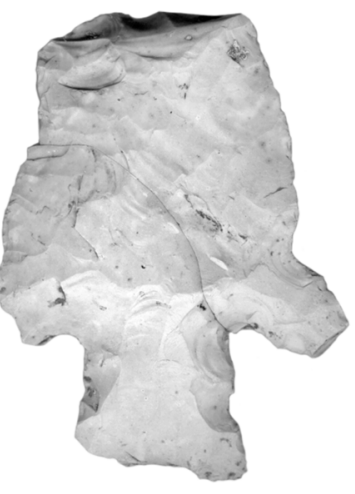

28

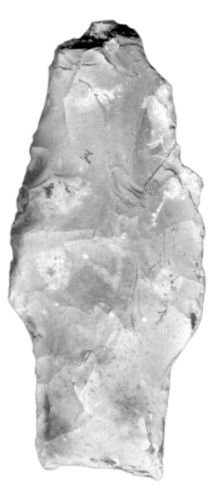

29

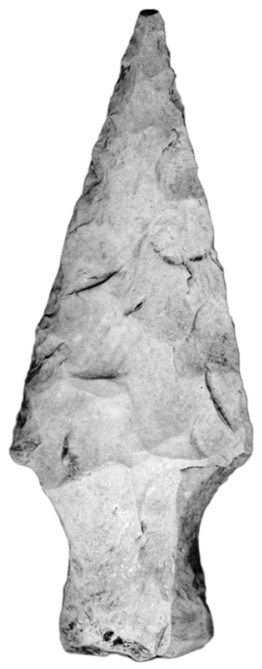

25

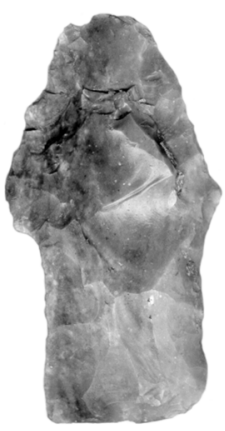

26

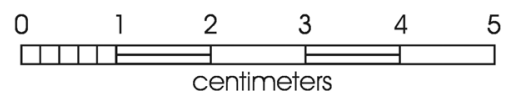

Figure E-1. Selected projectile points from Area A. Numbers identify specimen within database. 22) Nolan; 23, 24) Pedernales; 25, 26) Nolan; 27) possible Lange; 28) Lange; 29) possible Travis; 30) Wells; 32) Langtry. 


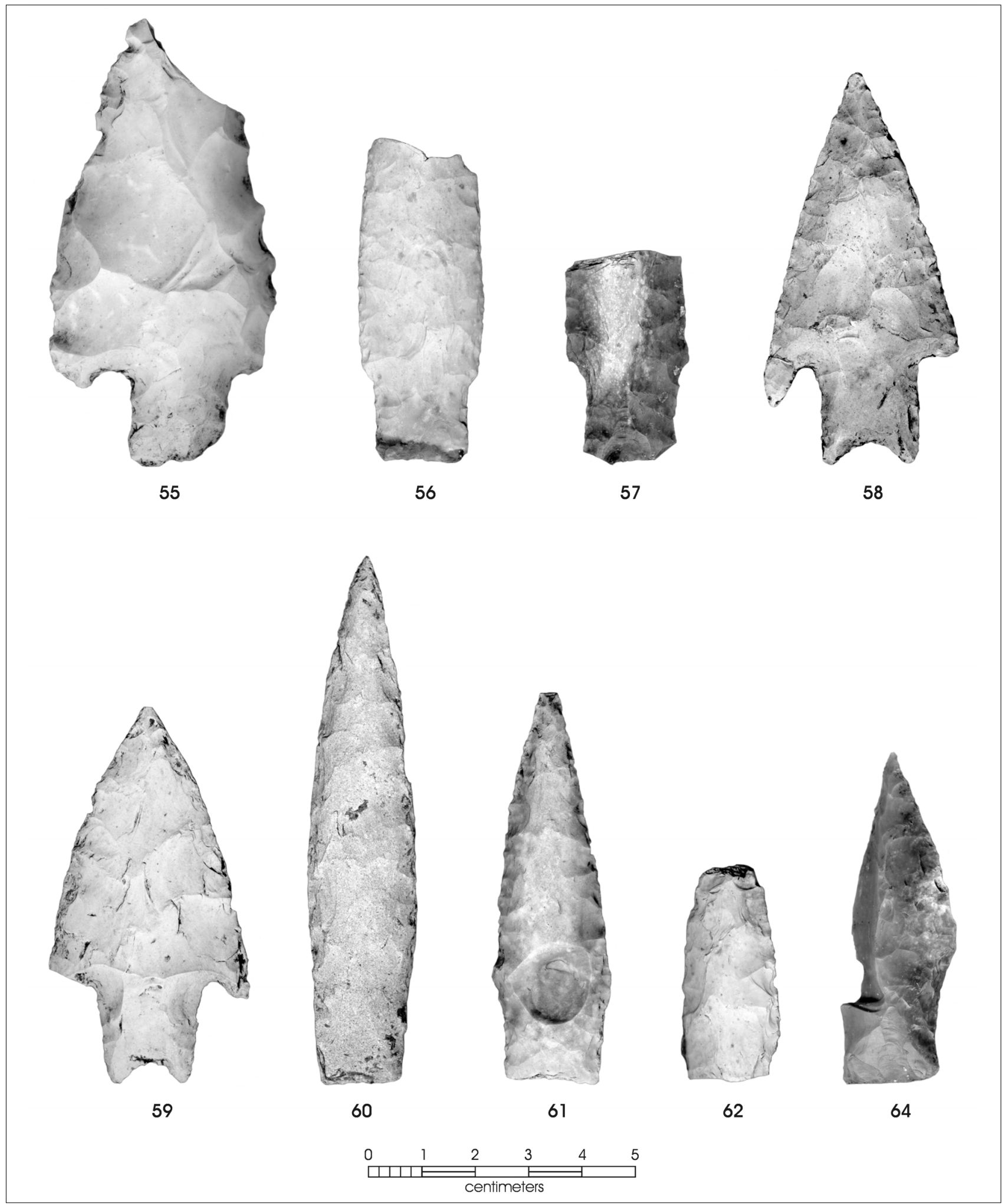

Figure E-1. continued... Selected projectile points from Area A. 55) Pedernales preform; 56, 57) Travis; 58, 59) Pedernales; 60) Nolan; 61) Travis; 62) possible Wells; 64) Nolan. 


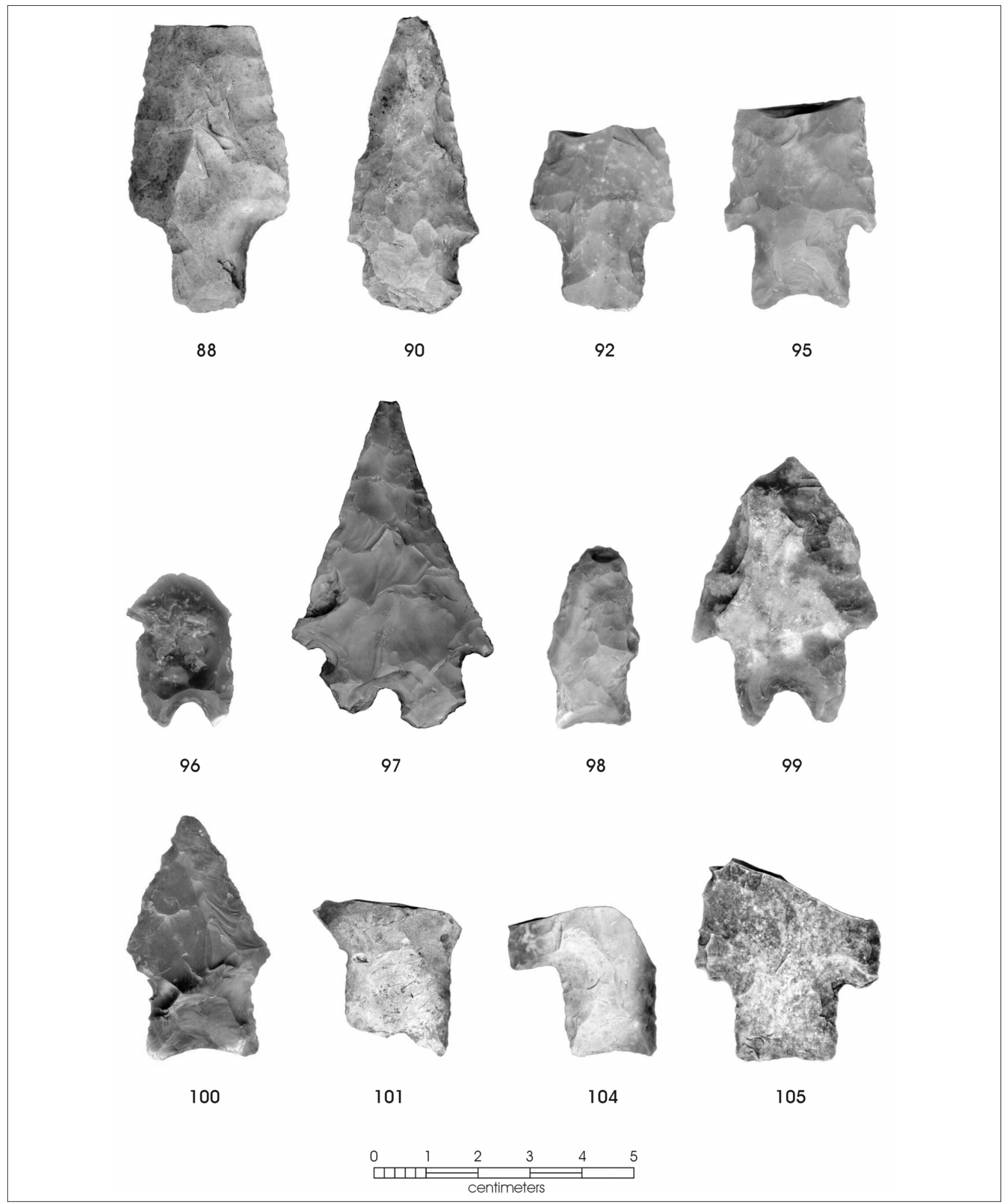

Figure E-2. Selected projectile points from Area B. 88) Nolan; 90) Williams; 92, 95, 96) Travis; 97) Montell; 98) Darl; 99) Pedernales; 100) Marshall; 101) Pedernales; 104, 105) Bulverde. 


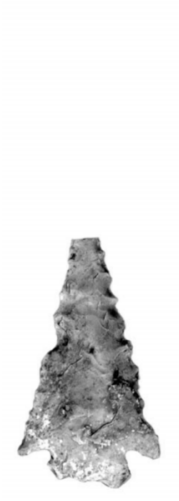

218

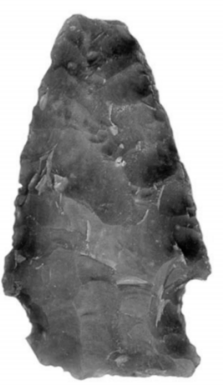

224

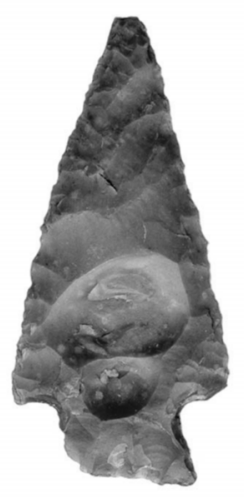

219

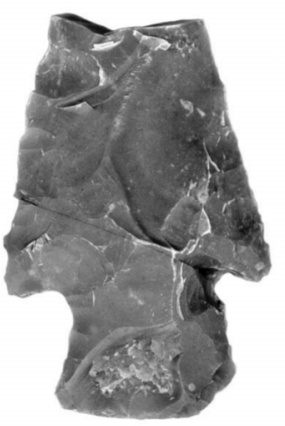

220

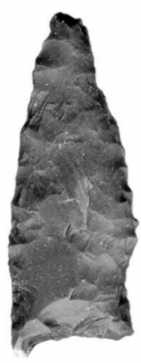

221

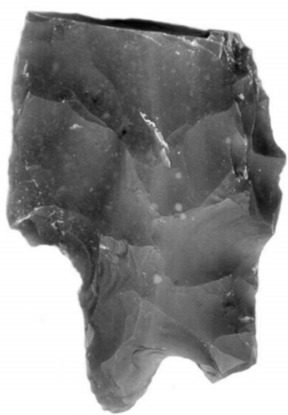

222

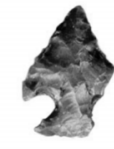

226

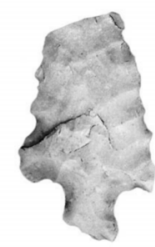

227

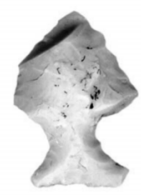

230

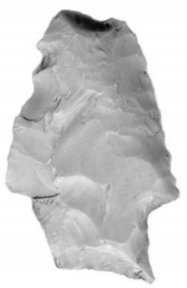

234

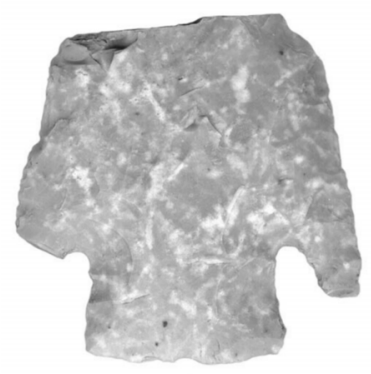

236

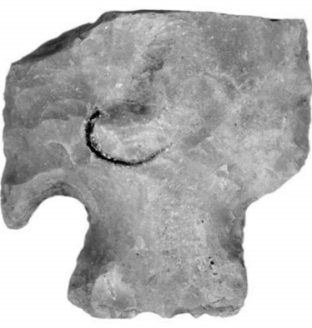

237

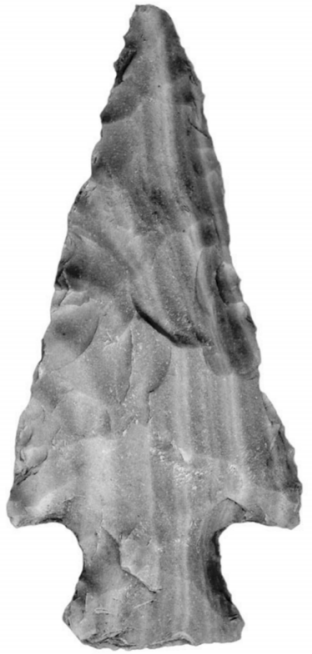

238

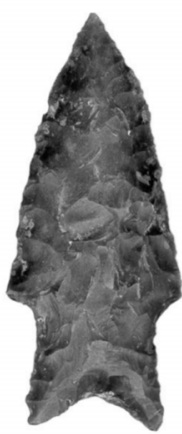

239

Figure E-3. Selected projectile points from Area C. 218) Scallorn; 219) Fairland; 220) Lange; 221) Darl; 222) Pedernales; 224) Ensor; 226, 227, 230) Scallorn; 234) Darl; 236) Castroville; 237, 238) Lange; 239) Darl. 


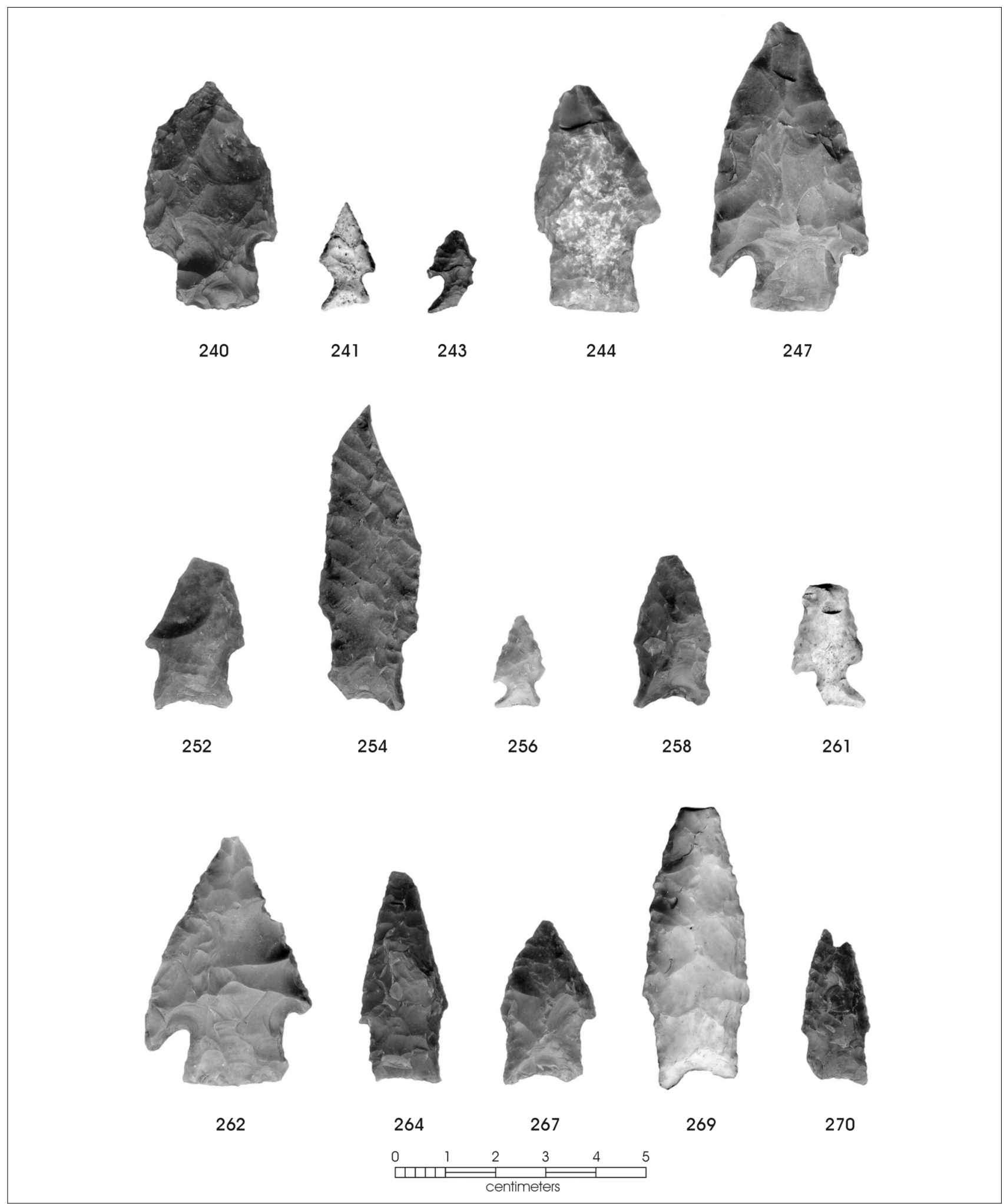

Figure E-3. continued... Selected projectile points from Area C. 240) Lange; 241, 243) Scallorn; 244) Bulverde; 247) Lange; 252, 254) Darl; 256) Scallorn; 258) Darl; 261) Scallorn; 262) Marcos; 264, 267, 269, 270) Darl. 


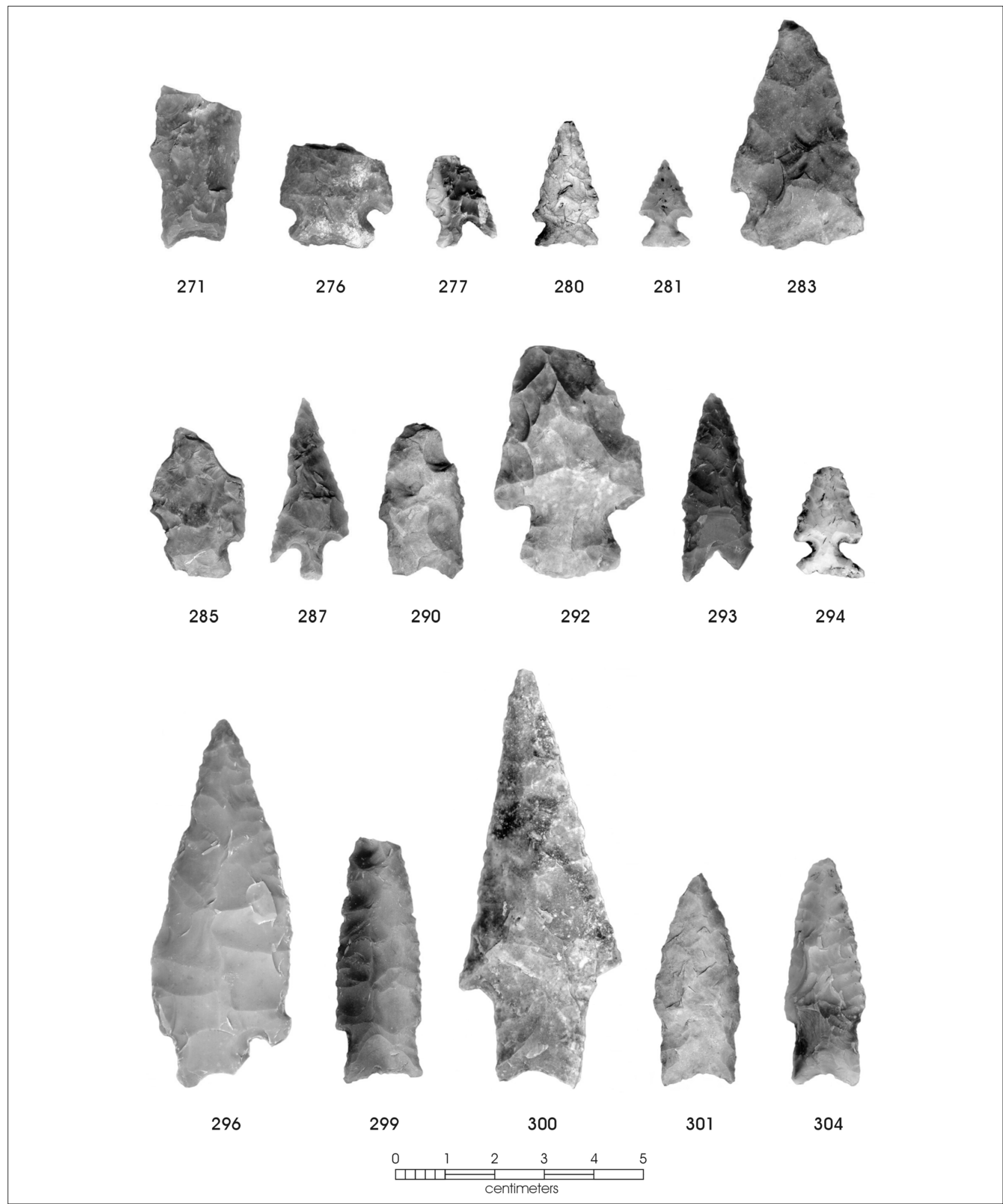

Figure E-3. continued... Selected projectile points from Area C. 271) Darl; 276) Fairland; 277, 280, 281) Scallorn; 283, 285) Ensor; 287) Bonham; 290) Darl; 292) Lange; 293) Darl; 294) Scallorn; 296) Pedernales; 299) Darl; 300) Pedernales; 301, 304) Darl. 


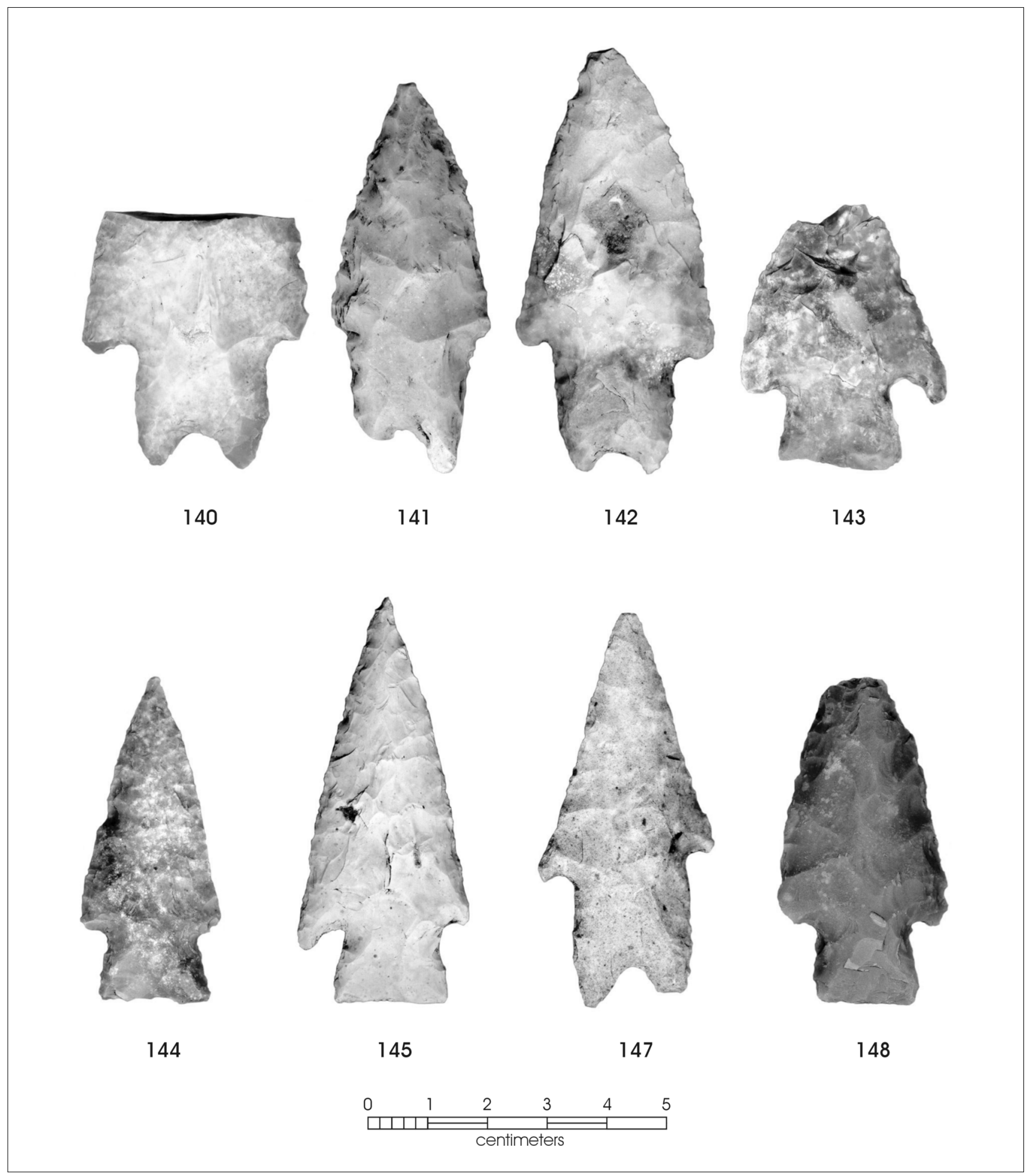

Figure E-4. Selected projectile points from Area E. 140-142) Pedernales; 143) Lange; 144) Darl; 145) Lange; 147) Pedernales; 148) Lange. 


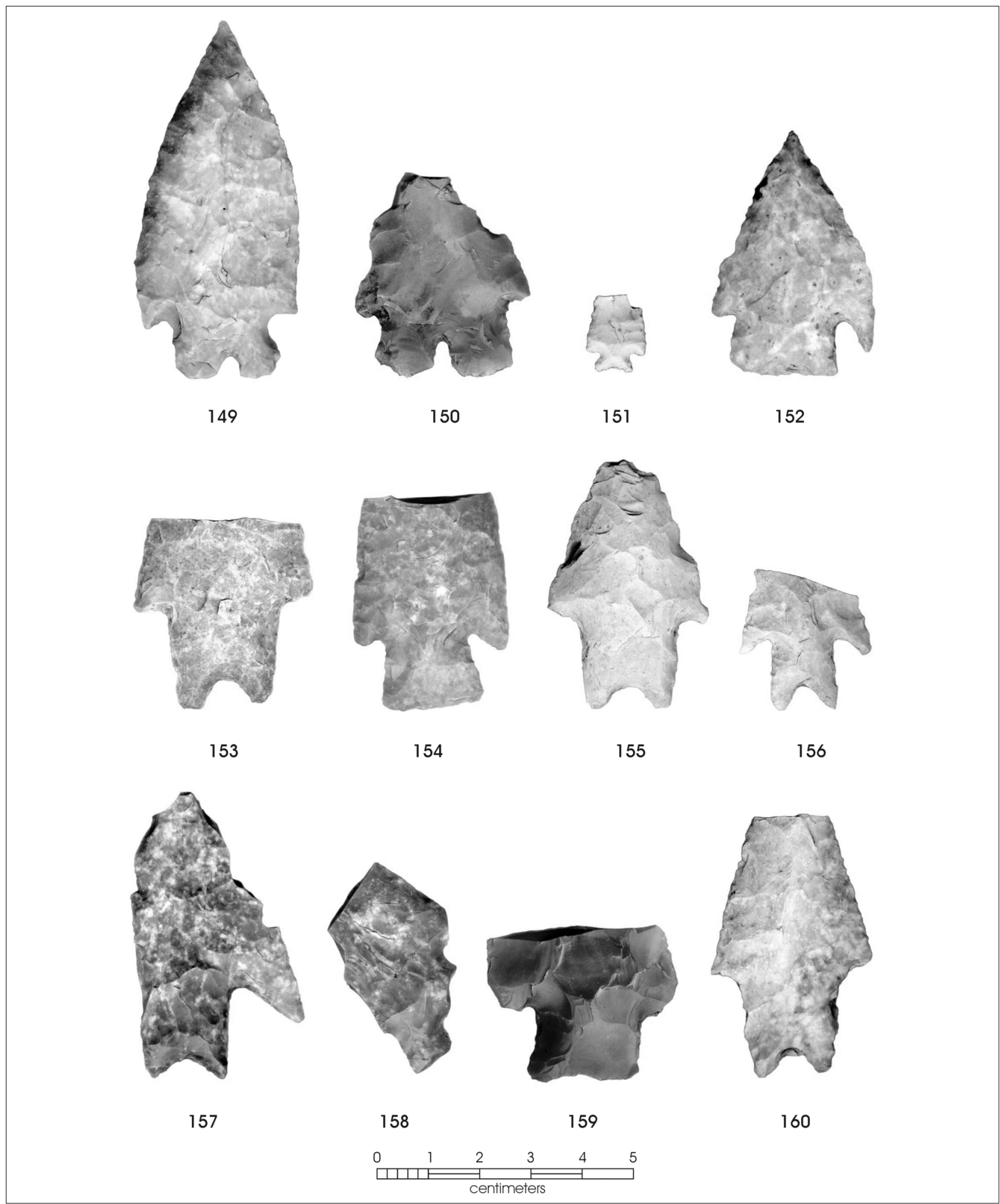

Figure E-4. continued... Selected projectile points from Area E. 149, 150) Montell; 151) Scallorn; 152) Castroville; 153) Pedernales; 154) Lange; 155-157) Pedernales; 158) Montell; 159) Lange; 160) Pedernales. 


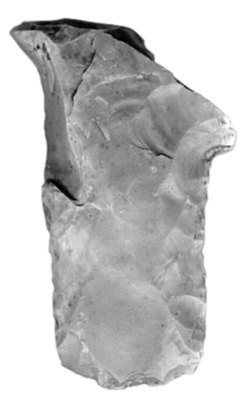

12

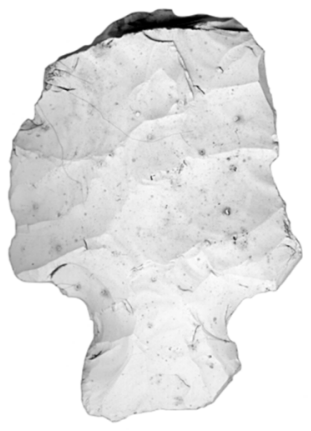

18

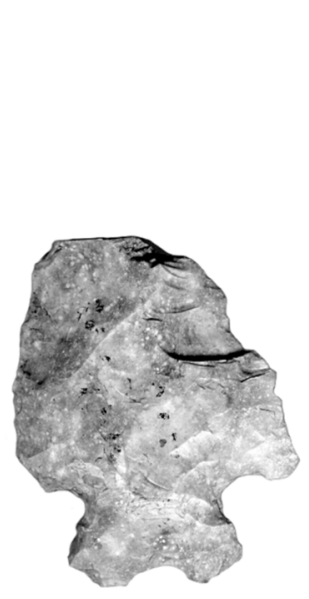

13

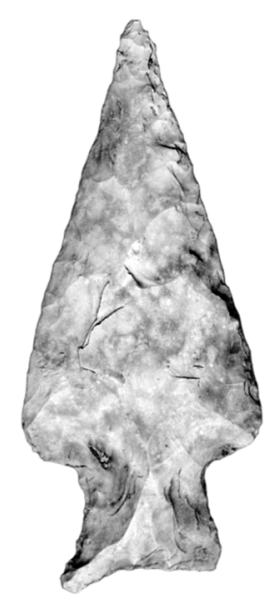

15

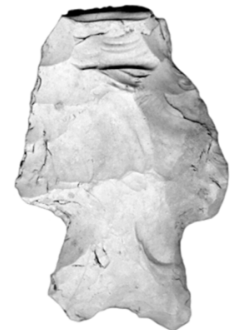

17

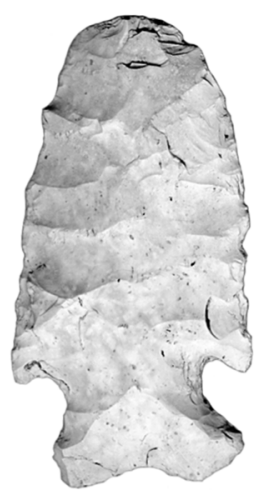

21

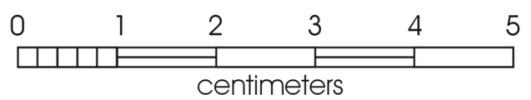

Figure E-5. Selected projectile points from Area F. 12) Andice; 13) Early Split Stem; 15) Uvalde; 17) Early Split Stem; 18) Uvalde; 20) Early Split Stem; 21) Martindale. 